RESEARCH

SERIES

NUMBER 61

January 2018

\section{EVALUATION OF PLC PROGRAMME PROVISION}

SEAMUS MCGUINNESS, ADELE BERGIN, ELISH KELLY, SELINA MCCOY, EMER SMYTH, DOROTHY WATSON AND ADELE WHELAN

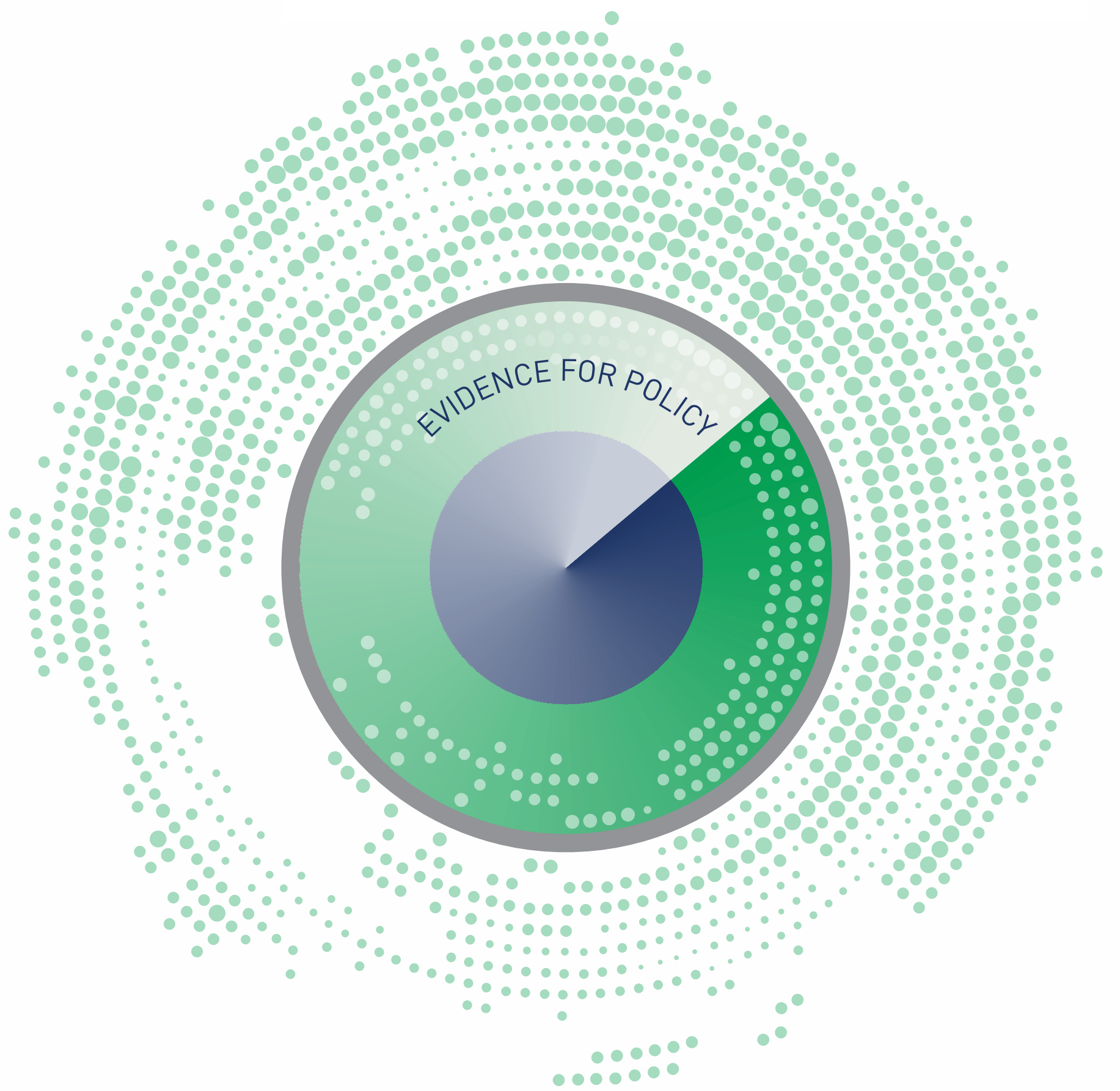




\section{EVALUATION OF PLC PROGRAMME PROVISION}

Seamus McGuinness, Adele Bergin, Elish Kelly, Selina McCoy, Emer Smyth, Dorothy Watson, Adele Whelan

January 2018

\section{RESEARCH SERIES}

\section{NUMBER 61}

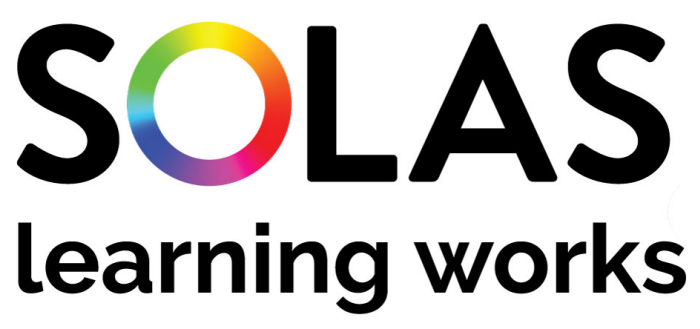

(C) The Economic and Social Research Institute

Whitaker Square, Sir John Rogerson's Quay, Dublin 2

ISBN 97807070004280 


\section{ABOUT THE ESRI}

The mission of the Economic and Social Research Institute is to advance evidencebased policymaking that supports economic sustainability and social progress in Ireland. ESRI researchers apply the highest standards of academic excellence to challenges facing policymakers, focusing on 12 areas of critical importance to 21st Century Ireland.

The Institute was founded in 1960 by a group of senior civil servants led by Dr T.K. Whitaker, who identified the need for independent and in-depth research analysis to provide a robust evidence base for policymaking in Ireland.

Since then, the Institute has remained committed to independent research and its work is free of any expressed ideology or political position. The Institute publishes all research reaching the appropriate academic standard, irrespective of its findings or who funds the research.

The quality of its research output is guaranteed by a rigorous peer review process. ESRI researchers are experts in their fields and are committed to producing work that meets the highest academic standards and practices.

The work of the Institute is disseminated widely in books, journal articles and reports. ESRI publications are available to download, free of charge, from its website. Additionally, ESRI staff communicate research findings at regular conferences and seminars.

The ESRI is a company limited by guarantee, answerable to its members and governed by a Council, comprising 14 members who represent a cross-section of ESRI members from academia, civil services, state agencies, businesses and civil society. The Institute receives an annual grant-in-aid from the Department of Public Expenditure and Reform to support the scientific and public interest elements of the Institute's activities; the grant accounted for an average of 30 per cent of the Institute's income over the lifetime of the last Research Strategy. The remaining funding comes from research programmes supported by government departments and agencies, public bodies and competitive research programmes.

Further information is available at www.esri.ie. 


\section{THE AUTHORS}

Seamus McGuinness is a Research Professor, Adele Bergin is a Senior Research Officer, Elish Kelly is a Senior Research Officer, Selina McCoy is an Associate Research Professor, Emer Smyth is a Research Professor, Dorothy Watson is an Associate Research Professor and Adele Whelan is a Research Officer at the ESRI. All members of the research team have adjunct research positions at Trinity College Dublin.

\section{ACKNOWLEDGEMENTS}

We would like to thank Fiona Hartley, Bryan Fields, Derek Walsh, Barry Ryan and Sue Hickey from SOLAS for their active engagement with the project. We are grateful to members of the PLC Evaluation Advisory Committee, the Department of Education and Skills, Education and Training Boards personnel, PLC providers, principals, learners and other key stakeholders who gave their time to engage in the project. We would also like to thank our ESRI colleague, Helen Russell, and Jim Gallacher of the Glasgow Caledonian University who reviewed an earlier draft and provided useful comments. Finally, our thanks go to the Director of the ESRI and two internal ESRI referees for their suggestions and contributions to this report.

The paper has been accepted for publication by the Institute, which does not itself take institutional policy positions. All ESRI Research Series reports are peer reviewed. The authors are solely responsible for the content and the views expressed. 


\section{FOREWORD}

Each year, further education and training (FET) is a very positive experience for many thousands of individuals across the country. It encompasses both a field of education and training and a distinct sector within that field. It has many and diverse purposes. Its very diversity and that of its learners is one of its key strengths.

There is a myriad of reasons why individuals choose to engage in FET. Some have aspirations to get a job, others to go to third-level education, still others to improve their reading and writing skills. Many see the personal and social benefits of reengaging in learning after a long absence. The FET sector has set out its vision for the future in the Further Education and Training Strategy 2014-2019.

If we are to succeed in this vision and keep FET accessible, effective and relevant to meet the aspirations of learners, then it needs to continuously adapt and improve. The FET sector and the high quality of its provision should be synonymous irrespective of where, when and how it is undertaken. It should also be backed up by evidence.

The national Post-Leaving Certificate (PLC) programme, more commonly known as 'PLC courses', is a well-known, well regarded and trusted FET brand. It has a proud history of delivering 'in-demand' employer skills and at the same time enabling others to achieve their ambition of attending third-level education. Evidence shows that the higher the education and training undertaken, the greater the chances of finding a job.

The Irish Government has set out a new strategy to ensure that we have the skills as a nation to become even more competitive and to ensure that all citizens can benefit from the opportunities that this will undoubtedly present. FET has a central role to play in this new skills strategy and in that regard the national PLC programme is a key pillar within FET.

However, a disruptive economic and social landscape and fast moving developments, for example in digital technology, green energy and communications, together with the need to demonstrate value for money means that there are very high expectations in relation to all FET programmes and services. People rightly expect FET to enable and empower them to manage and take advantage of these developments, while funders need to be assured that this money is spent wisely to optimise outcomes for learners. 
This report by the ESRI was commissioned by SOLAS and was prepared during a time of unprecedented change within the FET sector. Notwithstanding the priority to get the newly established SOLAS and the Education and Training Boards (ETB) up and running as quickly as possible, both maintained a clear focus on the importance of finding out how best to improve FET programmes and services so that under the newly restructured FET banner, higher quality learning experiences and better outcomes for all learners can become a reality. Having a reliable and informed evidence base on what is working well and what needs improvement is a good starting point.

This report adds significantly to the FET evidence base by providing a wealth of insights in respect of the many benefits for learners associated with participating in the national PLC programme. It also identifies areas where improvements to PLC are essential if they are to become more effective, responsive and efficient. With over 30,000 places, the national PLC programme represents just over half of all SOLAS-funded, full-time FET provision offered by the ETB sector. A report of this nature is essential for SOLAS to help it make well informed and balanced decisions with regard to how best to improve FET overall and the national PLC programme more specifically.

Given the centrality of the national PLC programme within FET, it is essential therefore that everybody is clear on the purpose of the PLC programme, that this purpose is not only appropriate for today but is future proofed to take account of new and emerging developments. This report underlines the importance of measuring the success of the national PLC programme and in particular the quality of the learning experience and the subsequent outcomes for PLC learners on the basis of how well this purpose has been served. We need not only to meet but to exceed the expectations of PLC learners.

In response to the findings of the ESRI evaluation, SOLAS submitted to the Minister for Education and Skills a comprehensive set of recommendations for his consideration to improve the national PLC programme. SOLAS now intends to establish a programme improvement implementation group that will report regularly to the SOLAS Board and to the Minister on how well improvements to the national PLC programme are being implemented and the resultant impact of these improvements.

SOLAS appreciates the substantial assistance it received from many organisations and individuals during the course of this evaluation. Members of the SOLAS PLC Evaluation Advisory Committee provided very helpful advice, insights and support. The Department of Education and Skills, Education and Training Boards personnel, PLC providers, policymakers, social partners, advocacy personnel and learners 
facilitated and shared their valuable experiences and perspectives. To all of them I convey the appreciation of SOLAS and the personal thanks of the Research and Evaluation project team in SOLAS.

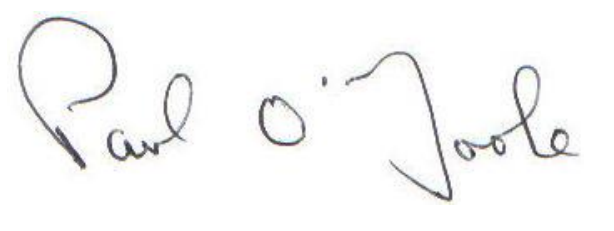

Paul O'Toole

Chief Executive Officer SOLAS 


\section{TABLE OF CONTENTS}

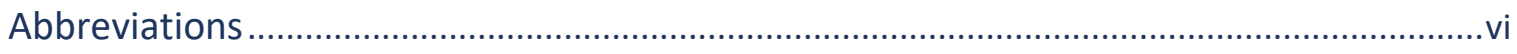

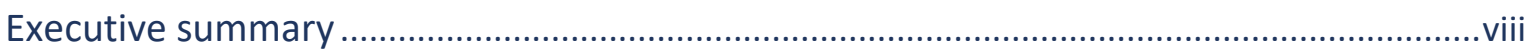

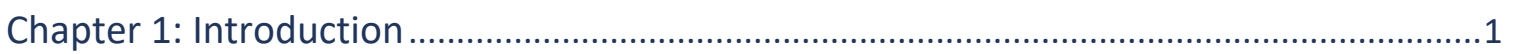

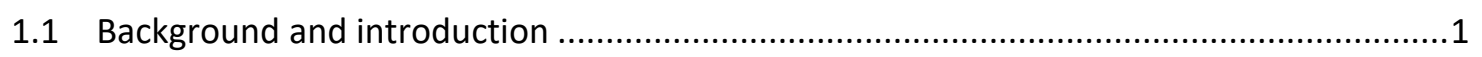

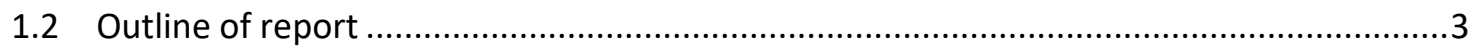

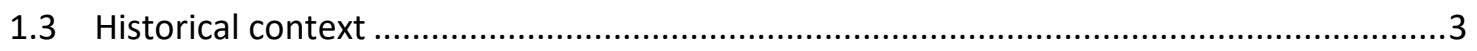

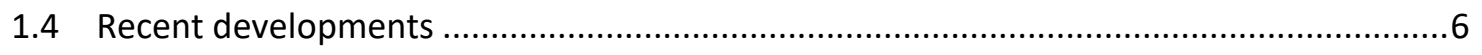

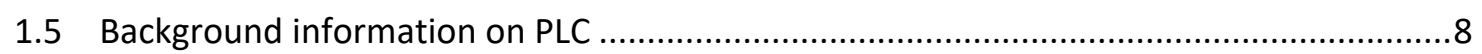

Chapter 2: PLC provision: Patterns from administrative data ............................................. 10

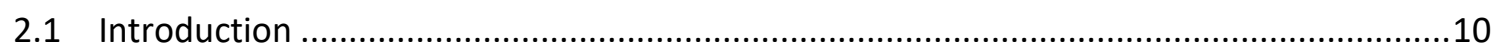

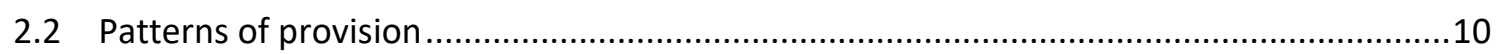

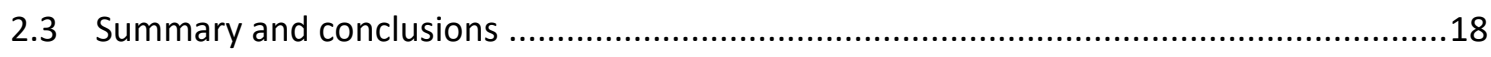

Chapter 3: Evidence from survey of principals: Resources, objectives and outcomes................20

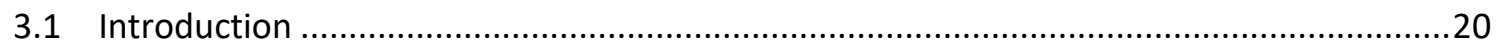

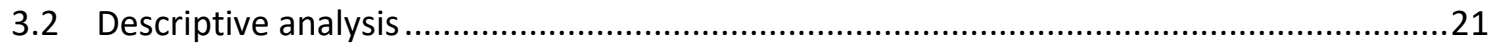

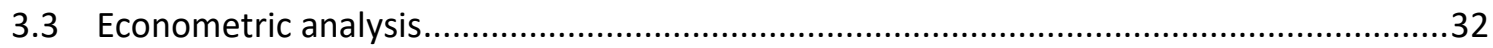

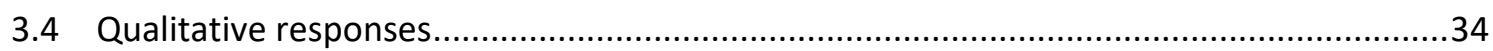

3.4.1 Providers' perspectives on the advantages of PLC provision...............................34

3.4.2 Principals' perspectives on future challenges for PLC provision..........................37

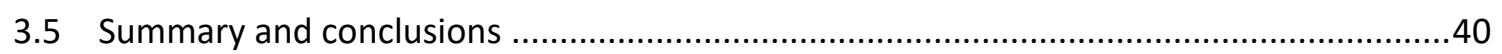

Chapter 4: Evidence from survey of learners: Measuring the impacts of PLC provision ..............41

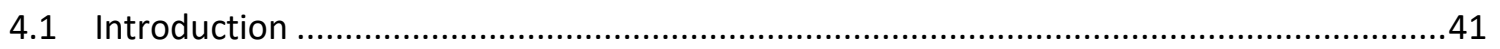

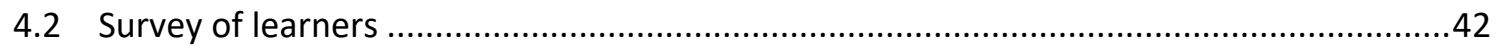

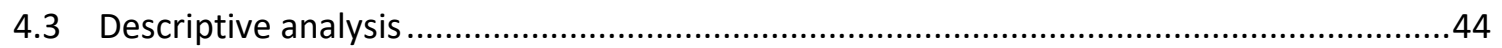

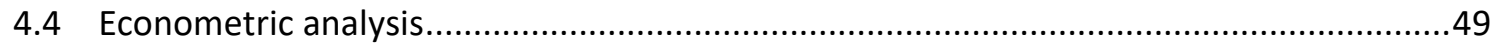

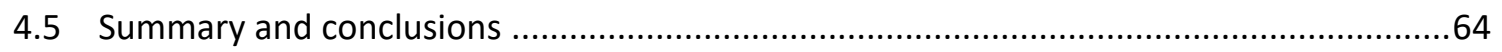

Chapter 5: Evidence from survey of learners: Student perceptions ......................................66

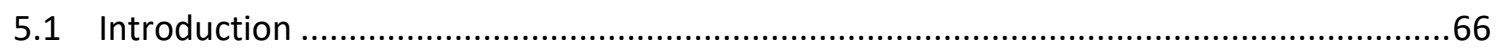

5.2 Conceptualising post-school pathways ............................................................67

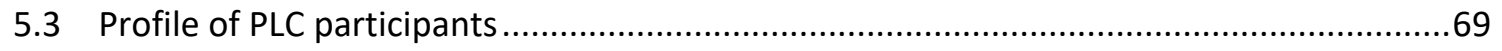

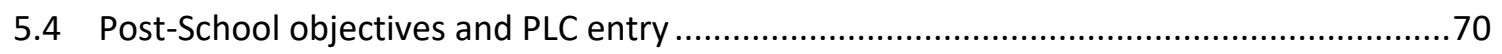

5.5 Experience of PLC and higher education courses ................................................ 73 


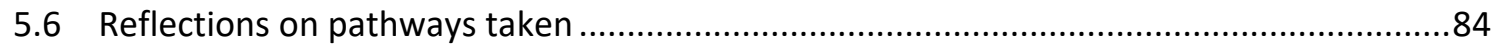

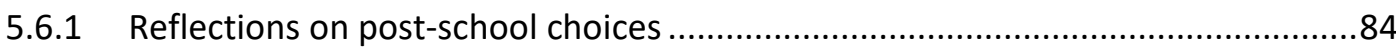

5.6.2 Life satisfaction, perceived social inclusion and financial wellbeing .....................89

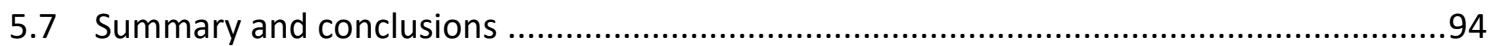

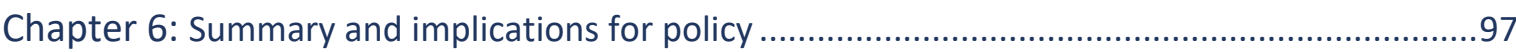

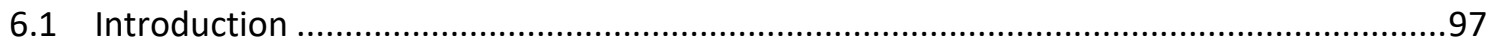

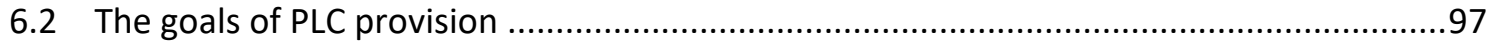

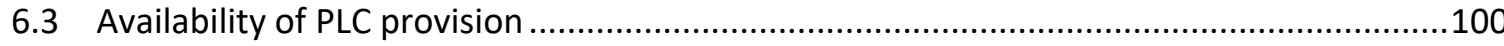

6.4 Labour market responsiveness of PLC provision …...........................................................101

6.4.1 Provision and labour market demand .................................................................

6.4.2 Employer engagement among providers ........................................................102

6.4.3 Employment outcomes among learners ............................................................103

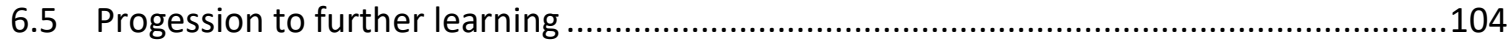

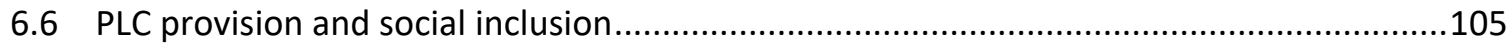

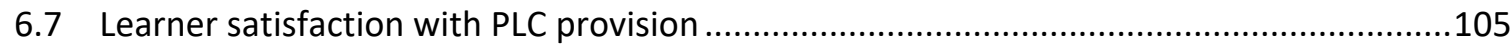

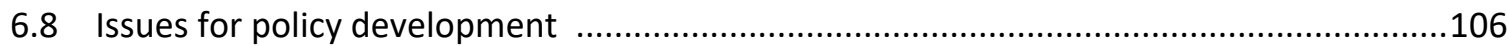

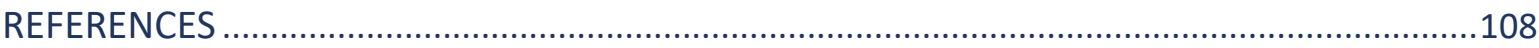

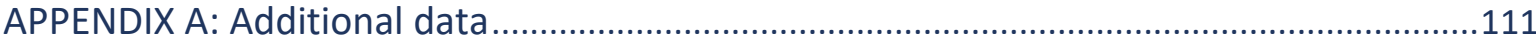

APPENDIX B: Note on sampling and weighting for the survey of PLC leavers ............................125

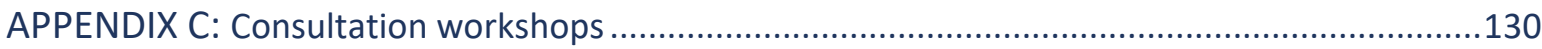

APPENDIX D: Questionnaire for survey of school and PLC leavers ............................................142

APPENDIX E: Questionnaire for survey of PLC providers .........................................................157 


\section{LIST OF TABLES}

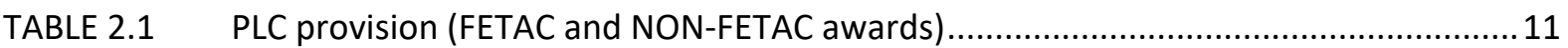

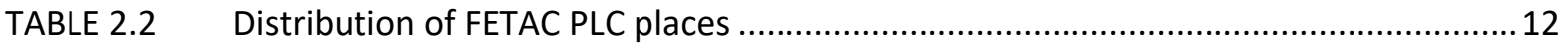

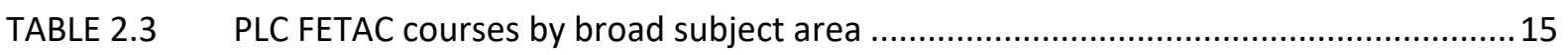

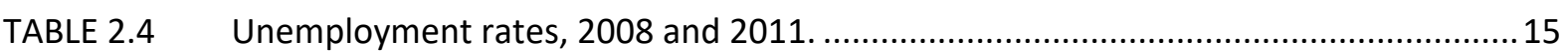

TABLE 2.5 PLC FETAC courses with the largest enrolments across broad subject areas in 2011-

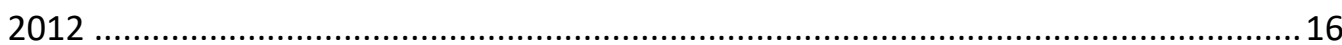

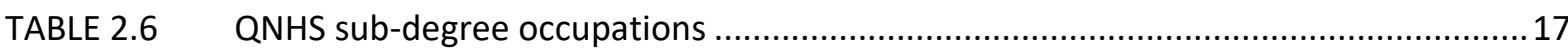

TABLE 2.7 Some examples of mapping DES enrolments (supply) with QNHS data (demand) for courses with limited progression components...........................................................18

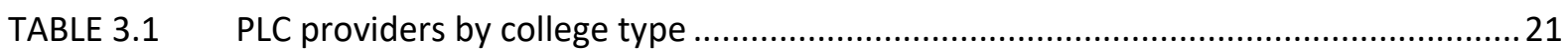

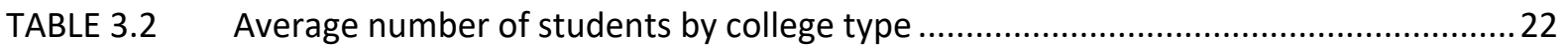

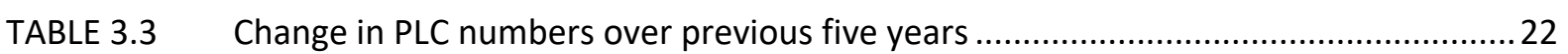

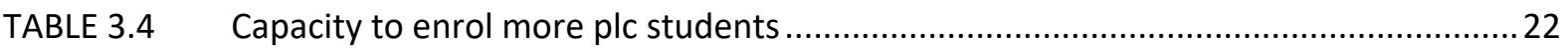

TABLE 3.5 Percentage accepting all PLC applicants by college type............................................22

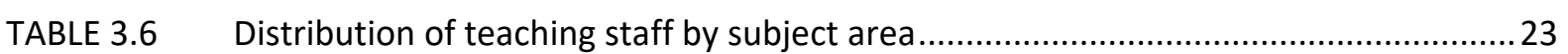

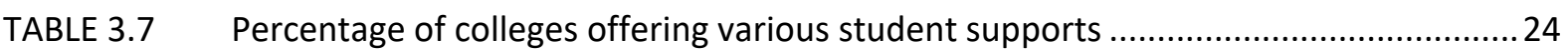

TABLE 3.8 Average adequacy score of available resources ..........................................................24

TABLE 3.9 How often do staff meet with employers in the local area? (\%) ..................................22

TABLE 3.10 Do learners take part in work experience as part of their PLC courses? (\%) ................26

TABLE 3.11 What length of time do PLC students typically spend on a work placement (days)? (\%)

TABLE 3.12 How easy is it, in general, for learners to obtain work placements? (\%) ....................26

TABLE 3.13 Who mainly organises the work experience placement? (\%) .......................................2

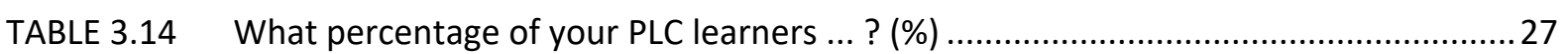

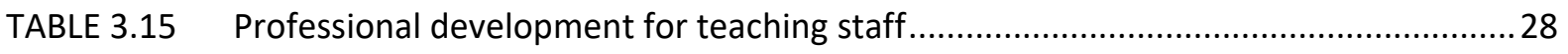

TABLE 3.16 Average influence of factors on establishing new course .........................................29

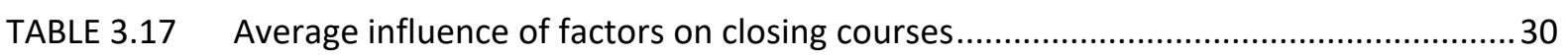

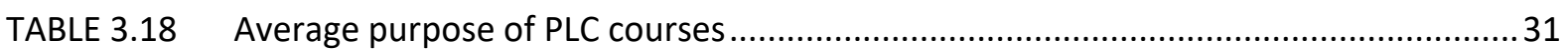

TABLE 3.19 Overall, approximately what percentages of students in your college/school complete

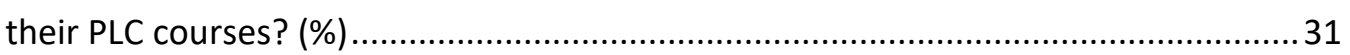

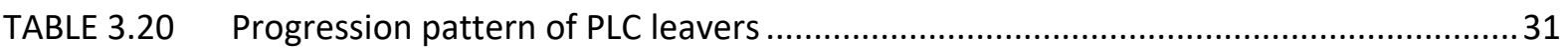

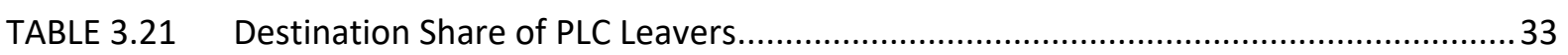

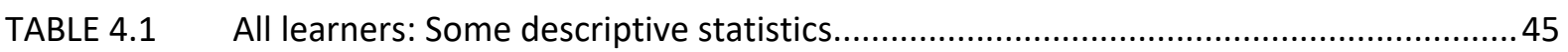

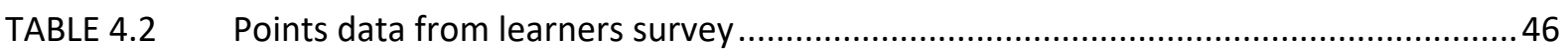

TABLE 4.3 All PLC learners: Did you participate in work experience during your PLC studies? ....46

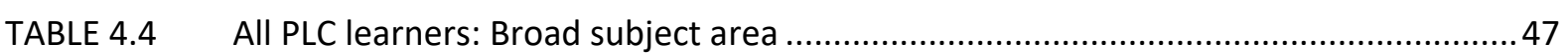

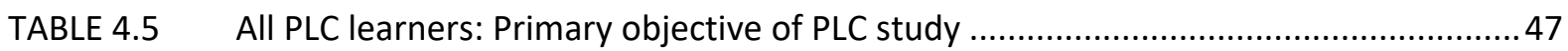

TABLE 4.6 All PLC learners: Primary objective of PLC study by broad subject area (\%) .................48

TABLE 4.7 All PLC learners: Did PLC course open up opportunities for further study at ... ? ........48

TABLE 4.8 All PLC learners: How would you describe your relationships with each of the

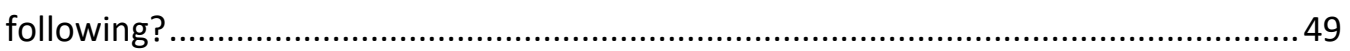

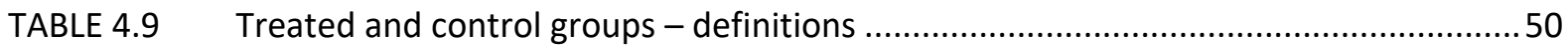

TABLE 4.10 Treated and control groups: Some descriptive statistics.............................................52 
TABLE 4.11 Treated and control groups: Some descriptive statistics for 2012 and 2015 ..............53

TABLE 4.12 Employed in 2015: Estimated impact relative to direct labour market entrants .........57

TABLE 4.13 Employed in 2015: Estimated impact relative to leaving certificate students who progressed straight to higher education

TABLE 4.14 Progression to higher education: Summary of estimates.........................................57

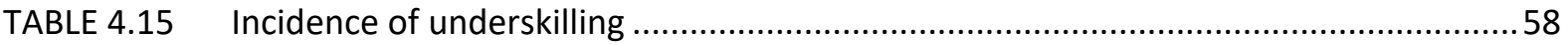

TABLE 4.16 Wages in current job (incl. two mills ratios; child \& parental degree excl.) .................61

TABLE 4.17 Occupational distribution of individuals with a PLC qualification (\%) ...........................63

TABLE 4.18 Unemployment rates by educational attainment: 2006 and 2009 (Q2) .....................63

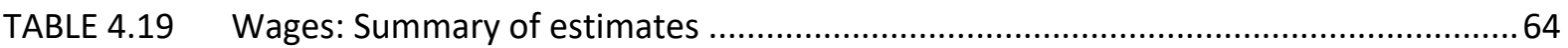

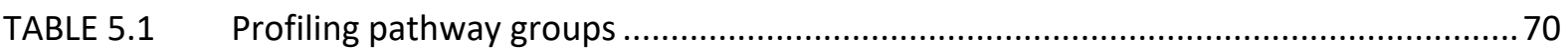

TABLE 5.2 Main factor in post-school decision-making .......................................................... 71

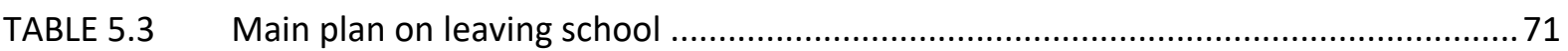

TABLE 5.4 Support services accessed during PLC/higher education studies (\%) ........................... 78

TABLE 5.5 How much more likely are leavers taking different pathways to feel they did not get the post-school choices they had planned? (odds ratios)

TABLE 5.6 How much more likely are leavers taking different pathways to regret the choice made on leaving school? (odds ratios)

TABLE 5.7 How much more likely are leavers taking different pathways to be in the group least satisfied with life? (odds ratios)

TABLE 5.8 How much more likely are leavers taking different pathways to be in the group least socially included? (odds ratios).

TABLE 5.9 How much more likely are leavers taking different pathways to experience difficulty in making ends meet? (odds ratios)

TABLE A1 QNHS sub-degree occupations in other category.................................................111

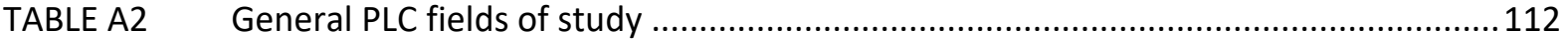

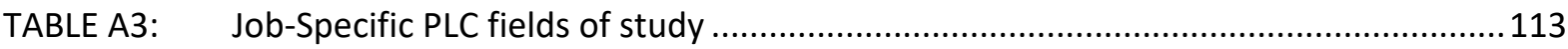

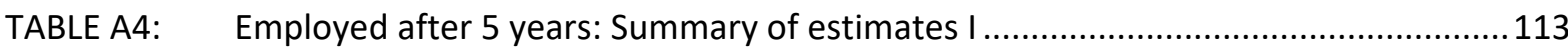

TABLE A5: Employed after 5 years: Summary of estimates II ...................................................114

TABLE A6: Progression to higher education: Summary of estimates........................................114

TABLE A7: Employed after 3 years: Summary of estimates I ..................................................115

TABLE A8: Employed after 3 years: Summary of estimates II ................................................115

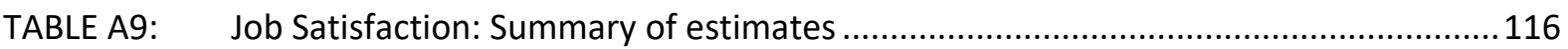

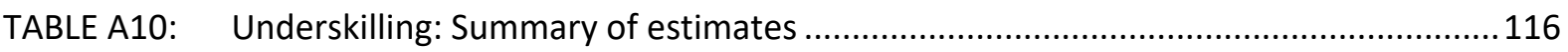

TABLE A11: Severe Underskilling: Summary of estimates ….................................................117

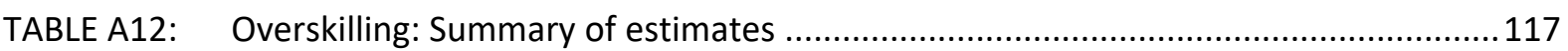

TABLE A13: First stage probit model for participating in a PLC course (relative to LC students who directly entered the labour market)

TABLE A14: First stage probit model for participating in a PLC course (relative to LC students who directly entered $\mathrm{HE}$ )

TABLE A15: Employed in 2015: Estimated impact for plc learners who completed their course relative to direct labour market entrants.

TABLE A16: Progression to higher education: Estimated Impact for PLC Learners who completed their course 
Table A17 Logistic regression: Probability of being in group who did not get what they planned on leaving school (odds ratios)

Table A18 Logistic regression: Probability of being in group who regret choice made on leaving school (odds ratios).

Table A19 Logistic regression: Probability of being in group who are least satisfied with their life (odds ratios; bottom quintile on satisfaction with everyday life)

Table A20 Logistic regression: Probability of being in group who are least socially included (odds ratios; bottom quintile on social inclusion)

Table A21 Logistic regression: Probability of being in group who experience difficulty making ends meet (odds ratios)

Table B.1: $\quad$ Sampling fraction by stratification group (\%) ................................................. 126

Table B.2: $\quad$ Response rate by stratification group.............................................................. 127

Table B.3: $\quad$ Population distribution, sample distribution and weight by stratification group ......128

Table B.4: $\quad$ Population distribution and sample distribution of DEIS school and school type by stratification group (\%)

\section{LIST OF FIGURES}

FIGURE 2.1 How does the ratio of enrolments vary compared to the HP deprivation index (2011-

2012)?

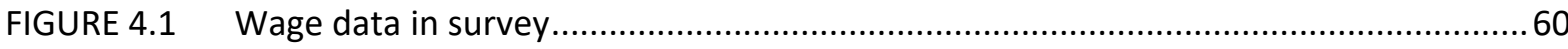

FIGURE 5.1 Source of advice on post-school choices by main pathway (\%) ................................72

FIGURE 5.2 Time spent (hours per week) on course of studies (\%) ............................................74

FIGURE 5.3 Percentage reporting difficulty was a major or moderate problem for them in their first year of PLC study

FIGURE 5.4 Percentage reporting difficulty was a major or moderate problem for them in their first year of higher education study ................................................................. 76

FIGURE 5.5 Sources of funding while on PLC or higher education course (\%) ............................77

FIGURE 5.6 Experience of teaching and learning in PLC and higher education courses (\%

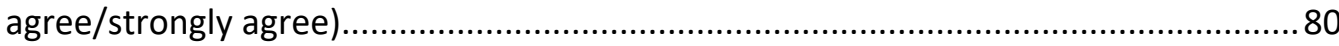

FIGURE 5.7 Supports and services in PLC and higher education (\% agree/strongly agree) ............81

FIGURE 5.8 Frequency of experience of workplace learning on PLC course (\%) ..........................8. 82

FIGURE 5.9 Frequency of experience of workplace learning on higher education course (\%) .......83

FIGURE 5.10 Extent to which skills and competencies have been achieved by all learners (\%) .......84

FIGURE 5.11 Did leavers get to do what they planned after leaving school? (\%) ..........................85

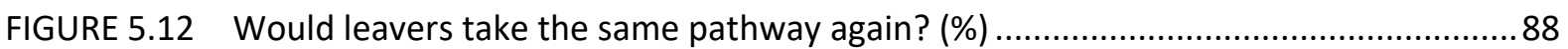

FIGURE 5.13 Satisfaction with life: Percentage in the least and most satisfied quintiles .................90

FIGURE 5.14 Perceived Social Inclusion: Percentage in the highest and lowest quintiles (most and

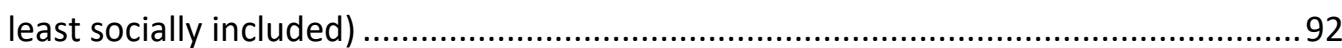

FIGURE 5.15 Ability to make ends meet for leaver households (\%) ...........................................94 


\section{ABBREVIATIONS}

AEO

BTEA

CPD

CSO

DES

DSP

EEC

EOS

ESF

ETB

ETBI

FET

FETAC

HE

HETAC

HP

IUQB

LC

LCA

LCVP

LMJ

NALA

NCSE

NCVA

NES

NFQ

NQAI

NQF

OLS

PLC

PSM

PPPDB
Adult Education Organisers

Back to Education Allowance

Continuous professional development

Central Statistics Office

Department of Education and Skills

Department of Social Protection

European Economic Community

Educational Opportunities Scheme

European Social Fund

Education and Training Boards

Education and Training Boards Ireland

Further education and training

Further Education and Training Awards Council

Higher education

Higher Education and Training Awards Council

Haase Pratchke (Deprivation Index)

Irish Universities Quality Board

Leaving Certificate

Leaving Certificate Applied

Leaving Certificate Vocational Programme

Labour market justification

National Adult Literacy Agency

National Council for Special Education

National Council for Vocational Awards

National Employment Survey

National Framework of Qualifications

National Qualifications Authority of Ireland

National Qualifications Framework

Ordinary least squares

Post-Leaving Certificate

Propensity score matching

Post-Primary Pupil Database 


$\begin{array}{ll}\text { QNHS } & \begin{array}{l}\text { Quarterly National Household Survey } \\ \text { QuI }\end{array} \\ \text { SEN } & \begin{array}{l}\text { Special educational need } \\ \text { SIAC }\end{array} \\ \text { STEM } & \text { Strategy Implementation Advisory Committee } \\ \text { SUSI } & \text { Science, technology, engineering and maths } \\ \text { VEC } & \text { Student Universal Support Ireland } \\ \text { VET } & \text { Vocational Educational Committees } \\ \text { VPT } & \text { Vocational education and training } \\ \text { VTOS } & \text { Vocational Preparation and Training } \\ & \text { Vocational Training Opportunities Scheme }\end{array}$




\section{EXECUTIVE SUMMARY}

Post-Leaving Certificate (PLC) courses represent the largest component of full-time further education and training (FET) provision in Ireland, with over 32,000 learners enrolled in such courses in 2015-2016. Recent research on the FET sector as a whole highlighted concerns around its structures and responsiveness to labour market conditions, among other issues (McGuinness et al., 2014). The SOLAS FET Strategy (2014) subsequently pointed to the need for a stronger evidence base in order to inform future policy development in the sector. This study, commissioned by SOLAS, provides a more detailed evaluation of PLC provision. In order to undertake a comprehensive evaluation, our approach has been to combine a variety of research modes in order to examine the underlying processes, experiences and outcomes of PLC provision. This involved three complementary research strands. Firstly, a desk-based analysis of administrative data was used to document the type of provision in terms of field of study and the distribution of PLC places across the country. Secondly, a survey of PLC principals was carried out in order to explore their perceptions of goals, adequacy of existing facilities and the benefits and challenges of PLC provision. Thirdly, a survey of PLC and Leaving Certificate leavers was conducted to assess their labour market outcomes as well as their experiences while taking PLC and higher education courses. Together, these strands provide comprehensive evidence to inform the future development of the sector.

What follows is a summary of the main findings.

\section{PLC PROVISION}

- There is a substantial amount of heterogeneity in the regional distribution of PLC places.

- The central goals of PLC provision include transitions to employment and vocational preparation for young people. Given this, we might expect PLC programmes to be targeted towards younger people who have a greater need for supports. However, the evidence shows that young people from disadvantaged regions, who have the highest risk of unemployment, do not have higher-than-average access to PLC programmes.

\section{LABOUR MARKET RESPONSIVENESS OF PLC PROVISION}

- The composition of PLC provision remained relatively stable and the level of enrolments increased during a period in which both the level and composition of labour market 
demand changed dramatically. ${ }^{1}$ This suggests that, contrary to what is implied by the Conditions of Approval, PLC provision does not appear to be highly responsive to changing labour market conditions and shocks. ${ }^{2}$

- Decisions around course provision and closure tends to be heavily driven by student demand, with less weight given to employer requirements, government objectives or national forecasting.

- The sector generally appears to be poorly connected to the requirements of the labour market and much more needs to be done to ensure that course provision is both reflective of and responsive to labour demand, specifically for vocational labour, for those who have recently qualified.

- PLC principals view provision as fulfilling a range of roles, with labour market, lifelong learning, progression to higher education and social inclusion all appearing to have equal weight.

- The distribution of teacher qualifications maps relatively closely to the aggregate enrolments data by subject area; regarding the latter, 52 per cent were in the arts and social science, 12 per cent were in STEM, 17 per cent in services, and 18 per cent in agriculture. Differences that do exist between the distribution in teacher qualification and student enrolments by subject area may be explained by differences in class size.

\section{LEARNER CHARACTERISTICS}

- Overall, participants in PLC programmes are disproportionately female, from less educated backgrounds, are more likely to be older and have children, and have greater special educational needs (SEN) prevalence rates than their counterparts enrolling directly in higher education.

- The majority (62 per cent) of PLC leavers are in the 200-400 points bands while the majority of the Leaving Certificate group (63 per cent) are in the 300-500 bands, so PLC learners have lower-than-average qualifications at Leaving Certificate level. This may reflect the fact that a higher proportion of the Leaving Certificate cohort went directly to higher education.

1 The Great Recession had a dramatic effect on employment in all sectors, but the largest employment losses were in Construction and Services (Bergin, Kelly and McGuinness, 2012).

2 The PLC Conditions of approval (DES, 2012) include "In approving courses the Department has regard to ensuring appropriate provision on a geographic basis" and "Providers must include a Labour Market Justification (LMJ) with applications for all new courses, showing: (i) How the course provision meets with Government policy; (ii) What particular skill gaps or areas of skill growth, both locally and nationally, the course will address; and (iii) Specific data and information on progression options, local agreements with employers, information on outcomes for previous learners." 


\section{LEARNER EXPERIENCES}

- PLC learners were asked about their primary objective for PLC study: 39 per cent reported that their main objective was to get a job immediately after the PLC course and a similar percentage reported that their main objective was to get a place on a higher education programme. Just under 20 per cent citied personal development as the key motivating factor for pursuing a PLC course.

- According to the PLC respondents, just over 70 per cent of learners undertook work experience during their PLC studies.

- Financial challenges constituted the single greatest difficulty for both PLC and higher education students, but the two groups differed somewhat in terms of the sources of funding they drew upon to meet college costs. Partly reflecting the differing age and socio-economic profile of the two groups, higher education students were more likely to receive direct and indirect support from their families; they were also more likely to be in paid employment. By contrast, greater caring responsibilities among the PLC group restricted their employment opportunities.

- PLC students reported that they were largely satisfied with the relevance of course design and the vast majority felt their teachers/tutors had the required knowledge. However, they were less positive about the prominence of workplace learning in their course (as were higher education participants), particularly regarding the opportunity to acquire work-related knowledge and skills and the opportunity to apply their learning in the workplace.

- In reflecting on choices made, PLC courses are still seen as a compromise, in a context of not achieving sufficient grades to pursue higher education, highlighting the continued lower status of further education in Ireland.

- Dissatisfaction levels with guidance counselling supports at second level were high for all groups of leavers; this is a key factor in school leavers later regretting their post-school choices.

- Differences across leavers in terms of the post-school options they pursued also emerge in relation to life satisfaction, measures of social inclusion and financial wellbeing. PLC participants fare less well, and second-level grades play a central role in shaping young peoples' opportunities to pursue post-school pathways that will maximise their potential for personal fulfilment and achievement. Family circumstances also play an important role in understanding wellbeing and particularly financial insecurity - those with children experience much greater challenges in this regard and this explains much of the difference between the leaver groups.

\section{LEARNER OUTCOMES}

- In order to assess the employment and educational outcomes of PLC leavers, this group was compared to a group of Leaving Certificate leavers who were similar in characteristics 
but who entered the labour market directly upon leaving school. The difference between the two groups is referred to as the counterfactual impact.

- In terms of employment outcomes, the estimated counterfactual impact of PLC provision shows that, by 2015, PLC participants were 16 per cent more likely to be in employment relative to similar individuals who entered the labour market directly on completion of their Leaving Certificate. We find that the employment effects are greater for PLC learners in more job-specific, rather than general, PLC programmes.

- In terms of progressing to higher education, the counterfactual impact reveals that PLC learners are 27 per cent more likely to advance to higher education, relative to similar individuals who entered the labour market directly on completion of their Leaving Certificate. The estimated counterfactual impacts on various measures of job quality, such as job satisfaction or level of skill match with the current job, showed no significant differences between the PLC learners and similar individuals who entered the labour market directly on completion of their Leaving Certificate. The incidence of underskilling (that is, the current job demanding more knowledge and skills than the respondent could offer) across various groups is somewhat surprising. Generally, we might expect underskilling rates to be highest for those with Leaving Certificate or higher education, as these qualifications may not be occupationally specific in nature. Instead, however, we found higher rates of underskilling among the PLC group. We should treat these results with some caution as we are capturing effects right at the onset of the respondents' careers and, therefore, cannot rule out the possibility of other differences between the groups emerging over time.

\section{ISSUES FOR POLICY DEVELOPMENT}

- The findings of this study point to the positive role played by PLC provision in providing educational opportunities for a diverse group of learners and in enhancing their access to employment and higher education. However, the findings also highlight a number of challenges for policy development in the PLC sector.

- Learners are almost equally divided between those taking PLC courses for skill formation (and hence employment access) and those taking them for progression to higher education. However, principals see courses as addressing multiple goals, suggesting greater potential for clarity around the orientation and purpose of specific courses.

- There is a need for greater responsiveness of job-specific PLC courses to changing labour market conditions in terms of the types of courses offered. Provision is currently constrained by legacy issues, including the skillset of existing staff, with relatively little input of information on skill gaps and employer demand. There is also evidence of a need for a greater focus on skill formation within some employment-oriented courses, adapting course content to focus on employability and integrating work experience placements into the learning experience for all learners. 
- PLC courses are offered across very different settings, with smaller institutions less likely to provide the full range of student supports and larger institutions operating under resource constraints relative to student numbers. There would appear to be scope to link smaller providers into local or regional networks, perhaps through the ETB, to facilitate access to specialist supports and to support engagement with employers. While good practice appears to have emerged in certain areas, there are undoubted challenges in building up sustained employer engagement and recognition of qualifications in the absence of a strong tradition of such involvement (see Raffe, 2015, on challenges in the British context).

- The issue of the appropriate level of funding to provide a varied learning experience and appropriate supports for a diverse group of learners merits further investigation, especially given that PLC courses are run using a slightly enhanced second-level funding model that may not take adequate account of the range of facilities and supports required.

- Finally, PLC provision cannot be seen in isolation from the broader educational system. The role of school-based guidance emerges as important in facilitating access to appropriate courses. Low take-up of guidance within PLC provision may be impacting on awareness of the potential pathways (education and employment) subsequently open to learners, an issue that merits further research. More fundamentally, there appear to be persistent difficulties, from the learner perspective at least, in the perceived status of PLC courses vis-à-vis higher education, which raise challenges in creating a valued pathway catering for a range of learners. 


\section{CHAPTER 1}

\section{Introduction}

\subsection{BACKGROUND AND INTRODUCTION}

This report provides a formal evaluation of Ireland's Post-Leaving Certificate (PLC) programme. The evaluation relies primarily on three research strands:

(i) desk-based analysis;

(ii) a survey of PLC principals; and

(iii) a survey of learners. ${ }^{3}$

Workshops with key stakeholders were also organised to supplement the analysis.

A comprehensive dataset on PLC provision does not exist. Therefore, there are no comprehensive measures of key variables that track participants and outcomes over time, such as enrolments, completion rates, levels of accreditation and progression. Furthermore, at the school/college level no information is available on factors such as the planning process, structure of delivery and teacher provision. This is why, in order to undertake a comprehensive evaluation, our approach has been to combine a variety of research modes in order to examine the underlying processes, experiences and outcomes. Each research strand provides a different contribution to the overall evaluation. For example, the PLC learner survey captures information at an individual level, allowing an evaluation of the experiences and outcomes of PLC learners. The survey of principals provides insights from a different perspective, containing information on the factors driving provision and how work-related learning is embedded into the different courses, thus allowing an evaluation of the processes underlying PLC provision.

The desk-based element includes a historical overview of policy developments and their impact on PLC provision, as well as a profile of current PLC programme provision disaggregated over course type, geographical location and level of deprivation. The survey of PLC principals provides information on the structure of PLC provider institutions,

3 Throughout the report, we use the terms 'learner' and 'leaver' interchangeably. 
including college type, composition of teachers and tutors, and the nature and level of supports. The survey also explores perceptions of the roles of PLC programmes, factors influencing course closures and openings, and progression rates at college level. ${ }^{4}$ Finally, the PLC leaver survey provides the main evidence base for the evaluation of outcomes and consists of the following key components:

- descriptive evidence of PLC participants, including age, gender, previous education level, socio-economic background, take-up of learner supports, as well as reflections on the guidance process and quality of experiences;

- a comprehensive analysis of learner experiences and outcomes, including multivariate estimates of the counterfactual impact of PLC provision relative to a number of comparison groups on a number of key pathways, such as employment and progression to higher education, as well as other outcomes including wages, and an examination of key indicators of quality of employment, such as job satisfaction and mismatch; ${ }^{5}$ and

- an assessment of learner experiences with respect to access to relevant work experience, skill formation, views on the learning process and guidance arrangements.

Based on all of the above findings, the report makes a series of recommendations that address:

- improving the effectiveness and quality of PLCs;

- identifying the most suitable structure for the delivery of PLC programmes;

- optimising progression to both employment/self-employment and further study/higher education;

- improving social inclusion;

- improving cost-effectiveness;

- ensuring geographical spread and diversity of programmes; and

- improving teaching and learning supports.

4 These inputs will include such factors as: PLC Conditions of approval; the use of labour market intelligence and occupational forecasting; structure of local, regional and national labour market demand; and employer inputs.

5 Comparison groups include: all Leaving Certificate school leavers; Leaving Certificate school leavers wno went straight to the labour market; and Leaving Certificate school leavers who went straight to higher education (all of whom constitute the counterfactual). 


\subsection{OUTLINE OF REPORT}

The report is structured as follows. The remainder of Chapter 1 describes the historical context and background information on PLC programmes in Ireland. Chapter 2 examines the pattern of enrolments, using administrative data over two separate time periods (2008-2009 and 20112012). Chapter 3 presents results of the survey of PLC principals on a range of issues, including structure, size and composition of PLC colleges, the perceived role of PLC programmes, resources available for PLC provision and progression patterns. Chapter 4 examines results of the survey of learners, providing a descriptive discussion of the main characteristics of respondents before progressing to estimate the impact of PLC provision on a series of outcome measures. Chapter 5 examines learners' perceptions with respect to access to relevant work experience, skill formation, views on the learning process and guidance arrangements. Chapter 6 concludes with a summary of the key findings and a consideration of implications for policy.

\subsection{HISTORICAL CONTEXT}

In Ireland, vocational education developed relatively late, largely because of delayed industrialisation, the low status of manual work and the emphasis of Church-run schools on providing an academic education (Coolahan, 1981). This context meant that Ireland lacked the structured involvement of employers in education/training institutions evident in some other European countries. Despite some technical education initiatives in the early part of the twentieth century, the main framework for vocational education and training (VET) was provided by the 1930 Vocational Education Act, which established 38 Vocational Educational Committees (VECS) whose schools provided two-year, full-time 'continuation education', designed to prepare young people for the labour market, alongside evening courses ('technical education') designed to improve the skills of those already employed. Initially focused on practical skills, with different course content for male and female students, the 1930s saw a broadening of provision to include other subjects, such as religious education and the Irish language. In 1947, standardised certification in the form of the Group Certificate was introduced for these continuation courses, but this was seen as of lower status than the Intermediate Certificate qualifications offered in voluntary secondary schools.

The 1950s saw increasing criticism of vocational education, with concerns expressed about schools losing out as a result of competition from 
secondary schools, a lack of qualified staff and the absence of transfer to further education. The reform of the Intermediate Certificate in 1966 was an attempt to provide a more comprehensive curriculum in both vocational and secondary schools. Many VECs adopted a community college model in the 1970s, reflecting their role in providing adult and further education as well as 'traditional' second-level education. Towards the end of the 1970s, VECs appointed Adult Education Organisers (AEOs) to coordinate adult education provision.

The European Economic Community was very influential in shaping VET in Ireland (Coolahan, 1981; O'Sullivan, 2005). The European Social Fund (ESF) provided funding for the establishment of pre-employment courses in over 120 schools in 1977 . These courses were targeted at post-junior cycle students and aimed to provide social, general and technical education combined with work experience. They were initially confined to vocational and community or comprehensive schools but were redeveloped as Vocational Preparation and Training (VPT) courses, VPT1 and VPT2, in 1984 and were extended to voluntary secondary schools (NESC, 1993). The programmes consisted of vocational studies, work experience and general studies. A second year was added to the courses in 1985 and these VPT2 courses became commonly known as PLC courses. These courses were primarily designed to provide vocational education in order to facilitate young people's transition to employment. However, commentators (see, for example, McNamara, 1990) pointed to the facts that the skills in question were not defined and that the evidence had not been provided to show that these skills were in short supply or that such shortages caused high unemployment levels (McNamara, 1990, p.163).

The Educational Opportunities Scheme (EOS) was introduced on a pilot basis in 1986 to provide one-year, full-time education for those aged over 24 years who had been unemployed for a year or more. It was reconstituted as the Vocational Training Opportunities Scheme (VTOS) in 1989, with ESF funding, and broadened to include those over 21 years. Currently, VTOS is provided full-time and delivered to students either generally attending a further education college or a PLC college in dispersed mode ('Dispersed VTOS') or in core groups ('Core VTOS'). Core VTOS refers to those who usually attend a stand-alone course at a VTOS centre or adult education centre. Dispersed VTOS provision is for VTOS students participating within groups that are pursuing full-time courses within other programmes recognised and resourced by the Department of Education and Skills. 
of the National Council for Vocational Awards (NCVA) to provide certification. It used a modular framework, integrating general studies and vocational modules with a focus on the development of personal and interpersonal skills (Trant, 2002). However, barriers to progress included lack of resources, rigid teaching contracts (reflecting second-level teaching structures), lack of progression routes and, more importantly, the continued low status of vocational education (Trant, 2002; Granville, 2003). The 1999 Qualifications Act established the National Qualifications Authority of Ireland (NQAI) and subsumed the NCVA into the Further Education and Training Awards Council (FETAC) as well as the FÁS and CERT certification systems: the new qualifications framework covered all qualifications, including vocational awards. In 2012, Quality and Qualifications Ireland (QQI) was established as a new integrated agency, replacing FETAC, the Higher Education and Training Awards Council (HETAC), the National Qualifications Authority (NQAI) and the Irish Universities Quality Board (IUQB). QQI is responsible for the maintenance, development and review of the National Framework of Qualifications (NFQ).

As well as changes in the qualifications framework, there have been significant changes in the institutional context within which (most) PLC courses are offered. In 2013, the 33 VECs were dissolved and replaced by 16 Education and Training Boards (ETBs). The ETBs were established under and governed according to the Education and Training Boards Act 2013. Each ETB is a statutory body with its own corporate status, with responsibility for education and training, youth work and a range of other statutory functions. While most PLC courses are offered in stand-alone further education colleges run by the ETB or other ETB schools/colleges (see Chapter 2), many voluntary secondary schools continue to offer PLC courses.

Despite its growing importance, the PLC sector has not been subject to a good deal of policy analysis or empirical research. Hannan et al. (1998) raised issues of fragmentation and rigidity in the system of vocational education in Ireland. The authors argued for more strategic concentration on PLC level expansion in a restricted range of subjects, in particular, to address the variable regional coverage of short cycle third-level provision (ibid., p.135). The authors also noted the tendency for institutes of technology to shift away from shorter certificate and diploma courses designed to provide middle-level technical skills for regional labour markets, and towards more degree-level provision (a process termed 'academic drift'), which was likely to make PLC providers even more crucial as a source of vocational labour. To address the information gap, the (then) 
Department of Education and Science commissioned a review of provision, which came to be known as the 'Mclver Report' (Mclver Consulting, 2003). Based on a survey of providers and further consultation with stakeholders, the report pointed to significant challenges for the sector given high levels of demand in the context of inadequate funding and facilities. The continued operation of PLC provision within the second-level system was seen as posing particular difficulties in securing greater status for, and recognition of, the sector. The recommendations of the report were not implemented.

The Mclver Report had focused on institutional factors but subsequent research by Hannan et al. (2003) and Watson, McCoy and Gorby (2006) provided new evidence on learner experiences and outcomes. These studies highlighted the growing importance of the sector as a pathway to second-chance education for adult learners. The results showed that those who participated in PLC courses were less likely to be unemployed one year after completion of the course, compared to those who entered the labour market directly after the Leaving Certificate (Watson et al., 2006). PLC participants were also found to be in higher status jobs than Leaving Certificate leavers five to six years after programme completion (Hannan et al., 2003). In contrast to the positive employment effects, participants in PLC courses were less likely to progress to further study than other school leavers of similar characteristics (in terms of age, gender, Leaving Certificate performance and social background). In other words, PLC courses were found to be an alternative, rather than a route, to third-level education. The extent to which these patterns hold a decade later is examined later in this report.

\subsection{RECENT DEVELOPMENTS}

On 1 July 2013, the 33 VECs were dissolved and replaced by 16 ETBs. The ETBs were established under and governed according to the Education and Training Boards Act 2013. Each ETB is a statutory body with its own corporate status, with responsibility for education and training, youth work and a range of other statutory functions. ETBs manage and operate second-level schools, further education colleges, community national schools and a range of adult and further education centres delivering education and training programmes. The Irish Vocational Educational Authority changed its name to Education and Training Boards Ireland (ETBI).

The new configuration paved the way for the establishment of SOLAS, the dissolution of FÁS and the transfer of its training functions to the newly 
formed ETBs. A year prior to these developments, on 1 January, 2012, operational responsibility for FÁS Community Employment and FÁS Employment Services transferred to the Department of Social Protection (DSP) although FÁS continued to provide ongoing support to DSP during 2012, in order to ensure continuity of service, systems support and payments to participants of Community Employment and other schemes.

FÁS was dissolved and SOLAS was formally established in October 2013 following the enactment of the Further Education and Training Act 2013. The 14-month period that followed saw immense change to both the policies and structures of the FET sector in Ireland. The new authority brought together the (previously separate) FET areas and was given a very clear mission by the Minister for Education and Skills:

SOLAS will be tasked with ensuring the provision of 21st century high quality further education and training programmes which are responsive to the needs of learners and the requirements of a changed and changing economy.

At the time of its establishment, all former FÁS training operations transferred to SOLAS. This included over 850 staff and 19 training centres. On 1 January 2014, seven former FÁS training centres, including 426 staff and their related training activity, transferred from SOLAS to four newly established ETBs. The remaining 12 training centres, including over 434 staff, subsequently transferred to eight ETBs, in July 2014. The transfers included budget, personnel, buildings, responsibility for contracted training and funding for community training centres, local training initiatives and specialist training provision in their respective regions.

Three key documents published by SOLAS in the first half of 2014 provide the first insight into what the sector delivers on an annual basis and the direction in which it is moving.

- The Further Education and Training Strategy 2014-2019 provides a roadmap for the FET sector up to 2019. It was prepared by SOLAS and approved by the Minister for Education and Skills.

- SOLAS Corporate Plan 2014-2017 outlines how SOLAS intends to deliver on its commitments in the Further Education and Training Strategy.

- The Further Education and Training Services Plan 2014 provides, for the first time, an overview of provision from the FET sector. It makes 
provision for $22,000+$ courses for around 340,000 learners, of whom approximately 90,000 would be unemployed new entrants.

The establishment of the National Apprenticeship Council in 2014 by the Minister for Education and Skills, on 18 November 2014, signalled the next phase in the implementation of recommendations from the review of the Irish apprenticeship system that was conducted by the Department of Education and Skills (DES) and published earlier that year. The Council was tasked with the expansion of the apprenticeship system into new sectors of the economy.

In 2015, the DES also initiated the establishment of a network of regional skills fora. There are nine regional skills fora organised around the eight nomenclature of territorial units for statistics (NUTS) 3 regions, with the border region divided into two. Each regional skills forum consists of representatives of all DES-overseen education and training providers in the region, namely, universities, institutes of technology, ETBs, Skillnets and local regional employer representatives and industry development agencies. A new national skills strategy - Ireland's National Skills Strategy 2025 - was published by the DES in 2016.

The FET Strategy Implementation Advisory Committee (SIAC), which is chaired by the DES and supported and hosted by SOLAS, oversees the implementation of the new FET strategy. Its membership comprises representatives of a number of lead partner organisations, such as QQI, ETBI, Aontas and NALA, as well as SOLAS. Of the 51 actions set out in the detailed FET Strategy Implementation Plan, 23 are assigned to SOLAS. One of these actions is to conduct a schedule of FET programme evaluations over the lifetime of the FET strategy. The ESRI was commissioned by SOLAS to undertake an evaluation of the national PLC programme in the autumn of 2015.

\subsection{BACKGROUND INFORMATION ON PLC}

The Post-Leaving Certificate (PLC) represents the cornerstone of further education and training (FET) in Ireland. In 2011, in the VEC sector, PLC enrolments accounted for over 50 per cent of FET enrolments, comprising 
over 80 per cent of full-time enrolments (McGuinness et al., 2014). ${ }^{6}$ During 2014, there were 32,544 PLC places available, at an estimated direct cost of $€ 169$ million (SOLAS, 2014), implying a direct cost per PLC student of approximately $€ 5,200$ (SOLAS Finance Department). ${ }^{7,8}$ Approximately 95 per cent of PLC places were located within the ETB sector during 2014, with the remaining five per cent of places offered by voluntary secondary and community and comprehensive schools. ${ }^{9}$

The central objective of PLC programmes is to provide specific vocational skills to learners, with programmes directly related to areas of labour demand. ${ }^{10}$ PLC programmes provide wide-ranging alternatives for learners: in the region of 2,500 named courses in over 60 subject areas are currently available. In addition to providing a viable alternative to thirdlevel education for school leavers, PLC programmes also constitute an important route back into education for adult learners and provide upskilling opportunities for unemployed learners seeking a route back into employment. Recent data indicate that 51 per cent of PLC enrolments were aged 21 or over in 2011 (Department of Education and Skills). ${ }^{11}$ PLC qualifications form part of the National Qualifications Framework (NQF) and facilitate progression to higher study for many learners. Given the importance of PLC programmes across a range of dimensions of Irish society, it is critical that any evaluation is based on rigorous research that takes account of provider and learner perspectives and assesses learner outcomes relative to comparable groups without PLC qualifications.

6 These figures refer to full-time equivalent (FTE) enrolments from the Department of Education and Skills (DES) in 2011. FÁs' training centres comprised the other large provider of FET. However, the FET sector includes many other, typically smaller, providers (see McGuinness et al., 2014 for a comprehensive list).

7 The first figure excludes any capital cost allocation.

8 The $€ 5,200$ figure consists of $€ 150$ million for PLC teacher costs, $€ 4$ million for PLC standard student caption and $€ 15$ million in grant support to PLC students (Source: private communication with SOLAS).

9 In terms of the FET sector as a whole, in 2011 VECs provided full- and part-time programmes. Full-time programmes included PLC courses, the Vocational Training Opportunity Scheme (VTOS), and Youthreach. Part-time programmes provided were: the Back to Education Initiative (BTEI); community education; adult literacy; intensive tuition in adult basic education (ITABE), and English for speakers of other languages (ESOL). In 2012, FÁS vocational training included apprenticeships, traineeships, specific skills training, and vocational training. These courses vary by duration (see McGuinness et al., 2014, for a complete discussion).

10 PLC providers must provide a labour market justification for all new courses before they can be approved (National Development Plan 2007-2013). Among other things, providers must demonstrate how the course aligns with Government policy and addresses skills gaps at either the local or national level.

11 Data received from the DES in relation to a previous ESRI study on FET. The data also indicate that 61 per cent of PLC enrolments in 2011 were female. 


\section{CHAPTER 2}

\section{PLC provision: Patterns from administrative data}

\subsection{INTRODUCTION}

In order to provide a detailed evaluation of PLC provision, it is first necessary to analyse the administrative data available in order to document the type of provision in terms of field of study and the distribution of PLC places across the country. This initial desk-based research element helped to inform the surveys of PLC principals and PLC and Leaving Certificate leavers, which are discussed in subsequent chapters. The main findings from this chapter show that there is a substantial amount of heterogeneity in the regional distribution of PLC places and that young people from disadvantaged regions, with the highest risk of unemployment, do not have higher-than-average access to such vocational educational programmes.

Contextual information on the size and composition of PLC provision in Ireland is available from the Department of Education and Skills (DES) enrolments data. As previously pointed out by McGuinness et al. (2014), data provision in the area for this time period is poor and no reliable microdata exist that allow for the accurate measurement of completion rates, attainment levels and progression patterns. ${ }^{12}$ In this section, we examine the pattern of PLC enrolments disaggregated over geographical region, subject area and county deprivation level. In order to draw further insights, we then categorise PLC courses into two subsets: (i) those with a strong general component (i.e. not specifically related to a particular occupation or job); and (ii) those with a strong labour market component that facilitates direct labour market entry. Finally, we examine the alignment between PLC courses that have a strong labour market component, using data from the Quarterly National Household Survey (QNHS) to estimate the demand for sub-degree newly qualified entrants to the labour market.

\subsection{PATTERNS OF PROVISION}

Our enrolment data are analysed over two separate time periods: 2008-

12 Currently, SOLAS are working to improve data provision as part of their Further Education and Training (FET) Strategy by introducing a learner's database and a course database. The Programme and Learner Support System (PLSS) project is being developed by SOLAS and ETBI and involves three strands, namely, the National Programme Database (NPD), Course Calendar Scheduling System CCSS, and the Learner Database. The first two strands have been developed and rolled out to all ETBs. The Learner Database has been piloted in Limerick/Clare ETB and is scheduled to be rolled out to all ETBs in 2017. 
2009 and 2011-2012. These periods partly reflect data availability, but they also relate to different points in the economic cycle. The information from 2008-2009 relates to the height of the crisis period and while that from 2011-2012 relates to the beginning of the recovery period. Table 2.1 shows the distribution of PLC awards by awarding bodies (FETAC and nonFETAC). Total enrolments increased by just over 4,000 (13 per cent) between 2008-2009 and 2011-2012, with the enrolment growth mostly related to a growth in FETAC enrolments. Non-FETAC enrolments, which include providers such as City and Guilds and EDEXCEL, grew marginally over the period; however, the total share declined from 18 per cent to 16 per cent. Given the nature of the DES data, it is only feasible for us to focus subsequently on enrolments by FETAC awarding bodies. It is not clear whether the shift from non-FETAC to FETAC awards is part of a longer-term trend. However, it is potentially a matter for concern given the high regard that employers have for such non-FETAC awards (McGuinness et al., 2014).

TABLE 2.1 PLC PROVISION (FETAC AND NON-FETAC AWARDS)

\begin{tabular}{l|cc|c|c}
\hline \multirow{2}{*}{ Awarding body } & \multicolumn{2}{|c|}{ 2008-2009 } & \multicolumn{2}{c}{ 2011-2012 } \\
& Freq. & $\%$ & Freq. & $\%$ \\
\hline FETAC & 26,552 & 82.3 & 30,423 & 83.6 \\
\hline Non-FETAC & 5,716 & 17.7 & 5,973 & 16.4 \\
Total & 32,268 & 100.0 & 36,393 & 100.0 \\
\hline Source: $\quad$ DES enrolments data & & & &
\end{tabular}

Source: $\quad$ DES enrolments data

We next examine the distribution of FETAC PLC places at county level. The distribution is expressed by share of total enrolments divided by population share. ${ }^{13}$ This allows us to assess the extent to which PLC enrolments lie above or below the expected level given the county's population. Specifically, a ratio greater than one indicates a higher density of enrolments relative to what might be expected for the given population. Table 2.2 indicates that there is a substantial amount of heterogeneity in the regional distribution of PLC places. For instance, in 2008-2009 the number of available PLC places in Offaly was approximately 12 per cent of what might be expected given the population; conversely, in Carlow, Cavan and Sligo, it was at least double, given their respective populations. There was some movement in the geographical distribution of places between 2008-2009 and 2011-2012: specifically, the ratio for Kilkenny, Laois, Leitrim and Longford increased significantly, while the largest falls were

13 PLC provision encompasses vocational education for young people as well as second chance education for older learners so the full population is the appropriate reference group. 
experienced in Monaghan and Wexford. It is unclear what drove the movements between 2008 and 2011. However, one would expect they may primarily be related to the opening and closure of colleges or courses rather than population changes.

\section{TABLE 2.2 DISTRIBUTION OF FETAC PLC PLACES}

\begin{tabular}{|c|c|c|c|}
\hline$\#$ & PLC county & Ratio 2008-2009 & Ratio 2011-2012 \\
\hline 1 & Carlow & 2.58 & 2.44 \\
\hline 2 & Cavan & 2.42 & 2.48 \\
\hline 3 & Clare & 0.28 & 0.35 \\
\hline 4 & Cork & 1.43 & 1.47 \\
\hline 5 & Donegal & 0.17 & 0.20 \\
\hline 6 & Dublin & 1.09 & 1.07 \\
\hline 7 & Galway & 1.12 & 1.16 \\
\hline 8 & Kerry & 0.71 & 0.63 \\
\hline 9 & Kildare & 0.24 & 0.36 \\
\hline 10 & Kilkenny & 0.70 & 0.92 \\
\hline 11 & Laois & 0.75 & 1.04 \\
\hline 12 & Leitrim & 0.41 & 0.62 \\
\hline 13 & Limerick & 1.21 & 1.10 \\
\hline 14 & Longford & 1.00 & 1.39 \\
\hline 15 & Louth & 1.56 & 1.66 \\
\hline 16 & Mayo & 0.86 & 0.97 \\
\hline 17 & Meath & 0.44 & 0.36 \\
\hline 18 & Monaghan & 1.15 & 0.64 \\
\hline 19 & Offaly & 0.12 & 0.11 \\
\hline 20 & Roscommon & 0.20 & 0.23 \\
\hline 21 & Sligo & 2.20 & 2.04 \\
\hline 22 & Tipperary & 0.89 & 0.92 \\
\hline 23 & Waterford & 1.19 & 1.34 \\
\hline 24 & Westmeath & 1.13 & 1.13 \\
\hline 25 & Wexford & 0.80 & 0.42 \\
\hline 26 & Wicklow & 0.88 & 0.87 \\
\hline
\end{tabular}

Source: DES enrolments data and CSO population data

It is not clear what determines the wide variation in the distribution of PLC places shown in Table 2.2. Variations could be related to national policy, for example, where places have been allocated to areas with high levels of unemployment or social disadvantage. Alternatively, the variations could reflect legacy effects: places exist in areas where they have always existed. 
McGuinness et al. (2014) concluded for the FET sector in general that there was a substantial amount of heterogeneity with respect to the patterns of provision in terms of the overall regional distribution of places and that legacy issues are more relevant for understanding spatial variation. ${ }^{14}$ This also holds for the PLC sector; Figure 2.1 shows no relationship between the county-level enrolment ratio and the level of deprivation. ${ }^{15}$ This is potentially worrying from a policy perspective as it demonstrates that young people from disadvantaged regions, who have the highest risk of unemployment, do not have higher-than-average access to PLC programmes.

FIGURE 2.1 HOW DOES THE RATIO OF ENROLMENTS VARY COMPARED TO THE HP DEPRIVATION INDEX (2011-2012)?

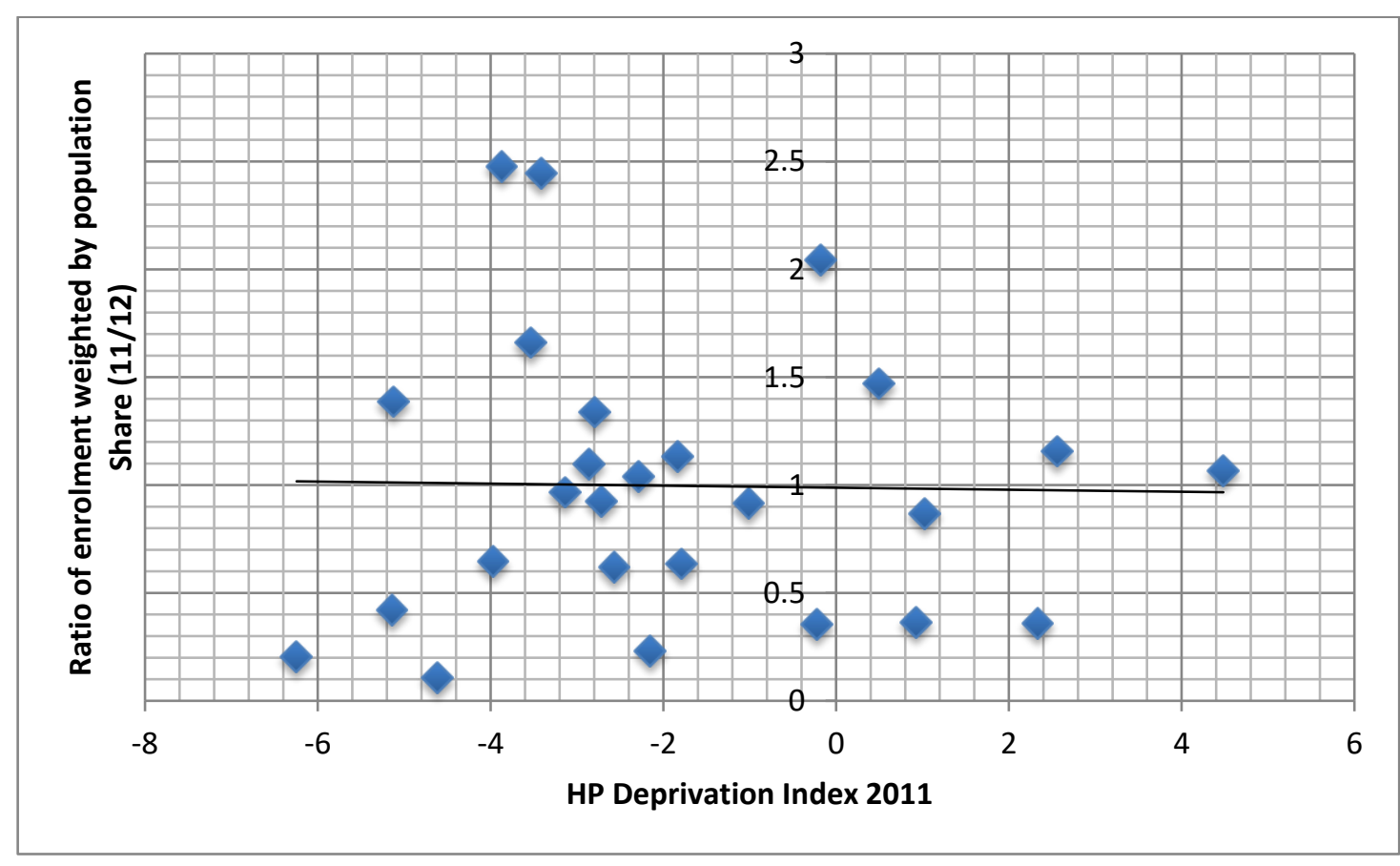

The Further Education and Training Strategy 2014-2019 (SOLAS, 2014) provides a framework aiming to address the substantial amount of heterogeneity with respect to the patterns of provision and facilitate the engagement between regional employers and education and training providers to ensure that the supply of skills is adequate to meet the needs of the local labour markets.

15 The Pobal Haase Pratchke (HP) deprivation index used here as method of measuring the relative affluence or disadvantage of a particular geographical (county) area using data compiled from various censuses. A scoring is given to the area based on a national average of zero and ranging from approximately - 10 (being the most disadvantaged) to +10 (being the most affluent). In addition to this, percentage data for the area is given under the following categories: Population Change; Age Dependency Ratio; Lone Parent Ratio; Primary Education Only; Third Level Education; Unemployment Rate (male and female); Proportion living in Local Authority Rented Housing. 
Sources: DES enrolments data, CSO population data and the Haase Pratchke (HP) index.

We next attempt to assess the degree to which PLC programmes are distributed by field of study and how these fields relate to the structure of the labour market. The rationale for this approach is that the conditions for approval for PLC programmes specifically state that programmes must be labour market relevant or have a progression element. ${ }^{16}$ Table 2.3 aggregates the enrolments data for 2008 and 2011 using the statistical field of study categories adopted by the Irish Central Statistics Office (CSO). Enrolments in education, social sciences, business, law and general programmes account for between 50 and 60 per cent of total enrolments in both periods. Agriculture, veterinary, health and welfare are typically just below 20 per cent of enrolments, while enrolments in service sector subjects account for approximately 15 per cent of the total. Finally, science, maths, computing, engineering, manufacturing and construction account for the smallest share, at about 10 per cent of the total. The relative proportion in each broad subject area appears to have remained relatively stable over the period, despite the labour market undergoing a substantial economic shock, which will have affected both the level and composition of labour demand. During this time period, the unemployment rate increased dramatically, from six per cent to just under 15 per cent (Table 2.4). Given that the composition has remained relatively stable, and the level of enrolments has increased during a period in which both the level and composition ${ }^{17}$ of labour market demand changed dramatically, it seems that, contrary to what is implied by the Conditions of Approval for PLC provision, the supply of places is not highly responsive to changing labour market conditions and shocks. ${ }^{18}$

16 The Conditions of Approval state, 'the Post Leaving Certificate (PLC) programme is a self-contained wholetime learning experience designed to provide successful participants with specific vocational skills to enhance their prospects of securing lasting, full-time employment or progression to other studies'. Course approval does not carry forward from year to year. Providers submit all courses they intend to run for approval regardless of whether they have previously been approved.

17 The Great Recession had a dramatic effect on employment in all sectors, but the largest employment losses were in construction and services (Bergin, Kelly and McGuinness, 2012).

18 The PLC Conditions of approval document (DES, 2012) includes the following statements: 'In approving courses the Department has regard to ensuring appropriate provision on a geographic basis' and 'Providers must include a Labour Market Justification (LMJ) with applications for all new courses, showing: (i) How the course provision meets with Government policy; (ii) What particular skill gaps or areas of skill growth, both locally and nationally, the course will address; and (ii) Specific data and information on progression options, local agreements with employers, information on outcomes for previous learners. 


\begin{tabular}{|c|c|c|c|}
\hline $\begin{array}{c}\text { Broad subject } \\
\text { area }\end{array}$ & PLC FETAC courses & $\begin{array}{c}\text { Enrolments } \\
\text { 2008-2009 (\%) }\end{array}$ & $\begin{array}{c}\text { Enrolments } \\
2011-2012(\%)\end{array}$ \\
\hline 1 & $\begin{array}{l}\text { General programmes } \\
\text { or humanities and arts }\end{array}$ & 19 & 19 \\
\hline 2 & $\begin{array}{l}\text { Education, social } \\
\text { sciences, business, law }\end{array}$ & 41 & 33 \\
\hline 3 & $\begin{array}{l}\text { Science, maths, } \\
\text { computing, } \\
\text { engineering, } \\
\text { manufacturing, } \\
\text { construction }\end{array}$ & 9 & 12 \\
\hline 4 & $\begin{array}{l}\text { Agriculture, veterinary, } \\
\text { health and welfare }\end{array}$ & 17 & 18 \\
\hline \multirow[t]{3}{*}{5} & $\begin{array}{l}\text { Services (e.g. } \\
\text { hairdressing, fitness) }\end{array}$ & 14 & 17 \\
\hline & TOTAL & 100 & 100 \\
\hline & $N$. & 26,552 & 30,423 \\
\hline
\end{tabular}

Source: DES enrolments data and CSO population data

TABLE 2.4 UNEMPLOYMENT RATES, 2008 AND 2011

\begin{tabular}{|c|c|}
\hline Year & Unemployment rates (\%) \\
\hline $\mathbf{2 0 0 8}$ & 6.4 \\
\hline $\mathbf{2 0 1 1}$ & 14.6 \\
\hline Source: & CSO QNHS \\
\hline
\end{tabular}

Table 2.5 provides a greater level of detail on courses with the largest enrolments by broad course area in descending order for 2011-2012. For instance, the largest number of enrolments were in early childhood care and education, which would be categorised under 'education, social sciences, business, law' (Number 2) in Table 2.3. These nine broad course areas account for almost half of all enrolments during $2011-2012 .{ }^{19}$ This gives us an indication of the composition of new (the inflow) labour supply at the sub-degree level. 
TABLE 2.5 PLC FETAC COURSES WITH THE LARGEST ENROLMENTS ACROSS BROAD
SUBJECT AREAS, 2011-2012

\begin{tabular}{|c|l|}
\hline \# Broad subject area & PLC FETAC courses 2011-2012 (QQI award titles) \\
\hline $\mathbf{2}$ & Early childhood care and education \\
\hline $\mathbf{5}$ & Sport and recreation \\
\hline $\mathbf{2}$ & Business studies \\
\hline $\mathbf{4}$ & Nursing studies \\
\hline $\mathbf{4}$ & Community and health services \\
\hline $\mathbf{2}$ & Office administration \\
\hline $\mathbf{5}$ & Hairdressing \\
\hline $\mathbf{1}$ & Art \\
\hline & Information technology \\
\hline Source: & DES enrolments data \\
Notes: & Courses are listed in descending order of enrolments. See Table 2.3 for full list of broad subject areas.
\end{tabular}

In order to estimate the composition of demand for newly qualified vocational labour for workers aged 15-24 years, we use the QNHS to identify occupations where the majority of workers are educated to a subdegree level. ${ }^{20}$ Specifically, we measure the number of workers within the QNHS in each sector that qualified in the previous 12 months, with a qualification of Leaving Certificate and below degree level who commenced their job with their current employer in the previous year. This approach will give us a broad estimate of the number of jobs likely to be available for newly qualified individuals within specific occupations. According to Table 2.6, almost 60 per cent of posts available to new entrants with vocational qualifications are in the sales and service occupations. The largest individual elements of demand are in retail and account for almost 30 per cent of the total. Waiters/waitresses account for a further 12.5 per cent. The data would suggest that the demand for newly qualified labour in construction and manufacturing was quite low in 2012. However, it is unclear to what extent this is a cyclical or permanent effect.

20 We restrict the analysis to individuals aged 15-24 as this represents the overwhelming majority of individuals qualifying over this period. 


\begin{tabular}{|c|c|c|}
\hline \multicolumn{2}{|c|}{ Detailed occupation } & $\%$ \\
\hline \multicolumn{2}{|r|}{ Sales and retail assistants, cashiers and checkout operators } & 28.9 \\
\hline \multicolumn{2}{|r|}{ Waiters and waitresses } & 12.5 \\
\hline \multicolumn{2}{|c|}{ Childminders and related occupations } & 5.7 \\
\hline \multicolumn{2}{|r|}{ Bar staff } & 5.3 \\
\hline \multicolumn{2}{|r|}{ Hairdressers, barbers, beauticians and related occupations } & 3.6 \\
\hline \multicolumn{2}{|r|}{ Cleaners and domestics } & 3.6 \\
\hline \multicolumn{2}{|c|}{ Kitchen and catering assistants } & 2.3 \\
\hline \multicolumn{2}{|c|}{ Care workers and home carers } & 2.2 \\
\hline \multicolumn{2}{|r|}{ Fishing and other elementary agriculture occupations } & 1.8 \\
\hline \multicolumn{2}{|r|}{ Elementary storage occupations } & 1.6 \\
\hline \multicolumn{2}{|c|}{ Food, drink and tobacco process operatives } & 1.6 \\
\hline \multicolumn{2}{|c|}{ Air travel assistants } & 1.4 \\
\hline \multicolumn{2}{|c|}{ Shelf fillers } & 1.3 \\
\hline \multicolumn{2}{|c|}{ Metal working production and maintenance fitters } & 1.3 \\
\hline \multicolumn{2}{|c|}{ Farmers } & 1.3 \\
\hline \multicolumn{2}{|c|}{ Other administrative occupations } & 1.3 \\
\hline \multicolumn{2}{|c|}{ Leisure and theme park attendants } & 1.2 \\
\hline \multicolumn{2}{|c|}{ Plumbers and heating and ventilating engineers } & 1.1 \\
\hline \multicolumn{2}{|c|}{ Electricians and electrical fitters } & 1.1 \\
\hline \multicolumn{2}{|c|}{ Elementary construction occupations } & 1.1 \\
\hline \multicolumn{2}{|c|}{ Receptionists } & 1.0 \\
\hline \multicolumn{2}{|c|}{ Construction operatives (NEC) } & 1.0 \\
\hline \multicolumn{2}{|c|}{ Housekeepers and related occupations } & 0.9 \\
\hline \multicolumn{2}{|c|}{ Sheet metal workers } & 0.8 \\
\hline \multicolumn{2}{|c|}{ IT user support technicians } & 0.7 \\
\hline \multicolumn{2}{|c|}{ Vehicle technicians, mechanics and electricians } & 0.7 \\
\hline \multicolumn{2}{|c|}{ Other (see Table A1 in Appendix A) } & 14.8 \\
\hline \multicolumn{2}{|c|}{ Total } & 100.0 \\
\hline $\begin{array}{l}\text { Source: } \\
\text { Note: }\end{array}$ & $\begin{array}{l}\text { QNHS, } 2012 \text { Q2 microdata (CSO) } \\
\text { Individuals aged 15-24 who qualified in the last year (2011-2012) with } \\
\text { qualification, and who commenced their job with their current employer in } \\
N E C=\text { Not elsewhere classified. }\end{array}$ & $\begin{array}{l}\text { Certificate } \\
\text { Ir (2011 or }\end{array}$ \\
\hline
\end{tabular}

In Table 2.7, we map the number of places in the largest components of PLC provision that have a direct labour market orientation and limited progression component at individual course level, against the estimated number of jobs among young people in occupations specific to these categories. ${ }^{21}$ The results clearly indicate that the annual enrolment levels greatly exceed the number of jobs likely to be available for completers,

21 Based on the QNHS using the same approach as Table 2.6. 
both in each given area and in any one year. For instance, the ratio of places to jobs in hairdressing is estimated to be 2.1 rising to 3.9 for community and health services and 4.0 for early childhood care and education. This provides further evidence that, generally, the sector is poorly connected to labour market needs, and that much more needs to be done to ensure that course provision is both reflective of and responsive to labour demand, specifically for newly qualified vocational labour.

TABLE 2.7 SOME EXAMPLES OF MAPPING DES ENROLMENTS (SUPPLY) WITH QNHS DATA (DEMAND) FOR COURSES WITH LIMITED PROGRESSION COMPONENTS

\begin{tabular}{l|c|c}
\hline$\#$ & \multicolumn{1}{c}{$\begin{array}{c}\text { PLC FETAC courses } \\
\text { (QQI award titles) }\end{array}$} & $\begin{array}{c}\text { Estimated ratio of } \\
\text { enrolments } \\
\text { to QNHS jobs }\end{array}$ \\
\hline $\mathbf{2}$ & Early childhood care and education & 4.0 \\
\hline $\mathbf{5}$ & Community and health services & 3.9 \\
\hline $\begin{array}{l}\text { Source: } \\
\text { Note: }\end{array}$ & $\begin{array}{l}\text { QNHS 2012, Q2 } \\
\text { QNHS occupations used for matching: childminders and related occupations, nursery nurses and } \\
\text { assistants and play workers; care workers and home carers, nursing auxiliaries and assistants; } \\
\text { hairdressers, barbers, beauticians and related occupations. }\end{array}$
\end{tabular}

\subsection{SUMMARY AND CONCLUSIONS}

The analysis of the administrative data indicates a substantial amount of heterogeneity in the regional distribution of PLC places. Furthermore, the provision by county is not consistently linked to the population or estimated demand for places. There is considerable variation across counties in the ratio of enrolments to the total population and there is no evidence of a relationship between the concentration of PLC places and county-level deprivation levels. The central goals of PLC provision include transitions to employment and vocational preparation for young people. Given this, we might expect PLC programmes to be targeted towards younger people who have a greater need for supports. Thus, the evidence is potentially worrying from a policy perspective as it demonstrates that young people from disadvantaged regions, who have the highest risk of unemployment, do not have greater access to PLC programmes than those in more advantaged areas. Additionally, despite considerable economic changes, there was little change over the time period (between 2008-2009 and 2011-2012) in the concentration of PLC provision across broad subject areas. The enrolments data suggest that the distribution of PLC places tends to be driven by legacy issues: places exist in areas where they have always existed, rather than because of strategic planning. With respect to PLC provision directly linked to particular jobs and occupations, there is 
evidence of substantial levels of oversupply in some areas. Consequently, there is little evidence that the number of places and composition of provision is reactive to changing labour market conditions. 


\section{CHAPTER 3}

\section{Evidence from survey of principals: Resources, objectives and outcomes}

\subsection{INTRODUCTION}

This chapter discusses the results arising from the survey of PLC principals, which collected information on a range of issues including structure, size, and composition of PLC colleges; the perceived role of PLC programmes; resources available for PLC provision; and progression patterns. ${ }^{22}$ The survey of principals provides insights into the factors driving provision and how work-related learning is embedded into the different courses. The survey was conducted between September 2015 and February 2016, and was issued to all principals: 156 in total, of whom 110 responses were received, a survey response rate of 70 per cent. Non-reponses were higher among the smaller schools and college providers. We estimate that the PLC providers who did respond account for over 80 per cent of student enrolments during 2014-2015. ${ }^{23}$

PLC principals view provision as fulfilling a range of roles, with labour market, lifelong learning, progression to higher education and social inclusion all appearing to have equal weight. Decisions around course provision and closure tend to be heavily driven by student demand, with less weight given to employer requirements, government objectives or national forecasting. The distribution of teacher qualifications maps relatively closely to the aggregate enrolments data, according to which 52 per were in the arts and social sciences, 12 per cent were in STEM, 17 per cent were in services and 18 per cent were in agriculture. Differences that do exist between the distribution of teacher qualifications and that of student enrolments may be explained by differences in class size. Finally, multivariate analysis reveals that the strategic direction adopted by colleges, particularly regarding the balance between employment and higher education-focused courses, were strongly associated with patterns of first destinations among learners; and progression rates to higher

22 A complete version of the questionnaire is included in Appendix $\mathrm{E}$.

23 The data from the survey of principals were re-weighted based on the index variable, including: size (smallest $30 \%$, middle $40 \%$, largest $30 \%$ ) in terms of total QQI enrolees (as per data from SOLAS); region (Dublin, BMW, elsewhere); and whether any non-QQI courses are provided (as per data from SOLAS). Six cases were not on the database from SOLAS, so for the purpose of weights calculation, we treated them as small providers with no non-QQI enrolees. 
education were found to be inversely related to the student-to-staff ratio.

\subsection{DESCRIPTIVE ANALYSIS}

Table 3.1 shows the distribution of PLC providers by college type as classified by the principals. ETB schools accounted for just over half of providers, followed by ETB colleges ( 26 per cent), voluntary providers (16 per cent) and others (four per cent). In terms of student numbers (Table 3.2), ETB colleges have on average the largest number of PLC students at, 706 followed by the 'other providers' category (274), ETB schools (105) and voluntary providers (74)..$^{24}$

TABLE 3.1 PLC PROVIDERS BY COLLEGE TYPE

College type

ETB second-level school that offers PLC courses

Consistent with the descriptive analysis in Chapter 2, in the five years leading up to the survey, 45 per cent of the providers indicated that the PLC enrolment figures were stable and 22 per cent reported an increase, while one-third of principals reported that numbers had declined over the previous five years (Table 3.3). It would appear that there exists substantial capacity within the PLC sector, given that the vast majority of respondents indicated an ability to expand the number of enrolments to some degree (Table 3.4). Generally speaking, the vast majority of providers tend to accept all applicants to PLC courses (Table 3.5). The one exception to this comprises providers in the 'other' category, who indicated a much lower acceptance rate; only half of this group accept all students, though it must be noted that the 'other' category is a very small group). 
College type

ETB stand-alone further education college/institute

Voluntary secondary/community/comprehensive school

offering PLC courses

N.

TABLE 3.3 CHANGE IN PLC NUMBERS OVER PREVIOUS FIVE YEARS

\begin{tabular}{l|r}
\hline \multicolumn{1}{c|}{ Change in attendance } & $\%$ \\
\hline Increased & 22 \\
Decreased & 33 \\
Stable & 45 \\
\hline N. & 109 \\
\hline
\end{tabular}

TABLE 3.4 CAPACITY TO ENROL MORE PLC STUDENTS

\begin{tabular}{|l|r|}
\hline \multicolumn{1}{c|}{ Capacity } & $\%$ \\
\hline Great extent & $\%$ \\
\hline Some extent & 68 \\
\hline None & 9 \\
\hline N. & 109 \\
\hline
\end{tabular}

TABLE 3.5 PERCENTAGE ACCEPTING ALL PLC APPLICANTS BY COLLEGE TYPE

\begin{tabular}{|l|r|}
\hline \multicolumn{1}{|c|}{ College type } & $\%$ \\
\hline ETB stand-alone further education college/institute & 75 \\
\hline ETB second-level school that offers PLC courses & 82 \\
\hline Voluntary secondary/community/comprehensive school offering PLC courses & 94 \\
\hline Other & 50 \\
\hline N. & 110 \\
\hline
\end{tabular}

Information was collected on the number of teachers and tutors employed within the responding schools/colleges by broad subject area. Table 3.6 shows the subject area in which staff are qualified, which may deviate somewhat from the area in which they teach. A total of 3,901 teaching staff were employed within the 110 institutions, of whom 61 per cent were teachers and 39 per cent were tutors. In terms of subject area, 45 per cent were qualified in the arts and social sciences, with approximately 20 per cent holding a qualification in STEM or service-related subjects. ${ }^{25}$ The

25 Science, technology, engineering and maths (STEM). 
remaining 14 per cent had qualifications in agriculture. This distribution maps relatively closely to the aggregate enrolments data, according to which 52 per were in the arts and social sciences, 12 per cent were in STEM, 17 per cent were in services and 18 per cent were in agriculture. Differences that do exist between the distribution in teacher qualification and in student enrolments may be explained by differences in class size. For example, we would expect STEM subjects to be associated with smaller classes on average. Regarding continuous professional development (CPD), 57 per cent of colleges reported that they had policies for enhancing teacher qualifications. ${ }^{26}$

TABLE 3.6 DISTRIBUTION OF TEACHING STAFF BY SUBJECT AREA

\begin{tabular}{|c|c|c|c|c|c|c|}
\hline Variable & Teachers & $\%$ & Tutors & $\%$ & Total & $\%$ \\
\hline $\begin{array}{l}\text { General programmes or } \\
\text { humanities and arts }\end{array}$ & 560 & 23 & 334 & 22 & 894 & 23 \\
\hline $\begin{array}{l}\text { Education, social sciences, } \\
\text { business, law }\end{array}$ & 629 & 27 & 236 & 16 & 865 & 22 \\
\hline $\begin{array}{l}\text { Science, maths, computing, } \\
\text { engineering, manufacturing, } \\
\text { construction }\end{array}$ & 488 & 20 & 264 & 17 & 752 & 19 \\
\hline $\begin{array}{l}\text { Agriculture, veterinary, health } \\
\text { and welfare }\end{array}$ & 373 & 16 & 169 & 11 & 542 & 14 \\
\hline Services & 333 & 14 & 515 & 34 & 848 & 22 \\
\hline Total & 2,383 & 100 & 1,518 & 100 & 3,901 & 100 \\
\hline
\end{tabular}

PLC schools and colleges reported offering a range of students supports (Table 3.7). The vast majority of schools and colleges offer career guidance, counselling, learning supports and class tutor supports. Just over 60 per cent offer disability services and supports; however, only 41 per cent offer financial supports and/or a student union, while 18 per cent offer childcare support. Larger providers are more likely to offer a range of supports to students than smaller providers, including career guidance, personal counselling, disability support, a student union, a class tutor system and childcare facilities. ${ }^{27}$

26 SOLAS has recently published the SOLAS/ETBI Professional Development Strategy for FET Practitioners (See SOLAS, 2016)

27 Results available from the authors. 


\begin{tabular}{|l|r|}
\hline \multicolumn{1}{|c|}{ Supports } & $\%$ \\
\hline Career guidance & 93 \\
\hline Class tutor supports & 86 \\
\hline Learning supports & 84 \\
\hline Counselling & 75 \\
\hline Disability support service & 61 \\
\hline DSP support & 57 \\
\hline Financial supports & 41 \\
\hline Students union & 39 \\
\hline Childcare & 18 \\
\hline N. & 109 \\
\hline
\end{tabular}

Principals were also asked to rate the available resources on a scale of one to four, where anything above two can be considered favourable. The average scores across a range of available resources are reported in Table 3.8. Generally, all resources were rated as adequate, with the exception of library/media centre resources. High levels of satisfaction among principals were recorded for the following categories: books and worksheets; computing facilities; number of teachers; and career guidance. Once again, we saw little variation in data when responses were assessed separately for large and small providers. ${ }^{28}$

TABLE 3.8 AVERAGE ADEQUACY SCORE OF AVAILABLE RESOURCES

\begin{tabular}{|l|c|}
\hline \multicolumn{1}{|c|}{ Variable } & Mean \\
\hline Books and worksheets & 2.9 \\
\hline Number of teachers & 2.8 \\
\hline Computing facilities & 2.8 \\
\hline Career guidance & 2.8 \\
\hline Technical equipment & 2.7 \\
\hline Number of classrooms & 2.6 \\
\hline Condition of the school building, classrooms etc. & 2.6 \\
\hline Administrative support & 2.5 \\
\hline Learning support provision & 2.3 \\
\hline Facilities for learners with disabilities & 2.3 \\
\hline Sports facilities & 2.1 \\
\hline Library / media centre & 1.8 \\
\hline N. & 109 \\
\hline Note: $\quad$ 1=poor, 2=fair, 3=good, 4=excellent & \\
\hline
\end{tabular}


Regarding work placements, the level of contact with local employers was variable, with just under 50 per cent of principals indicating that staff met with local employers up to once a year, while the remaining 50 per cent reported more than three meetings per year (Table 3.9). Principals indicated that work experience and job placements were discussed at the vast majority of meetings with employers. Consistent with the evidence from the learners survey (see Chapter 4), work experience does not appear to be a universal feature of PLC provision, given that 77 per cent of principals indicated that all learners took part in work experience (Table 3.10). In terms of duration, approximately 40 per cent of principals indicated that work experience placements typically lasted up to ten days, with a further 37 per cent reporting an average duration of 11-20 days (Table 3.11). Perceptions varied regarding the level of difficulty in achieving work placements, with respondents relatively equally split between those describing the process as 'easy' and 'quite difficult' (Table 3.12). In just under two-thirds of cases, students found their own work placements, with course co-ordinators responsible for organising just under one-quarter of placements (Table 3.13). In almost all cases, the principals stated that the employer was asked for feedback on the learner, with over 90 per cent of respondents also indicating that learners were assessed on the basis of their placements. ${ }^{29}$ With regard to the structure and relevance of placements, almost 87 per cent of principals indicated that PLC leaners received relevant work experience, with approximately one half organised on a day release basis and one half on a block release basis (Table 3.14). ${ }^{30}$ While 56 per cent of principals indicated that students were able to practice skills learned on the programme during work experience to 'a great extent', a further 40 per cent indicated that students had opportunities to practice skills only to 'some extent'. Finally, just under two-thirds of principals reported that students obtained employment through work experience 'to some extent', with a further 13 per cent indicating that students found employment in work experience companies to 'a great extent'. ${ }^{31}$

29 Results available from the authors.

30 Principals were asked what percentage of thir PLC learners do relevant work experience as part of their course and so the figures reported in the table are the average responses across Principals.

31 Results available from the authors. 
TABLE 3.9 HOW OFTEN DO STAFF MEET WITH EMPLOYERS IN THE LOCAL AREA? (\%)

\begin{tabular}{l|c}
\hline Never & $\%$ \\
\hline Less than once a year & 4.6 \\
\hline Once per year & 13.0 \\
\hline 3-4 times per year & 31.5 \\
\hline 5+ times per year & 40.7 \\
\hline $\mathbf{N}$ & 10.2 \\
\hline
\end{tabular}

TABLE 3.10 DO LEARNERS TAKE PART IN WORK EXPERIENCE AS PART OF THEIR PLC COURSES? (\%)

\begin{tabular}{l|c}
\hline & $\%$ \\
\hline Yes, all & 77.1 \\
\hline Yes, most & 20.2 \\
\hline A few & 2.7 \\
None & 0.0 \\
\hline N. & 109 \\
\hline
\end{tabular}

TABLE 3.11 WHAT LENGTH OF TIME DO PLC STUDENTS TYPICALLY SPEND ON A WORK PLACEMENT (DAYS)? (\%)

\begin{tabular}{l|c}
\hline & $\%$ \\
\hline $\mathbf{1 0}$ days & 39.1 \\
\hline $\mathbf{1 1}$-20 days & 37.1 \\
\hline $\mathbf{2 1}-\mathbf{3 0}$ days & 17.1 \\
\hline $\mathbf{3 1 - 6 0}$ days & 6.7 \\
\hline $\mathbf{N}$ & 105 \\
\hline
\end{tabular}

TABLE 3.12 HOW EASY IS IT, IN GENERAL, FOR LEARNERS TO OBTAIN WORK PLACEMENTS? (\%)

\begin{tabular}{l|c}
\hline & $\%$ \\
\hline Very easy & 3.7 \\
\hline Easy & 45.3 \\
Quite difficult & 49.1 \\
Very difficult & 1.9 \\
\hline $\mathbf{N .}$ & 108 \\
\hline
\end{tabular}




\begin{tabular}{l|c|}
\hline & $\%$ \\
\hline The student & 63.3 \\
\hline The course coordinator & 22.9 \\
\hline Someone else in the college/school & 2.8 \\
\hline Other & 11.0 \\
\hline $\mathbf{N}$. & 109 \\
\hline
\end{tabular}

TABLE 3.14 WHAT PERCENTAGE OF YOUR PLC LEARNERS ... ? (\%)

\begin{tabular}{l|c}
\hline $\begin{array}{l}\text { Get relevant work experience as part of their } \\
\text { course }\end{array}$ & 86.9 \\
\hline $\begin{array}{l}\text { Do work experience organised on a block basis } \\
\text { Do work experience organised on a day release } \\
\text { basis }\end{array}$ & 55.0 \\
\hline $\boldsymbol{N}$. & 51.8 \\
\hline
\end{tabular}

Principals were asked to detail the level and nature of available supports for staff training and development. Table 3.15 shows that a range of support systems were adopted in the majority of colleges; however, the most common forms of assistance, adopted by over 80 per cent of colleges, took the form of either professional development organised through the ETB network or the direct provision of training. In addition, over 70 per cent of principals also reported that staff pursuing additional training had either their fees paid or refunded by the college. Training places were relatively proportionately distributed across subject areas, with principals indicating that 35 per cent of teaching staff underwent CPD during 20142015 through short duration (e.g. one day) courses and 14 per cent underwent extended training (e.g. leading to a qualification) in the same year. ${ }^{32}$ 


\begin{tabular}{|l|c|}
\hline \multicolumn{1}{|c}{ Variable } & $\%$ \\
\hline The college/school has a mechanism/policy for enhancing teacher qualifications & 57.3 \\
\hline If yes, the college provides provision for: & \\
\hline - Training leave & 60.8 \\
\hline - Payment of fees & 72.2 \\
\hline - Refund of expenses & 73.1 \\
\hline - Direct provision of training & 80.0 \\
\hline - Professional development organised through ETB networks & 86.7 \\
\hline - Other & 48.3 \\
\hline
\end{tabular}

We next explore the relative importance of factors influencing decisions to establish new courses. There are guidelines designed to inform this process, called the Conditions of Approval, which set out a number of criteria that must be met. Providers must include a labour market justification (LMJ) with applications for all new courses showing:

- how the course provision meets with government policy;

- what particular skills gaps or areas of skill growth, both locally and nationally, the course will address; and

- specific data and information on progression options, local agreements with employers and outcomes for previous learners.

The factors considered within the survey reflect both those set out in the Conditions of Approval and other relevant considerations, such as meeting student demand and existing resources. The rating scale runs from one to five, with anything scored above three deemed to be of at least some importance. With the exception of the 'other' category, it appears that PLC providers take a broad range of factors into account when deciding to establish a new course (Table 3.16). The results suggest that decisions to establish new courses are more heavily dependent on meeting the student demand and existing resources rather than components relating to the Conditions of Approval, such as the demands of Government, requests from employers or areas highlighted through occupational forecasts. ${ }^{33} \mathrm{~A}$ relatively high focus is placed on meeting the demands of local labour market needs, while a much lower weight is given to considerations of the ETB framework. 
TABLE 3.16 AVERAGE INFLUENCE OF FACTORS ON ESTABLISHING NEW COURSE

\begin{tabular}{|l|c|}
\hline \multicolumn{1}{|c|}{ Variable } & Mean \\
\hline Meets student demand & 4.5 \\
\hline Meets the demand for workers in the local labour market & 4.3 \\
\hline There are staff with relevant skills in the college & 4.2 \\
\hline Meets the demand for workers in the regional labour market & 4.1 \\
\hline Is in line with existing resources & 4.1 \\
\hline Meets the demand for workers in the national labour market & 3.9 \\
\hline Has been highlighted by occupational forecasts & 3.8 \\
\hline Has been highlighted as an area of demand by Government & 3.7 \\
\hline Has been requested by employers & 3.6 \\
\hline ETB framework & 3.3 \\
\hline Other & 2.1 \\
\hline N. & 109 \\
\hline Note: $\quad$ 1=not at all, 5=to a great extent & \\
\hline
\end{tabular}

We next examine the relative importance of factors that influence college decisions to close courses (Table 3.17). Again, the factors considered within the survey reflect both the Conditions of Approval and other considerations, such as meeting the student demand and the availability of existing resources. As before, the rating scale runs from one to five, with anything scored above three deemed to be of at least some importance. Here a somewhat narrower picture emerges, with falling enrolments and the course not meeting the student demand constituting the most important reasons for closing courses. With respect to course closure, aspects relating to the Conditions of Approval and/or the structure of labour market demand seem to have relatively little weight in the decisionmaking process. 
TABLE 3.17 AVERAGE INFLUENCE OF FACTORS ON CLOSING COURSES

\begin{tabular}{|l|c|}
\hline \multicolumn{1}{|c|}{ Variable } & Mean \\
\hline Falling enrolments/undersubscribed & 4.3 \\
\hline Course does not meet student demand & 4.0 \\
\hline Course does not meet local labour market demand & 3.5 \\
\hline Course not in line with existing resources & 3.4 \\
\hline Oversupply of similar courses in adjacent colleges & 3.4 \\
\hline Course does not meet regional labour market demand & 3.3 \\
\hline The course does not meet national labour market demand & 3.1 \\
\hline There are no staff with relevant skills in the college & 2.9 \\
\hline Not highlighted as an area of demand by forecasts & 2.9 \\
\hline Course has not been requested by employers & 2.8 \\
\hline Not highlighted as an area of demand by Government & 2.8 \\
\hline ETB framework & 2.8 \\
\hline Other & 1.9 \\
\hline $\boldsymbol{N}$. & 109 \\
\hline Note: $1=n o t$ at all, 5=to a great extent & \\
\hline
\end{tabular}

In summary, decisions around course provision are most heavily related to meeting student demand and available teaching resources rather than responding to strategic need, whether that is related to local, regional or national labour market factors, or government policy. This evidence from the survey of PLC principals supports the finding from the administrative data in Chapter 2, which also indicates a lack of responsiveness in the sector to changing labour market needs.

It is clear that principals consider a range of factors in decisions relating to the structuring of PLC provision. For both administrative and historical reasons, PLC provision has been considered to fill a number of societal roles. While the Conditions of Approval place a heavy emphasis on the labour market aspect, PLCs are also acknowledged for their role in facilitating progression to further and higher education, as well as enhancing social inclusion and lifelong learning. This lack of clarity is reflected in principals' rating of the relative purpose of PLC courses (Table 3.18): all six options were rated with a relatively equal and high ranking, with enabling progression to higher education given a marginally higher ranking than other categories, while providing learners with a general education was given a slightly lower ranking. 


\begin{tabular}{l|c|}
\hline \multicolumn{1}{|c|}{ Variable } & Mean \\
\hline They enable progression to higher education & 1.4 \\
\hline They equip learners for entry to specific occupations & 1.5 \\
\hline They facilitate lifelong learning & 1.5 \\
\hline They equip learners for entry to general employment & 1.7 \\
\hline They facilitate social inclusion & 1.7 \\
\hline They provide learners with general education & 2.0 \\
\hline N. & 109 \\
\hline Note: $\quad$ 1=strongly agree, 5=strongly disagree & \\
\hline
\end{tabular}

In terms of completion rates, the average percentage reported for PLC students undertaking one-year courses was 76 per cent, with an average of 65 per cent of these students reported to have obtained a major award. The corresponding figures for students undertaking two-year courses was 70 per cent, for both completions and major award attainment (Table 3.19). Finally, Table 3.20 provides average progression patterns reported for PLC learners on completion of their courses by responding principals. ${ }^{34}$ Just over one-third of leavers were reported to enter employment, with approximately 28 per cent progressing to higher education, 19 per cent remaining in further education, and 12 per cent becoming unemployed.

TABLE 3.19 OVERALL, APPROXIMATELY WHAT PERCENTAGES OF STUDENTS IN YOUR COLLEGE/SCHOOL COMPLETE THEIR PLC COURSES? (\%)

\begin{tabular}{|l|c|c|}
\hline & 1 year courses (\%) & 2 year courses (\%) \\
\hline Students completing the course & 76.8 & 70.6 \\
\hline Students who obtain a major award & 65.5 & 70.2 \\
\hline N. & 103 & 53 \\
\hline
\end{tabular}

TABLE 3.20 PROGRESSION PATTERN OF PLC LEAVERS

\begin{tabular}{|l|c|}
\hline \multicolumn{1}{|c|}{ Variable } & $\%$ \\
\hline Progressing directly to employment & 33.1 \\
\hline Becoming unemployed & 12.2 \\
\hline Remaining who enter \remain further education & 19.0 \\
\hline Entering apprenticeships & 1.6 \\
\hline Progressing directly to higher education & 18.6 \\
\hline Progressing to higher education through the Higher Education Links Scheme & 9.1 \\
\hline Other & 6.4 \\
\hline N. & 109 \\
\hline
\end{tabular}
verify the responses as there is no reliable microdata source for this period. 


\subsection{ECONOMETRIC ANALYSIS}

In this section, we explore principals' decision-making processes regarding provision. In order to determine the extent to which reported rates of progression vary with provider characteristics, we undertook multivariate analysis, the results of which are reported in Table 3.21. We estimate separate models for education progression and for employment. Later in the report (Chapter 4), we look at objective measures of individual outcomes. We estimate ordinary least squares (OLS) regressions, where the dependent variables are: progression rates to employment; unemployment; further education; apprenticeship; higher education; and higher education links. ${ }^{35}$ The explanatory variables include: the number of enrolments; composition of staff by subject area; course provision; the ratio of teaching staff to students; college capacity; and factors determining course creation and closure. Given that there was a large number of potential explanatory variables, the small sample size created a 'degrees of freedom' problem, meaning that it was not feasible to include all potential explanatory variables in a single regression. Consequently, while key controls relating to provider size, staffing and course composition were included in all specifications, a more experimental approach was taken with regard to the relative importance of factors relating to course closure and creation. ${ }^{36}$

The final models are reported in Table 3.21. There was not a huge amount of variation in the data and statistically significant models could only be generated for employment and higher education, suggesting that progression rates to unemployment, further education, apprenticeship and higher education links are largely independent of provider characteristics. With respect to employment, the model indicates that higher progression rates tend to be associated with providers who tend to follow the ETB framework regarding decisions to close courses, indicating the potential importance of responding to strategic decisions at an ETB level. Higher levels of employment progression are also associated with a higher (lower) share of employment-focused (progression) courses, run as part of a sensitivity analysis and no significant changes were found. 
suggesting that some trade-off exists between the emphasis on employment and progression in colleges, which directly impacts on student outcomes. Colleges with higher levels of employment progression also reported higher levels of satisfaction regarding the progression patterns of PLC leavers, suggesting that employment progression is still perceived as a key indicator of success among principals. Finally, employment progression rates were higher among providers who indicated that they were unlikely to close courses due to the existence of similar provision in adjacent areas. ${ }^{37}$

\section{TABLE 3.21 DESTINATION SHARE OF PLC LEAVERS}

\begin{tabular}{|c|c|c|}
\hline & (1) & (5) \\
\hline VARIABLES & Employment & Higher education \\
\hline \multirow[t]{2}{*}{ Student-to-staff ratio } & -0.21 & $-0.81 * * *$ \\
\hline & $(0.363)$ & $(0.297)$ \\
\hline \multirow[t]{2}{*}{ Provider size $0-50$} & -6.05 & -5.86 \\
\hline & $(6.166)$ & (5.041) \\
\hline \multirow[t]{2}{*}{ Provider size 50-100 } & -11.24 & -7.60 \\
\hline & $(7.042)$ & $(5.758)$ \\
\hline \multirow[t]{2}{*}{ Provider size 100-250 } & -2.18 & -5.15 \\
\hline & (6.339) & (5.183) \\
\hline \multirow[t]{2}{*}{ Accept all students } & -0.24 & $-6.93 *$ \\
\hline & $(4.932)$ & $(4.033)$ \\
\hline \multirow[t]{2}{*}{ Share of teaching staff in arts } & 4.34 & -6.60 \\
\hline & (14.929) & $(12.207)$ \\
\hline \multirow[t]{2}{*}{ Share of teaching staff in social sciences } & 5.20 & 1.72 \\
\hline & $(15.163)$ & $(12.398)$ \\
\hline \multirow[t]{2}{*}{ Share of teaching staff in STEM } & 6.98 & -1.22 \\
\hline & $(16.541)$ & $(13.525)$ \\
\hline \multirow[t]{2}{*}{ Share of teaching staff in agriculture } & -2.10 & -11.19 \\
\hline & $(16.231)$ & $(13.272)$ \\
\hline \multirow[t]{2}{*}{ Higher education link, UK } & -6.06 & 2.77 \\
\hline & $(4.801)$ & (3.926) \\
\hline \multirow[t]{2}{*}{ Satisfaction with patterns of progression } & $12.24^{* *}$ & 4.40 \\
\hline & $(5.651)$ & $(4.621)$ \\
\hline \multirow[t]{2}{*}{$\begin{array}{l}\text { Percentage of Programmes with } \\
\text { employment focus }\end{array}$} & $0.25^{* * *}$ & $-0.13^{*}$ \\
\hline & $(0.080)$ & $(0.066)$ \\
\hline \multirow[t]{2}{*}{$\begin{array}{l}\text { Percentage of programmes with } \mathrm{HE} \\
\text { progression focus }\end{array}$} & $-0.22 * * *$ & $0.28 * * *$ \\
\hline & $(0.074)$ & $(0.060)$ \\
\hline
\end{tabular}

37 As mentioned in the text it was not possible to include all possible explanatory variables in the regressions. Alternative specifications were run incorporating other variables such as whether the PLC school/college has all or most students doing work experience but no significant effects were found. 
TABLE 3.21 DESTINATION SHARE OF PLC LEAVERS (CONTD.)

\begin{tabular}{|l|c|c|}
\hline & $(\mathbf{1})$ & (5) \\
\hline $\begin{array}{l}\text { VARIABLES } \\
\text { Percentage of programmes with personal }\end{array}$ & Employment & Higher education \\
\hline development focus & -0.09 & -0.10 \\
\hline $\begin{array}{l}\text { Percentage of programmes with social } \\
\text { inclusion focus }\end{array}$ & $(0.109)$ & $(0.089)$ \\
\hline Closure of courses due to staffing issues & 0.01 & 0.00 \\
\hline Closure of courses due to adjacent & $(0.115)$ & $(0.094)$ \\
\hline colleges running similar & $10.42^{*}$ & $-12.08^{* * *}$ \\
\hline Closure of courses due to ETB framework & $(5.289)$ & $(4.325)$ \\
\hline Constant & $-14.01^{* *}$ & -1.49 \\
& $(5.453)$ & $(4.459)$ \\
\hline Observations & $20.67^{* * *}$ & 4.70 \\
\hline R-squared & $(6.836)$ & $(5.589)$ \\
\hline
\end{tabular}

Notes: Standard errors in parentheses. ${ }^{* * *} p<0.01,{ }^{* *} p<0.05,{ }^{*} p<0.1$

With regard to higher education progression, there was a significant inverse relationship between rates of progression and the ratio of students to teaching staff. Higher education progression was higher (lower) among providers with a higher concentration of courses with a higher education (employment) focus, again demonstrating the impact of strategic planning on transition patterns. Higher education progression rates are lower where all students are accepted onto courses, perhaps reflecting a trade-off between a progression focus and an emphasis on social inclusion. Finally, providers with higher progression rates in higher education were less likely to indicate a tendency to close courses as a consequence of staff constraints.

\subsection{QUALITATIVE RESPONSES}

\subsubsection{Providers' perspectives on the advantages of PLC provision}

School principals were asked about the advantages of PLC provision in their own college or school, as well as at a national level. Many of the benefits cited related to both school and national level, and so responses to these two questions have been analysed together. The most commonly-cited advantage, mentioned by just under half ( 48 per cent) of providers, related to the learner-centred nature of PLC provision, with small class sizes and 
appropriate teaching methodologies facilitating student engagement:

Close personal attention, enhancing the learning experience and the self-confidence of the student.

Courses are run in [a] student friendly environment where teaching and learning are at the heart of what we do, a quality professional and stimulating learning environment is promoted and the values of respect, tolerance and integrity are encouraged.

A number of other advantages were each mentioned by around one-third of providers. These included being responsive to the local community; progression opportunities; inclusiveness; and the quality of staff. Provision at the heart of the local community was seen as key to facilitating educational participation among groups who might not otherwise access such opportunities:

[The] organic development of PLC courses meant that they are very much set locally and designed to meet needs of local communities.

In local areas people can do nationally recognised QQI courses without having to travel to big towns.

Courses provided to learners in their own locality so that they can up-skill without the need to move to a main urban centre.

Local provision was also seen to facilitate links with, and respond to, local employers:

Hands on, practical skills with good teamwork/collaboration. Learners gain a lot of transferable skills for a much wider employment range than their course.

One-third of providers mentioned the advantage of PLC provision in providing progression opportunities to higher education and labour market:

Courses equip students with the technical, social and educational skills needed to succeed in the workplace or in higher education.

Taking a PLC course was seen as a way of easing the transition to higher education for school leavers who might otherwise have struggled adapting:

All students are not ready for higher education when they finish second level. PLC is an excellent transition, learning how to learn, 
researching and writing assignments and projects as well as developing communication skills.

Excellent stepping-stone which bridges the gap between second level and third level. Prepares students very well for third level, both in terms of content of programmes, and in helping students to get into the habit of study.

Students who are too young to go to college the FETAC gives the student a chance to gain a practical qualification.

Social inclusion was seen as a key feature of PLC provision, offering 'second-chance' education to adults and a pathway for young people with very diverse backgrounds:

All of our courses are provided in a fully inclusive way. There are no formal entry requirements, thus removing the barrier to access that is the requirement to have the Leaving Certificate.

Give learners a second chance to do a course of study they have the passion and aptitude for.

The way in which PLC provision catered for a very broad group of learners at different life-cycle stages was seen as an advantage:

FE provision under the PLC programme is a highly visible, widely understood and valued provision, providing very many opportunities for a broad range of learners.

Great opportunity for those who mainstream education did not suit to re-enter education. Alternative access route to third level. Means of up-skilling for those who have been out of employment.

Staff quality was also mentioned by around one-third of providers, who highlighted the commitment and skills of their teaching staff:

Staff [are] well qualified and work as a team.

One-fifth of providers specifically highlighted the way in which PLC programmes could respond to the needs of local employers and contribute to the local economy:

Links with industry to make courses relevant and enhance employment prospects.

Providing a relative short duration vocational based education for learners who are at a level 5 educational situation. Enhancing 
standards in local services in healthcare and childcare. Providing employers with skilled workers who have had experience.

Around one in six providers focused on the personal care and support offered to students within PLC courses, which was seen as complementing the learner-centred nature of educational provision:

Care given by the staff to the students, they often require a lot of extra help in returning to education. Encouraging them to stay and complete their courses.

Good pastoral care systems, students are mentored and supported, confidence is built, they are nurtured and empowered and better equipped when they then enter the higher education sector.

Similarly, around one in six providers highlighted the nature of course provision, both in relation to the variety of courses offered within the sector and the existence of niche courses:

Many courses available in PLC colleges are not available in Higher

Education, such as hair dressing, beauty therapy, animal grooming.

A small number of providers highlighted the high quality of their facilities and their approach to assessment as the main advantages of PLC courses.

\subsubsection{Principals' perspectives on future challenges for PLC provision}

Principals were asked to identify future challenges for PLC provision in their college or school, and at the broader national level. As before, many of the benefits cited related to both school and national level, and so responses to these two questions have been analysed together.

The most frequently mentioned challenge, mentioned by over half ( 52 per cent) of principals, related to funding and resources. This covered a range of issues, including the lack of funding overall, the lack of capital investment, the approach to teacher allocation and the lack of CPD for teachers.

Staffing allocation is very inadequate considering the varied and diverse needs of the students. Cuts in Career Guidance provision is impacting adversely on students. 
The reduction in teacher allocation and the loss of the Guidance provision puts a strain on the timetable for students. Mental health issues [have] been increasing consistently for students.

Lack of teaching and other resources. We have a lot of practical /specialist courses that require constant updating and financing for equipment.

Lack of resources, lack of finances to improve physical buildings, lack of staff including support staff, administration, IT technicians etc. Support for in-service training.

Facilities - need 'common room', library, large hall. Resources, teaching personnel to meet guidance/support/learning support needs, dedicated classrooms to teach particular courses, e.g. kitchen.

Another commonly mentioned issue (41 per cent) related to the perceived competition between principals resulting from duplication of courses across the further and higher education sectors:

Competition from a myriad of other suppliers to the point where it has become ridiculous.

The attraction of students is a major factor as ITS are now enrolling everyone irrespective of their LC or LCA and thus is attracting larger numbers. However a very high majority of these students drop out in the first term.

This proliferation of places led to challenges in attracting students to PLC courses, a situation that was further exacerbated by the improving employment situation:

Decreasing numbers and competition from private providers. Also the provision of courses on a 12-month basis in other settings.

Enrolment continues to be an issue - find it difficult to compete with large stand-alone PLC colleges who can provide a lot more supports for their learners.

Improving economic conditions luring students directly to employment. Too many level 5 and 6 courses in ITs.

Over one-fifth of principals mentioned the challenges posed by the cap on PLC places in developing provision and responding to local needs:

Cap on numbers prevented us from running other courses when there was a demand. 
Caps on numbers and teacher allocation often create a situation where courses cannot be offered due to lack of teaching staff/tutors. Department of Education and Skills does not allow us to engage in the same level of flexibility that private providers have.

Lack of places, and lack of funding. If we had more PLC places, we could run, and fill, other employment and progression driven programmes, which would address a skills gap which exists in the [region].

A similar proportion (21 per cent) highlighted the ongoing challenge for the sector of remaining responsive to changing employment conditions and student needs:

Identifying and facilitating courses that meet a changing landscape.

One in six pointed to the constraints posed by offering PLC courses within an organisational structure designed for second-level education:

The management structure is all wrong in the FE college. It is the same as the second-level school. This is not suitable for what is more akin to a third-level college. This needs to change. We need a fit-for-purpose management structure.

FE remains in second-level status which is totally unsuitable for [the] sector.

Teachers on staff don't always have skills needed to teach new courses.

The main challenge is without doubt having to remain within [the] second-level provision model. This system is by far the biggest constraint on the FE Colleges.

One-tenth of principals pointed to the need for a national vision to drive PLC provision and greater coherence within the sector:

Structural reform of the sector is happening at a slow pace. PLC provision seems to be lost within the conversations surrounding the FET sector.

[There is a need for a] [c]learly defined Government policy re further education generally.

Principals highlighted a range of other challenges, including what they saw as a growing tendency to centralise provision, the need for financial 
support for students, issues around accreditation and the administrative burden placed on principals.

\subsection{SUMMARY AND CONCLUSIONS}

The evidence from the survey of principals shows that PLC provision is seen to fulfil a range of roles, including progression to employment, higher education, lifelong learning and social inclusion, with principals placing relatively equal weight on each component. There was limited evidence that factors related to the Conditions of Approval play a major role in establishing new courses, with falling enrolments the key factor behind course closures. Consistent with the evidence from the survey of learners (see Chapter 4), work experience does not appear to be a universal feature of PLC provision, with 77 per cent of principals indicating that all learners took part in work experience. The most commonly cited advantage of PLC provision, mentioned by just under half (48 per cent) of principals, related to the learner-centred nature of PLC provision, where small class sizes and appropriate teaching methodologies facilitated student engagement. The most frequently mentioned challenge, mentioned by over half ( 52 per cent) of principals, related to funding and resources. This category covers a range of issues, including the lack of funding overall, the lack of capital investment, the approach to teacher allocation and the lack of CPD for teachers. 


\section{CHAPTER 4}

\section{Evidence from survey of learners: Measuring the impacts of PLC provision}

\subsection{INTRODUCTION}

This chapter provides a descriptive analysis of the profile of PLC participants, including age, gender, previous educational attainment and socio-economic background. It presents a comprehensive analysis of learner outcomes, including multivariate estimates of the counterfactual impact of PLC provision, relative to various comparison groups, on a number of key outcomes, including employment, progression to higher education and wages. ${ }^{38}$ In addition, this chapter examines key indicators of the quality of employment, such as job satisfaction and mismatch.

The majority of PLC learners were female, on average six years older than the Leaving Certificate group and less likely to come from higher socioeconomic groups. Somewhat surprisingly, only just over 70 per cent of PLC learners reported undertaking work experience during their programmes. Of PLC participants, 39 per cent stated that their main reason for undertaking a PLC was to get a job immediately, with a similar percentage reporting that their main objective was to progress to higher education. Personal development was the key motivating factor for 20 per cent.

In terms of employment outcomes, the estimated counterfactual impact of PLC provision shows that, by 2015, PLC participants were 16 per cent more likely to be in employment relative to similar individuals who entered the labour market directly on completion of their Leaving Certificate. The employment effects are greater for PLC learners in more job-specific programmes than general ones. The counterfactual impact reveals that PLC learners are 27 per cent more likely to advance to higher education relative to similar individuals who entered the labour market directly on completion of their Leaving Certificate. The estimated counterfactual impacts on various measures of job quality, such as job satisfaction or level of skill match with the current job, showed no significant differences between the PLC learners and similar individuals who entered the labour market directly on completion of their Leaving Certificate. 


\subsection{SURVEY OF LEARNERS}

The main evidence on the effectiveness and impact of PLC provision comes from a comprehensive survey of learners. ${ }^{39}$ The objective of the survey was to collect information on school leavers, including PLC leavers, that would allow a sufficient time lag in order to enable the short-run effects of PLC participation to be observed on labour market outcomes relative to a control group and individuals following other educational pathways. The survey samples were drawn from the Department of Education and Skills (DES) Post-Primary Pupil Database (PPPDB), following a methodology developed for the 2006 and 2007 school leavers surveys. The PPPDB lists all pupils in the second-level system in Ireland, which covers the PLC sector as well. For the purposes of the sample, a school (or PLC) leaver was defined as someone who left full-time education in an official secondary, vocational, community or comprehensive school in the course of the previous academic year.

The research strategy was to complete a leavers' survey with two groups: Leaving Certificate leavers (who left their courses in 2009) and PLC leavers (who left their courses in 2010). Leaving Certificate leavers include those who studied for the Leaving Certificate Applied and the Leaving Certificate Vocational Programme, as well as the established Leaving Certificate. The sample was drawn with the assistance of the DES. Leaving Certificate leavers were identified by finding students in the final year (sixth year) of the Leaving Certificate Programme in 2009 (including the established Leaving Certificate, LCA and LCVP) who were not in the PPPDB in 2010 (i.e. not repeating the LC and not in a PLC programme). PLC leavers were identified by finding those who were in a PLC programme in 2010 and not in the PPPDB in 2011: they had left the PLC programme, either having completed or before completing the PLC course. ${ }^{40}$

A multimode approach to the fieldwork was undertaken. Respondents could complete the questionnaire online, by post, by telephone or through a face-to-face interview. A proxy questionnaire was developed, with a more limited subset of questions, which could be completed by a relative

39 A complete copy of the learner questionnaire is provided in Appendix D.

40 The ESRI selected a stratified random sample, with stratification based on gender, programme type (LC, LCVP, LCA, PLC) and, for the PLC students, whether they were under or over age 25 years on leaving the programme. The sampling fraction differed by these stratification groups, with PLC leavers and LCA leavers oversampled. 
if the original respondent was not available. ${ }^{41}$ The survey ran from September 2015 to February 2016. In total, 4,730 questionnaires were issued, with 1,220 successful responses. Of the 1,220 responses, 427 were completed by proxy and these proxy responses were evenly distributed across the Leaving Certificate and PLC categories. ${ }^{42}$ The survey response rate was 26 per cent, reflecting difficulties experienced during the fieldwork. ${ }^{43}$ This lower-than-expected response rate was attributable to a number of factors including: migration; the length of time that had lapsed since school completion; and inaccurate address information on the register. Both the longer time lag between the date of leaving and the survey and the economic climate in the intervening years, which raised the rate of out-migration, contributed to a lower response rate than had been typical of the school leavers surveys. For the present project, the time lag between leaving the course and interview was seven years for the Leaving Certificate leavers and six years for the PLC leavers. This meant that a relatively high proportion of the addresses were no longer valid. In order to ensure the representativeness of the data and thus enable our subsequent analysis, the captured data were weighted on the basis of gender, programme type and, for the PLC leavers, whether they were under or over 25 years at the time of leaving. ${ }^{44}$

In addition to a wide range of questions designed to capture information on the key characteristics, socio-economic background and educational experiences of respondents, the survey also collected information on a range of objective and subjective outcomes in both 2012 and 2015. Objective outcomes included details around employment and unemployment history, occupation, earnings and job quality. Subjective outcomes included how leavers reflected on their educational pathways, the choices they had made, their satisfaction with their labour market situation, and their expectations and plans for the future. Furthermore,

41 Only basic job charactieristics were collected in the proxy questionnaire. Therefore, a subset of this chapter, specifically the analysis on job quality, is performed using only data from the non-proxy survey.

42 Proxy respondents, such as parents or relatives, were used as suitable substitutes if they could adequately represent the 'leaver' by answering a reduced number of key questions from the survey.

43 This 26 per cent response rate can be broken down into 17 per cent for the non-proxy survey and a 9 per cent for the proxy survey.

44 The weights reflect differences in the sampling fraction and differences in response rate. Since LCA leavers are overrepresented in the sample (eight per cent) relative to their numbers in the population (three per cent), for instance, the weight has the effect of reducing their representation in results based on the weighted data to reflect the population distribution. For more information see Appendix B. 
additional detailed information was collected from respondents who participated in any kind of post-school education or training (including PLCs) on aspects of their experience, such as subjects studied, perceptions of teaching and learning, levels of accreditation, progression paths, the nature and relevance of work placements, and the perceived quality of their experience. ${ }^{45} \mathrm{~A}$ pilot survey was undertaken to ensure the questionnaire was clear and that it achieved these objectives.

In identifying the post-school pathways of leavers, it emerged that a small number of survey responses did not always match a leaver's status, particularly in terms of PLC participation (as recorded on the PPPDB). Where information was inconsistent, it was necessary to make a judgement based on the calendar information recorded in the survey to determine the post-school educational participation of respondents. It is interesting to note that a recent circular to schools (Circular 0063/2016) notified schools of revised procedures for the submission of data on PLC students by schools from the 2016-2017 academic year. Such returns are now generated by schools from the Programme and Learner Support System. These revised procedures will hopefully reduce the incidence of inconsistencies in the recording of PLC participants.

\subsection{DESCRIPTIVE ANALYSIS}

This section discusses the main characteristics of respondents, before estimating the impact of PLC provision on a series of outcomes relative to both a control group and students undertaking other educational pathways such as higher education. ${ }^{46}$ Table 4.1 provides basic descriptive statistics for PLC learners and for Leaving Certificate learners who did not subsequently take any further education courses. The Leaving Certificate grouping in Table 4.1 consists of individuals who entered the labour market directly and those who progressed directly to higher education. Table 4.1 reveals that the majority of PLC learners were female, on average six years older than the Leaving Certificate group, and less likely to come from higher socio-economic groups.

45 We currently do not have a datafile that matches the PLC learners to providers (and their associated school or college). The analysis in chapters four and five is at the individual level. 


\begin{tabular}{|l|c|c|}
\hline \multicolumn{1}{|c|}{ Characteristics } & PLC (\%) & $\begin{array}{c}\text { LC } \\
\text { (that did not take } \\
\text { FE) (\%) }\end{array}$ \\
\hline Female & 62.9 & 48.2 \\
\hline $\begin{array}{l}\text { Current age (in years) } \\
\text { Mother's highest level of education is degree or } \\
\text { higher }\end{array}$ & 31.2 & 24.3 \\
\hline
\end{tabular}

Note: $\quad$ LC excludes those who (i) report that they have subsequently taken a PLC course and/or (ii) who report their main status in any of September 2010, September 2012 and September 2015 as studying a further education course. Weighted data.

Table 4.2 provides information on the distribution of Leaving Certificate points, for the entire sample and then for PLC students and the Leaving Certificate group (who did not take further education). ${ }^{47,48}$ The table shows that the majority (62 per cent) of PLC leavers are in the 200-400 points band categories, while the majority of the Leaving Certificate group (63 per cent) are in the 300-500 band categories. The difference in the points distributions reflects the higher proportion of Leaving Certificate cohort who went directly to higher education.

47 Of the 1,220 survey respondants, points data were available for 791 cases. Participants in the non-proxy survey were asked if their Leaving Certificate results could be accessed from the State Examinations Commission. This resulted in information for an additional 134 cases; in total, points data were available for 998 respondants.

48 Individuals from the group may have progressed directly to higher education or the labour market. 
TABLE 4.2 POINTS DATA FROM LEARNERS SURVEY

\begin{tabular}{|c|c|c|c|}
\hline Points bands & All & PLC & $\begin{array}{l}\text { LC } \\
\text { (that did not take } \\
\text { FE) }\end{array}$ \\
\hline $0-100$ & 7.2 & 13.9 & 3.9 \\
\hline $101-200$ & 9.7 & 17.2 & 4.3 \\
\hline 201-300 & 20.1 & 31.0 & 13.4 \\
\hline $301-400$ & 31.3 & 31.0 & 30.3 \\
\hline 401-500 & 22.7 & 6.0 & 34.2 \\
\hline 501-600 & 8.9 & 0.9 & 13.9 \\
\hline$\#$ & 998 & 421 & 500 \\
\hline \multicolumn{4}{|c|}{$\begin{array}{l}\text { Note: } \quad \text { LC excludes those who (i) report that they have subsequently taken a PLC course and/or (ii) who } \\
\text { report their main status in any of September 2010, September } 2012 \text { and September } 2015 \text { as studying a } \\
\text { further education course. } \\
\text { Wote: } \quad \text { Weighted data }\end{array}$} \\
\hline
\end{tabular}

According to the PLC respondents, over 70 per cent of learners undertook work experience during their PLC studies. ${ }^{49}$ This seems somewhat unusual given that work experience is a compulsory component of PLC courses. ${ }^{50}$

TABLE 4.3 ALL PLC LEARNERS: DID YOU PARTICIPATE IN WORK EXPERIENCE DURING YOUR PLC STUDIES?

\begin{tabular}{l|r}
\hline & $\%$ \\
\hline Yes & 71.7 \\
No & 28.3 \\
Total & 100 \\
N & 382 \\
\hline Note: $\quad$ Weighted data & \\
\hline
\end{tabular}

Table 4.4 shows the broad fields of study reported by PLC learners. Overall, there is a similar pattern to the administrative data reported in Chapter 2 (Table 2.3). The shares of PLC learners in services, education, social sciences, business and law and STEM subjects are closely aligned to the administrative data, while the share in general programmes, humanities and arts is somewhat lower, while the share in agriculture, veterinary, health and welfare is somewhat higher than in the administrative data. ${ }^{51}$

49 This compares to $77 \%$ of PLC principals reporting that all their learners took part in work experience as part of their PLC courses (see Table 3.10).

50 One plausible explanation for this is that a large proportion left their course before completing the work experience component; however, when the sample is restricted to PLC learners who also report that they have completed their course, the proportion undertaking work experience rose to only 75.8 per cent.

51 It should be noted that the data in Table 2.3 only refer to FETAC courses, while Table 4.4 includes non-FETAC courses. 


\begin{tabular}{|l|c|}
\hline \multicolumn{1}{|c|}{ Programme } & $\begin{array}{c}\text { Share of PLC } \\
\text { learners (\%) }\end{array}$ \\
\hline General programmes or humanities and arts & 14.6 \\
\hline Education, social sciences, business and law & 30.6 \\
\hline Science, maths computing, engineering, manufacturing, construction & 10.9 \\
\hline Agriculture, veterinary, health and welfare & 26.3 \\
\hline Services (e.g. hairdressing, fitness) & 17.7 \\
\hline
\end{tabular}

PLC learners were asked about their primary objective for undertaking a PLC programme (Table 4.5). In response, 39 per cent said that their main goal was to get a job immediately after the PLC course, with a similar percentage reporting that their main goal was to progress to higher education. Almost 20 per cent cited personal development as the key motivating factor for pursuing a PLC course.

\begin{tabular}{l|r}
\hline Get a job right away after the PLC course & $\%$ \\
\hline Get a place on a higher education programme & 39.0 \\
\hline Personal development & 38.6 \\
\hline Other & 18.5 \\
\hline Total & 3.9 \\
\hline N & 100 \\
\hline Note: $\quad$ PLC learners were asked for their one primary objective so only one box could be ticked. Weighted data. & 232 \\
\hline
\end{tabular}

Table 4.6 breaks down this information on primary objectives by field of study. Although the sample sizes become quite small, the table reveals that the highest proportion of individuals wishing to progress to higher education can be found among those undertaking STEM subjects ( 58 per cent). Students most likely to report immediate employment as their main objective were in: education; social sciences; business and law; agriculture, veterinary, health and welfare; and services. Nevertheless, less than 50 per cent of students on these courses reported employment as their key objective. The percentage citing personal development as their primary objective were most likely to be in general programmes, the humanities and arts. 


\begin{tabular}{|l|c|c|c|c|c|c|}
\hline & $\begin{array}{c}\text { Get place on } \\
\text { HE programme }\end{array}$ & $\begin{array}{c}\text { Get job right } \\
\text { after PLC } \\
\text { course }\end{array}$ & $\begin{array}{c}\text { Personal } \\
\text { development }\end{array}$ & Other & Total & N. \\
\hline $\begin{array}{l}\text { General programmes or } \\
\text { humanities and arts }\end{array}$ & 36.3 & 29.6 & 26.5 & 7.6 & 100 & 33 \\
\hline $\begin{array}{l}\text { Education, social } \\
\text { sciences, business and }\end{array}$ & 32.9 & 49.4 & 13.4 & 4.3 & 100 & 64 \\
\hline \begin{tabular}{l} 
law \\
\hline $\begin{array}{l}\text { Science, maths } \\
\text { computing, engineering, }\end{array}$
\end{tabular} & 57.9 & 18.0 & 20.6 & 3.6 & 100 & 24 \\
\hline $\begin{array}{l}\text { manufacturing, } \\
\text { construction }\end{array}$ & 38.7 & 42.8 & 16.0 & 2.5 & 100 & 49 \\
\hline $\begin{array}{l}\text { Agriculture, veterinary, } \\
\text { health and welfare }\end{array}$ & 27.8 & 43.8 & 22.2 & 6.2 & 100 & 30 \\
\hline $\begin{array}{l}\text { Services (e.g. } \\
\text { hairdressing, fitness) }\end{array}$ & & & & & & \\
\hline
\end{tabular}

Note: $\quad$ PLC learners were asked for their one primary objective, so only one box could be ticked. Weighted data.

PLC respondents were also asked if they felt their PLC studies opened up opportunities for further study at a range of alternative institutions (Table 4.7). Over 40 per cent felt that their studies presented opportunities to attend an institute of technology, 24 per cent indicated that they presented opportunities to study at an Irish university and a further nine per cent at UK universities.

TABLE 4.7 ALL PLC LEARNERS: DID PLC COURSE OPEN UP OPPORTUNITIES FOR FURTHER STUDY AT ... ?

\begin{tabular}{l|r}
\hline \multicolumn{1}{|c|}{ Type of third-level college } & $\%$ \\
\hline Irish universities & 24.4 \\
\hline UK universities & 8.6 \\
\hline Institutes of technology & 41.2 \\
\hline Other & 10.4 \\
\hline N. & 288 \\
\hline Note: $\quad$ PLC learners could pick more than one option. Weighted data.
\end{tabular}

PLC learners were asked a range of questions related to their course experience. Specifically, they were asked to rate, on a scale of one to six, their relationships with other students, staff and administrative personnel (where one is 'unavailable and unsupportive' and six is 'available and supportive'). The average scores for all groups were high, indicating 
generally positive relationships, with the highest score reported for interactions with other students, followed by teaching staff, and the lowest score for administrative personnel (Table 4.8).

TABLE 4.8 ALL PLC LEARNERS: HOW WOULD YOU DESCRIBE YOUR RELATIONSHIPS WITH EACH OF THE FOLLOWING?

\begin{tabular}{|c|c|}
\hline Category & Average score \\
\hline Other students & 5.0 \\
\hline Teaching staff & 4.8 \\
\hline Administrative personnel & 4.4 \\
\hline$N$. & 280 \\
\hline
\end{tabular}

\subsection{ECONOMETRIC ANALYSIS}

As already stated, a key objective of our study is to assess the impact of PLC participation on outcomes such as progression to higher education, progression to employment and quality of employment. From a technical prospective, the counterfactual impact of PLC provision is only truly measured relative to individuals who had access to a PLC programme, did not participate in it and received no further 'treatment' (i.e. no other training or education exposure). Specifically, the counterfactual will most accurately be measured by comparing the outcomes of the PLC treatment group with the Leaving Certificate completers who entered the labour market on completion of their studies. Within this study, the direct labour market entrants form the principal control group against which the effectiveness of the PLC programme is assessed. Nevertheless, while the direct labour market entrant forms the basis of a counterfactual estimate, comparisons between PLC entrants and those undertaking other forms of treatments (for example, directly to higher education) are also informative and will be investigated within this framework. We are particularly interested in comparing the outcomes of PLC participants with those of similar individuals who progressed directly to higher education following completion of their Leaving Certificate.

In our assessment of the impact of the treatment, we explicitly recognise the heterogenous nature of PLC provision. Specifically, some programmes will tend to be directly targeted at immediate employment opportunities and, while such programmes also facilitate progression to further study, they can be classified as job specific in nature. The remainder of programmes, while providing opportunities for employment and further study, by virtue of the fact that they tend not to be targeted at specific 
occupations, we classify as general. ${ }^{52}$ The distinction between job-specific and general PLC provision is adopted for the vast bulk of our empirical estimates. However, in some cases sufficient information was not provided or the course title did not easily lend itself to a specific field of study for our classification purposes. Table 4.9 describes the construction of the various treatment and control groups. In our first treatment and control groups, we exclude Leaving Certificate learners who subsequently took a PLC course and/or have other further education exposure. This restriction leaves us with 421 observations in the PLC treatment group and 500 in the LC control group, which we consider a highly workable sample.

TABLE 4.9 TREATED AND CONTROL GROUPS - DEFINITIONS

Definitions

Original sample

of whom:

PLC

LC

Exclude cases where points data are not available:

PLC

Exclude LC Learners with PLC and/or further education exposure:

those who (i) report that they have subsequently taken a PLC course and/or (2) who report their main status in any of Sept. 2010, Sept. 2012 and Sept. 2015 as studying a further education course

PLC - Treatment group 'ALL PLC'

LC - Control group 'ALL LC'

\section{Exclude both PLC and LC Learners with other training} exposure:

those who report their main status in any of September 2010, September 2012 and September 2015 as:

'apprenticeship' , 'internship', 'other FÁS/SOLAS, Fáilte Ireland, Teagasc course', etc. and 'on a private training scheme'.

PLC

LC

Separate out LC Learners who went straight to HE: those who report their main status in Sept. 2010 to be higher education

PLC - Treatment group 'PLC'

52 Tables A2 and A3 in the Appendix describe the fields of study we have allocated to each category. 
LC - Straight to higher education - Control group 'higher

education LC'

LC - Rest (direct entrants to labour market) - Control group

'LM LC'

Distinguish between job-specific and general PLCs:

treatment group 'PLC' who undertook PLC programmes in

more labour-market-oriented fields of study versus those

who did not.

PLC - No detailed PLC course info provided

PLC - General - Treatment group 'General PLC'

PLC - Job Specific - Treatment group 'JS PLC'

LC - Straight to higher education - Control Group 'higher

education LC'

LC - Rest (Direct Entrants to Labour Market) - Control group 'LM LC'

Note: $\quad$ LC excludes those who (i) report that they have subsequently taken a PLC course and/or (ii) who report their main status in any of September 2010, September 2012 and September 2015 as studying a further education course.

The various PLC treatment groups refer to learners who participated in PLC courses and, for various reasons, not all of these learners will have completed their courses and attained certification. As a robustness check, we estimated the impact of PLC participation on some of the key outcome variables, including only those learners who report that they completed their PLC course. Specifically, we estimated the impact of PLC participation on progression to employment in 2015 and progression to higher education. The results are shown in Tables A15 and A16 in Appendix A. The broad picture remains the same and many of the estimates are stronger when we control for completion.

Table 4.10 provides basic descriptive information on the treatment group and the LC group (who have not done further education). There are some clear differences between the two groupings, suggesting a non-random self-selection process into PLC study. Specifically, the PLC participants are more likely to be female and older, and to have a lower points score than those in the LC (non-further-education) group. With respect to labour market outcomes, while the PLC group are more likely to be in employment in 2012 and less likely to be in higher education, the rates grow much more similar by $2015 .{ }^{53}$ 


\begin{tabular}{|l|c|c|}
\hline & All PLC & All LC \\
\hline & $\begin{array}{c}\text { Excluding LC learners with further } \\
\text { education exposure }\end{array}$ \\
\hline Current age (years) & \multicolumn{2}{|c|}{} \\
\hline Proportion female (\%) & 28.6 & 24.3 \\
\hline Average points (00's) & 65.2 & 48.9 \\
\hline \% in employment in 2012 & 3.0 & 4.3 \\
\hline \% in unemployment in 2012 & & \\
\hline \% in higher education in 2012 & 42.8 & 24.2 \\
\hline \% in employment in 2015 & 10.4 & 6.3 \\
\hline \% in unemployment in 2015 & 27.0 & 59.8 \\
\hline \% in higher education in 2015 & & 66.0 \\
\hline
\end{tabular}

Note: Employment refers to paid employment or self-employment; unemployment refers to unemployed but looking for work. Weighted data.

This broad pattern - of PLC learners being more likely to be in employment and less likely to be in higher education in 2012 than the other years - is more pronounced when we distinguish between general and job-specific PLCs. For example, as shown in Table 4.11, just under 36 per cent of those in general PLCs were in employment in 2012 as opposed to over 50 per cent of those in job-specific PLCs. By 2015, the percentage of people in employment and in higher education in the various treatment and control groups became comparable again. ${ }^{54}$

54 There are 573 PLC learners in the entire sample (see Table 4.9). Of these, 28 per cent were in employment and 19 per cent were in higher education in 2010, while the comparable figures for 2012 are 42 per cent and $24 \%$ and the related figures for 2015 are 57 per cent and seven per cent. 
TABLE 4.11 TREATED AND CONTROL GROUPS: SOME DESCRIPTIVE STATISTICS FOR 2012 AND 2015

\begin{tabular}{|c|c|c|c|c|c|}
\hline \multirow{3}{*}{$y_{2}^{2}$} & \multirow[t]{2}{*}{ PLC } & \multirow[t]{2}{*}{ higher } & LM LC & GEN & JS PLC \\
\hline & & & \multicolumn{3}{|c|}{ Excluding learners with other training exposure } \\
\hline & PLCs & $\begin{array}{l}\text { LC direct to } \\
\text { Higher } \\
\text { Education }\end{array}$ & $\begin{array}{l}\text { LC direct } \\
\text { to Labour } \\
\text { Market }\end{array}$ & $\begin{array}{c}\text { Genera } \\
\text { I PLCS }\end{array}$ & Job Specific PLCs \\
\hline Current age & 28.6 & 24.2 & 24.4 & 29.7 & 28.8 \\
\hline Proportion & 67.0 & 53.1 & 41.3 & 60.8 & 85.5 \\
\hline Average & 3.0 & 4.7 & 3.4 & 3.0 & 3.0 \\
\hline$\%$ in & 44.6 & 13.0 & 55.7 & 35.6 & 51.0 \\
\hline$\%$ in & 11.5 & 5.2 & 10.6 & 12.5 & 7.0 \\
\hline$\%$ in higher & 28.3 & 80.7 & 12.6 & 36.9 & 22.0 \\
\hline$\%$ in & 66.0 & 68.0 & 64.4 & 63.0 & 67.8 \\
\hline$\%$ in & 13.6 & 8.3 & 11.7 & 16.3 & 6.5 \\
\hline$\%$ in higher & 7.2 & 17.9 & 6.0 & 11.0 & 6.5 \\
\hline
\end{tabular}

We next measure the impact of PLC participation on a range of outcome variables, including progression to employment, progression to higher education and job quality indicators for those in employment (such as job satisfaction, earnings and mismatch). We adopt econometric techniques that, for example, compare the probability that PLC leavers are more likely to be in employment in 2012 and 2015 relative to Leaving Certificate students who entered the labour market or higher education directly after, controlling for a range of other factors.

An issue that arises in estimating the counterfactual, and relativities with respect to other forms of treatment, is that individuals are likely to selfselect into various options, and this self-selection is likely to be highly dependent on Leaving Certificate points. This suggests that estimates generated within a standard multivariate framework may not generate reliable results. For instance, PLC entrants have much lower concentrations in the 400-600 Leaving Certificate points range relative to those entering higher education directly. Conversely, PLC entrants have a Leaving Certificate profile that is much more similar to Leaving Certificate students who entered the labour market directly. To overcome any potential bias related to self-selection into various routes, we adopt propensity score matching (PSM) techniques, which ensure that the outcomes of the treatment group will be compared to those of the control group (and those undertaking other treatment) on a like-for-like basis. Consequently, while we present results generated from both the 
multivariate and PSM approaches in Appendix A, we deem the PSM results to be the most reliable and concentrate solely on these in the main body of the report. ${ }^{55}$

PSM analysis involved a two-stage estimation procedure. In stage one, a probit model assigns a probability of being assigned to the treatment group to all respondents (both control and treatment) based on observable characteristics. Individuals are matched on the basis of propensity scores, the underlying rationale being that this is equivalent to matching on observable characteristics ensuring that the treatment and control group are very similar in all aspects relevant to assignment to the treatment. In stage two, outcomes (such as earnings, employment and job satisfaction) of the treatment and control groups are compared, in order to get an estimate of the average effect of the treatment (in this case PLC study) on the treated (PLC students). In order to ensure that our PSM estimates are as reliable as possible, we apply a caliper approach to the Kernel algorithm to ensure that, at the point of estimation, all observable differences between the control and treatment groups are fully eradicated. The first stage of the PSM estimation procedure is informative in itself, as it reveals the key characteristics that distinguish PLC students from those of the specific control groups (direct entrants to the labour market and higher education).

The stage one equations show that relative to Leaving Certificate students who entered the labour market directly, the probability of participating in PLC study (i.e. being in the treatment group) is positively associated with age, being female, having a lower points score and not having taken the Leaving Certificate Applied programme. ${ }^{56}$ In addition, a proxy for social class (whether either or both of the individual's parents had a degree) was included in the first stage regression but the effect was not significant. The stage one equation for participating in a PLC programme, relative to Leaving Certificate students who went directly to higher education, show similar results, with age, being female and having a lower points score all being positive factors affecting an individual's likelihood of participating in a PLC programme. The impact for having taken the Leaving Certificate Applied programme is not significant in this model. Being from a higher 
social class has a negative effect on the likelihood of participating in a PLC programme, but this effect is only significant at the 10 per cent level. ${ }^{57}$

Turning first to employment outcomes, it is important to note that not all PLC completers or higher education direct entrants will have finished their studies at the end of 2012. ${ }^{58,59}$ For this reason, the estimated employment impacts are not highly informative. Perhaps not surprisingly, no difference was observed in the employment outcomes of either PLC participants, no matter how they were defined, or the relevant control groups. ${ }^{60}$ Tables 4.12 and 4.13 show the results for employment outcomes in 2015 relative to direct labour market entrants (4.12) and direct higher education entrants (4.13). The direct labour market entrant group is used to calculate the counterfactual estimate of PLC participation and the results show that by 2015 , PLC participants were 16 percentage points more likely to be in employment relative to similar individuals who entered the labour market directly on completion of their Leaving Certificate in 2009. Exploring this result in further detail, we find that the employment effects are greater for job-specific than general PLCs and for PLC participants who progressed directly to the labour market rather than to higher education. Nevertheless, given that many of the PLC cohort who progressed to higher education will have undertaken general PLCs and were still completing their studies in 2015, these particular estimates cannot be taken as definitive.

It is important to note that approximately 10 per cent of the PLC sample were in receipt of the Back to Education Allowance (BTEA). The BTEA is a non-statutory second-chance education scheme for jobseekers that was expanded rapidly between 2008 and 2013 as the rate of unemployment in Ireland rose rapidly, following the onset of the well documented recession. Individuals in receipt of the BTEA received a weekly allowance, equivalent to jobseeker welfare payments, while pursuing a second-level qualification (such as a PLC) or a third-level course. A recent evaluation of the BTEA programme found that it had a highly negative impact on participants' subsequent employment probabilities. Specifically, the results indicated that jobseekers who commenced a second-level option BTEA claim in September/October 2008 were between 28 and 30 percentage points less

57 See Appendix Tables A4-A12.

58 Some results on employment outcomes are available, which indicate, on the basis of PSM estimates, that, not surprisingly, individuals pursuing general PLCs are somewhat less likely to be employed in 2012 relative to Leaving Certificate direct labour market entrants. Conversely, job-specific PLCs and, to a lesser extent, general PLC graduates are somewhat more likely to be in employment in 2012 relative to direct higher education entrants.

59 For example, a proportion of PLC completers will have progressed to higher education during this period.

60 See Appendix A for details. 
likely to have left the Live Register in June 2012 relative to the control group of claimants who did not participate in the programme. This negative impact fell to 25 percentage points by June 2014 (Kelly et al., 2015). The evaluation was purely quantitative and the authors could not draw any conclusions with respect to the extent to which the negative employment impact was being driven by issues such as the quality of education, the effectiveness of the activation process or other factors. Nevertheless, the results from Kelly et al. (2015) suggest that some checks should be undertaken regarding the performance of the BTEA cohort within the current evaluation.

As a robustness check, we re-estimate the PLC treatment effect, excluding those on BTEA, and find that the estimated employment treatment effect in 2015 increases from 16 to 19 per cent. Relative to the control group we find that the individuals in receipt of the BTEA were 22 per cent less likely to be in employment in 2015. While the control group here is somewhat different to that used in the BTEA evaluation ${ }^{61}$, the result is highly consistent with that study. The results of this study further suggest that the negative aspects of the BTEA programme are unlikely to relate to the quality or nature of the educational aspect of delivery, given the highly positive employment impacts experienced by PLC participants not in receipt of the BTEA.

Transitions to higher education (Table 4.14) are assessed relative to the direct labour market entrants group only. Compared to the control group, PLC participants were 27 percentage points more likely to have participated in higher education by 2015 . Separating the effects out by PLC type, we find that PLC students undertaking general and job-specific PLCs were more likely than direct labour market entrants to have undertaken higher education by 2015, by 38 compared to 26 percentage points, respectively. The analysis shows that PLC provision acts as an important access platform to higher education for individuals who otherwise might never have pursued that particular educational option.

61 In the Kelly et al. (2015) study, the control group was drawn from the Live Register and consisted of individuals with similar characteristics to those of the BTEA participants (for instance, regarding age, previous occupation and labour market history). 


\begin{tabular}{|l|l|l|}
\hline \multicolumn{1}{|c|}{ Treatment group } & \multicolumn{1}{c|}{ Control group } & \multicolumn{1}{c|}{ Estimate } \\
\hline All PLC learners & All LC & 0.04 \\
\hline PLC & LC - direct LM entrants & $0.16^{* *}$ \\
\hline $\begin{array}{l}\text { PLC who went to higher education } \\
\text { PLC who did not progress to higher } \\
\text { education }\end{array}$ & LC - direct LM entrants & 0.08 \\
\hline $\begin{array}{l}\text { General PLCs } \\
\text { Job-specific PLCs }\end{array}$ & LC - direct LM entrants & $0.23^{* * *}$ \\
\hline
\end{tabular}

Note: $\quad$ Table shows the estimated impact on the probability of being in employment in 2015 from the PSM models. Levels of significance: ${ }^{* * *} p<0.01,{ }^{* *} p<0.05,{ }^{*} p<0.10$.

TABLE 4.13 EMPLOYED IN 2015: ESTIMATED IMPACT RELATIVE TO LEAVING CERTIFICATE STUDENTS WHO PROGRESSED STRAIGHT TO HIGHER EDUCATION

\begin{tabular}{|c|c|c|}
\hline Treatment group & Control group & Estimate \\
\hline PLC & $\begin{array}{l}\text { LC - straight to higher } \\
\text { education }\end{array}$ & 0.01 \\
\hline $\begin{array}{l}\text { PLC who went to higher } \\
\text { education }\end{array}$ & $\begin{array}{l}\text { LC - straight to higher } \\
\text { education }\end{array}$ & -0.08 \\
\hline $\begin{array}{l}\text { PLC who did not progress to } \\
\text { higher education }\end{array}$ & $\begin{array}{l}\text { LC - straight to higher } \\
\text { education }\end{array}$ & 0.06 \\
\hline General PLCs & $\begin{array}{l}\text { LC - straight to higher } \\
\text { education }\end{array}$ & -0.05 \\
\hline Job-specific PLCs & $\begin{array}{l}\text { LC - straight to higher } \\
\text { education }\end{array}$ & -0.03 \\
\hline
\end{tabular}

TABLE 4.14 PROGRESSION TO HIGHER EDUCATION: SUMMARY OF ESTIMATES

\begin{tabular}{l|l|c}
\hline \multicolumn{1}{c|}{ Treatment group } & \multicolumn{1}{c|}{ Control group } & PSM estimate \\
\hline PLC & LC - direct LM entrants & $0.27^{* * *}$ \\
\hline Job-specific PLCs & LC - direct LM entrants & $0.26^{* * *}$ \\
\hline General PLCs & LC - direct LM entrants & $0.38^{* * *}$ \\
\hline
\end{tabular}

Note: $\quad$ Progression to higher education is defined as reporting higher education to be main status in September 2010, 2012 or 2015 . 
For those in employment, we also examine several aspects of job quality, including job satisfaction and level of skill utilisation. In terms of job satisfaction, respondents were asked to rate their satisfaction with their current work. The model results did not reveal any significant differences in job satisfaction between the PLC treatment group and the direct labour market control group. ${ }^{62}$ Labour market mismatch describes the situation whereby the skill levels or education of the individual are to some degree misaligned with the productivity requirements of their role. Individuals can be mismatched as a consequence of being either overskilled or underskilled relative to the requirements of their job. To capture mismatch, respondents were asked to compare their acquired skills and knowledge to those required for their current job. In presenting these findings, 'underskilling' is defining as having too few skills relative to what is required. The concept is analogous to that of skill gaps usually captured in firm-level surveys. Learners were asked to rate, on a scale of one to five, the extent to which their job demands more skills and knowledge than they can actually offer, where one is 'not at all' and five is 'to a very great extent'. A response of four or five is deemed to be consistent with underskilling and a response of five is deemed consistent with severe underskilling. The incidence of underskilling is reported in Table 4.15.

\begin{tabular}{l|c|c|}
\hline & \% Underskilled & \% Severely underskilled \\
\hline \begin{tabular}{l|l} 
All PLC \\
ALL LC
\end{tabular} & 34 & 15 \\
\hline PLC & 35 & 15 \\
\hline $\begin{array}{l}\text { PLC who went to higher } \\
\text { education }\end{array}$ & 31 & 17 \\
\hline $\begin{array}{l}\text { PLC who did not } \\
\text { progress to higher } \\
\text { education }\end{array}$ & 36 & 15 \\
\hline $\begin{array}{l}\text { LC - direct labour market } \\
\text { entrants } \\
\text { LC - straight to higher } \\
\text { education }\end{array}$ & 37 & 13 \\
\hline \multicolumn{1}{|l|}{ Weighted data } & 36 & 16 \\
\hline Note: & & \\
\hline
\end{tabular}

62 See Table A9 in the appendix. 
Table 4.15 shows that PLC and LC learners have similar rates of underskilling, with around 35 per cent of respondents reporting that they are underskilled and around 15 per cent reporting that they are severely underskilled. The model results indicate that PLC participation has no impact on either the probability of being underskilled or being severely underskilled relative to Leaving Certificate students who entered the labour market directly. ${ }^{63}$ The incidence of underskilling across various groups is somewhat surprising. Generally, we might expect underskilling rates to be highest for those with Leaving Certificate education and/or higher education, as these qualifications may not be vocational in nature. The fact that the incidence of underskilling for PLC leavers is comparable to the rates for other groups and that, in the vocational cohort, it is higher for those who did not progress to higher education may raise issues around the appropriateness of skill formation within PLC programmes. This issue requires further examination.

Returning to the question that asked learners to rate, on a scale of one to five, the extent to which their knowledge and skills are utilised in their work (where one is 'not at all' and five is 'to a very great extent'), a response of one or two is deemed consistent with overskilling. The model results indicate that PLC participation has no significant effect on overskilling relative to those who enter the labour market directly. ${ }^{64}$ We should treat the results of both skill mismatch and job satisfaction with caution as we are capturing these effects right at the onset of respondents' careers and, therefore, cannot rule out the possibility of more substantial differences between the groups emerging over time.

Finally, we attempt to use these data to assess the impact of PLC participation on earnings. Due to data restrictions related to the smaller sample size responding to the wage questions, we are unable to adopt a PSM approach. As an alternative, we estimate a wage equation augmented with a Heckman selection term to account for non-random entry to the various educational routes. ${ }^{65}$ This allows us to examine wage impacts close to the beginning of learners' careers. The learners survey captures data on individuals after five years. We supplement the analysis using data from the National Employment Survey (NES), which allows us to examine potential wage differences after a number of years in the labour market.

63 See Tables A10 and A11 in the appendix.

64 See Table $A 12$ in the appendix.

65 This involves a two-stage procedure. In stage one, the probability of entering various educational routes is modelled and from this equation an inverse mills ratio, representative of a joint conditional error term, is extracted. In the second stage, the respective mills ratios are included in a wage model to control for selection effects. The stage-one model should include at least one variable that is excluded from the second stage equation: in this instance, parental social class is used as the identifying restriction. 
The wage distribution of respondents to the leavers survey is graphed in Figure 4.1, where it appears that hourly earnings do not follow a standard normal distribution, as they are somewhat skewed to the right. This suggests that relatively low proportions of respondents had progressed to a higher level of earnings at the time of the survey. This is to be expected as a major determinant of earnings growth is labour market experience, which is highly limited among our survey respondents given their relatively young age. The wage equation is well specified and indicates that hourly earnings are higher among workers who are employed full-time, located in larger firms and who are trade union members (Table 4.16). Hourly earnings tended to be lower among workers who were overskilled and worked longer hours. ${ }^{66}$ However, there is limited evidence of any substantial wage impacts related to education pathway, relative to the reference category of direct labour market entrants: PLC completers earn 19 percentage points less than the direct labour market entrants reference category. However, the result is statistically weak and cannot be relied upon beyond a 10 per cent confidence level.

\section{FIGURE 4.1 WAGE DATA IN SURVEY}

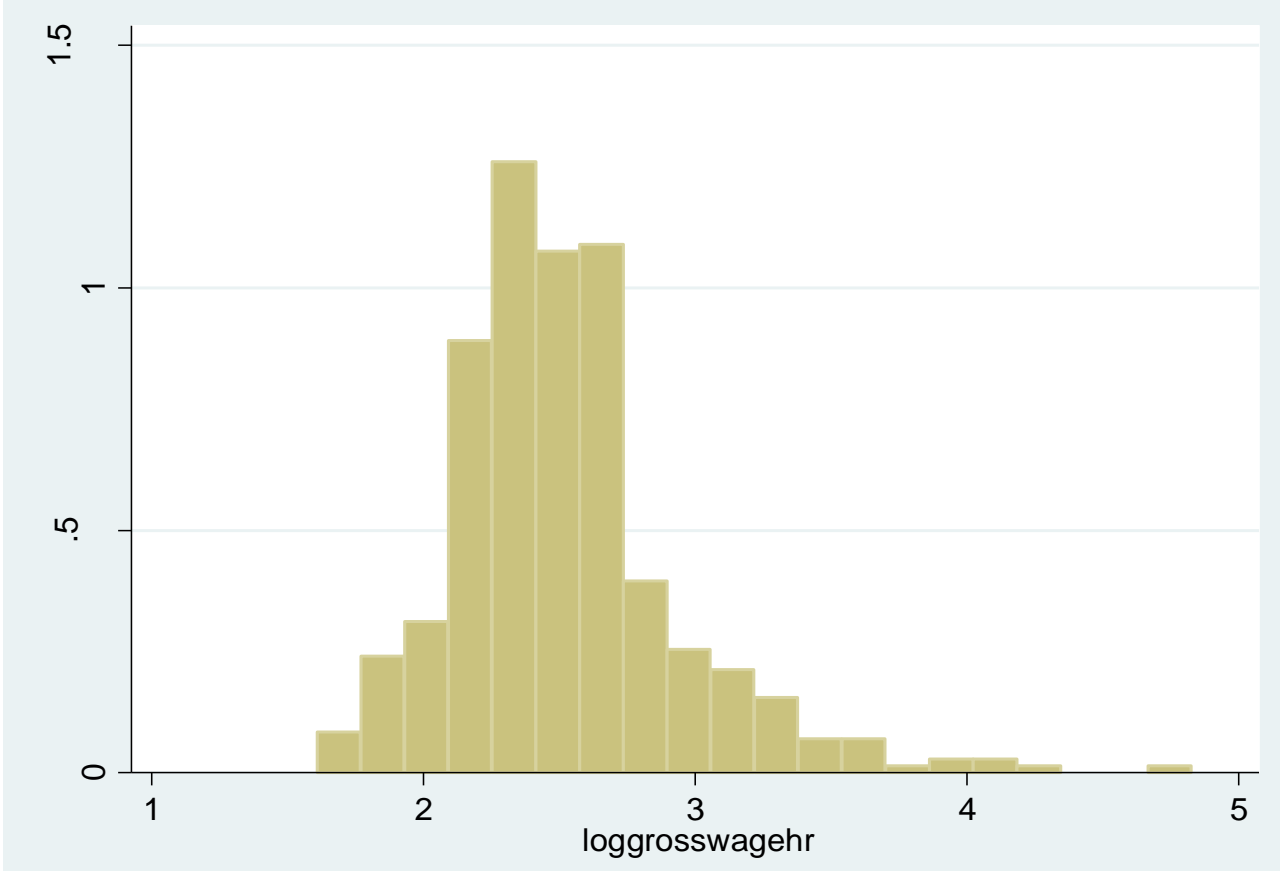

Note: $\quad$ We constructed a gross hourly wage variable. Dropped if gross hourly wage $<€ 5$ (8 cases) and dropped if gross hourly wage > $€ 125$ (10 cases).

66 Overskilling describes a situation whereby the worker feels that many of their skills and abilities are not required in their current job. 


\begin{tabular}{|l|c|}
\hline & Coeff. \\
\hline PLC & $-0.186^{*}$ \\
\hline LC direct to higher education & 0.021 \\
\hline PLC*higher education (Interaction, PLC who progress to higher & 0.113 \\
\hline education) & \\
\hline BASE is LC straight to labour market & \\
\hline Age & 0.008 \\
\hline Male & 0.010 \\
\hline Married/couple/civilp & -0.022 \\
\hline Points (banded) & 0.028 \\
\hline Underskilled & 0.023 \\
\hline Overskilled & $-0.194^{* *}$ \\
\hline Tenure & 0.013 \\
\hline Full-time, regular job & $0.358^{* * *}$ \\
\hline Full-time, temporary job & $0.416^{* * *}$ \\
\hline Public sector & -0.016 \\
\hline Hours & $-0.013^{* * *}$ \\
\hline Trade union member & $0.170^{* * *}$ \\
\hline Sector of Activity: (base services) & \\
\hline Agric & 0.147 \\
\hline Ind & 0.025 \\
\hline Construction & -0.033 \\
\hline Firm Size: (base 1-9) & \\
\hline 10-49 emp. & 0.080 \\
\hline 50-99 emp. & $0.164^{*}$ \\
\hline 100-249 emp. & 0.009 \\
\hline 250-999 emp & $0.226^{* *}$ \\
\hline 1,000 plus emp. & $0.199^{* * *}$ \\
\hline LC higher education mills ratio & 0.000 \\
\hline cons & 0.000 \\
\hline
\end{tabular}

It is fair to say that differences in earnings will tend to be relatively slight at the onset of individuals' careers, with premiums related to educational attainment only tending to become significant after a number of years in the labour market. In order to overcome this issue, we estimate the wage relationship using the 2003, 2006 and 2009 waves of the National Employment Survey (NES). The NES is a linked employer-employee survey that facilitates consistent estimates of the PLC wage premium across the entire population of employees in employment. Unfortunately, the post- 
secondary education category used in the NES does not distinguish apprentices from PLC qualifiers. Thus, in order to get a closer approximation of the PLC grouping, we excluded those with a technical/vocational qualification from the post-secondary education category used in the NES. ${ }^{67}$ We also excluded those with a post-secondary qualification working in craft and related occupations in the construction sector. ${ }^{68}$ Table 4.17 details the sectoral composition of post-secondary qualified workers, during the three time points. A good deal of volatility was observed, particularly between 2006 and 2009, as the economy moved from high levels of growth to recession. Over this time period, the share of post-secondary employment in high and mid skilled occupations, such as managerial, associate professional and craft posts, fell back considerably, while shares employed in occupations such as personal and protection services and 'other' rose considerably. During this period, the unemployment rate among post-secondary qualifiers increased from four to 15 per cent (Table 4.18), which was more severe than that experienced by individuals holding either second- or third-level qualifications. The evidence suggests that a good deal of the heavy job loss experienced by PLC qualifiers during the recession was concentrated among those workers who had been more successful in achieving occupational mobility during the boom. The high relative shift in both the level and composition of PLC workers during the downturn suggests that the returns to PLC workers are likely to exhibit a strong cyclical component, with wage premiums (relative to those with lower educational qualifications) likely to be lower during recessions due to higher rates of job loss among PLC qualifiers in more highly paid occupations.

67 Those with a technical/vocational qualification are defined as individuals who had completed an apprenticeship, NCVA level $2 / 3$ or equivalent.

68 Non-Irish nationals were excluded from the 2006 and 2009 models as well: it was not feasible to exclude non Irish nationals from the 2003 model as nationality information is not available in the March 2003 NES data. 


\begin{tabular}{|c|c|c|c|c|}
\hline \multicolumn{2}{|c|}{ Occupation } & $\begin{array}{l}\text { March } \\
2003\end{array}$ & $\begin{array}{l}\text { October } \\
2006\end{array}$ & $\begin{array}{l}\text { October } \\
2009\end{array}$ \\
\hline \multicolumn{2}{|c|}{ Managers and senior administrators } & 6.7 & 10.6 & 7.7 \\
\hline \multicolumn{2}{|c|}{ Professionals } & 6.5 & 8.6 & 5.4 \\
\hline \multicolumn{2}{|c|}{ Associate professional and technical } & 13.8 & 11.6 & 6.7 \\
\hline \multicolumn{2}{|c|}{ Clerical and secretarial } & 16.8 & 13.2 & 20.7 \\
\hline \multicolumn{2}{|c|}{ Craft and related trades } & 13.9 & 18.5 & 8.4 \\
\hline \multicolumn{2}{|c|}{ Personal and protective services } & 9.2 & 10.1 & 14.0 \\
\hline \multicolumn{2}{|c|}{ Sales } & 7.5 & 8.1 & 10.0 \\
\hline \multicolumn{2}{|c|}{ Plant and machine operatives } & 11.1 & 9.6 & 10.4 \\
\hline \multicolumn{2}{|c|}{ Other } & 14.6 & 9.7 & 16.7 \\
\hline \multicolumn{2}{|c|}{ Total } & 100 & 100 & 100 \\
\hline $\begin{array}{l}\text { Source: } \\
\text { Note: }\end{array}$ & \multicolumn{4}{|c|}{$\begin{array}{l}\text { Constructed using the CSO's NES data. } \\
\text { Individuals with a PLC qualification working in craft and related trade occupations in the construction } \\
\text { sector are excluded from this analysis, as are non-Irish nationals from the } 2006 \text { and } 2009 \text { data. We were } \\
\text { unable to exclude Irish non-nationals from the NES data for March 2003; however, it was only from } 2004 \\
\text { onwards that Ireland experienced the large inflow of immigrants. }\end{array}$} \\
\hline
\end{tabular}

\begin{tabular}{|l|c|c|}
\hline \multicolumn{1}{|c|}{ Educational attainment } & $\mathbf{2 0 0 6}$ & $\mathbf{2 0 0 9}$ \\
(Q2)
\end{tabular}

We estimate the returns to PLC education, applying the same restrictions mentioned above, on, applying the same restrictions mentioned above, by applying PSM to the 2003, 2006 and 2009 waves of the NES (Table 4.19). In this way, we again ensure that the earnings of PLC qualifiers are compared with those of individuals with secondary levels of schooling who are similar in all other observable ways: age, gender, occupational status, etc. The results revealed that while PLC qualifiers earned a wage premium of 4.4 per cent in 2003 (relative to those with Leaving Certificate qualifications), no significant effect was detected for 2006 and 2009. The results suggest that the long-run returns to PLC education over Leaving Certificates will tend to be cyclical in nature, with the limited data suggesting that these will be positive during normal periods of growth. We would expect to observe a more substantial positive premium for PLC qualifiers who subsequently progressed to higher education; however, this cannot at present be validated by any existing 
datasets.

TABLE 4.19 WAGES: SUMMARY OF ESTIMATES

\begin{tabular}{l|c|c|c|c|c}
\hline \multicolumn{1}{|c|}{ Variable } & Treated & Controls & Difference & Std. Err. & T-stat \\
\hline $\begin{array}{l}\text { In(HrWage } \\
\text { Rate) }\end{array}$ & & & & \\
\hline $\mathbf{2 0 0 3}$ & 2.62 & 2.57 & $0.044^{* * *}$ & 0.014 & 3.13 \\
\hline $\mathbf{2 0 0 6}$ & 2.82 & 2.81 & 0.008 & 0.016 & 0.54 \\
\hline $\mathbf{2 0 0 9}$ & 2.82 & 2.83 & -0.006 & 0.012 & -0.49 \\
\hline
\end{tabular}

Source: $\quad$ National Employers Survey, 2003, 2006, 2009

\subsection{SUMMARY AND CONCLUSIONS}

With regard to our sample, the majority of PLC learners were female, on average six years older than the Leaving Certificate group and less likely to come from higher socio-economic groups. Somewhat surprisingly, only just over 70 per cent of PLC learners reported undertaking work experience during their programmes. Of PLC participants, 39 per cent stated that their main reason for undertaking a PLC was to get a job immediately, with a similar percentage reporting that their main objective was to progress to higher education. Personal development was the key motivating factor for 20 per cent of PLC learners. Descriptive evidence indicates that by 2015 the percentages in employment and higher education from the PLC grouping are broadly comparable with those of the various control groups (direct labour market entrants and individuals who progressed to higher education on completion of their Leaving Certificate).

The direct labour market entrant groups are used to calculate the counterfactual estimate of PLC participation. The results show that by 2015, PLC participants were 16 per cent more likely to be in employment relative to similar individuals who entered the labour market directly on completion of their Leaving Certificate. We find that the employment effects are greater for job-specific than general PLCs, and for PLC participants who progressed directly to the labour market rather than to higher education. Regarding transitions to higher education, PLC participants were 27 percentage points more likely to have participated in higher education by 2015 compared to the control group of direct labour market entrants. Separating the higher education progression effects out by PLC type, we find that the effects were highest for individuals undertaking general PLCs. The analysis shows that PLC provision acts as an important access platform to higher education for individuals who might otherwise never have pursued that particular educational option. 
We find no statistically significant differences between the PLC treatment and Leaving Certificate labour market entrant control group in relation to job satisfaction, underskilling or overskilling. Nevertheless, we should treat these results with caution; we are capturing effects right at the onset of respondents' careers and, therefore, cannot rule out the possibility of more substantial differences between the groups emerging over time.

Finally, in terms of earnings, we detected no statistically significant differences from our survey data. In order to assess the longer-term earnings impacts of PLC participation, we undertook an analysis using the 2003, 2006 and 2009 waves of the National Employment Survey. The results revealed that while PLC qualifiers earned a wage premium of 4.4 per cent in 2003, no significant effect was detected for 2006 and 2009. The results suggest that the long-run returns to PLC education over Leaving Certificates will tend to be cyclical in nature, with the limited data suggesting that these will be positive during normal periods of growth. We would expect to observe a more substantial positive premium for PLC qualifiers who subsequently progressed to higher education; however, this cannot at present be validated by any existing datasets and, in this period of great change, points to the need for new wage data for Ireland. 


\section{CHAPTER 5}

\section{Evidence from survey of learners: Student perceptions}

\subsection{INTRODUCTION}

This chapter presents detailed analyses of people's experience of PLC programmes and how these experiences compare with those of other learners, in particular those taking higher education courses. The results highlight the distinct profile of PLC participants, in terms of gender, socioeconomic background, prevalence of special educational needs (SEN) and prior educational attainment. PLC courses are quite polarised in terms of course intensity and, in general, PLC participants do not participate in extra-curricular clubs and societies, unlike their higher education counterparts. In terms of the transition to PLC programmes, the single greatest challenge students face relates to the financial demands of their course, while the shift towards more self-directed teaching and learning methodologies constitutes a challenge for which PLC and higher education students alike feel ill-prepared. In reflecting on their choices, PLC participants are less positive than their counterparts who progressed to higher education on leaving school, reflecting the continued low status of further education in Ireland, as well as course experiences (particularly access to social and academic supports, the prominence of workplace learning and access to extra-curricular pursuits).

As outlined in Chapter 4, a comprehensive survey of learners was undertaken between September 2015 and February 2016, tracking school leavers approximately five years post leaving school. The objective of the survey was to provide rich insights into the experiences of leavers, including PLC leavers, in the post-school period. The survey samples were drawn from the Department of Education and Skills (DES) Post-Primary Pupil Database (PPPDB), following a methodology developed for the 2006 and 2007 school leavers surveys (see McCoy et al., 2007; Byrne et al., 2009). All data presented in this chapter have been weighted on the basis of gender, programme type and, for the PLC leavers, whether they were under or over 25 years at the time of leaving. As detailed in Chapter 4, a proxy questionnaire was developed with a more limited subset of questions, which could be completed by a relative if the original 
respondent was not available. ${ }^{69}$ Of the 1,220 responses, 427 were completed by proxy. ${ }^{70,71}$ The analysis in this chapter is predominately based on the non-proxy survey responses.

\subsection{CONCEPTUALISING POST-SCHOOL PATHWAYS}

In examining the main educational choices of school leavers, this chapter is framed within the broader concept of pathways. The concept of 'pathways' has been prominent in cross-national policy debates and is, according to Raffe (2003), best presented as a metaphor, rather than a theory or analytical tool. The concept has been used in three main ways:

- to distinguish the main types of pathways beyond compulsory schooling and into the labour market, to compare their strengths and weaknesses, and to determine their relative size and role in an effective transition system;

- to examine the relationships and interconnections between pathways, and to determine how best to organise systems of pathways; and

- to analyse the relationship between pathways and the 'navigations' of the young people who use them; in particular, to consider how pathways can be organised to reflect the perspectives and priorities of individuals and to enable them to manage and control their own itineraries (ibid, p.5).

The pathways concept was most recently applied, in an Irish context, in the Leaving School in Ireland study (McCoy et al, 2014), in which it served as a valuable tool for understanding the nature of social inequality in educational outcomes, and particularly post-school outcomes. A similar approach is taken here. In particular, this analysis compares the experiences of participants in the two main post-school pathways, namely higher education and PLC, with a view to assessing the strengths and weaknesses of these settings, with a focus on the PLC setting. It also throws light on the extent and nature of linkages across pathways, providing evidence on the levels of flexibility and connectedness in the Irish educational system.

Much of the analysis in this chapter differentiates learners into four main pathway groups, based on whether they had participated in each of the main post-school education and training settings. The main focus is on how people experience these different settings, particularly PLC participation, specifically the analysis on job quality, is performed using only data from the non-proxy survey.

70 A total of 4,730 questionnarires were issued, with 1,220 successful responses.

71 Proxy respondents, such as parents or relatives, were used as suitable substitutes if they could adequately represent the 'leaver' by answering a reduced number of key questions from the survey. 
so the classification is based on participation and not on completion:

- PLC;

- Higher education;

- PLC and higher education (PLC and HE);

- No PLC/higher education (LM entrants).

While the bulk of the PLC and higher education group progressed from PLC courses into higher education, this was not the case for all and some individuals participated in higher education prior to PLC participation. For the last group - no PLC/higher education (henceforth labelled LM entrants) - there is no evidence of participation in either PLC or higher education courses. These individuals may have participated in another form of postschool education or training; however, the majority of this group entered the labour market directly on leaving school.

While this analysis focuses on PLC participants, the relative expectations, experiences and reflections of other pathway groups provide valuable insights into the common and unique experiences of different groups.

This chapter presents four main themes:

- a profile of PLC participants and other post-school pathway groups;

- PLC entry, main objectives and guidance;

- experience of PLC and higher education courses; and

- reflections on the pathways taken.

As much of this chapter centres on how PLC and higher education participants reflect on their experiences, before, during and after their course of study, it predominantly draws on data from the non-proxy sample. The reduced set of questions completed by proxy respondents do not, by and large, allow any insights into subjective experiences and or decision-making processes. Given small sample sizes, much of the analysis presented is based on descriptive statistics. However, the final section presents multivariate models examining differences between pathway groups in terms of their reflections on post-school choices made, levels of regret and overall satisfaction with life, taking account of other factors that may influence these outcomes. Overall, the analysis provides valuable insights into how people experience PLC courses and the extent to which their experiences differ from those taking higher education routes. This 
focus on subjective experiences provides an important complement to the analysis of more objective labour market outcomes in Chapter 4.

\subsection{PROFILE OF PLC PARTICIPANTS}

Reflecting the stratified sampling approach (specifically targeting leavers from PLC programmes), a total of 45 per cent of the sample had participated in PLC courses, while 53 per cent had taken part in some form of higher education (Table 5.1). ${ }^{72}$ In line with earlier research (McCoy et al., 2010), pathways are highly gendered - with females overrepresented among the PLC groups, while males are disproportionally more likely to be in the LM entrants group. In terms of average age, those in the PLC groups are typically older than those in higher education or the LM. While PLC participants are more likely to be in relationships than those in other pathway groups, they are also more likely to have children. Almost onethird of the PLC group are parents, relative to less than four per cent of their higher education counterparts. Pathways are also socially patterned, with Table 5.1 showing wide variation in the proportions of those with parents who have a degree-level education. Six per cent of PLC participants have mothers with degrees, compared to nearly one-quarter of higher education participants. It is interesting to note the largely similar educational background of the PLC and LM entrants groups. It can also be noted that PLC participants who subsequently progress to higher education are typically from more highly educated backgrounds than their counterparts who do not make this transition. The same distinction applies in relation to Leaving Certificate performance - learners who subsequently progress to higher education show higher points attainment than those who do not progress ( 53 per cent of those progressing secure in excess of 300 points relative to 34 per cent of those who do not progress).

A total of 8.4 per cent of the leavers had a special educational need (SEN) that affected their learning while at school, with the figure somewhat higher for males (11.6 per cent compared to 6.7 per cent for females). While these SEN prevalence rates are lower than estimates based on cohort studies, they are broadly consistent with estimates based on administrative data (see Banks and McCoy (2011) for a discussion). SEN rates were somewhat lower among leavers progressing to higher education (four per cent), with levels of 11 per cent and 13 per cent among the two PLC groups. 
TABLE 5.1 PROFILING PATHWAY GROUPS

\begin{tabular}{|c|c|c|c|c|}
\hline & LM entrants & PLC & PLC and HE & HE \\
\hline Full sample \% & 17.2 & 30.2 & 14.8 & 37.8 \\
\hline Numbers & 210 & 368 & 181 & 461 \\
\hline Gender - \% male & 61.6 & 37.4 & 40.6 & 47.8 \\
\hline $\begin{array}{l}\text { Age - Mean age } \\
\text { (@ survey) }\end{array}$ & 24 & 30 & 31 & 24 \\
\hline \multicolumn{5}{|l|}{ Family type } \\
\hline$\%$ single & 83.7 & 66.0 & 76.2 & 87.6 \\
\hline$\%$ parents & 21.5 & 32.8 & 25.0 & 3.5 \\
\hline \multicolumn{5}{|l|}{$\begin{array}{l}\text { Parental } \\
\text { education }\end{array}$} \\
\hline \% Mother degree & 5.3 & 5.7 & 12.7 & 24.1 \\
\hline \% Father degree & 4.3 & 4.6 & 13.8 & 22.2 \\
\hline LCA \% & 12.9 & 9.8 & 5.5 & $*$ \\
\hline \multicolumn{5}{|l|}{ LC performance } \\
\hline$<100$ points & 14.1 & 13.5 & 10.6 & 0 \\
\hline $101-200$ points & 15.9 & 19.1 & 12.7 & 1.1 \\
\hline 201-300 points & 34.1 & 33.1 & 23.9 & 6.1 \\
\hline $301-400$ points & 25.3 & 27.5 & 39.4 & 33.1 \\
\hline 401-500 points & 8.2 & 5.6 & 9.2 & 42.3 \\
\hline 501-600 points & 2.4 & 1.2 & 4.2 & 17.3 \\
\hline SEN at school (\%) & 14.4 & 10.5 & 13.1 & 4.1 \\
\hline
\end{tabular}

Note: Weighted data

\subsection{POST-SCHOOL OBJECTIVES AND PLC ENTRY}

Leavers were asked to reflect on what they considered to be the most important influences regarding their decisions on what to do when they left school. A broad range of potential influences were given, reflecting instrumental and intrinsic motivations (Table 5.2). More intrinsicallyoriented responses include studying a subject of interest and personal fulfilment. These account for 41 per cent of learners overall, but a somewhat greater share of the PLC group (43 per cent) and the PLC and higher education group (50 per cent). Obtaining a secure job features much more prominently among the group who progressed to the labour market on leaving school. School leavers were also asked to reflect on their main plan on leaving school (Table 5.3); wide variation was found across groups regarding the emphasis placed on education and training. While 92 per cent of higher education entrants planned to progress to post-school education, this was the case for 64 per cent of the PLC and higher 
education group and just over half of the PLC and LM entrants groups.

Partly reflecting the socio-economic profile of the different groups, securing employment featured more frequently in the plans of the PLC groups and the group who progressed into the labour market.

\section{TABLE 5.2 MAIN FACTOR IN POST-SCHOOL DECISION-MAKING}

\begin{tabular}{l|c|c|c|c|c|}
\hline & LM entrants & PLC & PLC and HE & HE & All \\
\hline $\begin{array}{l}\text { Studying } \\
\text { subject of } \\
\text { interest }\end{array}$ & 27.2 & 32.8 & 43.6 & 27.8 & 31.5 \\
\hline $\begin{array}{l}\text { Getting } \\
\text { secure } \\
\text { job/having } \\
\text { an income }\end{array}$ & 33.7 & 22.0 & 18 & 4.5 & 14.9 \\
\hline $\begin{array}{l}\text { Personal } \\
\text { fulfilment/i } \\
\text { nteresting } \\
\text { job }\end{array}$ & 7.6 & 10.3 & 6.9 & 10.8 & 9.6 \\
$\begin{array}{l}\text { Other/no } \\
\text { reason } \\
\text { given }\end{array}$ & 31.5 & 34.9 & 31.5 & 56.9 & 44.0 \\
\hline \begin{tabular}{l} 
Note: Weighted data \\
\hline
\end{tabular} & & & & \\
\hline
\end{tabular}

TABLE 5.3 MAIN PLAN ON LEAVING SCHOOL

\begin{tabular}{l|c|c|c|c|c}
\hline & LM entrants & PLC & PLC and HE & HE & All \\
\hline \begin{tabular}{l|c|c|c|} 
Education/tr \\
aining
\end{tabular} & 50.5 & 53.1 & 64.1 & 91.5 & 71.1 \\
\hline Job & 39.8 & 33.5 & 30.5 & 4.7 & 21.4 \\
\hline $\begin{array}{l}\text { Other } \\
\text { Note: Weighted data }\end{array}$ & 9.7 & 13.4 & 5.4 & 3.8 & 7.5 \\
\hline
\end{tabular}

Research has highlighted the centrality of guidance and preparation for (young) people - both academically and socially - to meet the demands of post-school education (McCoy et al., 2014, p.195). Leavers were asked if they had received any advice on potential post-school options from a range of key sources - guidance counsellors, teachers, family members and people working or studying in an area of interest. As shown in Figure 5.1 , guidance counsellors constituted the most frequently cited source of advice, followed closely by mothers. Those who progressed to higher education were more likely to have received advice from their guidance counsellor, a parent or teacher than those in the other pathway groups. Overall, just half of leavers were satisfied with the advice available at school on potential post-school options, with 31 per cent dissatisfied and 18 per cent very dissatisfied with advice available. School leavers who 
progressed to higher education, were most likely to report dissatisfaction with advice available; this was the case for 52 per cent of those who progressed directly to higher education and 54 per cent of those who did so indirectly.

FIGURE 5.1 SOURCE OF ADVICE ON POST-SCHOOL CHOICES BY MAIN PATHWAY (\%)

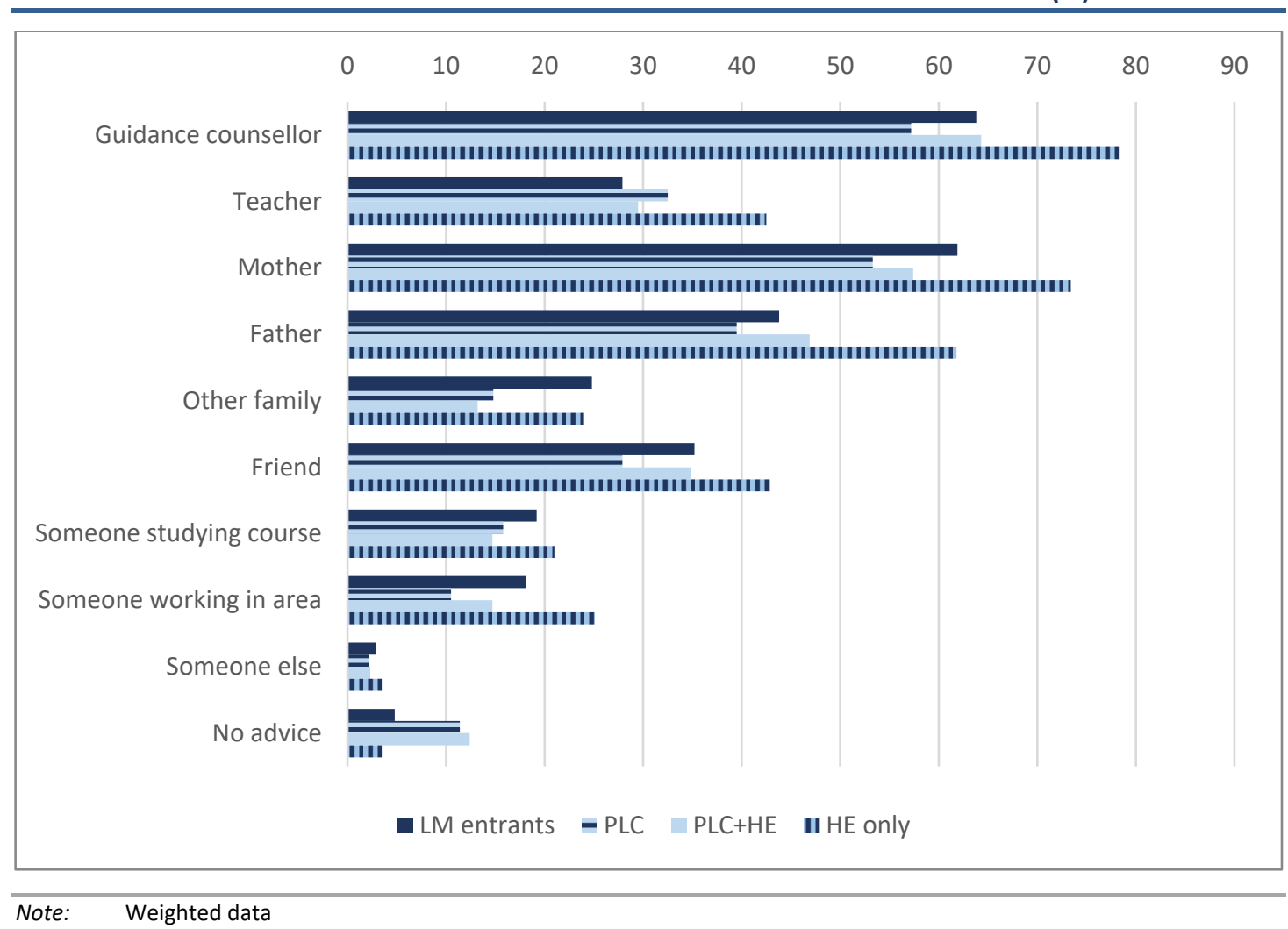

Patterns of PLC entry and progression highlight some interesting results. Examining patterns of PLC application among the non-proxy sample, 39 per cent applied to participate in a PLC programme, of whom 94 per cent subsequently enrolled. For only a very small minority (seven per cent), the awards received on their PLC programme differed from the course originally signed up for. Dropout rates were 16 per cent among those taking one PLC course and 18 per cent among those who progressed to a second course. The main reasons for dropout related to the course not being as expected, not liking the course content, financial difficulties, not liking college and gaining full-time employment. In terms of opportunities to transition to higher education, 40 per cent indicated their course provided access to an institute of technology, 26 per cent to an Irish university, 10 per cent to a UK university and 11 per cent to other higher education settings. Just 10 per cent indicated that their PLC course was part of the Higher Education Links Scheme, 28 per cent responded that the course was not part of this scheme and 62 per cent said they were unaware 
(presumably of this scheme). Of leavers progressed to higher education, 47 cent per cent were enabled by their PLC course to gain advanced entry to higher education (such as entering at second year).

\subsection{EXPERIENCE OF PLC AND HIGHER EDUCATION COURSES}

The learners survey provides valuable insights into school leavers' experiences of post-school education, across a range of dimensions. These include the intensity of their course, the extent to which they experienced difficulties, the nature of support services available, the way in which they funded their studies, their experience of teaching and learning, workplace learning opportunities offered and the extent to which they developed a range of skills and competencies. For the most part, similar questions were asked in relation to both PLC and higher education participation, so it is possible to compare student experience across these two distinct sectors.

As shown in Figure 5.2, PLC course intensity appears somewhat more polarised than is the case for higher education courses - greater proportions of PLC participants spend both few hours and many hours in class contact time (lectures/tutorials): over one-fifth of PLC participants spend less than nine hours per week in class, while 35 per cent spend in excess of 30 hours per week in class. Much greater proportions of higher education participants spend 10-19 or 20-29 hours per week in class (in total 64 per cent compared to 42 per cent of PLC participants). However, taking account of time spent on study, assignments and projects, higher education courses appear more time-intensive than PLC courses. Almost half of PLC course participants spend less than nine hours per week on such outside class coursework, compared to 30 per cent of higher education participants, the bulk of whom spend in excess of 20 hours on such activities. Participation in sports, clubs and societies appears more prevalent among higher education students - over 70 per cent spend at least one hour per week engaging in such college activities, while nearly 60 per cent of PLC students do not participate at all. A total of 60 per cent of PLC participants reported spending between one and five hours travelling to/from their course per week; travel time was even longer for a further one-quarter of PLC participants. Nearly 40 per cent of higher education participants reported spending more than six hours per week travelling to/from their college. 


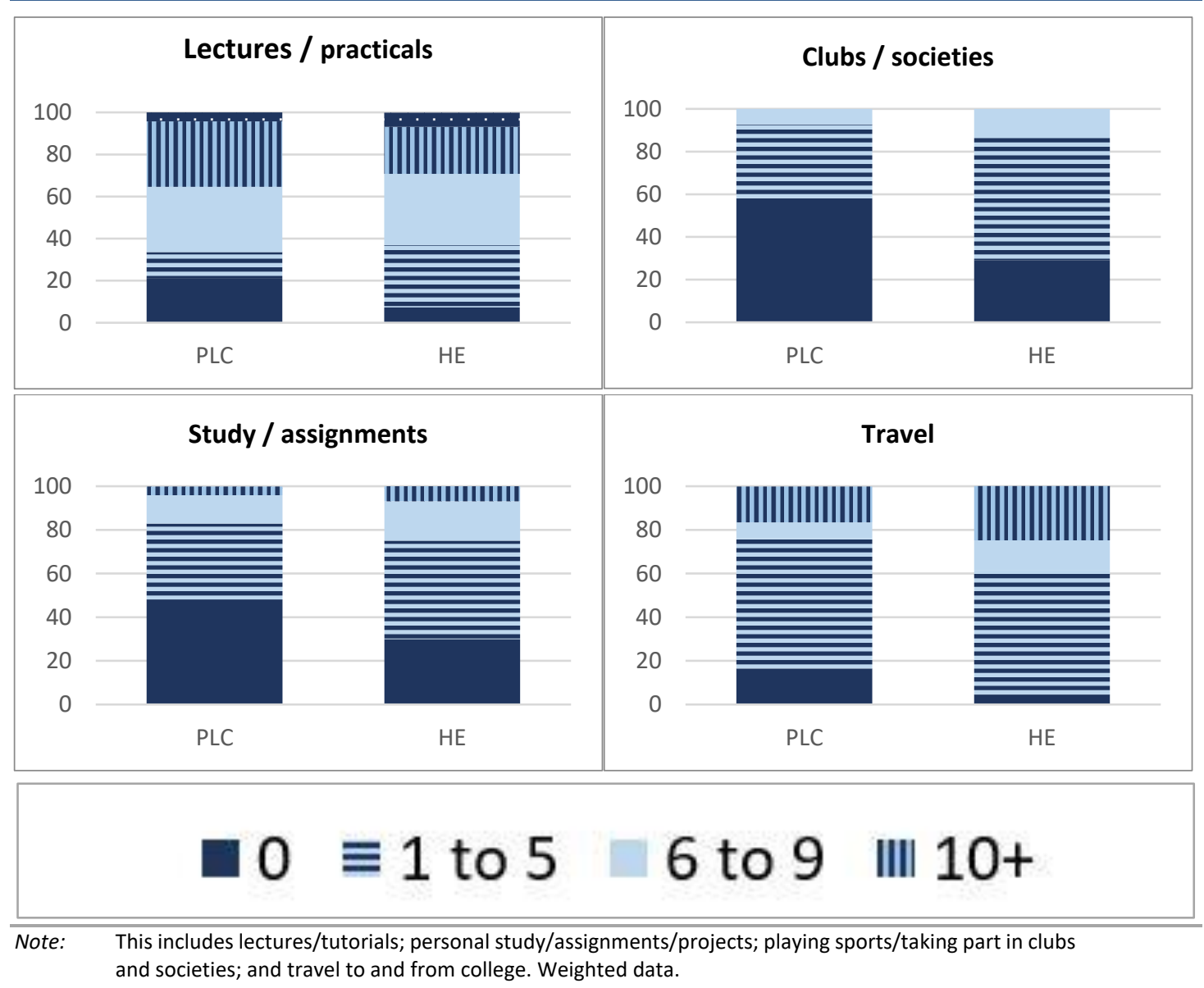

Previous research has shown that the first year of post-school study is an important point in time for young people, with student disengagement and dropout rates typically peaking in this year (McCoy et al., 2010; McCoy and Byrne, 2010; Lassibille and Gomez, 2008). Leavers were asked to indicate whether they experienced difficulties (course-related, financial and personal) during the first year of their PLC or higher education course of study. Figures 5.3 and 5.4 report the proportions indicating these difficulties to be a moderate or major problem for them in their PLC and higher education studies. The single greatest difficulty for PLC participants related to the costs involved, with 21 per cent reporting fees/other costs to be a major problem and 31 per cent reporting this to be a moderate problem. Not unrelated, 42 per cent reported difficulty in juggling the demands of work and study. Concerns over the demands of the course were less prevalent: 29 per cent reported concerns in terms of knowing what standard was expected, 28 per cent in terms of the level of difficulty of the course and 28 per cent in relation to completing coursework on time. The nature of difficulties experienced by higher education students were not dissimilar to their PLC counterparts, although slightly greater numbers reported financial concerns (56 per cent) and concerns around 
the demands of their course (just under 40 per cent were concerned about the level of difficulty of the course and 37 per cent in terms of knowing what standard was expected). While concerns around caring responsibilities featured more strongly for PLC students, fitting in with other students appeared to be of greater concern for higher education students, perhaps reflecting the typically larger scale of higher education institutions.

\section{FIGURE 5.3 PERCENTAGE REPORTING DIFFICULTY WAS A MAJOR OR MODERATE PROBLEM FOR THEM IN THEIR FIRST YEAR OF PLC STUDY}

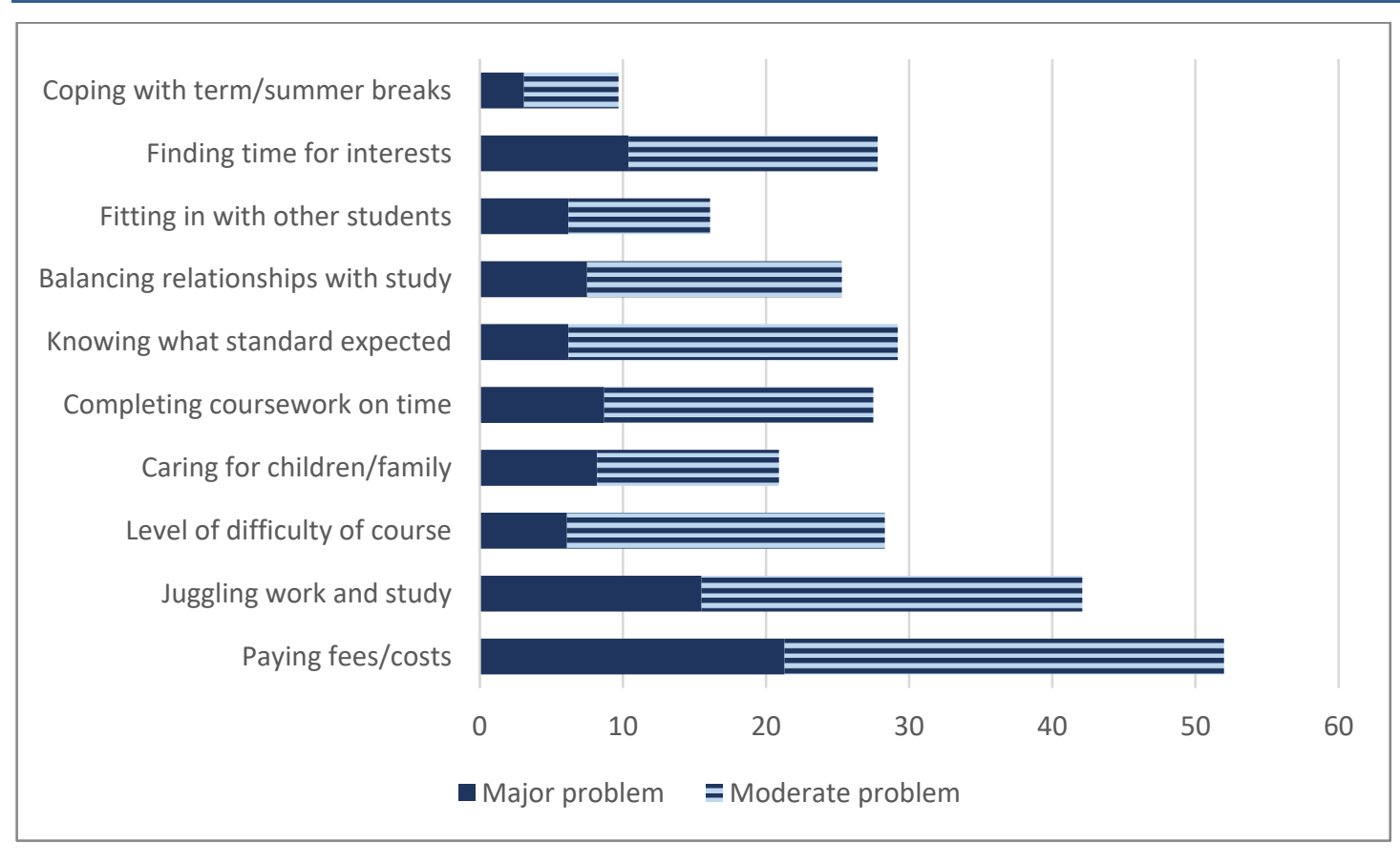

Note: Weighted data 
FIGURE 5.4 PERCENTAGE REPORTING DIFFICULTY WAS A MAJOR OR MODERATE PROBLEM FOR THEM IN THEIR FIRST YEAR OF HIGHER EDUCATION STUDY

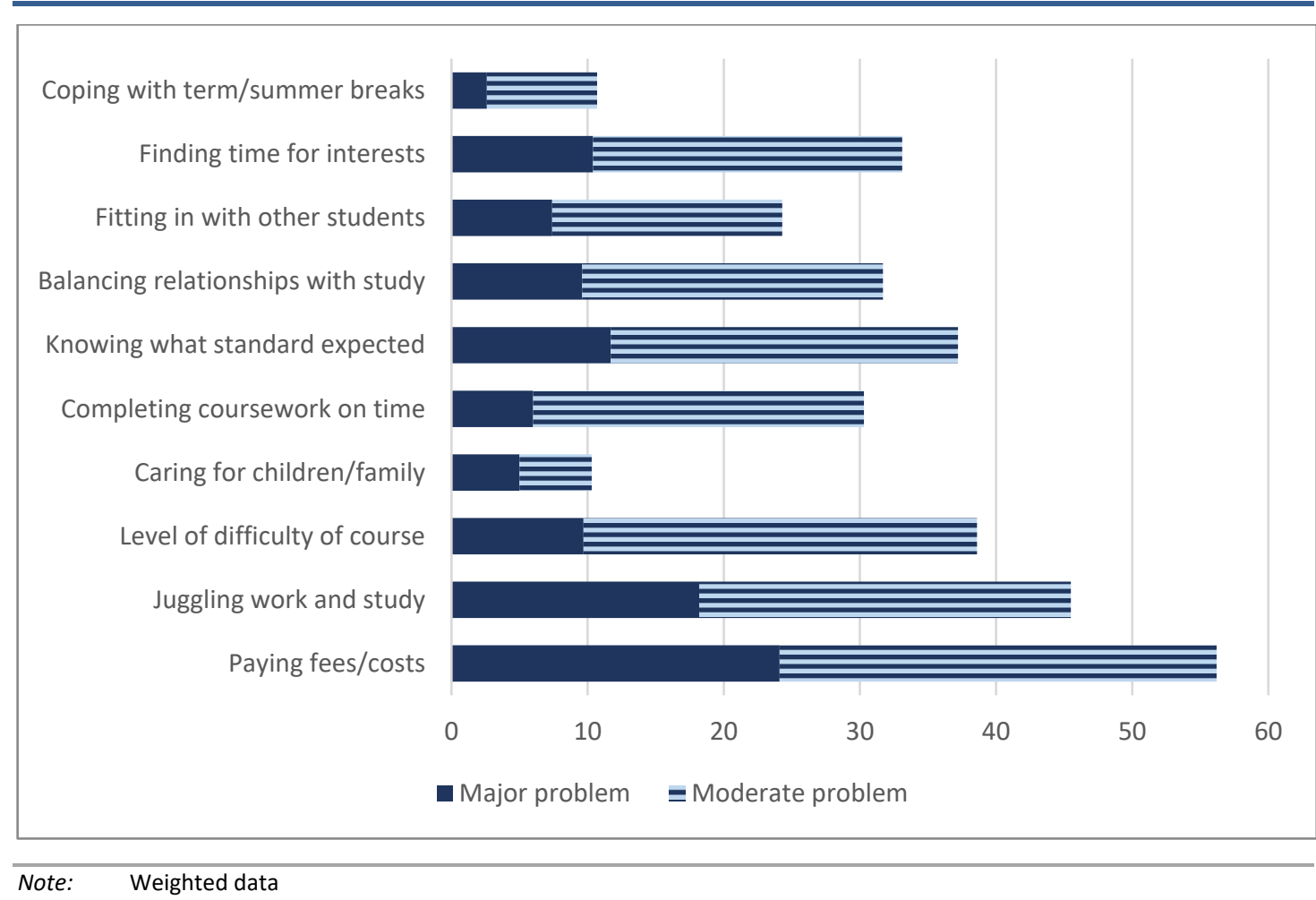

Respondents were asked to indicate all sources of support regarding the costs of participation in PLC or higher education study (Figure 5.5). For PLC students, almost 40 per cent received financial support from their family, with just under 30 per cent receiving indirect support (such as support with utilities, food, travel or accommodation costs). Just under one-quarter were eligible for the state maintenance grant, and one-quarter received support under the BTEA scheme. While just under 30 per cent relied on earnings from employment, 15 per cent were in the position to draw on savings. For higher education students the patterns differed somewhat, with much greater numbers availing of direct and indirect support from their families, presumably reflecting the typically more affluent profile of higher education entrants (McCoy et al., 2010). Two-thirds of higher education students received direct financial support from their families, compared to 40 per cent of PLC students. Similarly, 32 per cent of higher education participants benefited from indirect support from their families compared to 17 per cent of PLC students. Perhaps partly reflecting their differing levels of class contact time, or differences in the proportions engaged in caring responsibilities, higher education students were more likely than PLC students to be in paid employment, with 44 per cent using earnings from employment to meet the costs of living (relative to 29 per 
cent of PLC students). ${ }^{73}$ Higher education students were also more likely to draw on savings to meet costs. It can also be noted that receipt of the state maintenance grant was more prevalent among higher education students, with 38 per cent receiving support compared to 24 per cent of PLC students, though a smaller share of higher education students were enrolled on the BTEA programme.

FIGURE 5.5 SOURCES OF FUNDING WHILE ON PLC OR HIGHER EDUCATION COURSE (\%)

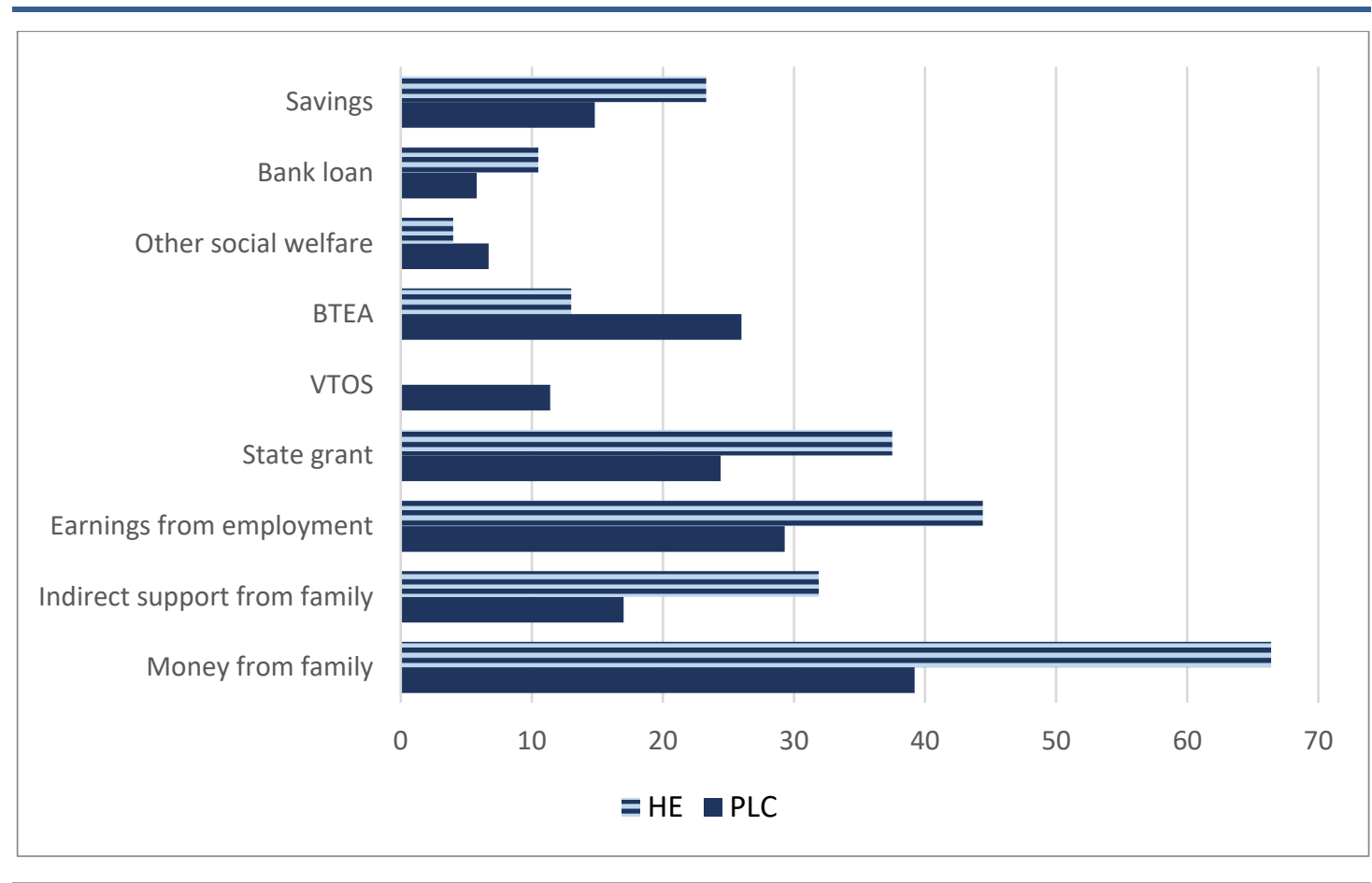

Note: Weighted data

Respondents were asked to indicate whether they had accessed a range of student supports during the course of their PLC and higher education studies. This included career guidance, counselling, learning supports, childcare and disability support services (Table 5.4). Just over one-third of PLC participants had accessed career guidance supports, somewhat lower than the figure for higher education students (39 per cent). Chapter 3 showed that career guidance is provided in 93 per cent of PLC centres (school or college), according to principal reports. The finding that just onethird of PLC participants report having accessed this support suggests that either students are not availing of career guidance that is provided, the support is not accessible (e.g. through limited hours available), or they are not satisfied with the nature of the service provided. Counselling services were accessed by 10 and 13 per cent of PLC and higher education participants. Despite considerably higher SEN prevalence levels among PLC participants (see Table 5.1), a comparable number of PLC and higher

73 As noted in Table 5.1, a significant share those who participated in PLC courses have children - between 25 and 33 per cent, compared to just four per cent of those who participated solely in higher education. 
education students accessed learning supports (15 per cent), while three and four per cent of these groups, respectively, accessed disability support services. Reflecting the differences in age and parenthood status, childcare supports were more significant for PLC students, with seven per cent availing of such services compared to four per cent of higher education students. The vast majority of PLC and higher education participants reported satisfaction with the services provided. However, this question was not asked of respondents who did not or could not access the relevant support.

Leavers who participated in PLC or higher education courses were also asked about their relationships with other students, teaching staff and administrative personnel in the relevant school or college setting. On a sixpoint scale, ranging from 'unavailable, unsupportive' to 'available, supportive, considerate', just under 45 per cent of PLC students and 48 per cent of higher education student ranked their fellow students in the most supportive category. Just under 40 per cent of PLC students and 30 per cent of higher education students rated the teaching staff in the most supportive category, with 25 and 21 per cent of PLC and higher education students rating administrative staff this highly.

TABLE 5.4 SUPPORT SERVICES ACCESSED DURING PLC/HIGHER EDUCATION STUDIES (\%)

\begin{tabular}{|l|c|c|}
\hline Whether support accessed, \% & PLC & HE \\
\hline Career guidance & 34.3 & 39.3 \\
\hline Counselling & 10.2 & 13.1 \\
\hline Learning supports & 15.5 & 15.2 \\
\hline Childcare & 7.3 & 3.3 \\
\hline Disability support services & 3.1 & 4.4 \\
\hline $\begin{array}{l}\text { Percentage rated 'very } \\
\text { supportive' }\end{array}$ & \\
\hline $\begin{array}{l}\text { Other students } \\
\text { Teaching staff }\end{array}$ & 44.9 & \\
\hline Administrative personnel & 39.4 & 48 \\
\hline Note: Weighted data & 24.6 & 30.1 \\
\hline
\end{tabular}

The learners survey gathered detailed information on the extent to which leavers felt well-prepared to meet the demands of post-school education and training. Similar questions were asked in relation to the transition to PLC and higher education study, allowing valuable comparisons across the two settings. Regarding the experience of teaching and learning in PLC and higher education courses, responses are highly similar across the two sectors. Just half of PLC and higher education participants felt that their schoolwork prepared them for post-school education. The vast majority of respondents felt that teaching and learning on their course was very 
different to school - accounting for 94 per cent of higher education participants and just under 80 per cent of those who enrolled on PLC programmes. These findings have also been highlighted in previous research that has shown how, for school leavers, the transition from school to post-school education is accompanied by an increase in independence, the requirement for self-directed learning and responsibility for learning. These significant changes in teaching and learning methodologies on transition to post-school education represented a difficulty for many young people and something for which they felt ill-prepared (McCoy et al., 2014, pp. 131).

The vast majority of students indicated that their course involved a lot of project work and tests (slightly more in the case of higher education students). Students were largely complementary in relation to course design, with close to 90 per cent of PLC and higher education students finding the course modules and work experience components relevant to the development of the relevant skills. ${ }^{74}$ Well over 90 per cent also felt that their teachers/tutors had relevant knowledge to teach the course. Finally, among leavers who progressed from a PLC course to higher education, 78 per cent indicated that their PLC course had prepared them for their higher education studies (not shown in a table). 
FIGURE 5.6 EXPERIENCE OF TEACHING AND LEARNING IN PLC AND HIGHER EDUCATION COURSES (\% AGREE/STRONGLY AGREE)

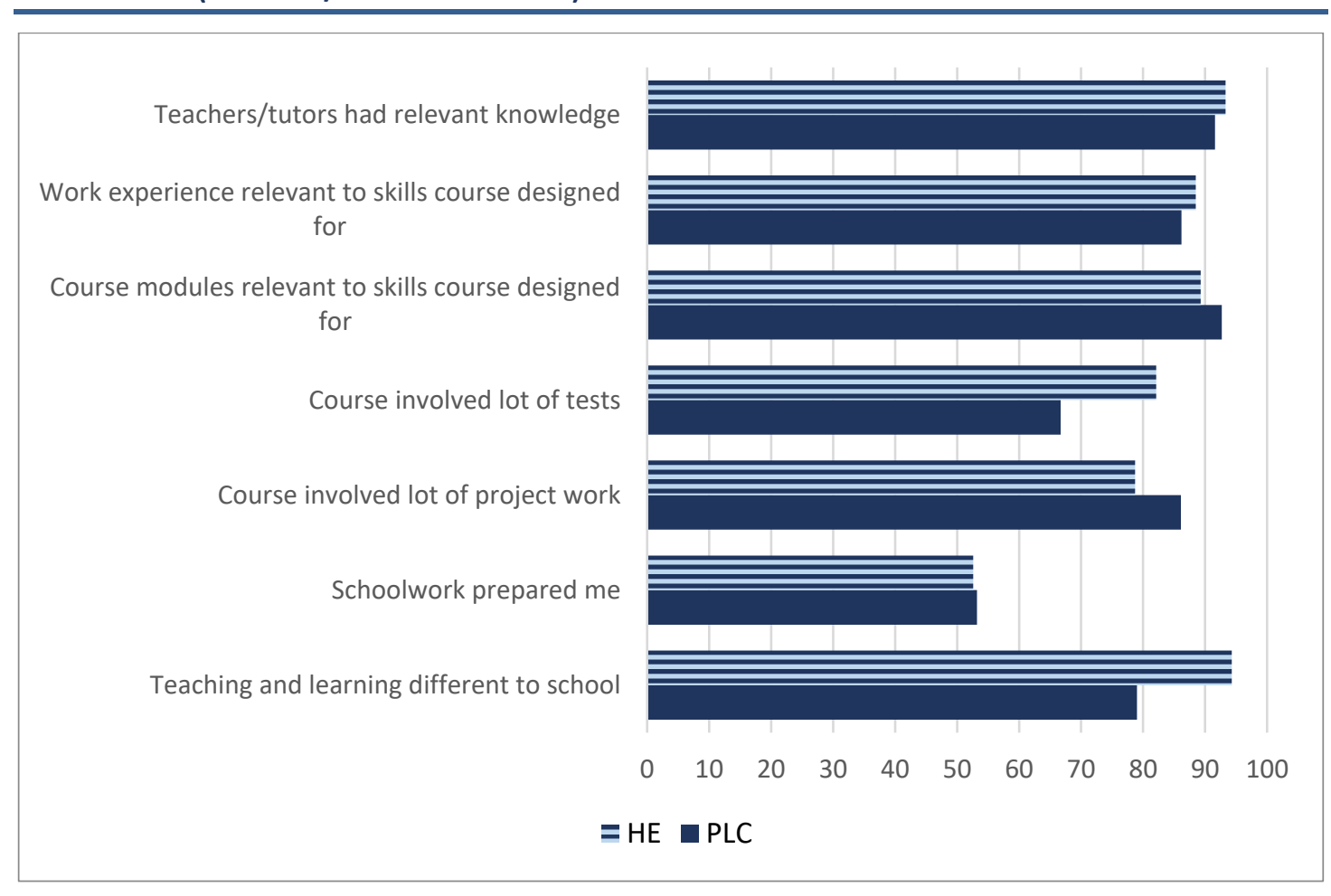

Note:

Weighted data

School leavers were also asked to reflect on the supports and feedback they received on their course, through another series of statements to which they were asked to agree or disagree. In total, 71 per cent of PLC students felt they could get extra help if required. While 82 per cent of PLC participants felt they got useful feedback on their performance, just 64 per cent felt they could give feedback on their course. Four-fifths of PLC students felt that advice on courses and careers was available and a similar number felt there was someone to talk to if needed. Over three-quarters were satisfied with the facilities in their college/school and 83 per cent indicated that they had access to the required equipment. Again, these findings are similar to those regarding the experiences of higher education students, although the latter were more likely to respond positively regarding facilities in their college. Higher education students were also somewhat more likely to report being able to give feedback on their course, with 75 per cent able to give feedback relative to 64 per cent of PLC students (also a finding in the McCoy et al., 2014, pp. 134-135). 
FIGURE 5.7 SUPPORTS AND SERVICES IN PLC AND HIGHER EDUCATION (\% AGREE/STRONGLY AGREE)

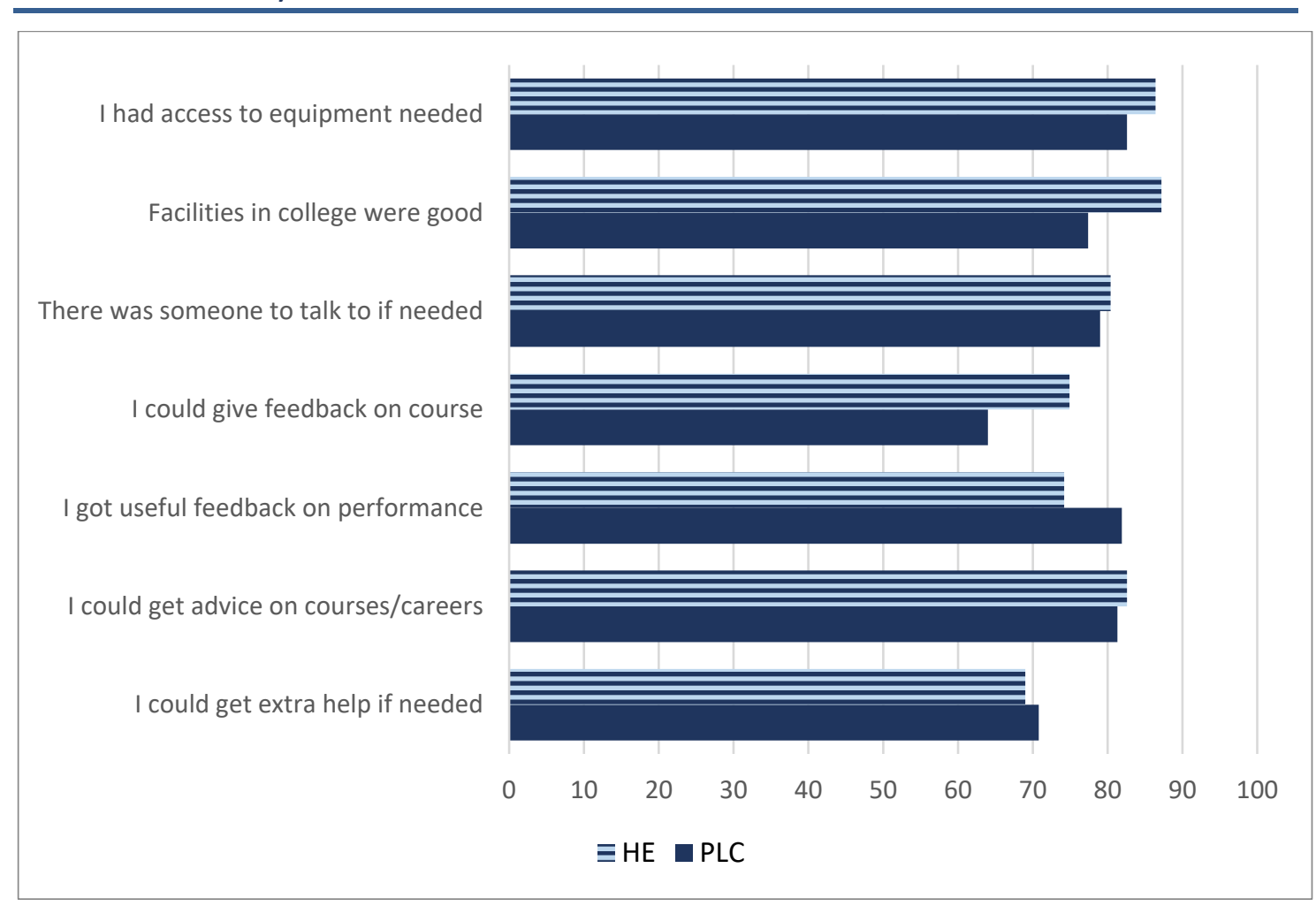

Note: Weighted data

As shown in Chapter 4, just under three-quarters of PLC students participated in a work experience programme as part of their course. ${ }^{75}$ This chapter presents additional insights, gained through their responses to a series of statements regarding work-related knowledge and skill formation or employability in their course. Respondents were asked to indicate the frequency with which different aspects of workplace learning, such as exploring how to apply their learning in the workplace, occurred (never/very little, sometimes, often/very often). One-quarter of the PLC cohort said they acquired work-related knowledge and skills 'never' or 'very little' while on their course (Figure 5.8). In contrast, just under half believed they gained such skills 'often' or 'very often'. Responses in relation to industry placement or work experience were less positive, with 37 per cent indicating they never or rarely gained such opportunities while on their PLC programme. While 43 per cent said they frequently explored how to apply their learning in the workplace, again a sizeable percentage (27 per cent) did not believe they had this opportunity. Further, just under one-third indicated that learning on their course did not contribute to their employability and 37 per cent rarely, if ever, gained the opportunity to combine classroom-based learning with workplace experience while on 
their PLC course.

For higher education students, similar concerns arose around workplace learning and employability (Figure 5.9). Just under one-quarter of higher education participants felt they did not get the opportunity to acquire work-related knowledge and skills. Among PLC students, 37 per cent did not benefit from industry placement or work experience opportunities on their course, compared to 44 per cent of higher education participants. However, higher education students appear more positive about their learning contributing to their employability - with 58 per cent indicating this occurred frequently on their course compared to 38 per cent of their PLC counterparts. A sizeable 40 per cent of higher education students felt that over the course of their studies they rarely had the opportunity to combine classroom-based learning with work experience.

FIGURE 5.8 FREQUENCY OF EXPERIENCE OF WORKPLACE LEARNING ON PLC COURSE (\%)

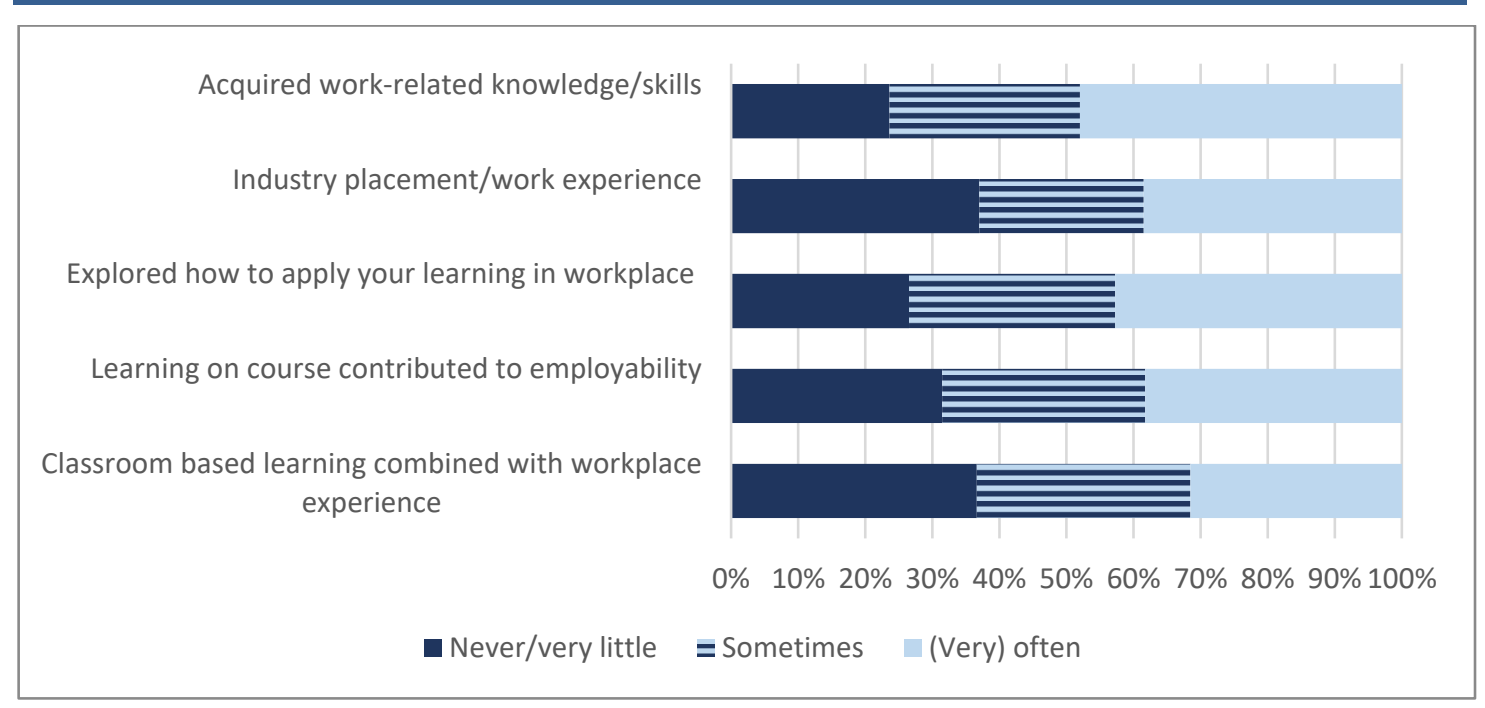

Note: Weighted data 
FIGURE 5.9 FREQUENCY OF EXPERIENCE OF WORKPLACE LEARNING ON HIGHER EDUCATION COURSE (\%)

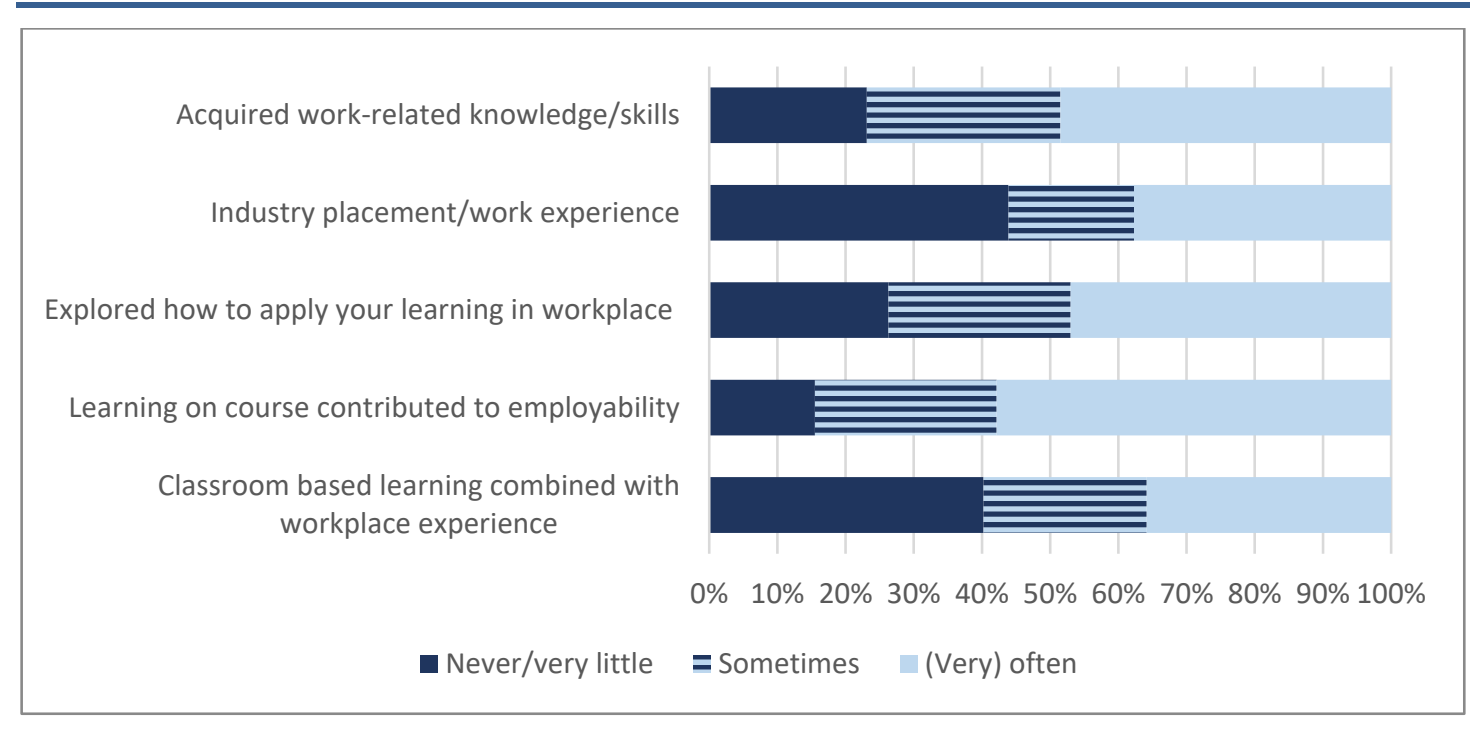

Finally, respondents were asked to assess the extent to which they had acquired a range of skills and competencies, by the time the survey was being conducted. These skills could have been acquired at any point, including during second-level education, post-school education or in the labour market. Overall, learners were most positive about their ICT skills, with 58 per cent indicating they had gained these skills to 'a great extent'. Almost half of respondents were highly positive about their written and oral communication skills. In line with earlier research (McCoy et al., 2014, p.158), leavers were least positive about their ability to write/speak in a foreign language - almost 70 per cent are highly critical of their skills in this domain. The majority of respondents were somewhat positive about their ability to perform well under pressure, while over half felt they were able to work well with others to 'a great extent'. In excess of 60 per cent were somewhat positive regarding both their ability to come up with new ideas/solutions and the analytical skills they had gained. Additional analyses examined the extent to which pathway groups differ in their selfassessed skills and competencies. For the most part, responses do not vary across the groups, despite wide differences in education duration. Those who had participated in higher education were slightly more positive about their written communication, oral communication and computer skills, but the differences are not substantial. Females emerged as being more positive across all domains, as did leavers from more highly educated backgrounds. 


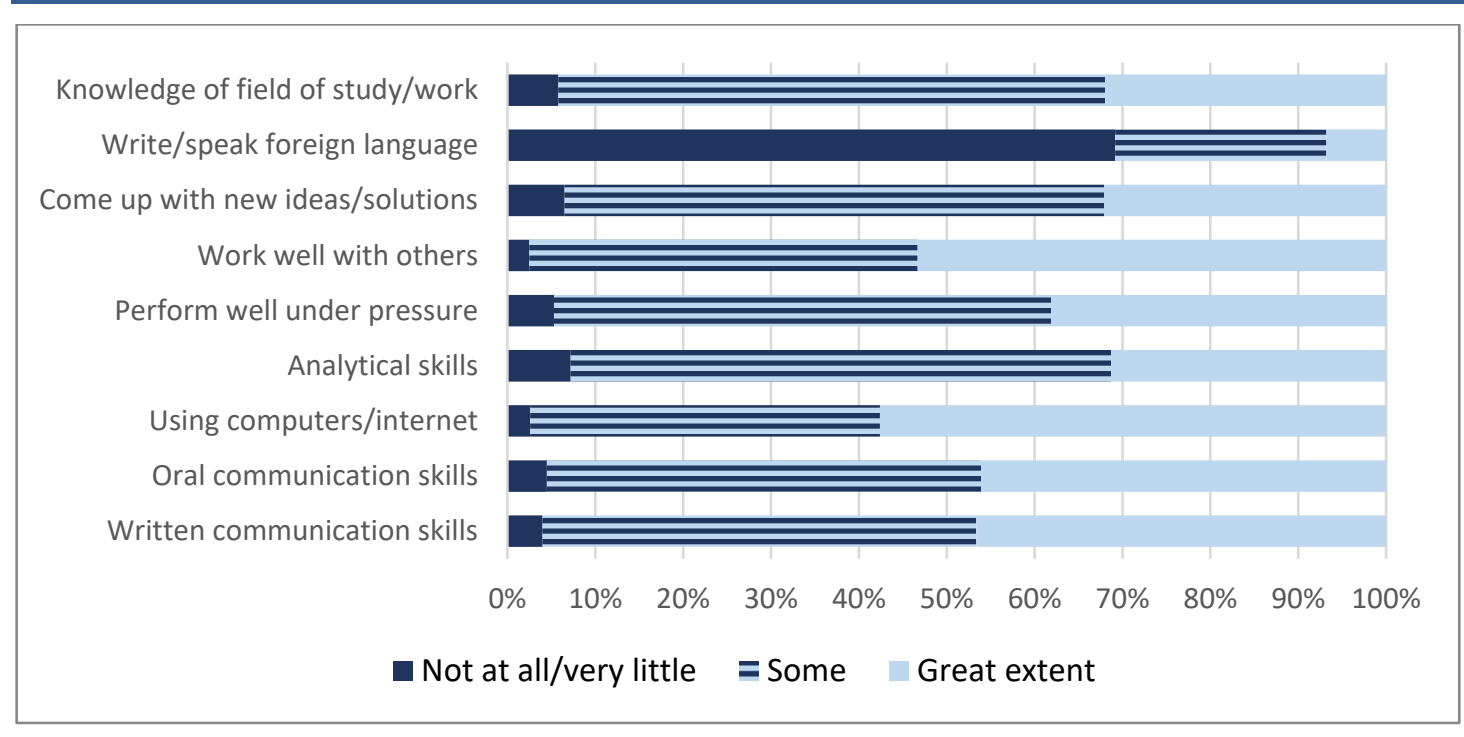

\subsection{REFLECTIONS ON PATHWAYS TAKEN}

\subsubsection{Reflections on post-school choices}

This final section examines subjective dimensions of young people's outcomes, including decision making, wellbeing and satisfaction with life five to six years after leaving school or a PLC programme. These areas, crucial to an in-depth assessment of the PLC programme, have received much less attention in the international and national literature, as compared to the educational and labour market trajectories of young people. The section begins with an examination of decision making and goal realisation among the school leavers, followed by an analysis of social inclusion, financial wellbeing and satisfaction with life (in section 5.6.2).

International research has highlighted that not all young people realise their aspirations, and outcomes reflect a complex set of interactions relating to individual, institutional and structural factors. Hodkinson and Sparkes (1997), for example, argues that decision making results from the ways opportunities are structured differently for individuals, reflecting the availability of different forms of capital. Similarly, Frigo et al. (2007) argue that decision-making styles vary from careful gathering of information and weighing up options to acting on intuition. However, they highlight economic/instrumental rationality models (decision making as a rational process) and structuralist models (decisions as the result of external forces) as key to understanding decision-making processes among young people. Respondents were asked whether they got to do what they 
planned after leaving school. Overall, 15 per cent of school leavers did not get to do what they had planned, with the figure somewhat higher for males (19 per cent, compared to 13 per cent for females). Goal realisation is also strongly differentiated by social background. Figure 5.11 shows results according to post-school pathway, with wide differences across the groups apparent. School leavers who pursued PLC courses were least satisfied in terms of goal realisation - less than 40 per cent felt they achieved their plans. Those who progressed to higher education are most likely to have achieved their goals (71 per cent), while the bulk of school leavers who progressed to higher education via PLC courses do not feel they achieved their goals fully ( 24 per cent did not achieve their goals and a further 34 per cent only partly achieved their goals). Among those entering the labour market, 48 per cent report realised their goals, although nearly one-third reported compromising their goals; in other words, realising their them 'to some extent'. Interestingly, the majority of PLC entrants who applied to (but did not enrol in) higher education felt they did not realise their goals.

FIGURE 5.11 DID LEAVERS GET TO DO WHAT THEY PLANNED AFTER LEAVING SCHOOL? (\%)

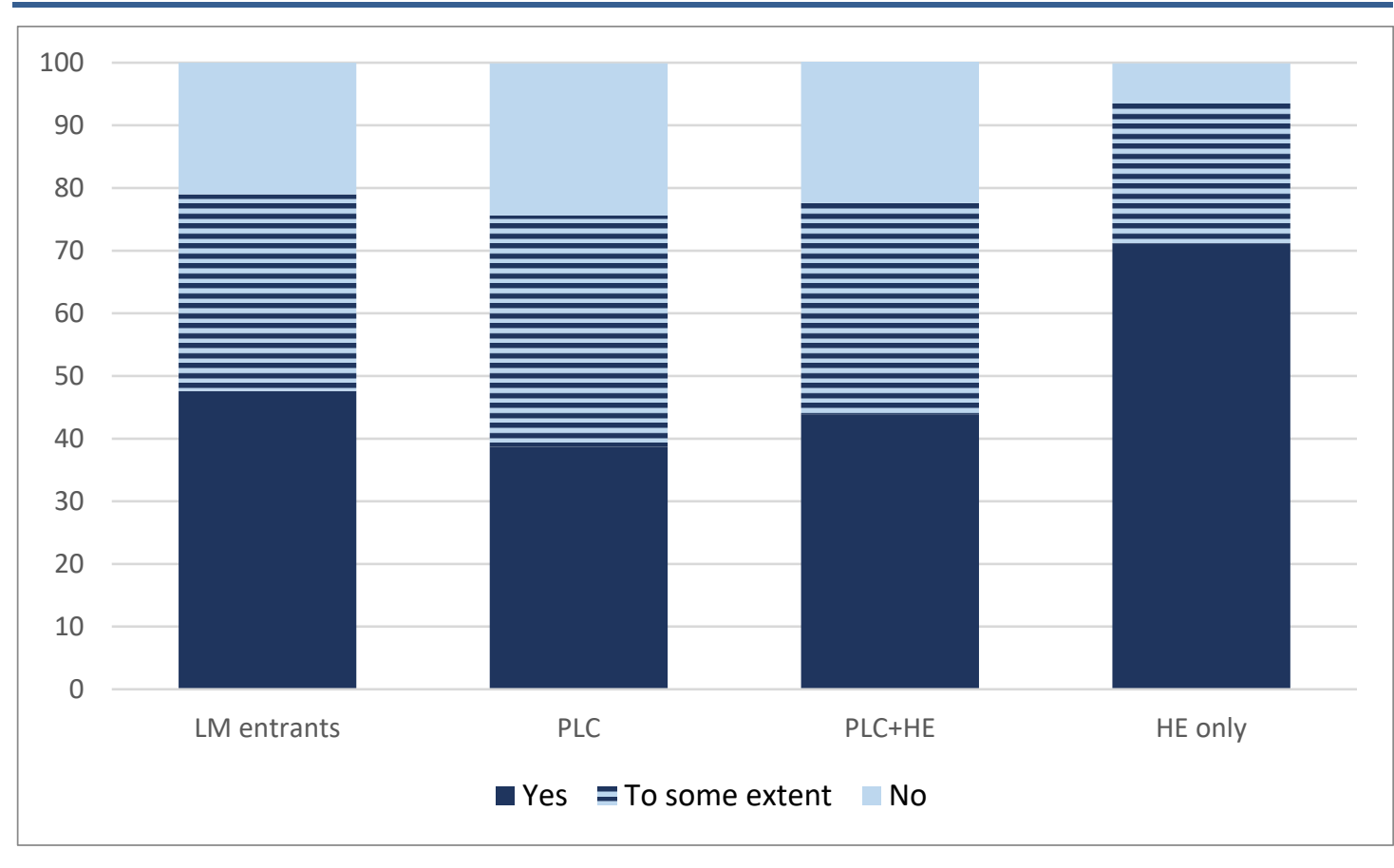

Note: Weighted data

Further analyses were undertaken to explore the simultaneous effects of post-school pathway, social background factors and Leaving Certificate performance on whether young people reported realising the plans they had made while at school, allowing a more like-for-like comparison across the pathway groups. Those who had not realised their plans are contrasted against those who had (partly or fully) secured their preferred outcome. In 
Table 5.5, we present odds ratio results where the outcome of the model is binary (not achieving goals versus achieving goals). An odds ratio of greater than one indicates an increase in the probability of not achieving goals, while an odds ratio of lower than one indicates a reduced probability of not achieving goals. Table 5.5 shows the summary results for the influence of main pathway, gender, social background and educational achievement on goal realisation. The full set of results is shown in Table A17 in Appendix A.

Model 1 shows the impact of the main pathway taken on young people reflecting that they did not realise their goals. In line with the descriptive results, young people who pursued PLC courses are most likely to report not realising their goals - they are nearly six times more likely to indicate this than those who progressed to higher education on leaving school. Those who enrolled on PLC and higher education courses are 4.7 times more likely to not realise their goals, while entrants to the labour market are nearly five times more likely to not realise their goals. Overall, males are 1.7 times more likely to not realise their goals than their female peers.

Model 2 takes into account a range of individual and family background factors (family type, parenthood, presence of a SEN and parental educational level), as these may underlie lower goal realisation for some groups. The results show that presence of a SEN while at school and having a child (at the time of the survey) are both associated with not achieving goals. Each of the pathway groups ('PLC', 'PLC and higher education' and 'LM entrants') remain significantly more likely to not achieve their goals even when we take account of these individual and family characteristics, although the magnitude of the effect is somewhat reduced. In other words, all else being equal, young people who progressed to PLC programmes are four times more likely to not achieve their goals than those who progressed to higher education.

Model 3 takes account of the impact of academic achievement on realising post-school plans. Not surprisingly, given the centrality of grades in terms of access to higher education, in particular, higher-performing leavers are significantly less likely to not realise their goals. The differences across the pathway groups become insignificant once we take account of educational achievement. Thus, PLC students are less likely to have achieved their goals because of their lower Leaving Certificate grades. In line with earlier research (McCoy et al., 2014, pp. 100), higher grades facilitate access to preferred post-school routes. PLC courses appear to have been a compromise in a context of not achieving adequate grades to pursue higher education, highlighting the continued lower status of PLC 
programmes in the Irish system (McGuiness et al., 2014, pp. 39).

TABLE 5.5 HOW MUCH MORE LIKELY ARE LEAVERS TAKING DIFFERENT PATHWAYS TO FEEL THEY DID NOT GET THE POST-SCHOOL CHOICES THEY HAD PLANNED? (ODDS RATIOS)

\begin{tabular}{l|c|c|c|}
\hline & $\begin{array}{c}\text { Model 1 } \\
\text { (Pathway and } \\
\text { gender) }\end{array}$ & $\begin{array}{c}\text { Model 2 (Add } \\
\text { controls for family } \\
\text { background) }\end{array}$ & $\begin{array}{c}\text { Model 3 (Add } \\
\text { controls for LC } \\
\text { points) }\end{array}$ \\
\hline $\begin{array}{l}\text { Higher education } \\
\text { (ref.) }\end{array}$ & 1.000 & 1.000 & 1.000 \\
\hline PLC & 5.568 & 4.059 & n.s. \\
\hline PLC + HE & 4.701 & 3.725 & n.s. \\
\hline LM entrants & 4.979 & 3.835 & n.s. \\
\hline & 1.691 & 1.788 & 1.593 \\
\hline Male & \multicolumn{3}{|l}{} \\
\hline \multicolumn{2}{|l}{$\begin{array}{l}\text { n.s. = not statistically significant. See Appendix Table A1.17 for the full model. All figures shown differ significantly } \\
\text { from the reference group (ref.). Non-proxy sample only. }\end{array}$} \\
\hline
\end{tabular}

School leavers were also asked whether they would take the same pathway if they were free to choose again. ${ }^{76}$ Overall, one-third of school leavers said they regret the choices they made, with somewhat higher levels of regret among males. School leavers who had not realised their goals were also more likely to say they would not pursue the same route. Clear differences were evident across the pathway groups, with young people pursuing PLC courses more likely to regret the pathway chosen, either partly or entirely (Figure 5.12). In total, 45 per cent of PLC participants would not take the same pathway again and 43 per cent of those who pursued PLC and higher education courses would not make the same decisions. Nearly one-quarter of higher education entrants would not take the same pathway.

Multivariate modelling was used to examine the simultaneous impact of a range of factors on regretting the pathway chosen on leaving school. Respondents who would not take the same route again are contrasted against those who would choose the same pathway again, either partly or entirely (Table 5.6; full results reported in Table A18 in Appendix A). In keeping with the descriptive results, there are significant differences across the pathway groups in Model 1, with the PLC groups nearly three

76 The question asked, 'Looking back, if you were free to choose again, would you take the same pathway (education, training or job)?' Respondents could respond 'yes', 'to some extent' or 'no'. 
times more likely to regret their pathway decisions. Over and above the effect of individual social background (Model 2), the PLC and 'PLC and higher education' groups are 2.2 and 2.4 times more likely to regret their choices, compared with those who progressed directly to higher education. Model 3 takes account of educational achievement; here, again, educational qualifications operate as a means of securing preferred outcomes. There are no longer significant differences across the pathway groups in terms of regret with post-school decisions. In other words, greater regret among the PLC groups is largely explained by their Leaving Certificate performance not being sufficiently high to allow access to higher education.

Additional analyses examined the role of guidance received at school on decision-making and regret. The results show that young people who express dissatisfaction with the guidance available while at school are significantly more likely to regret their choices on leaving school.

FIGURE 5.12 WOULD LEAVERS TAKE THE SAME PATHWAY AGAIN? (\%)

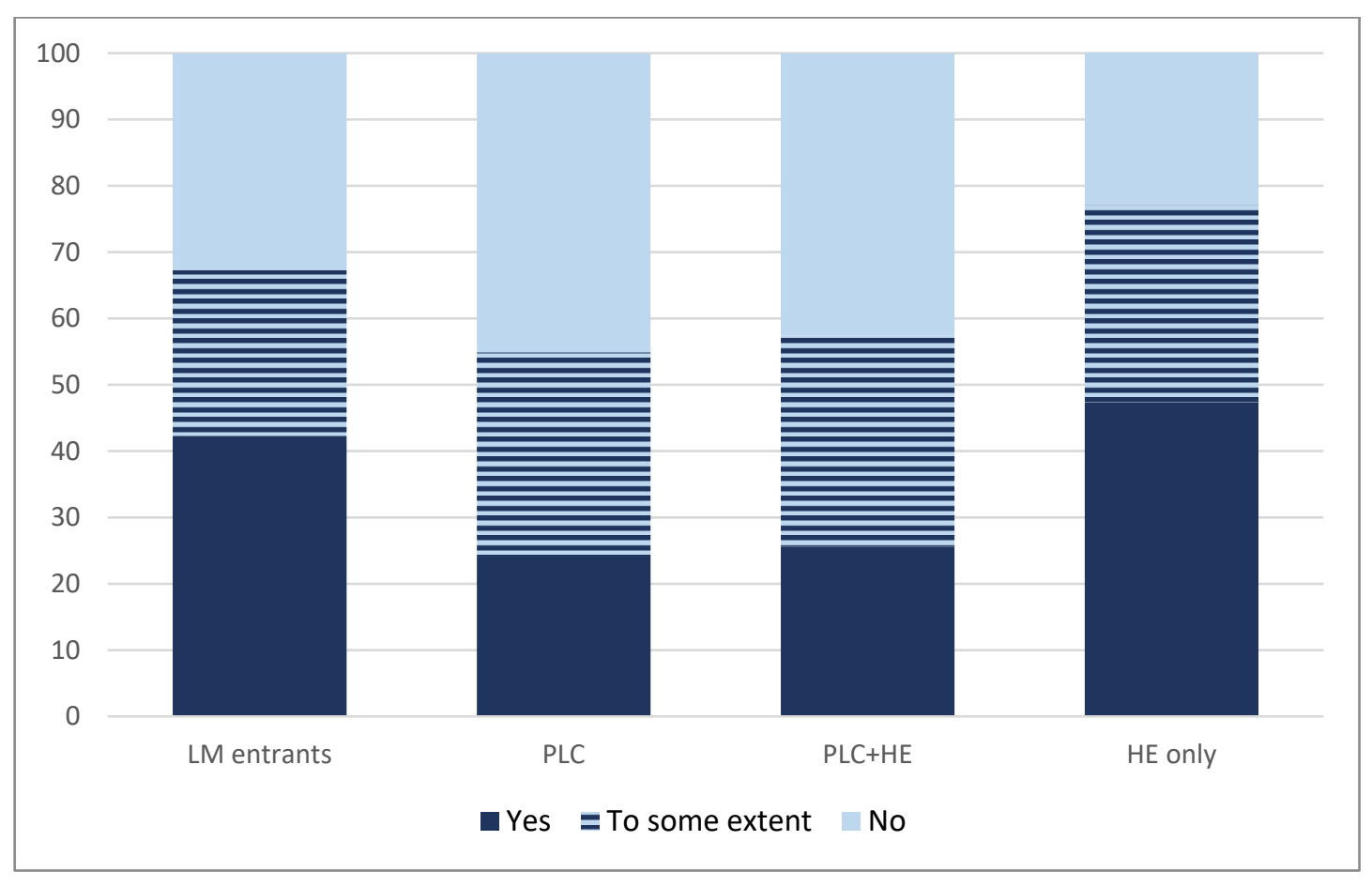

Note:

Weighted data 


\begin{tabular}{|c|c|c|c|}
\hline & $\begin{array}{c}\text { Model } 1 \\
\text { (Pathway and } \\
\text { gender) }\end{array}$ & $\begin{array}{l}\text { Model } 2 \text { (Adds } \\
\text { controls for family } \\
\text { background) }\end{array}$ & $\begin{array}{c}\text { Model } 3 \text { (Adds } \\
\text { controls for LC } \\
\text { points) }\end{array}$ \\
\hline $\begin{array}{l}\text { Higher education } \\
\text { (ref.) }\end{array}$ & 1.000 & 1.000 & 1.000 \\
\hline PLC & 2.649 & 2.199 & n.s. \\
\hline $\begin{array}{l}\text { PLC + higher } \\
\text { education }\end{array}$ & 2.715 & 2.411 & n.s. \\
\hline LM entrants & 1.826 & n.s. & n.s. \\
\hline Male & n.s. & n.s. & n.s. \\
\hline
\end{tabular}

\subsubsection{Life satisfaction, perceived social inclusion and financial wellbeing}

Overall, young people are broadly positive about their physical and mental health, with less than one in ten reporting their physical or mental health as fair or poor. School leavers were asked to rate their satisfaction, all things considered, with their life these days, on a ten-point scale from very dissatisfied (1) to very satisfied (10). Respondents were grouped according to quintiles (20 per cent groups) from most to least satisfied. Figure 5.13 shows results across the pathway groups, with young people who participated in PLC programmes disproportionately likely to be in the group of young people least satisfied with their life. Conversely, those who pursued higher education are much less likely to be among those dissatisfied with their lives: while 30 per cent of the PLC group are among the group most dissatisfied with life, this is the case for just 14 per cent of the higher education group.

Satisfaction with life also varies across social groups and for males and females, so multivariate models allow us to assess the extent to which these differences in life satisfaction reflect the gender and social composition of the pathway groups. Table 5.7 presents a series of multivariate models of the factors affecting life satisfaction, with the results showing the probability of being in the group least satisfied with life. Again, full model results are shown in Appendix A (Table A17). Overall, young people who enrolled in PLC courses are two and a half times more likely to be in this least satisfied group, at the time the survey took place 
(five to six years after leaving school), compared to those who progressed to higher education. Those who did not pursue higher education or PLC courses are also disproportionately more likely to be in the least satisfied group.

Even controlling for individual family circumstances and social background characteristics (Model 2), PLC participants are more dissatisfied with their lives, as recorded at the time of the survey. Relative to higher education entrants, all other pathway groups are twice as likely to be among the least satisfied group. It is interesting to note that those who are parents and those who experienced a SEN while at school are also more likely to be dissatisfied with their lives.

As in previous analysis, the final model takes account of educational performance in predicting dissatisfaction with life. Those who achieved higher Leaving Certificate grades have a lower risk of being in the group dissatisfied with life (results for the 401-500 and 501-600 groups are just outside statistical significance). Once again, when we take account of grades, differences across the pathway groups are no longer significant. Performance at second level clearly plays a central role in shaping life opportunities and in enabling access to the post-school educational pathways, particularly higher education, which maximises young peoples' life satisfaction and fulfilment.

\section{FIGURE 5.13 SATISFACTION WITH LIFE: PERCENTAGE IN THE LEAST AND MOST SATISFIED QUINTILES}

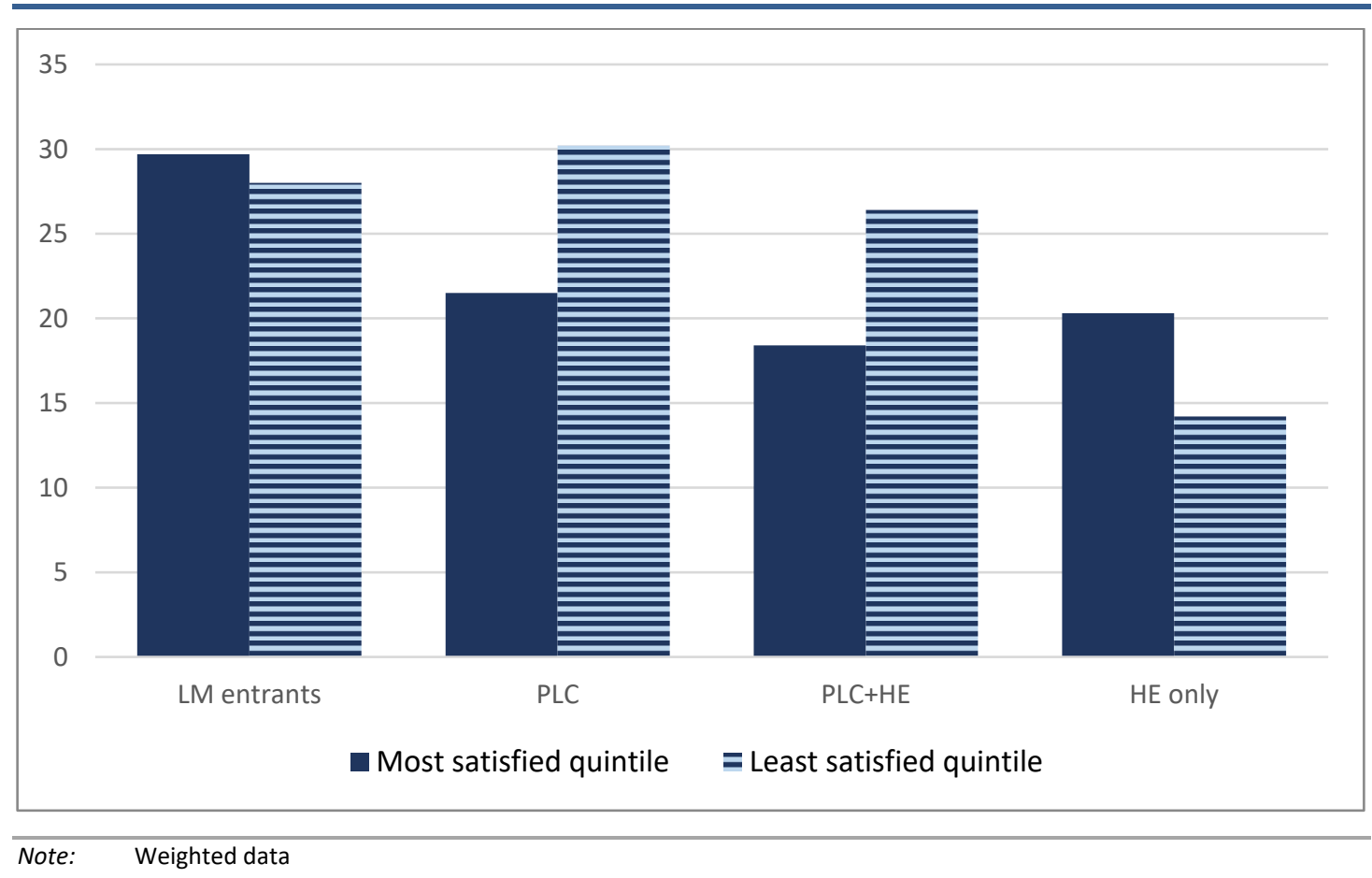




\begin{tabular}{|c|c|c|c|}
\hline & $\begin{array}{c}\text { Model } 1 \\
\text { (Pathway and } \\
\text { gender) }\end{array}$ & $\begin{array}{l}\text { Model } 2 \text { (Adds } \\
\text { controls for family } \\
\text { background) }\end{array}$ & $\begin{array}{c}\text { Model } 3 \text { (Adds } \\
\text { controls for LC } \\
\text { points) }\end{array}$ \\
\hline $\begin{array}{l}\text { Higher education } \\
\text { (ref.) }\end{array}$ & 1.000 & 1.000 & 1.000 \\
\hline PLC & 2.510 & 2.131 & n.s. \\
\hline $\begin{array}{l}\text { PLC + higher } \\
\text { education }\end{array}$ & 2.310 & 2.035 & n.s. \\
\hline LM entrants & 2.511 & 2.033 & n.s. \\
\hline Male & n.s. & n.s. & n.s. \\
\hline
\end{tabular}

The survey of leavers taps into two other important dimensions of quality of life: social inclusion and financial security. Respondents were asked a series of questions regarding their feelings of self-worth and participation in society. Responses to these items combine to produce a global measure of social inclusion (with high reliability, alpha .79). ${ }^{77}$ The items included:

- I generally feel that what I do in life is worthwhile;

- I feel left out of society;

- Life has become so complicated today that I almost can't find my way;

- I feel that the value of what I do is not recognised by others; and

- Some people look down on me because of my life situation or income.

Responses are differentiated into those in the lowest and highest quintiles - that is, those who are least and most socially included. Among school leavers who pursued PLC qualifications, 30 per cent fall in the least socially included quintile, compared to 15 per cent of higher education participants. While 25 per cent of higher education participants fare well in terms of this measure of social inclusion, this is the case for just 19 and 13 per cent of the PLC and PLC\&higher education groups. Those who did not pursue either higher education or PLC course fall close to the overall average in terms of social inclusion.

77 These items are drawn from Eurofound's European Quality of Life Survey (2015). 
FIGURE 5.14 PERCEIVED SOCIAL INCLUSION: PERCENTAGE IN THE HIGHEST AND LOWEST QUINTILES (MOST AND LEAST SOCIALLY INCLUDED)

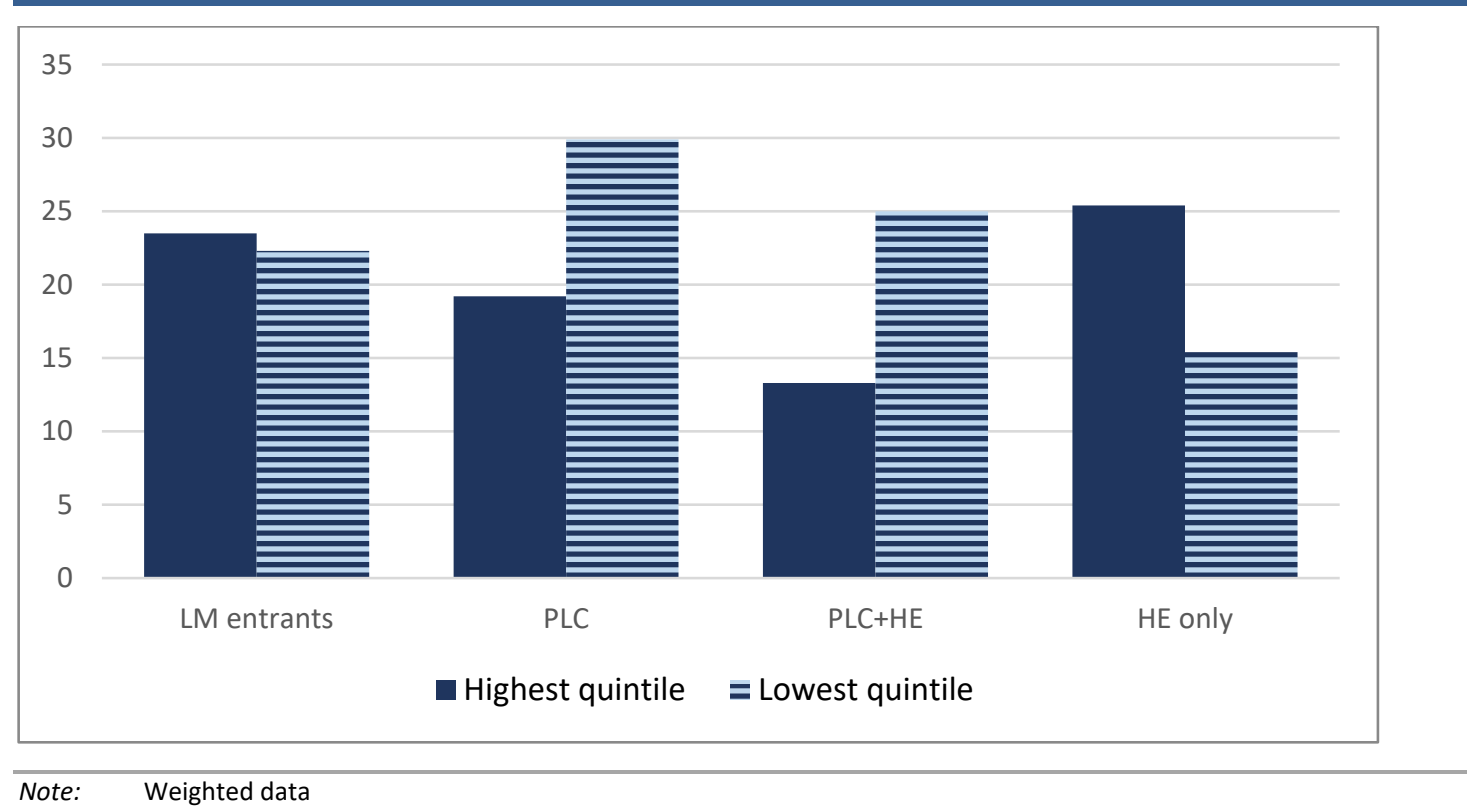

Within a multivariate approach, PLC participants are more likely to be in the least socially included group (Table 5.8 and Table A20 in Appendix A). Taking account of family and background characteristics, only the PLC group is more at risk in terms of social inclusion. Those with SEN at school fare less well in terms of social inclusion, while those with more highly educated mothers fare better. Other dimensions of wellbeing are also highly related to social inclusion. In particular, those experiencing mental health difficulties, those experiencing financial strain and those who did not achieve their goals on leaving school (and regret their choices) are much more likely to fare less well in terms of social inclusion.

TABLE 5.8 HOW MUCH MORE LIKELY ARE LEAVERS TAKING DIFFERENT PATHWAYS TO BE IN THE GROUP LEAST SOCIALLY INCLUDED? (ODDS RATIOS)

\begin{tabular}{|c|c|c|c|}
\hline & $\begin{array}{c}\text { Model } 1 \\
\text { (Pathway and } \\
\text { gender) }\end{array}$ & $\begin{array}{c}\text { Model } 2 \text { (Adds } \\
\text { controls for family } \\
\text { background) }\end{array}$ & $\begin{array}{c}\text { Model } 3 \text { (Adds } \\
\text { controls for LC } \\
\text { points) }\end{array}$ \\
\hline $\begin{array}{l}\text { Higher education } \\
\text { (ref.) }\end{array}$ & 1.000 & 1.000 & 1.000 \\
\hline PLC & 2.248 & 1.894 & n.s. \\
\hline $\begin{array}{l}\text { PLC + higher } \\
\text { education }\end{array}$ & 1.877 & n.s. & n.s. \\
\hline LM entrants & n.s. & n.s. & n.s. \\
\hline Male & n.s. & n.s. & n.s. \\
\hline
\end{tabular}


Recent research has highlighted the impact of financial wellbeing on broader socio-emotional wellbeing and quality of life (Watson et al., 2014). Further, earlier analysis (section 5.5) revealed that financial pressures constituted the single biggest difficulty facing young people during the course of their post-school studies. Respondents were asked about the extent to which their household is able to make ends meet (at the time of the survey), with possible responses ranging from 'very easily' to 'with great difficulty'. Overall, 14 per cent of respondents indicated they experienced (great) difficulty in making ends meet. Results were again strongly differentiated according to post-school pathway, with the PLC groups more likely to report experiencing financial difficulty. While onethird of higher education participants and 36 per cent of labour market entrants reported relative ease in terms of making ends meet, this was the case for 18 and 23 per cent of the PLC groups. One in five PLC participants report (great) financial difficulties, and an additional one-third report 'some difficulty' in making ends meet. This compares to less than 30 per cent of higher education entrants reporting any level of difficulty in meeting current living costs. Given the findings in Chapter 4 that showed similar employment chances and wage levels, these findings may reflect additional caring responsibilities and perhaps part-time employment among the PLC groups.

Multivariate models allow a greater understanding of the factors shaping financial insecurity. As shown in Table 5.9 and Table A21 in Appendix A, again PLC participants do less well (Model 1 ) than their counterparts who progressed to higher education on leaving school. However, much of this difference is accounted for by family circumstances. Respondents with children are significantly more likely to experience difficulty in making ends meet. Further analysis also shows that failure to achieve post-school goals and regret at decisions made play an important role in understanding financial insecurity, at least in the five to six years post leaving school/PLC programmes. 
FIGURE 5.15 ABILITY TO MAKE ENDS MEET FOR LEAVER HOUSEHOLDS (\%)

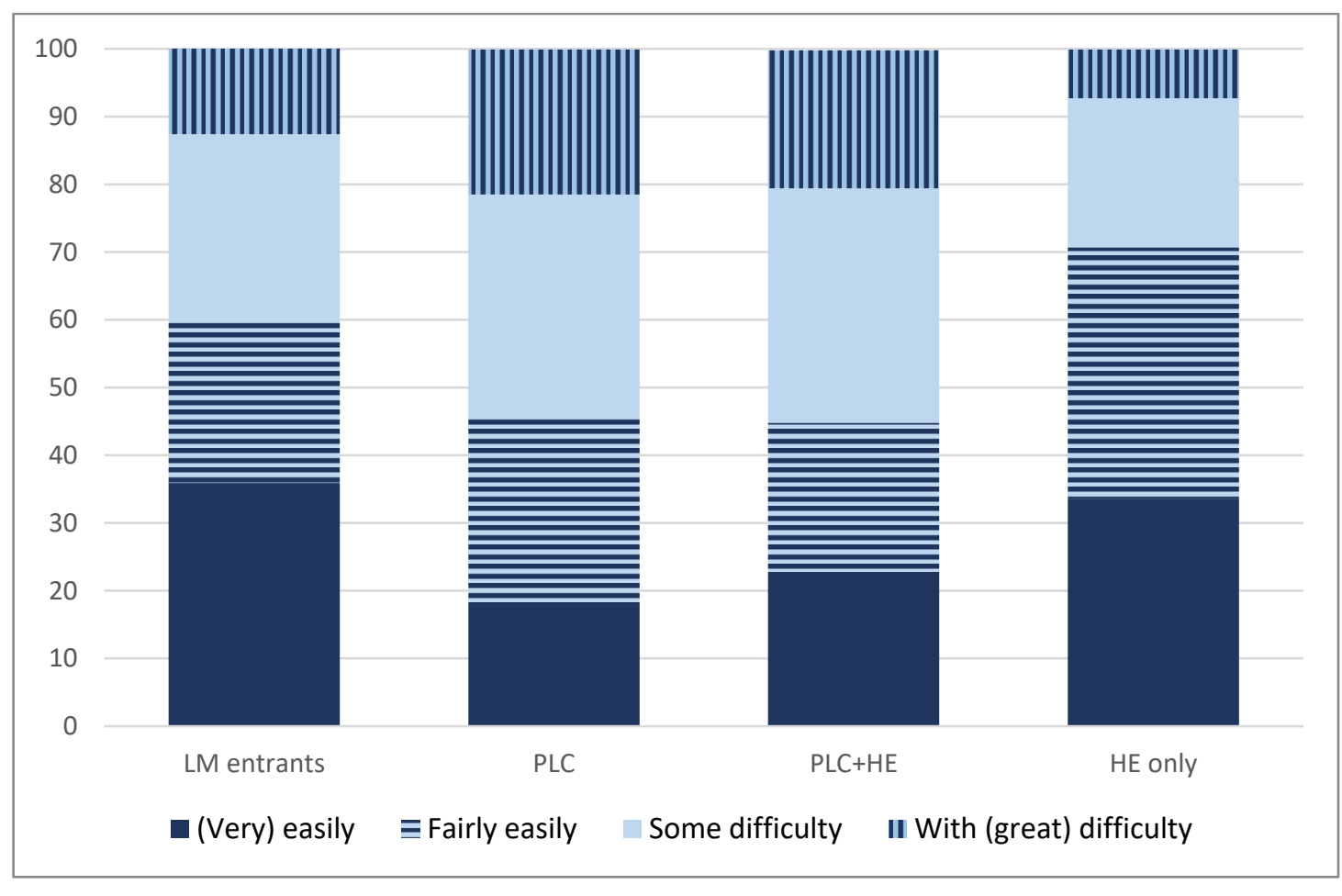

Note: Weighted data

TABLE 5.9 HOW MUCH MORE LIKELY ARE LEAVERS TAKING DIFFERENT PATHWAYS TO EXPERIENCE DIFFICULTY IN MAKING ENDS MEET? (ODDS RATIOS)

\begin{tabular}{|c|c|c|c|}
\hline & $\begin{array}{c}\text { Model } 1 \\
\text { (Pathway and } \\
\text { gender) }\end{array}$ & $\begin{array}{c}\text { Model } 2 \text { (Adds } \\
\text { controls for family } \\
\text { background) }\end{array}$ & $\begin{array}{c}\text { Model } 3 \text { (Adds } \\
\text { controls for LC } \\
\text { points) }\end{array}$ \\
\hline $\begin{array}{l}\text { Higher education } \\
\text { (ref.) }\end{array}$ & 1.000 & 1.000 & 1.000 \\
\hline PLC & 3.054 & n.s. & n.s. \\
\hline PLC + HE & 3.938 & 2.350 & n.s. \\
\hline LM entrants & 2.719 & n.s. & n.s. \\
\hline Male & n.s. & n.s. & n.s. \\
\hline
\end{tabular}

\subsection{SUMMARY AND CONCLUSIONS}

This chapter has looked at how school leavers participating in PLC programmes experience these programmes and how their educational experiences compare with other groups, particularly those taking higher education courses. Participants in PLC programmes are disproportionately female and from less educated backgrounds. They are also more likely to have experienced a SEN while at school than their counterparts directly 
enrolling in higher education. It is interesting to note that students who successfully progress from PLC to higher education programmes of study are typically from more highly educated backgrounds and have themselves received higher grades in the Leaving Certificate examination than those who do not progress. In terms of plans on leaving school, just half of the PLC group from this survey planned on pursuing education/training, while those enrolling in higher education were more definite in their plans for further study. This likely reflects the greater emphasis placed on higher education opportunities and application processes within second-level schools (McCoy et al., 2014). However, dissatisfaction levels with guidance counselling supports at second level were high for all pathway groups. Such dissatisfaction is a key factor in school leavers later reflecting with regret on their post-school choices.

The survey gathered valuable information on PLC students' experiences across a range of aspects of their programmes of study, including course intensity, transition difficulties, meeting the costs of education participation, academic and social supports available and teaching and learning approaches. Course intensity varied widely among PLC participants, with considerable numbers spending either fewer or more hours than average in class. Most likely reflecting the school-based nature of much PLC provision, the vast majority of PLC students do not participate in sports/clubs or societies, unlike their higher education counterparts. PLC students were also less likely to access career guidance supports and counselling supports. Despite considerably higher SEN prevalence rates among PLC entrants, proportions accessing learning supports and disability support services were comparable (at 15 and three to four per cent, respectively). PLC students were more likely than higher education students to rate their teachers as highly supportive/available, although both PLC and higher education students were generally less positive about administrative staff.

The single greatest difficulty faced on transition to PLC study related to the financial aspects of studying. Such concerns also arose among higher education participants, but the two groups of students (PLC and higher education) differed somewhat in terms of the sources of funding in meeting college costs. Partly reflecting the differing socio-economic profile of the two groups, higher education students were more likely to receive direct and indirect support from their families. However, higher education students were also more likely to be in receipt of the state maintenance grant. PLC students were more likely to be in receipt of the BTEA and less likely to be in paid employment. Beyond the financial demands of (fulltime) study, concerns around the academic demands of their course also 
arose among PLC students, but these were less prevalent than among higher education respondents. Overall, and in line with earlier research (McCoy et al., 2014), the significant changes in teaching and learning methodologies that accompanied the transition to post-school education (PLC and higher education), particularly the shift towards more independent learning approaches, represented a difficulty for many and something for which they felt ill-prepared.

PLC students reported that they were largely satisfied with the relevance of course design and the vast majority felt their teachers/tutors had the required knowledge. It is also interesting that the vast majority of those progressing to higher education felt their PLC course prepared them for it. However, for both PLC and higher education students, responses were less positive in relation to the prominence of workplace learning in their course. One-quarter of PLC participants acquired work-related skills 'never' or 'very little', while over one-third did not gain industry placement or work experience opportunities. In addition, one-third indicated that learning on their course did not contribute to their employability.

The final section provides some important insights into the lives and reflections of young people who pursued different pathways on leaving school. Perhaps reflecting the experiences of PLC students, particularly in relation to the range of supports available, the prominence of workplace learning on their courses and access to extra-curricular clubs and societies, PLC participants are less positive in their reflections than their counterparts who progressed to higher education on leaving school. For many, PLC courses are still seen as a compromise, in a context of not achieving adequate grades to pursue higher education, highlighting the continued lower status of further education in Ireland (McGuinness et al., 2014). Similar findings emerge in relation to life satisfaction, measures of social inclusion and financial wellbeing. PLC participants fare less well, and second-level grades play a central role in shaping young peoples' opportunities to pursue post-school pathways that will maximise opportunities for personal fulfilment and achievement. Additionally, family circumstances play an important role in understanding wellbeing and particularly financial insecurity - those with children experience much greater challenges in this regard and this explains much of the difference between the pathway groups. 


\section{CHAPTER 6}

\section{Summary and implications for policy}

\subsection{INTRODUCTION}

Post-Leaving Certificate (PLC) courses represent the largest component of full-time further education and training (FET) provision in Ireland, with over 32,000 learners enrolled in such courses in 2015-2016. Recent research on the FET sector as a whole highlighted concerns around its structures and responsiveness to labour market conditions, among other issues (McGuinness et al., 2014). The SOLAS FET Strategy (2014) subsequently pointed to the need for a stronger evidence base in order to inform future policy development in the sector. This study, commissioned by SOLAS, provides a more detailed evaluation of PLC provision. In doing so, it draws on three complementary research strands. Firstly, desk-based analysis of administrative data was carried out to document the type of provision in terms of field of study and the distribution of PLC places across the country. Secondly, a new survey of PLC principals was conducted in order to explore principals' perceptions of goals, adequacy of existing facilities and the benefits and challenges of PLC provision. Thirdly, a new survey of PLC and Leaving Certificate leavers was conducted to assess their labour market outcomes as well as their experiences while taking PLC and higher education courses. Together, these strands provide comprehensive evidence to inform the future development of the sector.

This chapter outlines the main findings and discusses their implications for policy.

\subsection{THE GOALS OF PLC PROVISION}

The development of vocational education in Ireland was initially slow, largely because of late industrialisation (Coolahan, 1981). Because of this, the tradition of structured involvement of employers in education and training provision found in some other European countries, such as Germany and the Netherlands, did not emerge in the Irish context. ${ }^{78}$ This has had significant implications for Ireland's vocational education and training (VET) sector.

From the 1970s onwards, Ireland's membership of the European

78 For an overview of differential institutional relations between education and labour market systems, see Müller and Gangl (2003). 
Community had a highly influential impact on VET in Ireland (Coolahan, 1981; O'Sullivan, 2005). The European Social Fund (ESF) provided funding for the establishment of pre-employment courses in over 120 schools in 1977. These courses were targeted at post-junior cycle students and aimed to provide social, general and technical education combined with work experience. Initially confined to vocational and community/comprehensive schools, they were redeveloped as Vocational Preparation and Training (VPT) courses (VPT1 and VPT2) in 1984 and extended to voluntary secondary schools (NESC, 1993). A second year was added to these courses in 1985 and VPT2 courses became commonly known as PLC courses. These courses were designed to provide vocational education to facilitate the transition to employment for young people by 'bridging the gap between the values and experiences normally part of traditional education and those current in the world of work (Department of Education, 1984, p. 5). However, commentators (e.g. McNamara, 1990) have highlighted the lack of clarity around the skills to be fostered and the relationship between the courses offered and labour market demand.

An important feature to note, and one that received a good deal of discussion in an earlier review of PLC provision (Mclver Consulting, 2003), is the fact that PLC courses continue to be provided within second-level school structures. This approach developed because of the initial focus of pre-employment courses on providing alternative pathways for at-risk young people, but has not changed despite the shift towards provision for those who have already completed the Leaving Certificate (and indeed, towards providing for older adults). A number of stand-alone further education colleges have emerged, while in other ETB colleges and voluntary secondary schools PLC students are taught in the same building as younger people taking regular junior and senior cycle courses. An enhanced capitation grant (reduced in 2011 and 2014) is payable to all PLC students to cover the cost of equipment, materials and general running expenses, but otherwise PLC providers are governed by second-level structures in terms of teacher contracts and length of the school year. Qualification specifications for PLC (as well as other further education) teachers and tutors are set by the Teaching Council in a parallel process to that used for primary and second-level teachers.

The numbers taking part in PLC courses doubled over the period 19841985 to 2015-2016 (DES Statistical Reports, various years). Furthermore, the remit of provision changed over time, with PLC courses becoming an increasingly important route for second-chance education for adults (Watson et al., 2006). Those aged 21 years or over made up only 4.5 per cent of PLC participants in 1988-1989 but this had increased dramatically 
to 45 per cent by 2015-2016. From the start, PLC students were predominantly female in profile, largely reflecting the dominance of commercial and secretarial courses in the early years of the programme (Lewis and Kellaghan, 1987). However, male participation has increased in relative terms over time, rising from 28 per cent in 2000 to 40 per cent in 2016 (DES Statistical Database). The remit of PLC courses has changed in other respects too. While initially developed as a route into employment, and therefore largely as an alternative to third-level education, PLC courses have increasingly become a route into higher education for a significant number. For example, in 2016, around one-fifth of applicants through the CAO process presented QQI or FETAC qualifications. The use of vocational qualifications as a route to accessing higher education is common in many other countries (see, for example, Moodie and Wheelehan, 2009, on Australia), though some countries, most notably Scotland, have adopted a different model by allowing students to embark on higher education courses within further education colleges (Gallacher, 2009).

As a result of these changes over time, PLC courses now can be seen as fulfilling a number of functions: vocational preparation for young people; social inclusion and second-chance education for older adults; and a progression route into higher education. This diversity of functions is not unique to the Irish context, with much international literature on further education discussing potentially competing goals and blurred boundaries between further education and other forms of education provision (see, for example, Avis, 2009; Gallacher, 2006). The multiple goals of PLC provision were echoed in the survey responses of principals who saw PLC courses in general as fulfilling a range of roles, including progression to employment, progression to higher education, lifelong learning and social inclusion, with principals placing relatively equal weight on each component. There was no evidence, from the survey data at least, that principals viewed these goals as competing. Thus, when asked about the focus of courses in their institution, there was no evidence of a trade-off between focusing on labour-market-oriented courses as opposed to education-oriented courses, with principals likely to mention that courses were addressing multiple goals. This contrasted somewhat with the views of learners, who were more likely to indicate a primary rationale for taking a PLC course, with some differences in the profiles of learners taking courses for labour market, progression or personal development reasons. In particular, those whose mothers had degrees and those with higher Leaving Certificate grades were more likely to take a PLC as a route into higher education while older learners and, to some extent, women were less likely to emphasise educational progression opportunities. These 
findings have important implications for policy, suggesting that while the PLC sector as a whole can fulfil multiple goals, there are important distinctions between courses focused primarily on the transition to employment and those focused on progression to further learning. These distinctions have consequences for information and guidance aimed at potential entrants as well as for course content and delivery.

\subsection{AVAILABILITY OF PLC PROVISION}

Analyses of administrative data indicate a substantial amount of heterogeneity in the regional distribution of PLC places. There is considerable variation across counties in the ratio of enrolments to the total population and no evidence of a relationship between the concentration of PLC places and county-level deprivation levels. Thus, young people from disadvantaged regions, who have the highest risk of unemployment, do not have greater access to vocational educational programmes than those in more advantaged areas. Furthermore, there has been little change over time (between 2008-2009 and 2011-2012) in the concentration of PLC provision. The enrolments data suggest that the distribution of PLC places tends to be driven by legacy issues rather than strategic planning, with little evidence that the number of places and composition of provision is reactive to changing labour market conditions, an issue explored in greater detail below.

PLC courses are offered in a range of settings, including stand-alone further education colleges, ETB schools and colleges, community/comprehensive schools, and voluntary secondary schools. As a result, the average number of learners varies significantly across settings. Larger providers are more likely to offer a range of supports to students than smaller providers, including career guidance, personal counselling, disability support, a student union, a class tutor system and childcare facilities. Interestingly, however, principals in smaller institutions express greater satisfaction with services for students (with the exception of technical and computer facilities), suggesting that while larger colleges are more likely to have certain facilities, they are seen as insufficient for the number of learners enrolled. These patterns were echoed in the qualitative responses by providers, over half of whom highlighted challenges relating to lack of funding and resources. Variation in the provision and resourcing of student services is likely to have important consequences for learners. While there may be logistical difficulties in smaller providers offering the full range of student support services, there is potential to perhaps access services centrally through the local ETB, for example. Findings from the survey of principals suggest that dissatisfaction with services for students appears to 
be driven by lack of funding and resource constraints. The sector's reliance on a second-level funding model may create potential constraints on providing the kinds of supports needed for adult learners. It highlights the need to re-evaluate whether the existing enhanced per capita allocation for PLC students is sufficient to facilitate provision of the range of services and supports appropriate to specialised skills development among adult learners. Of particular concern is the finding that only one-third of PLC learners reported having had access to career guidance during their course. This appears to suggest a gap in provision. The extent to which guidance is offered informally by PLC staff rather than through formal guidance provision would merit further investigation.

\subsection{LABOUR MARKET RESPONSIVENESS OF PLC PROVISION}

International research has found that young people who have taken VET tend to make a smoother transition into employment and are less likely to experience (prolonged spells of) unemployment than those who have attained academic or general qualifications (Müller and Gangl, 2003). The nature of such education is crucial, with courses that have closer linkages to the labour market leading to better labour market outcomes because of the occupationally specific skills they provide (CEDEFOP, 2013; de Lange et al., 2014). In such contexts, employer buy-in regarding course design and content in institution-based systems or providing employment experience in dual systems is found to have a decisive influence on the success of VET, ensuring its responsiveness to potentially changing labour market conditions. The existence of VET qualifications is not sufficient to enhance the transition to employment unless these underlying institutional structures are in place (Raffe, 2015). Similarly, where VET fails to keep pace with changing employment structures, as was the case in the rapid transformation of eastern European economies in the post-socialist period, those with VET qualifications tend to fare very poorly on the labour market (Kogan et al., 2011).

The study findings provide insights into the extent to which PLC provision is responsive to the labour market from a number of perspectives: the nature of the match (or mismatch) between provision and labour market demand at the aggregate level; labour market linkages at the level of PLC providers and courses; and employment outcomes among individual course participants.

\subsubsection{Provision and labour market demand}

The fact that the composition of PLC provision has remained relatively 
stable and the enrolments have increased during a period in which both the level and composition of labour market demand changed dramatically suggests that PLC provision does not appear to be highly responsive to changing labour market conditions and shocks. Data from the Quarterly National Household Survey (QNHS) were used to estimate the composition of demand for newly qualified vocational labour. Almost 60 per cent of the jobs available for these new entrants were in sales and services. Mapping enrolments and potential job opportunities for three employmentoriented fields (early childhood care and education, community and health services, and hairdressing) indicated an oversupply of leavers with qualifications in these areas.

\subsubsection{Employer engagement among providers}

Survey data from principals offer more detailed insights into some of the factors shaping this mismatch. The Conditions of Approval guidelines set out criteria to be used in deciding to offer a new PLC course, with these criteria focusing on meeting government policy, addressing skill gaps or areas of skill growth, and employer demand or progression opportunities. In practice, principals rate student demand and having staff with the relevant skills as influential factors in establishing a new course. While they also point to the role of local and regional labour market demand, they are less likely to refer to employer demand or occupational forecasts. Similarly, when it comes to discontinuing courses, principals are more responsive to falling enrolments and student perceptions than to labour market factors. These patterns suggest that, contrary to the Conditions of Approval guidelines, course provision is strongly influenced by (lack of) student demand rather than being directly responsive to labour market conditions. Legacy issues appear to play an important role, with existing staff skill sets and (perceived) student demand shaping the courses being offered. There is considerable potential to provide more systematic information on local and regional skill needs through the network of regional skills fora being created to help shape and reshape the kinds of courses provided. The findings also point towards the importance of continuous professional development (CDP) for existing staff in facilitating principals in adapting course offerings to meet labour market need. The majority (71 per cent) of principals report having at least one teacher who teaches both PLC and junior or senior cycle students; this may act as a constraint on making significant adaptations to course content.

Employer engagement at the local level also emerges as crucial. Half of principals report that their staff meet with local employers at least three times a year. However, logistical constraints mean that larger providers 
have more frequent contact with local employers, with one-fifth of small providers meeting with employers less than once a year (or never). There is perhaps potential for ETBs to act as a conduit for a greater linkage between employers and smaller providers at the local level. A further avenue for employer engagement is through work experience placements, which provide vocational skills for learners but which may also encourage employers to recruit from PLC courses. It is of concern that over one-fifth of PLC learners report not having taken part in a work experience placement during the course of their studies. The fact that this pattern did not differ by learners' original rationale for entering the course (to get a job or to progress to higher education) or by whether they subsequently went into the labour market or on to higher education raises concerns about labour market linkages on some courses. This finding is reinforced by evidence from principals, over three-quarters of whom indicate that not all learners take part in work experience. Concerns about labour market linkage are underlined by learner responses in relation to the employment orientation of their course, with almost one-third feeling that their learning did not contribute to their employability and one-quarter considering that they did not acquire job-related knowledge and skills. These perceptions did not differ between those who went on to higher education and those who went directly into the labour market, suggesting a need to revisit course content to enhance learner employability, especially on courses designed to be oriented towards employment.

\subsubsection{Employment outcomes among learners}

Principals reported that on completing their courses, just over one-third of leavers from their institution entered employment, with approximately 28 per cent progressing to higher education, 19 per cent remaining in further education, and 12 per cent becoming unemployed. The survey of learners provides more detailed evidence on labour market outcomes among those who had taken PLC courses, comparing them with a control group of those who had taken the Leaving Certificate and progressed directly into the labour market. Thirty-nine per cent of PLC learners had taken the course with the aim of obtaining a job straight away. After three years, no significant differences were observed in the employment chances for PLC and Leaving Certificate labour market entrants. In contrast, in 2015 (after five years) the PLC treatment group were, on average, 16 per cent more likely to be in employment compared to the Leaving Certificate direct labour market entrants. This effect seems to be driven by the 24 per cent advantage among those who had taken more job-specific PLCs relative to the direct labour market entrants. 
As well as looking at employment chances, analyses were conducted to assess job quality among the different leaver groups. The estimated counterfactual impacts on various measures of job quality, such as job satisfaction or level of skill match with the current job, showed no significant differences between the PLC and Leaving Certificate groups. The incidence of underskilling (that is, the current job demanding more knowledge and skills than the respondent could offer) across various groups is somewhat surprising. Generally, we might expect underskilling rates to be highest for those with Leaving Certificate or higher education, as these qualifications may not be occupationally specific in nature. The fact that the incidence of underskilling for PLC leavers is comparable to the rates for other groups, viewed in conjunction with the findings on employability, highlights the need to review course content and delivery methods, especially on employment-related courses, to ensure that they further enhance labour market preparation.

In terms of the wage impacts of PLC participation, we find little evidence of variations in earnings by level of acquired education, not surprising given the early stages of the employment career. In order to estimate the longer-run effects of PLC participation, wage returns were estimated using various waves of the National Employment Survey. The returns to PLC education reveal that while PLC qualifiers earned a wage premium of 4.4 per cent in 2003, no significant difference was detected in 2006 and 2009. The results suggest that the long-run returns to PLC education over Leaving Certificate qualifications will tend to be cyclical in nature, with the limited data suggesting that these will be positive during normal periods of growth.

\subsection{PROGESSION TO FURTHER LEARNING}

Thirty-nine per cent of the PLC learners had taken their course in order to get a place on a higher education programme: employment and progression orientations were equally prevalent among the learner group. Four in ten participants saw their course as opening up opportunities for further study at institutes of technology, while only one-quarter saw it as providing opportunities to study at university. Of those who had intended to go on to higher education, two-thirds actually did so. Those who did not make the transition tended to have lower Leaving Certificate grades. It is also interesting to note that one-third of those who entered a PLC course intending to get a job immediately after completing the course went on to take a higher education course, suggesting that the experience of studying at PLC level may reorient some learners towards further learning opportunities. 
In terms of the estimated counterfactual impact, PLC learners are 27 per cent more likely to progress to higher education than the direct labour market entrants control group with similar characteristics (such as points score, gender and age). This impact is highly significant, with a stronger effect found for those PLC learners in more general rather than job-specific programmes. Thus, PLC courses appear to facilitate progression to higher education for a group of people who would likely not participate otherwise. The accounts of principals also highlight the role of PLC courses in acting as a stepping-stone towards higher education, by enhancing learner confidence and providing the skills to manage the transition. At the same time, it is worth noting that courses do not seem to serve as a stepping-stone in the same way for those with lower Leaving Certificate grades, though the numbers in the study sample are too small to be definitive.

\subsection{PLC PROVISION AND SOCIAL INCLUSION}

As indicated above, one of the goals of PLC provision is to facilitate social inclusion. PLC learners are more likely to be from less educated family backgrounds, are more likely to be older and have children, and have greater SEN prevalence rates than their counterparts directly enrolling in higher education. In terms of the distribution of Leaving Certificate points, the majority (62 per cent) of PLC leavers are in the $200-400$ points band while the majority of the Leaving Certificate group (63 per cent), most of whom went on to higher education, are in the 300-500 band. Thus, PLC provision tends to provide access to post-school educational opportunities for a more socially diverse group. Given the role of PLC provision in facilitating access to higher education and employment (see above), courses appear to be playing a role in enhancing social inclusion. In keeping with national enrolment data (see above), PLC participants in the survey are disproportionately female. Although there has been a reduction in the female-intensity of take-up over time, there may be a case for looking at the courses on offer, in order to provide VET opportunities for men. There may also be value in addressing potential gender stereotyping in course entry through guidance at the school level.

\subsection{LEARNER SATISFACTION WITH PLC PROVISION}

Previous sections of this chapter have focused largely on the objective outcomes for PLC leavers. The survey data also provided very detailed information on learner perceptions of PLC provision, an important evidence base for policy development. In keeping with earlier research (McCoy et al., 2014), the majority of PLC students reported a mismatch 
between the types of teaching and learning experienced at second-level education and at PLC level, with around half feeling their schoolwork had not prepared them for this transition. Learners were largely satisfied with the relevance of course design and the vast majority felt their teachers and tutors had the required knowledge and were supportive. However, they were less positive about the prominence of workplace learning in their course (see above).

In reflecting on the choices made, almost half of all learners surveyed indicated that they did not get to do what they planned on leaving school or only did so 'to some extent'. In addition, one-third of learners overall said they would not take the same pathway again, while a further 30 per cent would only do so to some extent. Those who had taken PLC courses, regardless of whether they went on to higher education or not, were more likely to indicate that they had not secured the outcome they wanted and would have taken a different pathway (echoing McCoy et al.'s 2014 findings on an earlier cohort of leavers). Thus, PLC courses appear to be seen as a compromise, in a context of not achieving the required grades to pursue higher education, highlighting the continued lower status of further education in Ireland. Dissatisfaction with guidance within second-level education emerged as a key factor among school leavers who later reflected with regret on their post-school choices.

Differences across learners also emerge in relation to life satisfaction and financial wellbeing. PLC participants fare less well, with lower levels of life satisfaction and greater dissatisfaction with their financial situation. Second-level grades are found to play a central role in shaping young people's opportunities on leaving school, which, in turn, influence the extent to which they can maximise their potential for personal fulfilment and achievement. Family circumstances also play an important role in understanding wellbeing, particularly financial insecurity; those with children experience far greater challenges in this regard and this factor explains much of the difference between the PLC group and others. Earlier analyses pointed to the lack of a significant difference between those with second-level and PLC qualifications, in terms of wage levels. However, the family circumstances, and more disadvantaged profile of this group, appear to lead to greater financial difficulties.

\subsection{ISSUES FOR POLICY DEVELOPMENT}

The study findings point to the positive role played by PLC provision in providing educational opportunities for a diverse group of learners and in enhancing their access to employment and higher education. However, 
the findings also highlight a number of challenges for policy development in the PLC sector. Firstly, learners are almost equally divided between those taking a PLC course for skill formation (and hence employment access) and those taking one in order to progress to higher education. From the point of view of PLC principals, PLC courses address multiple goals, suggesting the potential for greater clarity around the orientation and purpose of specific courses.

Secondly, there is a need for job-specific PLC courses to be more responsive to changing labour market conditions in terms of the types of courses offered. Provision is currently constrained by legacy issues, which includes the skill sets of existing staff, with relatively little input of information on skill gaps and employer demand. There is also evidence of a need for a greater focus on skill formation within some employmentoriented courses; such course content needs to be adapted to focus on employability and to integrate work experience placements into the learning experience for all learners.

Thirdly, PLC courses are offered across very different settings, with smaller institutions less likely to provide the full range of student supports and larger institutions operating under resource constraints relative to student numbers. There would appear to be scope to link smaller providers into local or regional networks, perhaps through the ETB, to facilitate access to specialist supports and to support engagement with employers. While good practice appears to have emerged in certain areas, clear challenges present in building up sustained employer engagement and recognition of qualifications in the absence of a strong tradition of such involvement (see Raffe, 2015, on challenges in the British context). The issue of the appropriate level of funding to provide a varied learning experience and appropriate supports for a diverse group of learners merits further investigation, especially given that PLC courses are run using a slightly enhanced second-level funding model, which may not take adequate account of the range of facilities and supports required. Finally, PLC provision cannot be seen in isolation from the broader educational system. The role of school-based guidance emerges as important in facilitating access to appropriate courses. Low take-up of guidance within PLC provision may be impacting on awareness of the potential pathways (education and employment) subsequently open to learners, an issue that merits further research. More fundamentally, there appear to be persistent difficulties, from the learner perspective at least, regarding the perceived status of PLC courses vis-à-vis higher education, an issue that presents challenges in creating a valued pathway catering for a range of learners. 


\section{REFERENCES}

Avis, J. (2009). 'Further education: policy hysteria, competitiveness and performativity'. British Journal of Sociology of Education, Vol. 30, No. 5, 653-662.

Banks, J. and S. McCoy (2011). A study on the prevalence of special educational needs, ESRI and NCSE, Dublin.

Bergin, A., E. Kelly and S. McGuinness (2012). 'Explaining changes in earnings and labour costs during the recession', ESRI Economic Renewal Series 009, ESRI, Dublin.

Byrne, D., S. McCoy and D. Watson (2009). School leavers' survey report 2007, ESRI and Department of Education and Science, Dublin.

CEDEFOP (2013). labour market outcomes of vocational education in Europe, CEDEFOP, Luxembourg.

Coolahan, J. (1981). Irish education: History and structure, IPA, Dublin.

De Lange, M., M. Gesthuizen and M.H. Wolbers (2014). 'Youth labour market integration across Europe: The impact of cyclical, structural, and institutional characteristics'. European Societies, Vol. 16, No. 2, pp. 194212.

Department of Education (1984). Vocational preparation programme, Department of Education, Dublin.

Department of Education and Skills (2012). PLC conditions of approval, Department of Education and Skills, Dublin.

FETAC (2005). Further education and training in Ireland - A quantitative analysis of the sector, FETAC, Dublin.

Frigo, T., J. Bryce, M. Anderson and P. McKenzie (2007). Australian young people, their families and post-school plans: A research review, Australian Council for Educational Research Report, Camberwell, Victoria.

Gallacher, J. (2006). 'Blurring the boundaries or creating diversity? The contribution of the further education colleges to higher education in Scotland'. Journal of further and higher education, Vol. 30, No. 1, pp. 43-58.

Gallacher, J. (2009). 'Higher education in Scotland's colleges: A distinctive tradition?' Higher Education Quarterly, Vol. 6, No.4, pp. 384-401.

Granville, G. (2003). "'Stop making sense”: Chaos and coherence in the formulation of the Irish qualifications framework'. Journal of Education and Work, Vol. 1, No. 3, 259-270.

Hannan, D.F., B. McCabe and S. McCoy (1998). Trading qualifications for jobs: Overeducation and the Irish youth labour market, ESRI General Research Series, ESRI, Dublin. 
Hannan, D.F., S. McCoy and A. Doyle (2003). Expanding post-school learning opportunities: Nature and effects of growth in post-school education/training in the 1990s, ESRI, Dublin.

Hodkinson, P and A.C. Sparkes (1997). 'Careership: A sociological theory of career decision-making'. British Journal of Sociology of Education, Vol. 18, No. 1, pp. 29-44.

Kelly, E., S. McGuinness and J.R. Walsh (2015). An evaluation of the Back to Education Allowance, ESRI Research Series Number 47, ESRI, Dublin.

Kis, V. (2010). Learning for jobs. OECD reviews of vocational education and training: Ireland, OECD, Paris.

Kogan, I., C. Noelke and M. Gebel (eds.) (2011). Making the transition: Education and labour market entry in Central and Eastern Europe, Stanford University Press, Stanford.

Lassibille, G. and L.N. Gomez (2008). 'Why do higher education students drop out? Evidence from Spain', Education Economics, Vol. 16, No. 1.

Lewis, M. and T. Kellaghan (1987). 'Vocationalism in Irish second-level education'. Irish Journal of Education, Vol. 21, No. 1, pp. 5-35.

McCoy, S. and D. Byrne (2010). 'Non-progression among higher education new entrants: A multivariate analysis', chapter 6 in Mooney, O., V. Patterson, M. O'Connor and A. Chantler (eds), A study of progression in Irish higher education, HEA, Dublin.

McCoy, S. and E. Smyth (2003). 'Educational expenditure: Implications for equality', in Callan, T., A. Doris and D. McCoy (eds), Budget Perspectives 2004, ESRI and the Foundation for Fiscal Studies, Dublin.

McCoy, S., D. Byrne, P.J. O'Connell, E. Kelly and C. Doherty (2010). Hidden disadvantage? A study of the low participation in higher education by the non-manual group, HEA, Dublin.

McCoy, S., E. Kelly and D. Watson (2007). School leavers' survey report 2006, ESRI and Department of Education and Science, Dublin.

McCoy, S., E. Smyth, D. Watson and M. Darmody (2014). Leaving school in Ireland: A longitudinal study of post-school transitions, ESRI Research Series No. 36, ESRI, Dublin.

McGuinness, S., A. Bergin, E. Kelly, S. McCoy, E. Smyth, A. Whelan and J. Banks (2014). Further education and training in Ireland: Past, present and future, ESRI Research Series No. 35, ESRI, Dublin.

Mclver Consulting (2003). Report of the Steering Group to the PLC Review Established by the Department of Education and Science, Department of Education and Science and National Development Plan, Dublin.

McNamara, G. (1990). 'European rhetoric and national reality: A study of policy and practice in the vocational preparation and training programme in Ireland', Curriculum, Vol. 1, No. 3, pp. 162-169. 
Moodie, G., and L. Wheelahan (2009). 'The significance of Australian vocational education institutions in opening access to higher education'. Higher Education Quarterly, Vol. 6, No. 4, pp. 356-370.

Müller, W. and M. Gangl (2003). Transitions from education to work in Europe: The integration of youth into EU labour markets, Oxford University Press, Oxford.

NESC (1993). Education and training policies for economic and social development, NESC, Dublin.

O'Sullivan, D. (2005). Cultural politics and irish education since the 1950s, IPA, Dublin.

Raffe, D. (2015). 'First count to five: Some principles for the reform of vocational qualifications in England', Journal of Education and Work, Vol. 2, No.2, pp. 147-164.

Raffe, D. (2003). 'Pathways linking education and work: A review of concept, research and policy debates'. Journal of Youth Studies, Vol. 6, No. 1, pp. 3-19.

SOLAS (2014). Further education and training strategy 2014-2019, SOLAS, Dublin.

SOLAS (2016). Further education and training professional development strategy 2017-2019, SOLAS, Dublin.

Trant, M.L. (2002). 'The quest for an inclusive curriculum and assessment culture: The National Council for Vocational Awards 1991-2001', Irish Educational Studies, Vol. 21, No. 1, pp. 19-32.

Watson, D., S. McCoy and S. Gorby (2006). The Post-Leaving Certificate sector in Ireland: A multivariate analysis of educational and employment outcomes, ESRI and Department of Education and Science, Dublin.

Watson, D., B. Maître, C.T. Whelan and J. Williams (2014). Growing Up in Ireland: Dynamics of child economic vulnerability and socio-emotional development - An analysis of the first two waves of the Growing Up in Ireland study, ESRI, Dublin. 


\section{APPENDIX A: ADDITIONAL DATA}

TABLE A1 QNHS SUB-DEGREE OCCUPATIONS IN OTHER CATEGORY

\section{Sports coaches, instructors and officials}

Typists and related keyboard occupations

Business sales executives

Nursery nurses and assistants and playworkers

Security guards and related occupations

Merchandisers and window dressers

Chemical and related process operatives

Marketing associate professionals

Printers

Customer service occupations (NEC)

Customer service managers and supervisors

Assemblers and routine operatives (NEC)

Taxi and cab drivers and chauffeurs

Refuse and salvage occupations

Nursing auxiliaries and assistants

IT and telecommunications professionals (NEC)

Fitness instructors

Pensions and insurance clerks and assistants

Assemblers (electrical and electronic products)

Stock control clerks and assistants

Actors, entertainers and presenters

Pharmacy and other dispensing assistants

Large goods vehicle drivers

Bakers and flour confectioners

Farm workers

Welding trades

Butchers 


\begin{tabular}{|l|l|}
\hline \multicolumn{1}{|c|}{ Ref. } & \\
\hline $\mathbf{0 9 0}$ & Personal development \\
\hline $\mathbf{1 4 0}$ & Teacher training and education science (broad programmes) \\
\hline $\mathbf{2 1 0}$ & Arts (broad programmes) \\
\hline $\mathbf{2 1 1}$ & Fine arts \\
\hline $\mathbf{2 1 2}$ & Music and performing arts \\
\hline $\mathbf{2 1 3}$ & Audio-visual techniques and media production \\
\hline $\mathbf{2 1 4}$ & Design \\
\hline $\mathbf{2 2 2}$ & Foreign languages \\
\hline $\mathbf{3 1 1}$ & History and archaeology \\
\hline $\mathbf{3 1 2}$ & Psychology \\
\hline $\mathbf{3 2 1}$ & Sociology and cultural studies \\
\hline $\mathbf{3 4 0}$ & Journalism and reporting \\
\hline $\mathbf{3 4 1}$ & Business and administration (broad programmes) \\
\hline $\mathbf{3 4 2}$ & Wholesale and retail sales \\
\hline $\mathbf{3 4 4}$ & Marketing and advertising \\
\hline $\mathbf{3 4 5}$ & Accounting and taxation \\
\hline $\mathbf{3 8 0}$ & Management and administration \\
\hline $\mathbf{4 8 1}$ & Law \\
\hline $\mathbf{4 8 2}$ & Computer science \\
\hline $\mathbf{5 4 2}$ & Computer use \\
\hline $\mathbf{5 4 3}$ & TExtiles, clothes, footwear, leather \\
\hline $\mathbf{5 8 1}$ & Materials (wood, paper, plastic, glass) \\
\hline $\mathbf{5 8 2}$ & Architecture and town planning \\
\hline $\mathbf{7 2 6}$ & Building and civil engineering \\
\hline $\mathbf{8 1 2}$ & Therapy and rehabilitation \\
\hline & Pharmacy \\
\hline
\end{tabular}


TABLE A3: JOB-SPECIFIC PLC FIELDS OF STUDY

\begin{tabular}{|l|l|}
\hline \multicolumn{1}{|c|}{ Ref. } & \\
\hline $\mathbf{2 1 5}$ & Craft skills \\
\hline $\mathbf{3 4 6}$ & Secretarial and office work \\
\hline $\mathbf{5 2 0}$ & Engineering and engineering trades (broad programmes) \\
\hline $\mathbf{5 2 1}$ & Mechanics and metal work \\
\hline $\mathbf{5 2 3}$ & Electronics and automation \\
\hline $\mathbf{5 2 5}$ & Motor vehicles, ships and aircraft \\
\hline $\mathbf{5 4 0}$ & Manufacturing and processing (broad programmes) \\
\hline $\mathbf{6 2 0}$ & Agriculture, forestry and fishery (broad programmes) \\
\hline $\mathbf{6 2 1}$ & Crop and livestock production \\
\hline $\mathbf{6 2 2}$ & Horticulture \\
\hline $\mathbf{6 4 1}$ & Veterinary \\
\hline $\mathbf{7 2 0}$ & Health (broad programmes) \\
\hline $\mathbf{7 2 3}$ & Nursing and caring \\
\hline $\mathbf{7 6 1}$ & Childcare and youth services \\
\hline $\mathbf{8 1 5}$ & Hair and beauty services \\
\hline $\mathbf{8 5 0}$ & Security services (broad programmes) \\
\hline $\mathbf{8 6 1}$ & Protection of persons and property \\
\hline
\end{tabular}

TABLE A4: EMPLOYED AFTER 5 YEARS: SUMMARY OF ESTIMATES I

\begin{tabular}{|c|c|c|c|c|c|}
\hline & Treatment group & Control group & Estimate & S.E. & $p$ value \\
\hline Probit & All PLC & All LC & 0.01 & 0.039 & 0.840 \\
\hline $\begin{array}{l}\text { PSM- } \\
\text { caliper } \\
\text { width est'r }\end{array}$ & All PLC & All LC & 0.04 & 0.060 & 0.490 \\
\hline Probit & PLC & $\begin{array}{l}\text { LC - direct LM } \\
\text { entrants }\end{array}$ & 0.07 & 0.054 & 0.161 \\
\hline $\begin{array}{l}\text { PSM- } \\
\text { caliper } \\
\text { width est'r }\end{array}$ & PLC & $\begin{array}{l}\mathrm{LC}-\text { direct } \mathrm{LM} \\
\text { entrants }\end{array}$ & 0.16 & 0.066 & 0.014 \\
\hline Probit & PLC & $\begin{array}{l}\text { LC - straight to } \\
\text { higher } \\
\text { education }\end{array}$ & 0.03 & 0.050 & 0.607 \\
\hline $\begin{array}{l}\text { PSM- } \\
\text { caliper } \\
\text { width est'r }\end{array}$ & PLC & $\begin{array}{l}\text { LC - straight to } \\
\text { higher } \\
\text { education }\end{array}$ & 0.01 & 0.078 & 0.920 \\
\hline
\end{tabular}


TABLE A5:

EMPLOYED AFTER 5 YEARS: SUMMARY OF ESTIMATES II

\begin{tabular}{|c|c|c|c|c|c|}
\hline & $\begin{array}{l}\text { Treatment } \\
\text { group }\end{array}$ & Control group & Estimate & S.E. & p value \\
\hline Probit & LM PLCs & $\begin{array}{l}\text { LC - direct LM } \\
\text { entrants }\end{array}$ & 0.15 & 0.075 & 0.051 \\
\hline $\begin{array}{l}\text { PSM- caliper } \\
\text { width est'r }\end{array}$ & LM PLCs & $\begin{array}{l}\text { LC - direct LM } \\
\text { entrants }\end{array}$ & 0.24 & 0.099 & 0.015 \\
\hline Probit & LM PLCs & $\begin{array}{l}\text { LC - straight to } \\
\text { higher } \\
\text { education }\end{array}$ & 0.01 & 0.075 & 0.888 \\
\hline $\begin{array}{l}\text { PSM- caliper } \\
\text { width est'r }\end{array}$ & LM PLCs & $\begin{array}{l}\text { LC - straight to } \\
\text { higher } \\
\text { education }\end{array}$ & -0.03 & 0.099 & 0.795 \\
\hline Probit & General PLCs & $\begin{array}{l}\text { LC - direct LM } \\
\text { entrants }\end{array}$ & 0.05 & 0.067 & 0.464 \\
\hline $\begin{array}{l}\text { PSM- caliper } \\
\text { width est'r }\end{array}$ & General PLCs & $\begin{array}{l}\text { LC - direct LM } \\
\text { entrants }\end{array}$ & 0.09 & 0.087 & 0.318 \\
\hline Probit & General PLCs & $\begin{array}{l}\text { LC - straight to } \\
\text { higher } \\
\text { education }\end{array}$ & -0.07 & 0.070 & 0.288 \\
\hline $\begin{array}{l}\text { PSM- caliper } \\
\text { width est'r }\end{array}$ & General PLCs & $\begin{array}{l}\text { LC - straight to } \\
\text { higher } \\
\text { education }\end{array}$ & -0.05 & 0.085 & 0.516 \\
\hline
\end{tabular}

TABLE A6:

PROGRESSION TO HIGHER EDUCATION: SUMMARY OF ESTIMATES

\begin{tabular}{|c|c|c|c|c|c|}
\hline & $\begin{array}{l}\text { Treatment } \\
\text { group }\end{array}$ & Control group & Estimate & S.E. & p value \\
\hline Probit & All PLC & All LC & -0.22 & 0.042 & 0.000 \\
\hline $\begin{array}{l}\text { PSM- caliper } \\
\text { width est'r }\end{array}$ & All PLC & All LC & -0.12 & 0.059 & 0.047 \\
\hline Probit & PLC & $\begin{array}{l}\text { LC - direct LM } \\
\text { entrants }\end{array}$ & 0.26 & 0.040 & 0.000 \\
\hline $\begin{array}{l}\text { PSM-caliper } \\
\text { width est'r }\end{array}$ & PLC & $\begin{array}{l}\text { LC - direct LM } \\
\text { entrants }\end{array}$ & 0.27 & 0.050 & 0.000 \\
\hline Probit & LM PLCs & $\begin{array}{l}\text { LC - direct LM } \\
\text { entrants }\end{array}$ & 0.25 & 0.065 & 0.000 \\
\hline $\begin{array}{l}\text { PSM-caliper } \\
\text { width est'r }\end{array}$ & LM PLCs & $\begin{array}{l}\mathrm{LC} \text { - direct LM } \\
\text { entrants }\end{array}$ & 0.26 & 0.078 & 0.001 \\
\hline Probit & $\begin{array}{l}\text { Progression } \\
\text { PLCs }\end{array}$ & $\begin{array}{l}\text { LC - direct LM } \\
\text { entrants }\end{array}$ & 0.35 & 0.058 & 0.000 \\
\hline $\begin{array}{l}\text { PSM- caliper } \\
\text { width est'r }\end{array}$ & $\begin{array}{l}\text { Progression } \\
\text { PLCs }\end{array}$ & $\begin{array}{l}\text { LC - direct LM } \\
\text { entrants }\end{array}$ & 0.38 & 0.070 & 0.000 \\
\hline
\end{tabular}

Note: $\quad$ Progression to higher education is defined as reporting higher education to be main status in September 2010, 2012 or 2015. 


\begin{tabular}{|c|c|c|c|c|c|}
\hline & Treatment group & Control group & Estimate & S.E. & $p$ value \\
\hline Probit & All PLC & All LC & 0.15 & 0.037 & 0.000 \\
\hline $\begin{array}{l}\text { PSM- } \\
\text { caliper } \\
\text { width est'r }\end{array}$ & All PLC & All LC & 0.17 & 0.057 & 0.002 \\
\hline Probit & PLC & $\begin{array}{l}\text { LC-direct LM } \\
\text { entrants }\end{array}$ & -0.05 & 0.055 & 0.328 \\
\hline $\begin{array}{l}\text { PSM- } \\
\text { caliper } \\
\text { width est'r }\end{array}$ & PLC & $\begin{array}{l}\mathrm{LC} \text { - direct LM } \\
\text { entrants }\end{array}$ & -0.01 & 0.067 & 0.826 \\
\hline Probit & PLC & $\begin{array}{l}\text { LC - straight to } \\
\text { higher } \\
\text { education }\end{array}$ & 0.31 & 0.042 & 0.000 \\
\hline $\begin{array}{l}\text { PSM- } \\
\text { caliper } \\
\text { width est'r }\end{array}$ & PLC & $\begin{array}{l}\text { LC - straight to } \\
\text { higher } \\
\text { education }\end{array}$ & 0.30 & 0.063 & 0.000 \\
\hline
\end{tabular}

TABLE A8: EMPLOYED AFTER 3 YEARS: SUMMARY OF ESTIMATES II

\begin{tabular}{|c|c|c|c|c|c|}
\hline & $\begin{array}{l}\text { Treatment } \\
\text { group }\end{array}$ & Control group & Estimate & S.E. & p value \\
\hline Probit & LM PLCs & $\begin{array}{l}\text { LC - direct LM } \\
\text { entrants }\end{array}$ & -0.03 & 0.078 & 0.726 \\
\hline $\begin{array}{l}\text { PSM-caliper } \\
\text { width est'r }\end{array}$ & LM PLCs & $\begin{array}{l}\text { LC - direct LM } \\
\text { entrants }\end{array}$ & 0.05 & 0.102 & 0.639 \\
\hline Probit & LM PLCs & $\begin{array}{l}\text { LC - straight to } \\
\text { higher } \\
\text { education }\end{array}$ & 0.37 & 0.077 & 0.000 \\
\hline $\begin{array}{l}\text { PSM-caliper } \\
\text { width est'r }\end{array}$ & LM PLCs & $\begin{array}{l}\text { LC - straight to } \\
\text { higher } \\
\text { education }\end{array}$ & 0.35 & 0.084 & 0.000 \\
\hline Probit & $\begin{array}{l}\text { Progression } \\
\text { PLCs }\end{array}$ & $\begin{array}{l}\text { LC - direct LM } \\
\text { entrants }\end{array}$ & -0.13 & 0.068 & 0.054 \\
\hline $\begin{array}{l}\text { PSM-caliper } \\
\text { width est'r }\end{array}$ & $\begin{array}{l}\text { Progression } \\
\text { PLCs }\end{array}$ & $\begin{array}{l}\mathrm{LC} \text { - direct LM } \\
\text { entrants }\end{array}$ & -0.11 & 0.088 & 0.194 \\
\hline Probit & $\begin{array}{l}\text { Progression } \\
\text { PLCs }\end{array}$ & $\begin{array}{l}\text { LC - straight to } \\
\text { higher } \\
\text { education }\end{array}$ & 0.19 & 0.062 & 0.001 \\
\hline $\begin{array}{l}\text { PSM- caliper } \\
\text { width est'r }\end{array}$ & $\begin{array}{l}\text { Progression } \\
\text { PLCs }\end{array}$ & $\begin{array}{l}\text { LC - straight to } \\
\text { higher } \\
\text { education }\end{array}$ & 0.25 & 0.073 & 0.001 \\
\hline
\end{tabular}


TABLE A9: JOB SATISFACTION: SUMMARY OF ESTIMATES

\begin{tabular}{|c|c|c|c|c|c|c|}
\hline & $\begin{array}{l}\text { Treatme } \\
\text { nt group }\end{array}$ & $\begin{array}{l}\text { Control } \\
\text { group }\end{array}$ & Estimate & S.E. & $p$ value & $n$ \\
\hline Probit & All PLC & All LC & -0.04 & 0.056 & 0.471 & 410 \\
\hline $\begin{array}{l}\text { PSM- caliper } \\
\text { width est'r }\end{array}$ & All PLC & All LC & -0.05 & 0.072 & 0.454 & 357 \\
\hline Probit & PLC & $\begin{array}{l}\text { LC - direct } \\
\text { LM entrants }\end{array}$ & -0.07 & 0.085 & 0.413 & 212 \\
\hline $\begin{array}{l}\text { PSM- caliper } \\
\text { width est'r }\end{array}$ & PLC & $\begin{array}{l}\text { LC - direct } \\
\text { LM entrants }\end{array}$ & 0.14 & 0.137 & 0.315 & 86 \\
\hline Probit & PLC & $\begin{array}{l}\text { LC - straight } \\
\text { to higher } \\
\text { education }\end{array}$ & -0.01 & 0.071 & 0.893 & 327 \\
\hline $\begin{array}{l}\text { PSM- caliper } \\
\text { width est'r }\end{array}$ & PLC & $\begin{array}{l}\text { LC - straight } \\
\text { to higher } \\
\text { education }\end{array}$ & -0.04 & 0.102 & 0.668 & 244 \\
\hline
\end{tabular}

TABLE A10: $\quad$ UNDERSKILLING: SUMMARY OF ESTIMATES

\begin{tabular}{|c|c|c|c|c|c|c|}
\hline & $\begin{array}{c}\text { Treatment } \\
\text { group }\end{array}$ & $\begin{array}{l}\text { Control } \\
\text { group }\end{array}$ & Estimate & S.E. & p value & $\mathbf{n}$ \\
\hline Probit & All PLC & All LC & 0.04 & 0.064 & 0.490 & 409 \\
\hline $\begin{array}{l}\text { PSM- caliper } \\
\text { width est'r }\end{array}$ & All PLC & All LC & 0.01 & 0.080 & 0.905 & 360 \\
\hline Probit & PLC & $\begin{array}{l}\text { LC - direct } \\
\text { LM entrants }\end{array}$ & 0.04 & 0.085 & 0.645 & 211 \\
\hline $\begin{array}{l}\text { PSM- caliper } \\
\text { width est'r }\end{array}$ & PLC & $\begin{array}{l}\text { LC - direct } \\
\text { LM entrants }\end{array}$ & -0.02 & 0.112 & 0.881 & 161 \\
\hline Probit & PLC & $\begin{array}{l}\text { LC - straight } \\
\text { to higher } \\
\text { education }\end{array}$ & -0.04 & 0.082 & 0.665 & 334 \\
\hline $\begin{array}{l}\text { PSM- caliper } \\
\text { width est'r }\end{array}$ & PLC & $\begin{array}{l}\text { LC - straight } \\
\text { to higher } \\
\text { education }\end{array}$ & -0.02 & 0.121 & 0.857 & 246 \\
\hline
\end{tabular}

\footnotetext{
Note: $\quad$ We define underskilling based on responses to a question asking learners to rate on a scale of one to five the extent to which their job demands more skills and knowledge than they can actually offer, where one is 'not at all' and five is 'to a very great extent'. A response of four and five is deemed to be consistent with underskilling and a response of five is deemed to be consistent with severe underskilling.
} 
TABLE A11: SEVERE UNDERSKILLING: SUMMARY OF ESTIMATES

\begin{tabular}{|c|c|c|c|c|c|c|}
\hline & $\begin{array}{c}\text { Treatment } \\
\text { group }\end{array}$ & $\begin{array}{l}\text { Control } \\
\text { group }\end{array}$ & Estimate & S.E. & $p$ value & $n$ \\
\hline Probit & All PLC & All LC & 0.04 & 0.041 & 0.274 & 409 \\
\hline $\begin{array}{l}\text { PSM- caliper } \\
\text { width est'r }\end{array}$ & All PLC & All LC & -0.03 & 0.061 & 0.596 & 354 \\
\hline Probit & PLC & $\begin{array}{l}\text { LC - direct } \\
\text { LM entrants }\end{array}$ & 0.05 & 0.031 & 0.113 & 187 \\
\hline $\begin{array}{l}\text { PSM-caliper } \\
\text { width est'r }\end{array}$ & PLC & $\begin{array}{l}\text { LC - direct } \\
\text { LM entrants }\end{array}$ & -0.03 & 0.076 & 0.690 & 161 \\
\hline Probit & PLC & $\begin{array}{l}\text { LC - straight } \\
\text { to higher } \\
\text { education }\end{array}$ & 0.04 & 0.048 & 0.345 & 334 \\
\hline $\begin{array}{l}\text { PSM- caliper } \\
\text { width est'r }\end{array}$ & PLC & $\begin{array}{l}\text { LC - straight } \\
\text { to higher } \\
\text { education }\end{array}$ & -0.13 & 0.094 & 0.157 & 253 \\
\hline $\begin{array}{l}\text { We define } \\
\text { the extent } \\
\text { is 'not at } \\
\text { with unde }\end{array}$ & derskilling based o & sponses to a questic & king learners to & n a scale o & $\begin{array}{l}\text { five } \\
\text { one } \\
\text { tent }\end{array}$ & \\
\hline
\end{tabular}

TABLE A12: $\quad$ OVERSKILLING: SUMMARY OF ESTIMATES

\begin{tabular}{|c|c|c|c|c|c|c|}
\hline & $\begin{array}{l}\text { Treatment } \\
\text { group }\end{array}$ & $\begin{array}{l}\text { Control } \\
\text { group }\end{array}$ & Estimate & S.E. & $p$ value & $n$ \\
\hline Probit & All PLC & All LC & 0.01 & 0.032 & 0.767 & 402 \\
\hline $\begin{array}{l}\text { PSM-caliper } \\
\text { width est'r }\end{array}$ & All PLC & All LC & 0.02 & 0.047 & 0.675 & 356 \\
\hline Probit & PLC & $\begin{array}{l}\text { LC - direct } \\
\text { LM entrants }\end{array}$ & 0.04 & 0.031 & 0.276 & 164 \\
\hline $\begin{array}{l}\text { PSM- caliper } \\
\text { width est'r }\end{array}$ & PLC & $\begin{array}{l}\text { LC - direct } \\
\text { LM entrants }\end{array}$ & 0.05 & 0.047 & 0.273 & 165 \\
\hline Probit & PLC & $\begin{array}{l}\text { LC - straight } \\
\text { to higher } \\
\text { education }\end{array}$ & -0.03 & 0.040 & 0.382 & 329 \\
\hline $\begin{array}{l}\text { PSM- caliper } \\
\text { width est'r }\end{array}$ & PLC & $\begin{array}{l}\text { LC - straight } \\
\text { to higher } \\
\text { education }\end{array}$ & 0.02 & 0.078 & 0.826 & 247 \\
\hline \multicolumn{7}{|c|}{$\begin{array}{l}\text { Wote: We define overskilling based on responses to a question asking learners to rate on a scale of one to five } \\
\text { the extent to which their knowledge and skills are utilised in their work, where one is 'not at all' and five } \\
\text { is 'to a very great extent'. A response of one or two is deemed to be consistent with overskilling. In our } \\
\text { broadest treatment and control groups, 'ALL PLC' and 'ALL LC': 7\% of PLC learners and } 9 \% \text { of } L C \text { learners } \\
\text { are classified as overskilled. }\end{array}$} \\
\hline
\end{tabular}


TABLE A13: $\quad$ FIRST STAGE PROBIT MODEL FOR PARTICIPATING IN A PLC COURSE (RELATIVE TO LC STUDENTS WHO DIRECTLY ENTERED THE LABOUR MARKET)

\begin{tabular}{|l|c|c|c|}
\hline & Coefficient & Standard Error & P>Z \\
\hline Current age (yrs) & 0.198 & 0.037 & 0.00 \\
\hline Male & -0.481 & 0.134 & 0.00 \\
\hline Points (banded) & -0.117 & 0.062 & 0.06 \\
\hline Took LC Applied & -0.978 & 0.230 & 0.00 \\
\hline $\begin{array}{l}\text { Either parent has a } \\
\text { degree }\end{array}$ & 0.043 & 0.188 & 0.82 \\
\hline Constant & -3.670 & 0.932 & 0.00 \\
\hline Observations & 492 & & \\
\hline Pseudo R2 & 0.1649 & & \\
\hline
\end{tabular}

TABLE A14: FIRST STAGE PROBIT MODEL FOR PARTICIPATING IN A PLC COURSE (RELATIVE TO LC STUDENTS WHO DIRECTLY ENTERED HE)

\begin{tabular}{|l|r|r|r|}
\hline & Coefficient & Standard Error & P>Z \\
\hline Current age (yrs) & 0.330 & 0.049 & 0.00 \\
\hline Male & -0.493 & 0.136 & 0.00 \\
\hline Points (banded) & -0.935 & 0.075 & 0.00 \\
\hline Took LC Applied & 0.608 & 0.718 & 0.40 \\
\hline Either parent has a & -0.274 & 0.153 & 0.07 \\
\hline degree & -4.083 & 1.221 & 0.00 \\
\hline Constant & & & \\
\hline & & & \\
\hline Observations & 658 & & \\
\hline Pseudo R2 & 0.4664 & & \\
\hline
\end{tabular}


TABLE A15: EMPLOYED IN 2015: ESTIMATED IMPACT FOR PLC LEARNERS WHO COMPLETED THEIR COURSE RELATIVE TO DIRECT LABOUR MARKET ENTRANTS

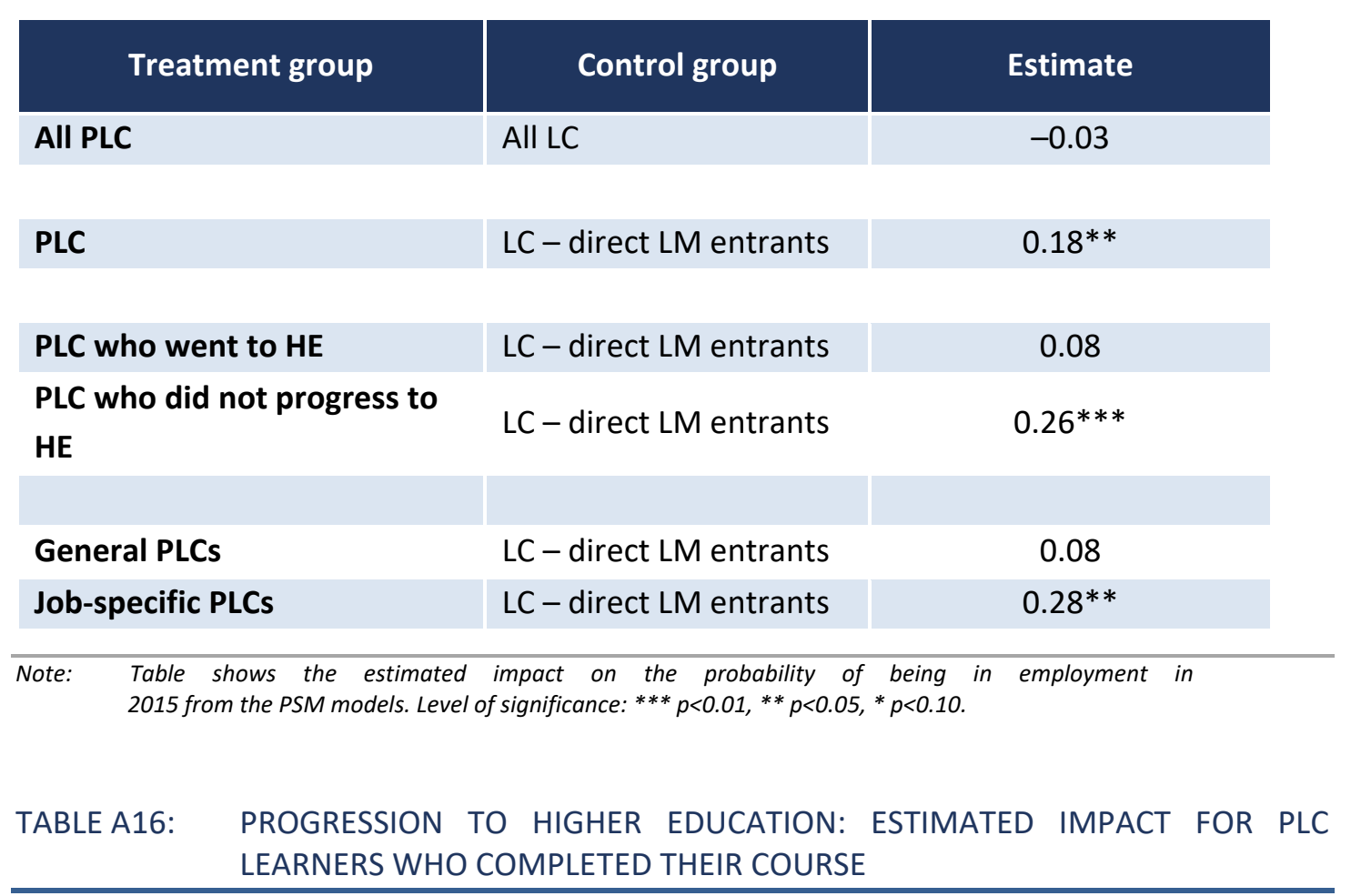

\begin{tabular}{|c|c|c|}
\hline Treatment group & Control group & Estimate \\
\hline PLC & LC - direct LM entrants & $0.36 * * *$ \\
\hline Job Specific PLCs & LC - direct LM entrants & $0.31 * * *$ \\
\hline General PLCs & LC - direct LM entrants & $0.41 * * *$ \\
\hline $\begin{array}{l}\text { Progression to higher ed } \\
2010,2012 \text { or } 2015 .\end{array}$ & fined as renortina hiaher & $n$ status in \\
\hline
\end{tabular}


TABLE A17 LOGISTIC REGRESSION: PROBABILITY OF BEING IN GROUP WHO DID NOT GET WHAT THEY PLANNED ON LEAVING SCHOOL (ODDS RATIOS)

\begin{tabular}{|c|c|c|c|c|}
\hline Variable & & Model 1 & Model 2 & Model 3 \\
\hline \multicolumn{5}{|l|}{ Pathway } \\
\hline Pathway & PLC & $5.568 * * *$ & $4.059 * * *$ & 1.918 \\
\hline \multirow[t]{2}{*}{ (Ref: HE only) } & $\mathrm{PLC}+\mathrm{HE}$ & $4.701 * * *$ & $3.725 * * *$ & 1.922 \\
\hline & LM entrants & $4.979 * * *$ & $3.835 * * *$ & 1.677 \\
\hline Sex (Ref: female) & Male & $1.691 * *$ & $1.788 * *$ & $1.593 *$ \\
\hline \multicolumn{5}{|l|}{$\begin{array}{l}\text { Family } \\
\text { Characteristics }\end{array}$} \\
\hline Family type & Single & & 1.018 & 1.022 \\
\hline \multicolumn{5}{|l|}{ (Ref: all other types) } \\
\hline Children (ref: no) & Yes & & $1.864 *$ & 1.633 \\
\hline Mother's education & Degree & & 0.562 & 0.683 \\
\hline \multicolumn{5}{|l|}{$\begin{array}{l}\text { (Ref: less than } \\
\text { degree) }\end{array}$} \\
\hline Father's education & Degree & & 1.047 & 1.308 \\
\hline \multicolumn{5}{|l|}{$\begin{array}{l}\text { (Ref: less than } \\
\text { degree) }\end{array}$} \\
\hline SEN & Yes & & $2.051^{*}$ & 1.840 \\
\hline \multicolumn{5}{|l|}{ Leaving Certificate } \\
\hline LCA & Took LCA & & & 1.052 \\
\hline LC points & $\begin{array}{l}101-200 \\
\text { points }\end{array}$ & & & 0.632 \\
\hline \multirow[t]{5}{*}{ (Ref. $<100$ points) } & $\begin{array}{l}201-300 \\
\text { points }\end{array}$ & & & 0.579 \\
\hline & $\begin{array}{l}301-400 \\
\text { points }\end{array}$ & & & $0.324 *$ \\
\hline & $\begin{array}{l}401-500 \\
\text { points }\end{array}$ & & & $0.216^{*}$ \\
\hline & $\begin{array}{l}501-600 \\
\text { points }\end{array}$ & & & $0.085^{*}$ \\
\hline & Missing & & & 0.702 \\
\hline Constant & & $0.048 * * *$ & $0.048 * * *$ & $0.176 * *$ \\
\hline Observations & & 687 & 687 & 687 \\
\hline
\end{tabular}

Notes: $\quad{ }^{* * *} p<0.001,{ }^{* *} p<0.01,{ }^{*} p<0.05$. Non-proxy sample only $(n=800)$. 
TABLE A18 LOGISTIC REGRESSION: PROBABILITY OF BEING IN GROUP WHO REGRET CHOICE MADE ON LEAVING SCHOOL (ODDS RATIOS)

\begin{tabular}{|c|c|c|c|c|}
\hline Variable & & Model 1 & Model 2 & Model 3 \\
\hline \multicolumn{5}{|l|}{ Pathway } \\
\hline Pathway & PLC & $2.649 * * *$ & $2.199 * * *$ & 1.583 \\
\hline \multirow[t]{2}{*}{ (Ref: HE only) } & $\mathrm{PLC}+\mathrm{HE}$ & $2.715^{* * *}$ & $2.411 * * *$ & 1.760 \\
\hline & LM entrants & $1.826^{*}$ & 1.625 & 1.333 \\
\hline Sex (Ref: female) & Male & 1.245 & 1.323 & 1.258 \\
\hline \multicolumn{5}{|l|}{$\begin{array}{l}\text { Family } \\
\text { characteristics }\end{array}$} \\
\hline Family type & Single & & 0.884 & 0.860 \\
\hline \multicolumn{5}{|l|}{$\begin{array}{l}\text { (Ref: all other } \\
\text { types) }\end{array}$} \\
\hline Children (ref: no) & Yes & & 1.459 & 1.490 \\
\hline $\begin{array}{l}\text { Mother's } \\
\text { education }\end{array}$ & Degree & & 0.575 & 0.587 \\
\hline \multicolumn{5}{|l|}{$\begin{array}{l}\text { (Ref: less than } \\
\text { degree) }\end{array}$} \\
\hline Father's education & Degree & & 1.260 & 1.277 \\
\hline \multicolumn{5}{|l|}{$\begin{array}{l}\text { (Ref: less than } \\
\text { degree) }\end{array}$} \\
\hline SEN & Yes & & 1.029 & 1.007 \\
\hline \multicolumn{5}{|l|}{ Leaving Certificate } \\
\hline LCA & Took LCA & & & 0.620 \\
\hline LC points & $101-200$ points & & & 1.061 \\
\hline \multirow[t]{5}{*}{ (Ref. $<100$ points) } & 201-300 points & & & 1.075 \\
\hline & $301-400$ points & & & 0.810 \\
\hline & $401-500$ points & & & 0.573 \\
\hline & 501-600 points & & & 0.402 \\
\hline & Missing & & & 0.774 \\
\hline Constant & & $0.258^{* * *}$ & $0.295^{* * *}$ & 0.479 \\
\hline Observations & & 687 & 687 & 687 \\
\hline
\end{tabular}


TABLE A19 LOGISTIC REGRESSION: PROBABILITY OF BEING IN GROUP WHO ARE LEAST SATISFIED WITH THEIR LIFE (ODDS RATIOS; BOTTOM QUINTILE ON SATISFACTION WITH EVERYDAY LIFE)

\begin{tabular}{|c|c|c|c|c|}
\hline Variable & & Model 1 & Model 2 & Model 3 \\
\hline \multicolumn{5}{|l|}{ Pathway } \\
\hline Pathway & PLC & $2.510 * * *$ & $2.131^{* *}$ & 1.625 \\
\hline \multirow[t]{2}{*}{ (Ref: HE only) } & $\mathrm{PLC}+\mathrm{HE}$ & $2.310 * *$ & $2.035^{* *}$ & 1.589 \\
\hline & LM entrants & $2.511 * *$ & $2.033^{*}$ & 1.556 \\
\hline Sex (Ref: female) & Male & 1.408 & 1.382 & 1.299 \\
\hline \multicolumn{5}{|l|}{$\begin{array}{l}\text { Family } \\
\text { characteristics }\end{array}$} \\
\hline Family type & Single & & 1.568 & 1.672 \\
\hline \multicolumn{5}{|l|}{ (Ref: all other types) } \\
\hline Children (ref: no) & Yes & & $1.476^{*}$ & 1.284 \\
\hline Mother's education & Degree & & 0.484 & 0.518 \\
\hline \multicolumn{5}{|l|}{$\begin{array}{l}\text { (Ref: less than } \\
\text { degree) }\end{array}$} \\
\hline Father's education & Degree & & 1.208 & 1.355 \\
\hline \multicolumn{5}{|l|}{$\begin{array}{l}\text { (Ref: less than } \\
\text { degree) }\end{array}$} \\
\hline SEN & Yes & & $2.231 * *$ & $2.195^{* *}$ \\
\hline \multicolumn{5}{|l|}{ Leaving Certificate } \\
\hline LCA & Took LCA & & & 0.601 \\
\hline LC points & $\begin{array}{l}101-200 \\
\text { points }\end{array}$ & & & 0.453 \\
\hline \multirow[t]{5}{*}{ (Ref. $<100$ points) } & $\begin{array}{l}\text { 201-300 } \\
\text { points }\end{array}$ & & & 0.524 \\
\hline & $\begin{array}{l}301-400 \\
\text { points }\end{array}$ & & & $0.303^{* *}$ \\
\hline & $\begin{array}{l}401-500 \\
\text { points }\end{array}$ & & & 0.414 \\
\hline & $\begin{array}{l}501-600 \\
\text { points }\end{array}$ & & & 0.317 \\
\hline & Missing & & & 0.775 \\
\hline Constant & & $0.136^{* * *}$ & $0.097^{* * *}$ & $0.245^{*}$ \\
\hline Observations & & 687 & 687 & 687 \\
\hline
\end{tabular}




\begin{tabular}{|c|c|c|c|c|}
\hline Variable & & Model 1 & Model 2 & Model 3 \\
\hline \multicolumn{5}{|l|}{ Pathway } \\
\hline Pathway & PLC & $2.248 * * *$ & $1.894^{*}$ & 1.479 \\
\hline \multirow[t]{2}{*}{ (Ref: HE only) } & $\mathrm{PLC}+\mathrm{HE}$ & $1.877^{* *}$ & 1.652 & 1.312 \\
\hline & LM entrants & 1.401 & 1.164 & 0.990 \\
\hline Sex (Ref: female) & Male & 1.197 & 1.197 & 1.143 \\
\hline \multicolumn{5}{|l|}{$\begin{array}{l}\text { Family } \\
\text { characteristics }\end{array}$} \\
\hline Family type & Single & & 1.177 & 1.131 \\
\hline \multicolumn{5}{|l|}{ (Ref: all other types) } \\
\hline Children (ref: no) & Yes & & 1.406 & 1.440 \\
\hline Mother's education & Degree & & $0.517^{*}$ & $0.513^{*}$ \\
\hline \multicolumn{5}{|l|}{$\begin{array}{l}\text { (Ref: less than } \\
\text { degree) }\end{array}$} \\
\hline Father's education & Degree & & 1.296 & 1.317 \\
\hline \multicolumn{5}{|l|}{$\begin{array}{l}\text { (Ref: less than } \\
\text { degree) }\end{array}$} \\
\hline SEN & Yes & & $1.814^{*}$ & $1.815^{*}$ \\
\hline \multicolumn{5}{|l|}{ Leaving Certificate } \\
\hline LCA & Took LCA & & & 0.579 \\
\hline LC points & $\begin{array}{l}101-200 \\
\text { points }\end{array}$ & & & 0.928 \\
\hline \multirow[t]{5}{*}{ (Ref. $<100$ points) } & $\begin{array}{l}201-300 \\
\text { points }\end{array}$ & & & 0.786 \\
\hline & $\begin{array}{l}301-400 \\
\text { points }\end{array}$ & & & 0.565 \\
\hline & $\begin{array}{l}401-500 \\
\text { points }\end{array}$ & & & 0.454 \\
\hline & $\begin{array}{l}501-600 \\
\text { points }\end{array}$ & & & 0.662 \\
\hline & Missing & & & 0.545 \\
\hline Constant & & $0.170 * * *$ & $0.153^{* * *}$ & $0.293 *$ \\
\hline Observations & & 534 & 534 & 534 \\
\hline
\end{tabular}

Notes: $\quad{ }^{* * *} p<0.001,{ }^{* *} p<0.01,{ }^{*} p<0.05$. Non-proxy sample only. 
TABLE A21 LOGISTIC REGRESSION: PROBABILITY OF BEING IN GROUP WHO EXPERIENCE DIFFICULTY MAKING ENDS MEET (ODDS RATIOS)

\begin{tabular}{|c|c|c|c|c|}
\hline Variable & & Model 1 & Model 2 & Model 3 \\
\hline \multicolumn{5}{|l|}{ Pathway } \\
\hline Pathway & PLC & $3.054^{* * *}$ & 1.319 & 0.876 \\
\hline \multirow{2}{*}{$\begin{array}{l}\text { (Ref: higher } \\
\text { education only) }\end{array}$} & $\mathrm{PLC}+\mathrm{HE}$ & $3.938 * * *$ & $2.350 *$ & 1.738 \\
\hline & LM entrants & $2.719 * *$ & 1.470 & 0.738 \\
\hline Sex (Ref: female) & Male & 0.686 & 0.815 & 0.735 \\
\hline \multicolumn{5}{|l|}{$\begin{array}{l}\text { Family } \\
\text { characteristics }\end{array}$} \\
\hline Family type & Single & & 0.904 & 0.899 \\
\hline \multicolumn{5}{|l|}{ (Ref: all other types) } \\
\hline Children (ref: no) & Yes & & $4.298 * * *$ & $3.915 * * *$ \\
\hline Mother's education & Degree & & $0.380^{*}$ & 0.428 \\
\hline \multicolumn{5}{|l|}{$\begin{array}{l}\text { (Ref: less than } \\
\text { degree) }\end{array}$} \\
\hline Father's education & Degree & & 0.459 & 0.547 \\
\hline \multicolumn{5}{|l|}{$\begin{array}{l}\text { (Ref: less than } \\
\text { degree) }\end{array}$} \\
\hline SEN & Yes & & 1.501 & 1.442 \\
\hline \multicolumn{5}{|l|}{ Leaving Certificate } \\
\hline LCA & Took LCA & & & 0.882 \\
\hline LC points & $\begin{array}{l}101-200 \\
\text { points }\end{array}$ & & & $0.272^{*}$ \\
\hline \multirow[t]{5}{*}{ (Ref. $<100$ points) } & $\begin{array}{l}201-300 \\
\text { points }\end{array}$ & & & 0.369 \\
\hline & $\begin{array}{l}301-400 \\
\text { points }\end{array}$ & & & $0.179 * *$ \\
\hline & $\begin{array}{l}401-500 \\
\text { points }\end{array}$ & & & $0.207^{*}$ \\
\hline & $\begin{array}{l}501-600 \\
\text { points }\end{array}$ & & & 0.324 \\
\hline & Missing & & & 0.492 \\
\hline Constant & & $0.127^{* * *}$ & $0.166^{* * *}$ & 0.709 \\
\hline Observations & & 506 & 506 & 506 \\
\hline
\end{tabular}

Notes: $\quad{ }^{* * *} \mathrm{p}<0.001,{ }^{* *} \mathrm{p}<0.01,{ }^{*} \mathrm{p}<0.05$. Non-proxy sample only. 


\section{APPENDIX B: NOTE ON SAMPLING AND WEIGHTING FOR THE SURVEY OF PLC LEAVERS:}

\subsection{SAMPLING STRATEGY}

The goal was to complete a survey of two groups of leavers: Leaving Certificate leavers (who left in 2009) and PLC leavers (who left in 2010). The Leaving Certificate leavers group included those who studied for the Leaving Certificate Applied, the Leaving Certificate Vocational Programme and the established Leaving Certificate.

The sampling was accomplished with the assistance of the Department of Education and Science. The sampling frame was the Post-Primary Pupil Database (PPPDB), a listing of all pupils in the second-level system in Ireland, which also covers the Post-Leaving Certificate (PLC) sector. Leaving Certificate leavers are identified by finding students in the second year of the Leaving Certificate Programme in 2009 (including the established Leaving Certificate, LCA and LCVP) who were not in the PPPDB in 2010 (i.e. not repeating the Leaving Certificate and not in a PLC programme). PLC leavers were identified by finding those who were in a PLC programme in 2010 and not in the PPPDB in 2010 (or left the PLC programme, either having completed or before completing the PLC course).

The DES provided the ESRI with an anonymised database of leavers for the two groups. The database contained a record for each leaver showing:

- a unique ID number assigned by the DES;

- programme type (Leaving Certificate, LCA, LCVP,PLC);

- programme year (e.g. first, second or third year of the programme);

- school type (secondary, vocational, C\&C);

- DEIS status;

- sex of student; and

- year of birth.

The ESRI selected a stratified random sample with stratification based on gender, programme type (Leaving Certificate, LCVP, LCA, PLC) and, for the PLC students, whether they were under or over age 25 on leaving the programme. The sampling fraction differed by these stratification groups, with PLC leavers and LCA leavers oversampled, as shown in Table B.1. 


\begin{tabular}{|l|r|}
\hline \multicolumn{1}{|c|}{ Stratum } & Sampling fraction \\
\hline $\mathbf{1 1 0}$ male, LC, all ages & 4.8 \\
\hline $\mathbf{1 2 0}$ male, LCVP, all ages & 4.8 \\
\hline $\mathbf{1 3 0}$ male, LCA, all ages & 16.3 \\
\hline $\mathbf{1 4 0}$ male, PLC, under $\mathbf{2 5}$ & 9.0 \\
\hline $\mathbf{1 4 1}$ male, PLC, over $\mathbf{2 5}$ & 9.0 \\
\hline $\mathbf{2 1 0}$ female, LC, all ages & 5.0 \\
\hline $\mathbf{2 2 0}$ female, LCVP, all ages & 5.0 \\
\hline $\mathbf{2 3 0}$ female, LCA, all ages & 16.3 \\
\hline $\mathbf{2 4 0}$ female, PLC, under $\mathbf{2 5}$ & 9.0 \\
\hline $\mathbf{2 4 1}$ female, PLC, over 25 & 9.0 \\
\hline
\end{tabular}

\section{Sampled leavers offered the chance to opt out}

The ESRI selected the sample and returned the unique ID numbers to the DES. The DES attached the contact details from the PPPDB. The ESRI (and our partner research organisation, Amárach) printed the letters (on DES letterhead). The Department then sent a letter to each sampled leaver informing them of the survey and offering them the chance to opt out.

The letter contained a tear-off section with the unique ID number so that any leaver choosing to opt out could be removed from the sample before contact details were released. The leavers were also afforded the opportunity to opt out online using the unique ID number.

We allowed two weeks for a response from students.

\section{Contact details released to the ESRI and Amárach}

Having removed the details of any individuals who opted out, the contact information for the remaining sampled leavers was released by the DES to the ESRI so that the fieldwork could be conducted.

\section{Response rates}

Table B.2 shows the response rates by each of the eight strata. The response rate was higher among Leaving Certificate leavers (especially the LCA and LCVP) than among PLC leavers. The PLC leavers under the age of 25 had a higher response rate than those over age 25 . This was partly a result of prioritising the younger PLC leavers and the LCA leavers in the fieldwork, as these groups were particularly important to evaluating the impact of the PLC programme. 


\begin{tabular}{|l|r|r|r|}
\hline & Gross sample & Completed sample & Response rate (\%) \\
\hline $\mathbf{1 1 0}$ male, LC, all ages & 675 & 177 & 26 \\
\hline $\mathbf{1 2 0}$ male, LCVP, all ages & 310 & 93 & 30 \\
\hline $\mathbf{1 3 0}$ male, LCA, all ages & 198 & 53 & 27 \\
\hline $\mathbf{1 4 0}$ male, PLC, under 25 & 604 & 160 & 26 \\
\hline $\mathbf{1 4 1}$ male, PLC, over 25 & 347 & 53 & 15 \\
\hline $\mathbf{2 1 0}$ female, LC, all ages & 620 & 167 & 27 \\
\hline $\mathbf{2 2 0}$ female, LCVP, all ages & 320 & 111 & 35 \\
\hline $\mathbf{2 3 0}$ female, LCA, all ages & 132 & 46 & 35 \\
\hline $\mathbf{2 4 0}$ female, PLC, under 25 & 932 & 251 & 27 \\
\hline $\mathbf{2 4 1}$ female, PLC, over 25 & 592 & 109 & 18 \\
\hline Total & 4,730 & 1,220 & 100 \\
\hline
\end{tabular}

Both the longer time lag between the date of leaving and the survey and the economic climate in the intervening years, which had raised the rate of out-migration, contributed to a lower response rate than had been typical in past surveys of school leavers. For the present project, the time lag between leaving the course and interview was seven years for the Leaving Certificate leavers and six years for the PLC leavers. This meant that a relatively high proportion of the addresses were no longer valid.

\subsection{WEIGHTING THE DATA}

Data from all sample surveys must be reweighted or statistically adjusted prior to analysis, particularly in producing point estimates such as means and proportions. The purpose of this adjustment is to compensate in the completed sample for any potential biases that may occur due to a disproportionate selection, sampling error or differential response rates among sub-groups of the population. This process ensures that the completed sample is representative of the target population from which it has been selected.

The weighting of the data in this case involved calibrating the sample to population control totals from the same eight cells used in stratification for sampling (see Table B.3). Weighting was on the basis of gender, programme type and, for the PLC leavers, whether they were under or over 25 at the time of leaving. The weights reflect differences in the sampling fraction and differences in response rate. Since LCA leavers are overrepresented in the sample (eight per cent) relative to the population (three per cent), for instance, the weight has the effect of reducing their 
representation in results based on the weighted data to reflect the population distribution.

TABLE B.3: POPULATION DISTRIBUTION, SAMPLE DISTRIBUTION AND WEIGHT BY STRATIFICATION GROUP

\begin{tabular}{|l|r|r|r|}
\hline $\mathbf{1 1 0}$ male, LC, all ages & $\begin{array}{c}\text { Population } \\
\text { distribution }\end{array}$ & $\begin{array}{c}\text { Completed } \\
\text { sample } \\
\text { distribution }\end{array}$ & Weight \\
\hline $\mathbf{1 2 0}$ male, LCVP, all ages & $20 \%$ & $15 \%$ & 1.40 \\
\hline $\mathbf{1 3 0}$ male, LCA, all ages & $9 \%$ & $8 \%$ & 1.23 \\
\hline $\mathbf{1 4 0}$ male, PLC, under $\mathbf{2 5}$ & $2 \%$ & $4 \%$ & 0.40 \\
\hline $\mathbf{1 4 1}$ male, PLC, over $\mathbf{2 5}$ & $10 \%$ & $13 \%$ & 0.74 \\
\hline $\mathbf{2 1 0}$ female, LC, all ages & $6 \%$ & $4 \%$ & 1.29 \\
\hline $\mathbf{2 2 0}$ female, LCVP, all ages & $18 \%$ & $14 \%$ & 1.32 \\
\hline $\mathbf{2 3 0}$ female, LCA, all ages & $9 \%$ & $9 \%$ & 1.02 \\
\hline $\mathbf{2 4 0}$ female, PLC, under $\mathbf{2 5}$ & $1 \%$ & $4 \%$ & 0.31 \\
\hline $\mathbf{2 4 1}$ female, PLC, over $\mathbf{2 5}$ & $15 \%$ & $21 \%$ & 0.73 \\
\hline
\end{tabular}

The weighted data were checked to ensure that the completed sample distributions matched the population distributions by school type attended and by whether the school was DEIS or non-DEIS. This was done within three broad groups: Leaving Certificate leavers, PLC leavers under age 25 and PLC leavers over age 25. As shown in Table B.4, the match was very close. The population and weighted sample distributions across the groups by DEIS and school type are within one percentage point of each other. This indicates that the adjustment by stratum was all that was needed to recalibrate the sample prior to analysis - no additional adjustment by school type or DEIS status was needed. 
TABLE B.4: POPULATION DISTRIBUTION AND SAMPLE DISTRIBUTION OF DEIS SCHOOL AND SCHOOL TYPE BY STRATIFICATION GROUP (\%)

\begin{tabular}{|c|c|c|c|c|}
\hline & & $\begin{array}{c}\text { Sample } \\
\text { distribution } \\
\text { (weighted) }\end{array}$ & $\begin{array}{l}\text { Population } \\
\text { distribution }\end{array}$ & Difference \\
\hline \multicolumn{5}{|l|}{ DEIS status } \\
\hline \multirow[t]{3}{*}{ Non-DEIS } & $1 \mathrm{LC}$ & 50 & 50 & 1 \\
\hline & 2 PLC under 35 & 17 & 16 & 0 \\
\hline & 3 PLC over 25 & 8 & 9 & -1 \\
\hline \multirow[t]{3}{*}{ DEIS } & $1 \mathrm{LC}$ & 10 & 11 & -1 \\
\hline & 2 PLC under 35 & 8 & 8 & 0 \\
\hline & 3 PLC over 25 & 7 & 6 & 1 \\
\hline Total & & 100 & 100 & \\
\hline \multicolumn{5}{|l|}{ School type } \\
\hline \multirow[t]{3}{*}{$\mathrm{C} \& \mathrm{C}$} & $1 \mathrm{LC}$ & 10 & 10 & 0 \\
\hline & 2 PLC under 35 & 1 & 1 & 0 \\
\hline & 3 PLC over 25 & 0 & 1 & 0 \\
\hline \multirow[t]{3}{*}{ Secondary } & $1 \mathrm{LC}$ & 37 & 37 & 1 \\
\hline & 2 PLC under 35 & 1 & 1 & 0 \\
\hline & 3 PLC over 25 & 0 & 1 & 0 \\
\hline \multirow[t]{3}{*}{ Vocational } & $1 \mathrm{LC}$ & 13 & 13 & -1 \\
\hline & 2 PLC under 35 & 24 & 23 & 0 \\
\hline & 3 PLC over 25 & 14 & 14 & 0 \\
\hline Total & & 100 & 100 & \\
\hline
\end{tabular}

Note: The weights as described in Table B.3 have been applied to the sample figures. 


\section{APPENDIX C: CONSULTATION WORKSHOPS}

This synthesis of consultative workshops was compiled by SOLAS. A series of consultation workshops was conducted as a complementary strand of research to this evaluation.

The consultative strand of the research consisted of four half-day workshops designed to gather qualitative data from participants based on findings from the first three strands of the research. ${ }^{79}$ The workshops were held over a four day period, 23-26 February 2016.

The first workshop was confined to the CEOs of the 16 ETBs and was held in the offices of Education and Training Boards Ireland (ETBI). Eleven CEOs attended. The remaining three workshops were held in the 'Clock Tower' building, in the offices of the Department of Education and Skills. In total, participants attended the Clock Tower workshops, which was in line with the target. They included a wide cross-section of interested parties, including representatives from all ETBs, government departments, state agencies, employer representative groups, teacher unions, third-level institutions, employers as well as other bodies linked to adult learning.

The ESRI made a comprehensive presentation on their initial findings from the desk-based research, the survey of PLC college/school principals and the survey of learners. The workshop participants were asked to consider and present their views on the ESRI findings in relation to:

- geographic spread of PLC courses;

- capacity of PLC provision to respond to changes in the economy and labour market;

- the range of fields of learning covered by the PLC programme;

- demand from employers for PLC graduates (sub-degree qualifications);

- the aim of the PLC programme;

- factors influencing the introduction of new courses and termination of others;

- teacher and tutor qualifications; and

79 The ESRI emphasised that the results were preliminary at the stage the workshops were held and may change when all of the field work is completed. At that point, the data sets of both the survey of learners and the survey of principals surveys were incomplete. 
- constraints in responding to future needs.

They were also asked to comment on what they regarded as positive and negative elements of the findings and, on the basis of the findings, to suggest improvements to the PLC programme.

In order to facilitate participant feedback process, delegates were divided into six roundtable discussion groups to consider the ESRI initial findings. A spokesperson from each group presented feedback, which was recorded on flipcharts.

The views expressed are presented below, together with the comments on positive and negative elements of the research findings and suggested improvements. It is noteworthy that certain recurring issues were emphasised in the feedback across a wide range of the themes. These issues included: teacher contracts, the second-level model in which the programme operates, subject matter expertise, the 'cap' on PLC places, funding for equipment, and curriculum and award constraints.

In each of the sections below, a short introduction or summary of the relevant research finding is followed by a bulleted list of the most common views expressed at the workshops.

\section{Geographic spread of PLC courses}

Relevant finding from the research: The distribution of PLC courses nationally follows no discernible pattern and that provision does not appear to be reactive to economic needs. The data also shows that the distribution remained relatively static between 2008 and 2011.

- This is mainly a legacy issue and can be explained by the historical build-up of numbers. It is often driven by the need to re-orientate the school, based on changes in second-level enrolment numbers.

- Some colleges are turning people away because of the 'cap', which can limit expansion of provision, while some PLC colleges have been taking increased numbers above the 'cap'.

- Provision is often driven by teacher skill sets.

- Provision per county needs to be looked at in the overall context of what is being provided more generally in the county by way of further education and training (FET) (e.g. training centres, institutes of technology etc.). Some institutes of technology have developed Level 5 courses aimed at the same cohort as the PLC target group. 
- Since 2010 there has been an improvement in the spread and rationalisation of courses. However, there is still a need for better coordination and planning.

- Access can be a problem in some rural areas (transport issues). Should we have large PLC centres localised or mixed provision?

- While the provision appears to be correct (per head of population) in the greater Dublin area, the spread is not proportional in the rest of the country based on population trends.

- A forecasting model such as that used for school provision should be considered for the allocation of places. It was suggested that the 'cap' on places be reviewed to allow underserved areas to increase provision. ETBs need to internally review their allocation of places on a geographic basis and increase the flexibility in the use of buildings/infrastructure, especially between PLC colleges/schools and training centres.

\section{Capacity of PLC provision to respond to changes in the economy and labour market}

Some of the discussion around capacity fits more appropriately under different theme headings and is therefore reported on under the relevant theme heading.

- The system is based on a second-level model which cannot respond effectively to labour market needs.

- The academic year is restrictive - a continuous intake cycle is needed rather than the academic year model which currently applies.

- There is a significant lack of resources with regard to capital equipment.

- Teacher contracts which are based on the second-level model are an issue third-level courses are not subject to this constraint. Currently one year + one day contracts lead to a permanent contract. There is a need to acknowledge the need for different types of teaching and training staff. Contracts need to reflect this reality.

- Greater flexibility is needed in terms of curriculum design and the time taken to approve a course. A move towards delegated authority for award development would increase response time.

- Decisions to run courses are based on enrolment numbers only - cannot be labour market driven because of this.

- Greater links with industry are needed and employers should be consulted more on skill shortages. 
- Consideration should be given to the development of competency based centres that employers would have confidence in.

- The low pay rates that apply in certain occupations can act as a disincentive for learners to engage in certain courses.

- Requirements under Section 30 of the Teaching Council Act are negatively impacting on the capacity to recruit suitable teaching staff, especially in the high skilled industry areas.

- PLCs can break the cycle of educational disadvantage and unemployment for many individuals.

- PLCs may not be serving the needs of immigrants to allow them to integrate fully into Irish society.

\section{Theme 3-Range of fields of learning covered by PLC}

Relevant finding from the research: The desk-based research indicates that there is a heavy emphasis, within PLC provision, on certain areas such as early childhood care and education, community and health services, and hairdressing. The research also shows that the vast majority of awards made during 2009 (70 per cent) and 2012 (84 per cent) were FETAC awards.

- Teaching Council requirements are seen to limit the range of provision on offer.

- Provision is driven by staff capability rather than market needs in many instances.

- Student demand is another factor that influences provision.

- STEM subjects are a major challenge for many students, particularly for those who did not take these subjects in school. As a result they need initial guidance on what will be expected from them before they take on these subjects at PLC level.

- The range of fields covered by PLC provision is more extensive than the survey indicates. Fields of learning do not always represent the complexity of provision.

- The same fields of learning are offered in PLC as in institutes of technology.

- The range of provision could also be influenced by policy issues such as the current requirement for FETAC qualifications for those working in childcare.

- A wider range of qualifications could be offered by utilising other awarding bodies (non-QQI); this would also facilitate a move towards a shorter qualification period.

- QQI awards do not always reflect the skills that are needed in the labour market. 
- Good PLC pathway linkages exist with institutes of technology but not with employers (in the same way as the linkages that exist in apprenticeship).

- PLC s should focus more on technology-based sectors.

- Moving some PLC provision into training centres would improve integration of training centre resources with further education colleges and facilitate a broader range of provision.

- It should be acknowledged that PLC to higher education progression routes and employment outcomes are not mutually exclusive.

\section{Theme 4-Demand from employers for PLC graduates (sub-degree}

\section{qualifications)}

Relevant finding from the research: Limited relationship between PLC provision and skill demand in the labour market. Based on the research findings it is unclear in many instances that the emphasis of provision coincides with labour demand.

- During the feedback session it was pointed out that the term sub-degree is inappropriate and considered to be pejorative.

- The majority view is that there is a strong employer demand for PLC graduates.

- There is a large demand for PLC graduates. Level 7 and Level 8 qualifications are not always suited to employer needs and in many cases lead to over-qualification.

- Opportunities for PLC will improve as the economy grows.

- Employer demand varies geographically; this is not reflected in the survey data.

- Replacement of old jobs will still be significant in the future as half of them will be in the mid to low skill categories - areas of particular relevance for FET.

- Meeting demand from employers only can result in narrowly-based courses, which restrict learner mobility.

- The issue of work experience during PLC courses is a concern. There are difficulties in getting work experience. Some kind of support infrastructure was suggested as a means to assist learners to secure work experience.

- The PLC is an accessible form of education, which can lead to progression.

- It is relatively easy to tailor a PLC course to meet a particular need (easier than a degree-level course).

- Employers are now looking for employees with Level 5 and Level 6 qualifications, which could reduce churn in the labour market. 


\section{Theme 5 - Aim of the PLC programme}

The views expressed on the aims and objectives of the programme were wide ranging and in many cases overlapped with the other themes which formed part of the overall discussion. The discussion included observations on the DES' Conditions of Approval (2012) as well as commentary on specific aims of particular PLC courses and the fitness for purpose of such courses. The main issues to emerge in the feedback are outlined below.

- The notion of progression to higher education is a relatively new development in the aim for PLC. Social inclusion is also regarded as a very important aim of the programme, more so in recent years. The aims of PLC need to be kept broad. ${ }^{80}$

- There is a mismatch between DES and DSP objectives for the programme education/activation into employment.

- The value of PLC and its place in the larger context of education need to be clarified.

- It is difficult to change the aims of the PLC programme. 'A broad brush approach is better.' There is a need to review the relevance of programmes. In many cases, labour market demand does not necessarily mean that learners will want to do courses that address such demands.

- There is a requirement to offer QQI awards and follow those award specifications, even though they do not necessarily reflect the skills needed in the labour market. The UCD Horizons model would be a better option but FET does not have the facilities to do this.

- Many students need further general education after leaving school and this is provided by the PLC programme. Many school leavers enrolling in a PLC course need another year to mature (especially if they have not completed a transition year). Students who undertake a PLC course learn to take responsibility for their own work and to complete assignments and demonstrate skills. This improves their outcomes when they progress to higher education.

- Institutes of technology are clamouring for agreement with PLC colleges to ensure a supply of Level 5 students for their courses. 'If we want a job market focus for PLCs, then there is a tension between these two supply issues.'

\section{Theme 6 - Factors influencing introduction of new courses and termination of others}

Relevant finding from the research: Decisions in relation to providing new

80 In the survey, PLC learners were asked about their primary objective for undertaking a PLC programme: 39 per cent said that their main goal was to get a job immediately after the PLC course, and a similar percentage reported that their main goal was to progress to higher education. Almost 20 per cent cited personal development as the key motivating factor for pursuing a PLC course. 
PLC courses and terminating 'old' courses tend to be driven by student demand, with less weight given to employer requirements, government objectives or national forecasting.

- Demand from companies to set up courses to meet a specific need can leave a college with a course, a teacher and no demand after the initial need is met. This is problematic.

- In some instances it is only possible to introduce a new course when a staff member retires because of the nature of teacher contracts. Even though this can be lead to the introduction of a new course, it is also restrictive.

- The current practice is mainly based on student demand and existing student footfall rather than labour market demand. This is the most significant cultural change required in this regard. The new DES Regional Skills Fora is seen as a positive measure to inform future course provision/development.

- There is a long development period in relation to new certification; it can take a few years to one to develop. This is another factor. Third party certification bodies such as CIDESCO are not QQI approved.

- There is little engagement with the DSP in relation to new PLCs and the DSP referral process introduces further complications.

- Getting a critical mass of students to engage in a new course can be difficult.

- The degree to which new courses can be introduced and others terminated is limited by a variety of factors such as the 'cap' on places, second-level teacher contracts. Moreover, the availability of course-specific physical resources can prevent or delay the introduction of new courses.

- Strategic partnerships with industry could be useful. There is a need to 'sweat the assets, through a combination of measures - employer resources and continuous intake'.

\section{Theme 7 - Teacher and tutor qualifications}

Relevant finding from the research: PLC teacher and tutor initial qualifications are as follows: 45 per cent in the arts and social sciences; 22 per cent in services; 19 per cent in STEM; and 14 per cent in agriculture. Is this structure likely to be a constraint in responding to future changing needs?

- The requirements under Section 30 of the Teaching Council Act are seen as a major challenge.

- There is a need for more people from industry to be engaged in teaching. 'The system does not allow for the voice of industry'. A new model to staff the 
teaching of PLCs is required. The core skills of teachers could be supplemented by people working within the relevant field. It is very difficult to attract teachers for certain disciplines, such as nursing, veterinary, architecture and ICT, who can comply with the regulations of the Teaching Council.

- There is a need for more continuing professional development (CDP) for teachers. Former FÁS instructors cannot teach in further education colleges - this needs to be addressed.

- PLC teachers comprise a mix of secondary school teachers and industry experts who in some cases are only qualified one level up from the level they are teaching. There is a need for subject matter expertise but also for a minimum teaching qualification.

- History shows that teachers have always been flexible in relation to moving between disciplines. Very few are still working in their original fields. Funding would help in encouraging teachers to engage in CPD. Qualification allowances for teachers no longer exist.

\section{Theme 8-Constraints in responding to future needs}

- Capital investment is a major constraint. Sharing facilities with training centres could assist in this regard.

- The current funding model for the PLC programme, which is based on secondlevel provision, the second-level teacher contract arrangement and the requirements of Section 30 of the Teaching Council Act are all impacting negatively on responsiveness.

- 'The failure of DSP referral protocol to function in terms of PLC is an issue.' 'DSP, ETBs and SOLAS are constraints in themselves as they are not fully bedded down yet.'

- Decision making has been removed from college level to a central ETB level, resulting in a lack of responsiveness.

- Availability of accurate information on employer needs is an issue. Ongoing analysis is required, based on longitudinal surveys. A lot of information available on employers' needs is not based on hard information. It is mostly based on roundtable discussions.

- Esteem of PLC courses by parents and society is an issue. It is largely considered a form of second chance education. 'A lot of further education students expect to progress to higher education, is this realistic?' There is a guidance issue in this regard.

- The successes of PLC courses are not well advertised. Development of a 'skills passport' for PLC learners should be considered. 
- Level 6 higher education awards and Level 6 further education awards are not seen as equal. The credit values are different for each. This needs to be addressed as it can impact on progression.

- Lack of childcare support for participants is a constraint. Support exists for other similar FET programmes but not for PLCs - 'hard to explain this away'. Likewise, special needs are not funded adequately.

- Institutes of technology develop Level 5 and Level 6 programmes when their own numbers drop. This has an impact on PLC provision.

- The limited award titles from QQI also pose a constraint.

- The geographic spread within ETBs themselves is an issue. Transport infrastructure restricts access for some people.

- New QQI validation requirements will impact in a negative way on the desire to provide new programmes.

- The QQI brand is a concern as it is not widely recognised by employers in the same way as C\&G, ITEC etc.

- Until recently, guidance training did not include FET provision; the focus was mainly on the CAO route.

\section{Theme 9 - Positive and Negative elements of the findings}

\section{Positive elements of the findings}

- High progression and employment rates were achieved.

- A large percentage (37 per cent) of PLC learners achieved 300-400 CAO points, which indicates that PLC was a first choice for many students.

- A relatively high percentage of PLC leavers became self-employed compared to Leaving Certificate leavers.

- Local arrangements are in place for progression in the fields of learning on offer.

- The range of fields of learning on offer is responsive to learner demand.

- The diversity in age among PLC learners shows flexibility within the system.

- Positive student experiences emerged, with high satisfaction rates.

- The PLC programme provides a non-traditional route for access to higher education.

- There is a good balance between learners' and employers' needs.

- There are high retention rates in higher education following progression. 
- It provides a holistic approach to education with a rounded experience.

- It seems that after five years there is a positive correction for social disadvantage arising from PLC participation (bridging the gap).

- The PLC programme is good for social cohesion; it helps to retain training and jobs in the local labour market.

\section{Negative elements of the findings}

- A high proportion of students did not engage in work experience.

- There is a mismatch between supply and labour market demand, with oversupply in certain areas.

- Additional supports are required (such as childcare and transport).

- Staffing structures/contracts can be of indefinite duration.

- The proportion of courses without employment outcomes is a concern.

- There are limited links to employers.

- Participation is mainly female, which relates to the type of courses on offer.

- Courses can be accessed without suitability/aptitude testing.

- Counterfactual data would be useful.

- The survey response rates were low.

\section{Suggested improvements to the PLC programme}

A wide range of improvements were proposed based on the research findings and the direct experiences of the workshop participants, the most significant of which are outlined below.

- CPD: A comprehensive CPD programme to retrain teachers in other fields of learning is required. CPD should take three forms: subject matter; pedagogy; and change of vocational area. The former FÁS approach could inform this process. A one-year period for retraining over a 40 year career should be regarded as a worthwhile investment. The notion of moving teachers between provision types should be explored (e.g. from PLC to Youthreach to adult education). It must be recognised that many courses need teaching staff with vocational qualifications.

- Contracts: There is a need to look at the teacher contract to make it more appropriate to current needs in FET. A move away from the teacher allocation model to a pay/non-pay model, to include administration and guidance services, which have now begun moving towards mentoring, would be more appropriate. A review of the application of Section 30 of the Teaching Council Act to the PLC sector should also be undertaken. 
- Continuous intake: Break from the traditional school calendar. Continuous intake and other more flexible forms of delivery are required, including modular provision.

- Targets/linkages: Set national targets for progression and employment with improved industry links. Sectoral leadership on skills is an issue: 'There is no go to body for employers like CERT for liaison.' A greater understanding of industry needs would assist in improving provision. More detailed occupational profiles would assist in this regard.

- Funding: Develop an integrated funding model with student supports built in. The silo type model in use at the moment can include up to 17 different budgets across FET.

- Awards: There are restrictions imposed by QQI awards, such as the protracted time to validate awards. Recognition of industry/vendor qualifications within major awards would help to improve the provision. The QQI award in work experience only attracts 15 credits. This needs to be revisited in the context of credit value, how it is assessed, as well as employer and learner expectations about work experience.

- Name of PLC: Consideration should be given to changing the name 'Post-Leaving Certificate', since many students have not completed a Leaving Certificate. The PLC programme does not constitute one single programme, as the Leaving Certificate does, and should not be described in this way. It is very diverse with different pillars within the programme. It needs to be rebranded.

- Guidance: There is a need for improved guidance, with an emphasis on adult guidance requirements, in order to create better awareness of what is on offer in the sector. A significant proportion of PLC students do not come from secondlevel education. Guidance counsellors should be informed about FET provision as part of their training. Second-level schools should be better informed regarding PLC provision; however, career guidance is not getting the support it needs. Standard eligibility criteria are also needed for entry to the programmes.

- Integration: It should be recognised that $H R / I R$ issues arise regarding the integration of FET provision.

- Pathways: Progression from further education to higher education is overly complicated and needs to be simplified. Some form of standardisation of progression pathways should be developed.

- Structures: A middle management structure was suggested together with dedicated staff for employer engagement and work placement/experience.

- Supports: SUSI supports to PLC students are less than those provided to thirdlevel students. Notwithstanding a similar maintenance allowance, a third-level student will be supported for the full registration fee $(€ 3,000+)$, while a PLC 
student will only be exempted from the $€ 200$ levy. A typical PLC course will have additional charges of $€ 300-€ 500$, which may mean that, for a SUSI grant recipient, a PLC course will be more expensive than a third-level course.

- Social welfare recipients: There are inconsistencies for social welfare recipients choosing a PLC course rather than a course in an ETB training centre. Unless on VTOS, the PLC student is required to pay the course levy (€200). Participants on attending a training centre course will not incur costs. 


\section{APPENDIX D: QUESTIONNAIRE FOR SURVEY OF SCHOOL AND PLC LEAVERS}

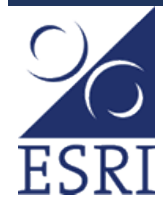

PIN No.

Thank you for agreeing to participate in our survey. All of the information provided is confidential and will not be disclosed to anyone outside the ESRI. The reports we produce deal only with general results. Individual information is not reported. You do not need to answer any particular question if you do not wish to.

\section{Section A: Personal Reflections}

A1. Are you male or female?

A2. What is your date of birth?

A3. When did you leave school?
Male ........ $\square_{1} \quad$ Female...... $\square_{2}$

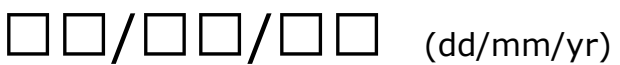

Month

Year

A4. All things considered, how satisfied would you say you are with your life these days? Please tell me on a scale of 1 to 10, where 1 means very dissatisfied and 10 means very satisfied. (Please tick one box)

\begin{tabular}{c|c|c|c|c|c|c|c|c|c|} 
Very dissatisfied & \multicolumn{1}{|c|}{$\square_{3}$} & $\square_{4}$ & $\square_{5}$ & $\square_{6}$ & $\square_{7}$ & $\square_{8}$ & $\square_{9}$ & $\square_{10}$ \\
\hline$\square_{1}$ & $\square_{2}$ & $\square_{3}$ &
\end{tabular}

A5. How frequently do you do each of the following? (Please tick one box on each line)

\begin{tabular}{|l|c|c|c|c|c|} 
& $\begin{array}{l}\text { Every day } \\
\text { or almost } \\
\text { every day }\end{array}$ & $\begin{array}{l}\text { At least } \\
\text { once a } \\
\text { week }\end{array}$ & $\begin{array}{l}\text { One to } \\
\text { three times } \\
\text { a month }\end{array}$ & $\begin{array}{l}\text { Less } \\
\text { often }\end{array}$ & Never \\
\hline Take part in sports or physical exercise & $\square_{1}$ & $\square_{2}$ & $\square_{3}$ & $\square_{4}$ & $\square_{5}$ \\
\hline Use the Internet other than for work & $\square_{1}$ & $\square_{2}$ & $\square_{3}$ & $\square_{4}$ & $\square_{5}$ \\
\hline $\begin{array}{l}\text { Attend religious services, apart from } \\
\text { weddings, funerals or christenings }\end{array}$ & $\square_{1}$ & $\square_{2}$ & $\square_{3}$ & $\square_{4}$ & $\square_{5}$ \\
\hline $\begin{array}{l}\text { Participate in social activities of a club, } \\
\text { society, or an association }\end{array}$ & $\square_{1}$ & $\square_{2}$ & $\square_{3}$ & $\square_{4}$ & $\square_{5}$ \\
\hline $\begin{array}{l}\text { Do unpaid voluntary work for a } \\
\text { community, educational, cultural, } \\
\text { sporting or other association }\end{array}$ & $\square_{1}$ & $\square_{2}$ & $\square_{3}$ & $\square_{4}$ & $\square_{5}$ \\
\hline
\end{tabular}

A6. Below is a list of skills and competences. To what extent do you think you have the following competences at the moment? (Please tick one box on each line)

\begin{tabular}{|l|l|l|l|l|c|c|}
\multicolumn{2}{|c|}{$\begin{array}{c}\text { Not } \\
\text { at all }\end{array}$} & \multicolumn{3}{c|}{$\begin{array}{c}\text { a great } \\
\text { extent }\end{array}$} \\
\hline 1 & Good written communication skills & $\square_{1}$ & $\square_{2}$ & $\square_{3}$ & $\square_{4}$ & $\square_{5}$ \\
\hline 2 & Good oral communication skills & $\square_{1}$ & $\square_{2}$ & $\square_{3}$ & $\square_{4}$ & $\square_{5}$ \\
\hline 3 & Ability to use computers and the internet & $\square_{1}$ & $\square_{2}$ & $\square_{3}$ & $\square_{4}$ & $\square_{5}$ \\
\hline 4 & Analytical skills & $\square_{1}$ & $\square_{2}$ & $\square_{3}$ & $\square_{4}$ & $\square_{5}$ \\
\hline 5 & Ability to perform well under pressure & $\square_{1}$ & $\square_{2}$ & $\square_{3}$ & $\square_{4}$ & $\square_{5}$ \\
\hline 6 & Ability to work well with others & $\square_{1}$ & $\square_{2}$ & $\square_{3}$ & $\square_{4}$ & $\square_{5}$ \\
\hline 7 & Ability to come up with new ideas and solutions & $\square_{1}$ & $\square_{2}$ & $\square_{3}$ & $\square_{4}$ & $\square_{5}$ \\
\hline 8 & Ability to write and speak in a foreign language(s) & $\square_{1}$ & $\square_{2}$ & $\square_{3}$ & $\square_{4}$ & $\square_{5}$ \\
\hline 9 & Knowledge of the field in which you are studying or working & $\square_{1}$ & $\square_{2}$ & $\square_{3}$ & $\square_{4}$ & $\square_{5}$ \\
\hline
\end{tabular}


A7. To what extent do you agree/disagree with the following statements? (Please tick one box on each line)

\begin{tabular}{|c|c|c|c|c|c|}
\hline & $\begin{array}{l}\text { Strongly } \\
\text { Agree }\end{array}$ & Agree & $\begin{array}{l}\text { Neither agree nor } \\
\text { disagree }\end{array}$ & Disagree & $\begin{array}{l}\text { Strongly } \\
\text { disagree }\end{array}$ \\
\hline $\begin{array}{l}\text { I generally feel that what I do in life is } \\
\text { worthwhile }\end{array}$ & $\square_{1}$ & $\square_{2}$ & $\square_{3}$ & $\square_{4}$ & $\square_{5}$ \\
\hline I feel left out of society & $\square_{1}$ & $\square_{2}$ & $\square_{3}$ & $\square_{4}$ & $\square_{5}$ \\
\hline $\begin{array}{l}\text { Life has become so complicated today that } \\
\text { I almost can't find my way }\end{array}$ & $\square_{1}$ & $\square_{2}$ & $\square_{3}$ & $\square_{4}$ & $\square_{5}$ \\
\hline $\begin{array}{l}\text { I feel that the value of what I do is not } \\
\text { recognised by others }\end{array}$ & $\square_{1}$ & $\square_{2}$ & $\square_{3}$ & $\square_{4}$ & $\square_{5}$ \\
\hline $\begin{array}{l}\text { Some people look down on me because of } \\
\text { my job situation or income }\end{array}$ & $\square_{1}$ & $\square_{2}$ & $\square_{3}$ & $\square_{4}$ & $\square_{5}$ \\
\hline
\end{tabular}

A8. How would you rate your health overall?

\begin{tabular}{|c|c|c|}
\hline Excellent & Very good & Good \\
\hline$\square_{1}$ & $\square_{2}$ & $\square_{3}$ \\
\hline
\end{tabular}

A9. How would you rate your mental health overall?

\begin{tabular}{|c|c|c|c|c|}
\hline Excellent & Very good & Good & Fair & Poor \\
\hline$\square_{1}$ & $\square_{2}$ & $\square 3$ & $\square_{4}$ & $\square 5$ \\
\hline
\end{tabular}

A10. Do you have any chronic (long-standing) physical or mental health problem, illness or disability? By chronic (long-standing) I mean illnesses or health problems which have lasted, or are expected to last, for 6 months or more.

$$
\text { Yes......... } \square_{1} \rightarrow \text { Go to A11 No....... } \square_{2} \rightarrow \text { Go to B1 }
$$

A11. Are you limited in your daily activities by this physical or mental health problem, illness or disability?

\begin{tabular}{|c|c|c|}
\hline Yes, severely & $\begin{array}{c}\text { Yes, to some } \\
\text { extent }\end{array}$ & No \\
\hline$\square_{1}$ & $\square_{2}$ & $\square_{3}$ \\
\hline
\end{tabular}

\section{SECTION B: CURRENT Situation}

B1. What is/was your main status in each of these three periods: September 2010, September 2012 and September 2015? (Please tick one box only in each column.)

\begin{tabular}{|l|c|c|c|}
\hline In paid employment & \multicolumn{1}{c}{ Sept 2010} & \multicolumn{1}{c|}{ Sept 2012} & $\square_{1}$ \\
\hline Self-employment & $\square_{1}$ & $\square_{1}$ & $\square_{2}$ \\
\hline Unemployed and looking for work & $\square_{2}$ & $\square_{2}$ & $\square_{3}$ \\
\hline Unemployed and not looking for work & $\square_{3}$ & $\square_{3}$ & $\square_{4}$ \\
\hline Studying Higher Education course & $\square_{4}$ & $\square_{4}$ & $\square_{5}$ \\
\hline Studying Further Education course e.g. PLC & $\square_{5}$ & $\square_{5}$ & $\square_{6}$ \\
\hline Apprenticeship & $\square_{6}$ & $\square_{6}$ & $\square_{7}$ \\
\hline Internship & $\square_{7}$ & $\square_{7}$ & $\square_{8}$ \\
\hline Other FÁS/Solas, Fáilte Ireland, Teagasc course etc. & $\square_{8}$ & $\square_{8}$ & $\square_{9}$ \\
\hline On a private Training Scheme & $\square_{9}$ & $\square_{9}$ & $\square_{10}$ \\
\hline Engaged in home duties & $\square_{10}$ & $\square_{10}$ & $\square_{11}$ \\
\hline Unable to work due to permanent disability or illness & $\square_{12}$ & $\square_{11}$ & $\square_{12}$ \\
\hline Taking a year out or travelling & $\square_{13}$ & $\square_{12}$ & $\square_{13}$ \\
\hline Other, please specify & $\square_{14}$ & $\square_{14}$ & $\square_{14}$ \\
\hline
\end{tabular}

B2. Have you ever participated in the following programmes/schemes? (Tick all that apply)

\begin{tabular}{|l|l|}
\hline Vocational Training Opportunities Scheme (VTOS) & $\square_{1}$ \\
\hline Back to Education Allowance (BTEA) & $\square_{2}$ \\
\hline Springboard Course & $\square_{3}$ \\
\hline JobBridge Internship & $\square_{4}$ \\
\hline Momentum & $\square_{5}$ \\
\hline
\end{tabular}




\begin{tabular}{|l|l|}
\hline Skillnets & $\square_{6}$ \\
\hline Youthreach & $\square_{7}$ \\
\hline Not Applicable & $\square_{8}$ \\
\hline
\end{tabular}

B3. Could you tell me the highest level of education you have completed?

\begin{tabular}{|l|l|}
\hline Primary or below & $\square_{1}$ \\
\hline Lower Secondary (Junior/Inter Cert or equiv) & $\square_{2}$ \\
\hline Upper Secondary (Leaving Cert or equiv) & $\square_{3}$ \\
\hline Post-Secondary Non-Tertiary (e.g. PLC) & $\square_{4}$ \\
\hline Non-Degree (Certificate/Diploma) & $\square_{5}$ \\
\hline Ordinary Degree & $\square_{6}$ \\
\hline Honours Degree & $\square 7$ \\
\hline Masters & $\square 8$ \\
\hline Other (please specify): & $\square 9$ \\
\hline
\end{tabular}

B4. Since the age of $\mathbf{1 8}$, please indicate the total time you have spent in each of the following activities?

\begin{tabular}{|l|l|l|}
\hline In employment (full-time/part-time), self-employment or farming & Years & Months \\
\hline Unemployed (and seeking work) & & \\
\hline Ill/disabled and outside labour force & & \\
\hline On home duties/ Caring for children & & \\
\hline In full-time education & & \\
\hline Other (please specify): & & \\
\hline
\end{tabular}

B5. Which of the following best describes your current marital status?

\begin{tabular}{|l|l|l|l|}
\hline Single & $\square_{1}$ & Living as a couple & $\square_{3}$ \\
\hline Married & $\square_{2}$ & Divorced/Widowed/Separated & $\square_{5}$ \\
\hline Civil Partnership & $\square_{3}$ & & \\
\hline
\end{tabular}

B6. Do you have any children?

Yes $\ldots \ldots . . . \square_{1} \quad$ No......... $\square_{2}$

B7. Which of the following best describes your living situation in September 2012 and 2015 ?

\begin{tabular}{|c|c|c|}
\hline & Sept 2012 & Sept 2015 \\
\hline Lodgings/digs & $\square_{1}$ & $\square_{1}$ \\
\hline With parents/relatives & $\square_{2}$ & $\square_{2}$ \\
\hline College residence on/off campus & $\square_{3}$ & $\square_{3}$ \\
\hline Rented house/flat & $\square 4$ & $\square 4$ \\
\hline Own household & $\square_{5}$ & $\square_{5}$ \\
\hline Other (please specify & $\square_{6}$ & $\square_{6}$ \\
\hline
\end{tabular}

B8. A household may have different sources of income and more than one household member may contribute to it. Thinking of your household's total monthly income: is your household able to make ends meet...?

\begin{tabular}{|c|c|c|c|c|c|}
\hline Very easily & Easily & $\begin{array}{l}\text { Fairly } \\
\text { easily }\end{array}$ & $\begin{array}{l}\text { With some } \\
\text { difficulty }\end{array}$ & $\begin{array}{l}\text { With } \\
\text { difficulty }\end{array}$ & $\begin{array}{l}\text { With great } \\
\text { difficulty }\end{array}$ \\
\hline$\square_{1}$ & $\square_{2}$ & $\square_{3}$ & $\square_{4}$ & $\square_{5}$ & $\square_{6}$ \\
\hline
\end{tabular}


C1. What programme were you taking in your last year at second-level school or Youthreach where applicable?

(Please tick one box only. Do not include PLC or other Further Education courses, if taken.)

\begin{tabular}{|l|l|}
\hline Leaving Certificate & $\square_{1}$ \\
\hline Leaving Certificate Applied Programme & $\square_{2}$ \\
\hline Leaving Certificate Vocational Programme (includes link modules) & $\square_{3}$ \\
\hline Junior Certificate & $\square_{4}$ \\
\hline Other (please specify) & $\square 5$ \\
\hline
\end{tabular}

C2. (a) At this last examination, what subjects did you sit for, what level paper did you take and what grades did you get?

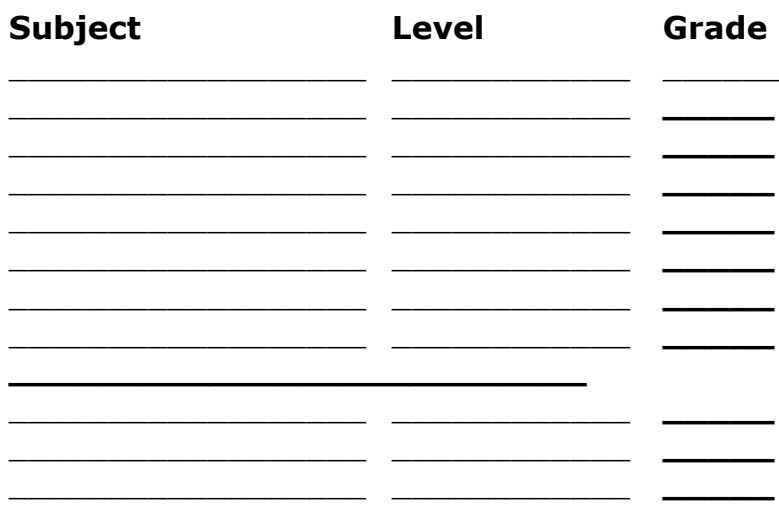

(b) If you sat the Leaving Certificate Applied:

(i) Did you receive: [Tick one only]

Pass $\square 1$

Merit $\quad \square 2$

Distinction $\square 3$

Fail $\square 4$

Record of experience $\square 5$

(ii) Vocational Specialisms taken

(iii) Languages Taken

(c) If you cannot provide complete details on subject level and grade on last examination sat in Question C3 (a) or (b) above, perhaps you can complete the following: (i) how many honours and pass subjects you sat for in your last examination; (ii) of these, in how many did you achieve an A, B or C; a D; or an E, F or NG?

\begin{tabular}{|l|c|c|c|c|}
\hline \multicolumn{1}{|c|}{ LEVEL } & $\begin{array}{c}\text { No. of } \\
\text { Subjects }\end{array}$ & $\begin{array}{c}\text { No. of } \\
\text { A,B,C's }\end{array}$ & $\begin{array}{c}\text { No. of } \\
\text { D's }\end{array}$ & $\begin{array}{c}\text { No. of } \\
\text { E,F or NG's }\end{array}$ \\
\hline Honours Subjects & & & & \\
\hline Pass Subjects & & & & \\
\hline
\end{tabular}

(d) What points were you awarded in your Leaving Certificate? (if applicable)

\section{LEAVING CERT, LEAVING CERT VOCATIONAL OR LEAVING CERT APPLIED RESULTS}

We are interested in finding out how students get on in the Leaving Certificate exams. This is very important as it means we can discover what helps students do well at school in order to improve the school system. If you have not been able to provide full details of your subject, levels, and grades, we would be very grateful if you could give us permission to access your exam results from the State Examinations Commission. The information will be completely confidential. You will not be identified in any way. We are only interested in overall patterns not in individual students or schools.

C3. (e) If you AGREE that we can access your Leaving Certificate exam results, please tick the box 'YES': Yes.... $\square_{1} \quad$ No...... $\square_{2}$

We are interested in finding out how those who attended different types of schools and colleges are getting on today. We would be very grateful if you could give us permission to access information on the school or college you attended from the Post-Primary Pupil Database maintained by the Department of Education and Skills. The information would include the school roll number and school type. The information is confidential and we will not identify you or your school in any of our publications.

C4. If you AGREE that we can obtain this information, please tick the box 'YES':

Yes..... $\square_{1} \quad$ No...... $\square_{2}$ 
C5. Did you experience any particular special educational need or disability that affected your learning while at school?

Yes..... $\square_{1} \rightarrow$ Go to C6 No...... $\square 2 \rightarrow$ Go to D1

C6. If Yes, did you have this special educational need or disability formally assessed?

$$
\text { Yes..... } \square_{1} \quad \text { No...... } \square_{2}
$$

\section{Section D: Personal Reflections on School Experiences}

D1. Thinking back to your last year in school (not including any PLC or other Further Education courses you may have taken), when you were deciding what to do after you left school:

(a) Did you get any advice from any of the following people? (Please tick all that apply in column A.)

(b) Of those who gave you advice, who do you think was the most help to you in deciding what to do after you left school? (Tick one box only in column B.)

\begin{tabular}{|c|c|c|}
\hline & $\begin{array}{l}\text { A. Any Advice } \\
\text { Tick all that apply }\end{array}$ & $\begin{array}{l}\text { B. Most He } \\
\text { Tick One }\end{array}$ \\
\hline Career guidance counsellor in school & $\square_{1}$ & \\
\hline Another teacher in school & $\square_{2}$ & \\
\hline Mother & $\square_{3}$ & [ \\
\hline Father & $\square 4$ & $\sqsubset$ \\
\hline Other family member (please specify ___ & $\square 5$ & \\
\hline Friend(s) & $\square 6$ & \\
\hline Someone studying the course & $\square 7$ & \\
\hline Someone working in the area & $\square_{8}$ & \\
\hline Someone else (specify ___ & $\square 9$ & \\
\hline Received no advice & $\square_{10}$ & \\
\hline Other source (please specify & $\square_{11}$ & \\
\hline
\end{tabular}

D2. How satisfied were you with the information you received at school on the different options open to you on leaving school?

\begin{tabular}{|c|c|c|c|}
\hline Very satisfied & Satisfied & Dissatisfied & Very dissatisfied \\
\hline$\square_{1}$ & $\square_{2}$ & $\square_{3}$ & $\square_{4}$ \\
\hline
\end{tabular}

D3. Which of the following were the most important influences in making your decision about what you would do when you left school?

Please select your top 3 in order, where 1 is the most important influence, 2 is the second most important and 3 is the third most important influence.

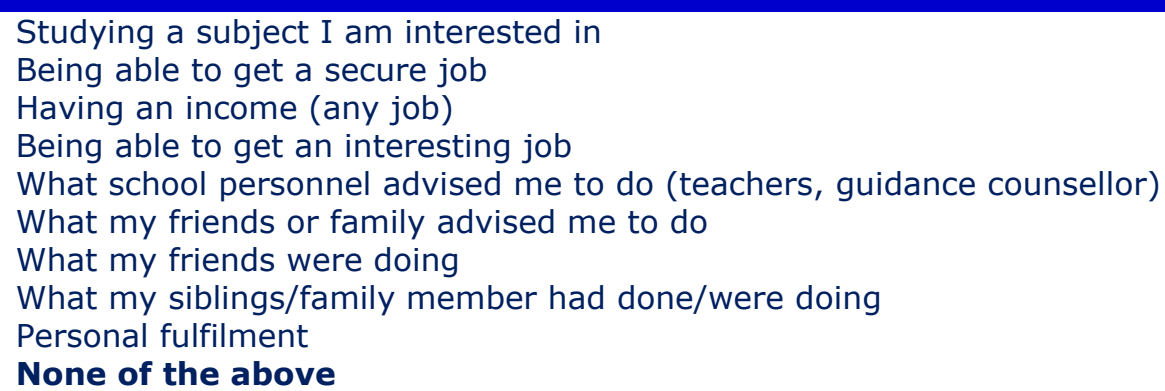

D4. What did you plan to do immediately on leaving school? (Please tick one box)

Go on to a post-school education or training course

Get a job

Travel/ take time-out

Take on caring responsibilities at home

Other, please specify

D5. Did you get to do what you planned after leaving school?

\begin{tabular}{|c|c|c|}
\hline Yes & To some extent & No \\
\hline$\square_{1}$ & $\square_{2}$ & $\square_{3}$ \\
\hline
\end{tabular}


D6. Looking back if you were free to choose again would you take the same pathway (education, training or job)?

\begin{tabular}{|c|c|c|}
\hline Yes & To some extent & No \\
\hline$\square_{1}$ & $\square_{2}$ & $\square_{3}$ \\
\hline
\end{tabular}

\section{SECTION E: PLC}

E1. Since leaving school, did you ever apply for a Post Leaving Certificate (PLC) Course?

$$
\text { Yes......... } \square_{1} \rightarrow \text { Go to E2 } \quad \text { No........ } \square_{2} \rightarrow \text { Go to F1 }
$$

E2. Did you ever take up a Post Leaving Cert (PLC) Course?

$$
\text { Yes......... } \square_{1} \rightarrow \text { Go to E3 No........ } \square_{2} \rightarrow \text { Go to F1 }
$$

\begin{tabular}{|c|c|c|c|c|c|c|c|c|c|c|}
\hline $\begin{array}{l}\text { Course } \\
\text { Name }\end{array}$ & Institution & $\begin{array}{l}\text { Field } \\
\text { of } \\
\text { Study }\end{array}$ & Level & $\begin{array}{l}\text { Award } \\
\text { Achieved }\end{array}$ & $\begin{array}{l}\text { No. of } \\
\text { Modules } \\
\text { completed }\end{array}$ & $\begin{array}{l}\text { Start } \\
\text { Date } \\
\mathrm{mm} / \mathrm{yy}\end{array}$ & $\begin{array}{l}\text { End } \\
\text { Date } \\
\mathrm{mm} / \mathrm{yy}\end{array}$ & $\begin{array}{l}\text { Duration of } \\
\text { course }\end{array}$ & $\begin{array}{l}\text { Course } \\
\text { Completed } \\
\text { (See Note 2) }\end{array}$ & $\begin{array}{l}\text { Final } \\
\text { Grade }\end{array}$ \\
\hline & & & $\begin{array}{l}\text { FETAC } 4 \square 1 \\
\text { FETAC } 5 \square 2 \\
\text { FETAC } \square_{3} \\
\text { Other } \square_{3} \\
\text { (See Note 1) }\end{array}$ & $\begin{array}{l}\text { Major } \square_{1} \\
\text { Minor } \square_{2} \\
\text { None } \square_{3}\end{array}$ & & & & $\begin{array}{l}1 \text { Year } \square_{1} \\
2 \text { Year } \square_{2}\end{array}$ & $\begin{array}{l}\text { Yes } \square_{1} \\
\text { No } \square_{2}\end{array}$ & $\begin{array}{l}\text { Pass } \square_{1} \\
\text { Merit } \square_{2} \\
\text { Dist. } \square_{3}\end{array}$ \\
\hline & & & $\begin{array}{l}\text { FETAC } 4 \square_{1} \\
\text { FETAC } 5 \square_{2} \\
\text { FETAC } 6 \square_{3} \\
\text { Other } \square_{4}\end{array}$ & $\begin{array}{l}\text { Major } \square_{1} \\
\text { Minor } \square_{2} \\
\text { None } \square_{3}\end{array}$ & & & & $\begin{array}{l}1 \text { Year } \square_{1} \\
2 \text { Year } \square_{2}\end{array}$ & $\begin{array}{l}\text { Yes } \square_{1} \\
\text { No } \square_{2}\end{array}$ & $\begin{array}{l}\text { Pass } \square_{1} \\
\text { Merit } \square_{2} \\
\text { Dist. } \square_{3}\end{array}$ \\
\hline & & & $\begin{array}{l}\text { FETAC } 4 \square_{1} \\
\text { FETAC } 5 \square_{2} \\
\text { FETAC } 6 \square_{3} \\
\text { Other } \square_{4}\end{array}$ & $\begin{array}{l}\text { Major } \square_{1} \\
\text { Minor } \square_{2} \\
\text { None } \square_{3}\end{array}$ & & & & $\begin{array}{l}1 \text { Year } \square_{1} \\
2 \text { Year } \square_{2}\end{array}$ & $\begin{array}{l}\text { Yes } \square_{1} \\
\text { No } \square_{2}\end{array}$ & $\begin{array}{l}\text { Pass } \square_{1} \\
\text { Merit } \square_{2} \\
\text { Dist. } \square_{3}\end{array}$ \\
\hline & & & $\begin{array}{l}\text { FETAC } 4 \square_{1} \\
\text { FETAC } 5 \square_{2} \\
\text { FETAC } 6 \square_{3} \\
\text { Other } \square_{4}\end{array}$ & $\begin{array}{l}\text { Major } \square_{1} \\
\text { Minor } \square_{2} \\
\text { None } \square_{3}\end{array}$ & & & & $\begin{array}{l}1 \text { Year } \square_{1} \\
2 \text { Year } \square_{2}\end{array}$ & $\begin{array}{l}\text { Yes } \square_{1} \\
\text { No } \square_{2}\end{array}$ & $\begin{array}{l}\text { Pass } \square_{1} \\
\text { Merit } \square_{2} \\
\text { Dist. } \square_{3}\end{array}$ \\
\hline
\end{tabular}

E3. If yes, please provide details of all Post Leaving Cert Courses (PLC) taken below:

Note1: 'Other' includes accreditation bodies such as City and Guilds, Microsoft, Edexcel, etc.

Note2: Course was completed if you signed up for a major award and were awarded a major award or if you signed up for a minor award and were awarded a minor award. Course was incomplete if you signed up for a major award and were awarded a minor award.

E4. Were any of the course awards that you achieved different from the courses that you originally signed up for?

$$
\text { Yes..... } \square_{1} \quad \text { No...... } \square_{2}
$$

E5. If you left any PLC course listed above before completion, why did you leave? (Tick all that apply)

$\begin{array}{lc}\text { Not applicable } & \square_{\mathbf{1}} \\ \text { The course was too difficult } & \square_{\mathbf{2}} \\ \text { The course was not what I expected } & \square_{\mathbf{3}} \\ \text { I did not like the content of the course } & \square_{\mathbf{4}} \\ \text { I did not like the college } & \square_{\mathbf{5}} \\ \text { I did not get on well with my classmates } & \square_{\mathbf{6}} \\ \text { I failed my assessments/exams } & \square_{\mathbf{7}} \\ \text { I/my family were experiencing financial difficulties } & \square_{\mathbf{8}} \\ \text { It was too far to travel } & \square_{\mathbf{9}} \\ \text { I got a full-time job } & \square_{\mathbf{1 0}} \\ \text { Other, please specify } & \square_{\mathbf{1 1}}\end{array}$

If you took more than one PLC course, please answer the following questions with respect to the course you took most recently. 
E6. In taking the PLC course (your most recent, if more than one), did you hope it would help you ... (Please tick your one primary objective)

Get a place on a Higher Education programme

Get a job right away after the PLC course

Personal Development

Other, please

E7. Did your PLC course open up opportunities for further study at.. (Tick all that apply)

\begin{tabular}{|l|l|l|l|}
\hline Irish Universities & $\square_{1}$ & Institutes of Technology & $\square_{3}$ \\
\hline UK Universities & $\square_{2}$ & Other (please specify): & $\square_{4}$ \\
\hline
\end{tabular}

E8. Was your PLC course part of a HE Links Scheme?

$$
\text { Yes......... } \square_{1} \quad \text { No........ } \square_{2} \quad \text { Don't know....... } \square_{3}
$$

E9. Did your PLC course entitle you to advanced entry into a Higher Education course (e.g. direct entry to second year)?

$$
\text { Yes......... } \square_{1} \quad \text { No........ } \square_{2}
$$

E10. Did you receive any type of grant to cover such expenses as fees or maintenance?

$$
\text { Yes......... } \square_{1} \quad \text { No........ } \square_{2}
$$

E11. If yes, did you receive any of the following supports/schemes?

\begin{tabular}{|l|l|}
\hline Vocational Training Opportunities Scheme (VTOS) & Yes/No \\
\hline Back to Education Allowance (BTEA) & Yes/No \\
\hline
\end{tabular}

E12. During your PLC studies, did you access any of the following student supports? If so, how satisfied were you with the service provided?

\begin{tabular}{|l|c|c|c|c|c|}
\multicolumn{7}{|c|}{$\begin{array}{c}\text { Tick one } \\
\text { Yes No }\end{array}$} & $\begin{array}{c}\text { Very } \\
\text { satisfied }\end{array}$ & Satisfied & Dissatisfied & Very \\
dissatisfied
\end{tabular}

E13. Did you participate in work experience during your PLC studies? $\quad$ Yes.... $\square_{1} \quad N_{0} \ldots . . . \square 2$

E14. If yes, how long did your work experience last? (number of weeks)

E15. During term-time, how many HOURS PER WEEK do/did you spend on the following activities? (Please enter the total number of hours over the whole week including the weekend)

\begin{tabular}{|l|c|}
\hline Lectures/Tutorials/Practical etc & No. of Hours per Week \\
\hline Personal Study, doing assignments/project work at home & $\mathbf{h r s / w k}$ \\
\hline Playing sports/taking part in clubs and societies & $\mathbf{h r s} / \mathbf{w k}$ \\
\hline Travelling between accommodation and college (to \& from) & $\mathbf{h r s} / \mathbf{w k}$ \\
\hline
\end{tabular}

E16. How did your overall result compare to that of other students that completed your study programme?

\begin{tabular}{|c|c|c|c|c|c|c|}
\hline $\begin{array}{c}1 \\
\text { Much lower than average }\end{array}$ & 2 & 3 & 4 & \multicolumn{2}{c}{$\begin{array}{c}6 \\
\text { Cuch higher than average tell }\end{array}$} \\
\hline$\square_{1}$ & $\square_{2}$ & $\square_{3}$ & $\square_{4}$ & $\square_{5}$ & $\square_{5}$ \\
\hline
\end{tabular}


E17. In relation to your Post Leaving Cert (PLC) studies, to what extent do you agree or disagree with the following statements? Tick one box on each line

\begin{tabular}{|c|c|c|c|c|c|}
\hline & & $\begin{array}{l}\text { Strongly } \\
\text { Agree }\end{array}$ & Agree & Disagree & $\begin{array}{l}\text { Strongly } \\
\text { Disagree }\end{array}$ \\
\hline 1 & $\begin{array}{l}\text { The teaching and learning on my PLC course was very } \\
\text { different to school }\end{array}$ & $\square_{1}$ & $\square 2$ & $\square 3$ & $\square_{4}$ \\
\hline 2 & My schoolwork prepared me for my PLC studies & $\square_{1}$ & $\square_{2}$ & $\square 3$ & $\square 4$ \\
\hline 3 & My course involved a lot of project work & $\square_{1}$ & $\square_{2}$ & $\square 3$ & $\square 4$ \\
\hline 4 & My course involved a lot of tests and exams & $\square_{1}$ & $\square_{2}$ & $\square 3$ & $\square 4$ \\
\hline 5 & I could get extra help with my coursework if needed & $\square_{1}$ & $\square_{2}$ & $\square 3$ & $\square 4$ \\
\hline 6 & $\begin{array}{l}\text { I could get advice on future careers or courses in college if } \\
\text { required }\end{array}$ & $\square_{1}$ & $\square_{2}$ & $\square_{3}$ & $\square 4$ \\
\hline 7 & I got useful feedback on my performance & $\square 1$ & $\square 2$ & $\square 3$ & $\square 4$ \\
\hline 8 & I had the chance to give feedback on my course & $\square_{1}$ & $\square_{2}$ & $\square_{3}$ & $\square_{4}$ \\
\hline 9 & There was someone I could talk to if needed & $\square 1$ & $\square 2$ & $\square 3$ & $\square 4$ \\
\hline 10 & The facilities in the college were good & $\square_{1}$ & $\square 2$ & $\square 3$ & $\square 4$ \\
\hline 11 & I had access to all the equipment that I needed & $\square_{1}$ & $\square_{2}$ & $\square_{3}$ & $\square 4$ \\
\hline 12 & $\begin{array}{l}\text { The teachers/tutors had a lot of relevant knowledge on } \\
\text { subject matter to share }\end{array}$ & $\square 1$ & $\square 2$ & $\square 3$ & $\square 4$ \\
\hline 13 & $\begin{array}{l}\text { The course modules were relevant to the skills the course } \\
\text { was designed to teach }\end{array}$ & $\square 1$ & $\square 2$ & $\square 3$ & $\square 4$ \\
\hline 14 & $\begin{array}{l}\text { The work experience was relevant to the skills the course } \\
\text { was designed to teach }\end{array}$ & $\square 1$ & $\square_{2}$ & $\square 3$ & $\square 4$ \\
\hline
\end{tabular}
E18. The following are some difficulties which sometimes affect students in their first year of further study. For each, please indicate to what extent these are/were a problem for you in your first year. Tick one box on each line

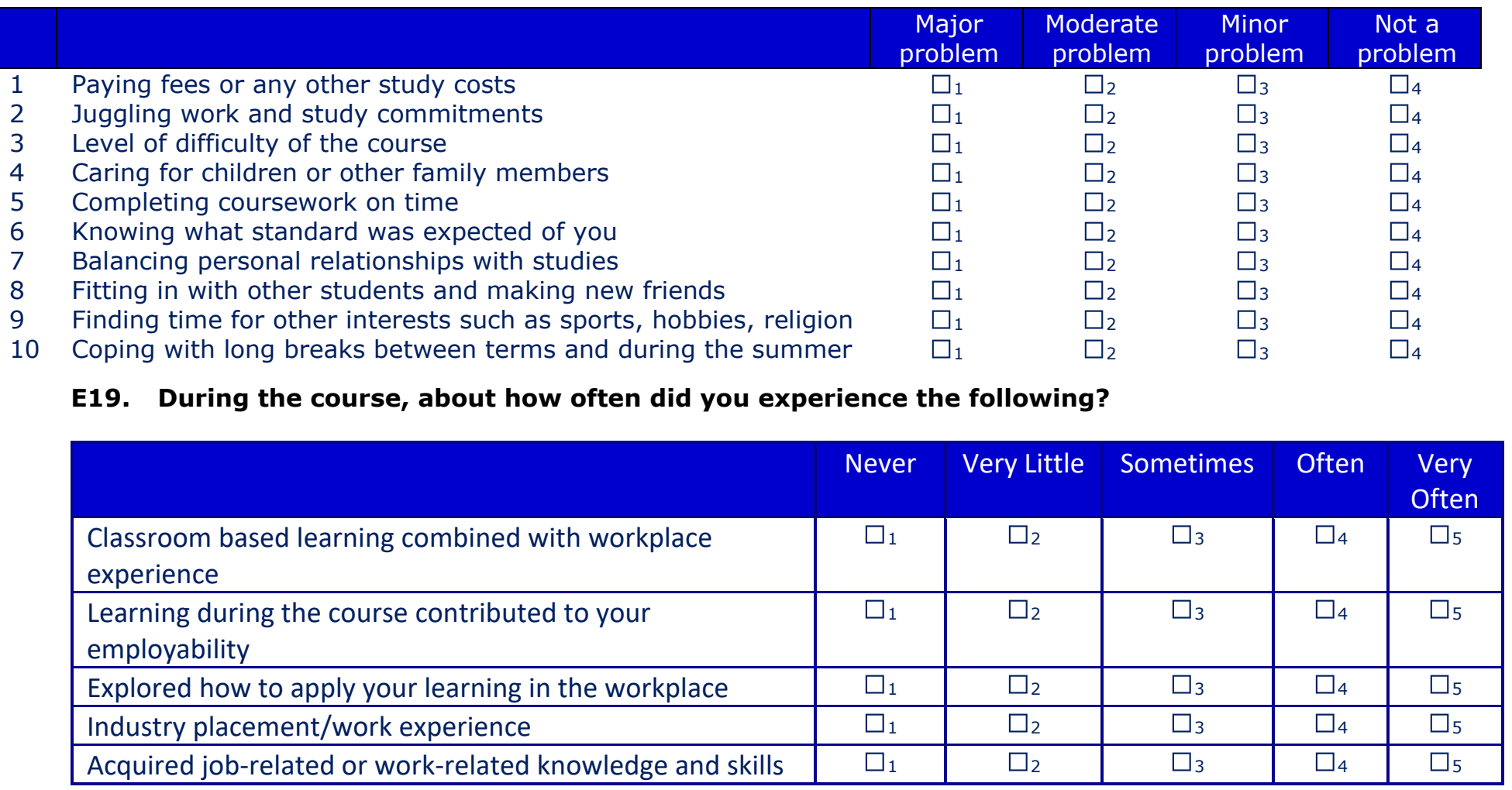


E20. How would you describe your relationships with each of the following? (Please tick one box on each line)

\begin{tabular}{|l|c|c|c|c|c|c|} 
& \multicolumn{1}{|c|}{$\begin{array}{c}1 \\
\text { Unavailable, } \\
\text { unsupportive, sense } \\
\text { of alienation }\end{array}$} & 2 & 3 & 5 & \multicolumn{3}{c}{$\begin{array}{c}\text { Available, } \\
\text { supportive, } \\
\text { considerate }\end{array}$} \\
\hline Other Students & $\square_{1}$ & $\square_{2}$ & $\square_{3}$ & $\square_{4}$ & $\square_{5}$ & $\square$ \\
\hline Teaching Staff & $\square_{1}$ & $\square_{2}$ & $\square_{3}$ & $\square_{4}$ & $\square_{5}$ & $\square_{6}$ \\
\hline Administrative Personnel & $\square_{1}$ & $\square_{2}$ & $\square_{3}$ & $\square_{4}$ & $\square_{5}$ & $\square$ \\
\hline
\end{tabular}

E21. How do/did you fund your studies during your Post Leaving Cert Course (PLC)?

\begin{tabular}{|l|c|}
\hline Money from your family & Tick all that apply \\
\hline Indirect support from your family (e.g. food, accommodation) & $\square_{\mathbf{1}}$ \\
\hline Earnings from employment & $\square_{\mathbf{2}}$ \\
\hline A State grant & $\square_{\mathbf{3}}$ \\
\hline Vocational Training Opportunities Scheme (VTOS) & $\square_{\mathbf{4}}$ \\
\hline Back to Education Allowance (BTEA) & $\square_{\mathbf{5}}$ \\
\hline Other Social welfare payment & $\square_{\mathbf{6}}$ \\
\hline A bank loan & $\square_{\mathbf{7}}$ \\
\hline Savings & $\square_{\mathbf{9}}$ \\
\hline Employer assistance & $\square_{\mathbf{1 0}}$ \\
\hline The Fund for Students with Disabilities & $\square_{\mathbf{1 1}}$ \\
\hline Other, please specify & $\square_{\mathbf{1 2}}$ \\
\hline
\end{tabular}

\section{SECTION F: Higher EdUCATION}

F1. Since leaving school, did you ever apply for a Higher Education Course (HE) Course?

$$
\text { Yes......... } \square_{1} \rightarrow \text { Go to F2 No....... } \square_{2} \rightarrow \text { Go to G1 }
$$

F2. Since leaving school, did you ever take a Higher Education Course (HE)?

$$
\text { Yes......... } \square_{1} \rightarrow \text { Go to F3 No........ } \square_{2} \rightarrow \text { Go to G1 }
$$

\begin{tabular}{|c|c|c|c|c|c|c|c|}
\hline Course Name & Institution & $\begin{array}{l}\text { Field of } \\
\text { Study }\end{array}$ & $\begin{array}{l}\text { Level }(6, \\
7,8 \text { or } 9)\end{array}$ & $\begin{array}{l}\text { Start } \\
\text { Date } \\
\mathrm{mm} / \mathrm{yy}\end{array}$ & $\begin{array}{l}\text { End } \\
\text { Date } \\
\mathrm{mm} / \mathrm{yy}\end{array}$ & $\begin{array}{l}\text { Completed } \\
\text { (Tick one) } \\
\text { Yes No }\end{array}$ & $\begin{array}{l}\text { Overall } \\
\text { Grade }\end{array}$ \\
\hline & & & & & & $\square_{1} \square_{2}$ & \\
\hline & & & & & & $\square_{1} \quad \square_{2}$ & \\
\hline & & & & & & $\square_{1} \quad \square_{2}$ & \\
\hline & & & & & & $\square 1$ & \\
\hline
\end{tabular}

F3. If yes, please provide details of all Higher Education courses below:

F4. If you left any Higher Education course before completion, why did you leave? (Tick all that apply)

$\begin{array}{ll}\text { Not applicable } & \square_{\mathbf{1}} \\ \text { The course was too difficult } & \square_{\mathbf{2}} \\ \text { The course was not what I expected } & \square_{\mathbf{3}} \\ \text { I did not like the content of the course } & \square_{\mathbf{4}} \\ \text { I did not like the college } & \square_{\mathbf{5}} \\ \text { I did not get on well with my classmates } & \square_{\mathbf{6}} \\ \text { I failed my exams } & \square_{\mathbf{7}} \\ \text { I/my family were experiencing financial difficulties } & \square_{\mathbf{8}} \\ \text { It was too far to travel } & \square \mathbf{9} \\ \text { I got a full-time job } & \square_{\mathbf{1 1}} \\ \text { Other, please specify } & \square \mathbf{1 2}\end{array}$

If you took more than one HE course, please answer the following questions with respect to the one you took most recently. 
F5. Did you receive any of the following types of grant to cover such expenses as fees or maintenance?

\begin{tabular}{|c|c|}
\hline & Yes No \\
\hline Back to Education Allowance (BTEA) & $\square_{1} \quad \square_{2}$ \\
\hline Springboard & $\square_{1}$ \\
\hline Higher Education Grant (SUSI) & $\square_{1}$ \\
\hline The Fund for Students with Disabilities & $\square_{1}$ \\
\hline The Student Assistance Fund & $\square_{1}$ \\
\hline
\end{tabular}

F6. How do you rate your overall grade compared to other students that graduated from your study programme?

\begin{tabular}{|l|l|l|l|l|l|}
\hline $\begin{array}{l}1 \\
\text { Much lower than average }\end{array}$ & 3 & 4 & 5 & \multicolumn{2}{l|}{$\begin{array}{l}\text { Much higher than average } \\
\text { Cannot tell }\end{array}$} \\
\hline$\square_{1}$ & $\square_{2}$ & $\square_{3}$ & $\square_{4}$ & $\square_{5}$ & $\square_{6}$ \\
\hline
\end{tabular}

F7. During your Higher Education studies, did you access any of the following student supports? If so, how satisfied were you with the service provided?

\begin{tabular}{|c|c|c|c|c|c|}
\hline & $\begin{array}{l}\text { Please } \\
\text { Tick one } \\
\text { Yes No }\end{array}$ & $\begin{array}{c}\text { Very } \\
\text { satisfied }\end{array}$ & Satisfied & Dissatisfied & $\begin{array}{c}\text { Very } \\
\text { dissatisfied }\end{array}$ \\
\hline Career Guidance & $\square_{1} \quad \square_{2}$ & $\square_{1}$ & $\square_{2}$ & $\square_{3}$ & $\square_{4}$ \\
\hline Counselling & $\square_{1} \quad \square_{2}$ & $\square_{1}$ & $\square_{2}$ & $\square_{3}$ & $\square_{4}$ \\
\hline Learning Supports & $\square_{1} \quad \square_{2}$ & $\square_{1}$ & $\square_{2}$ & $\square_{3}$ & $\square_{4}$ \\
\hline Childcare & $\square_{1} \quad \square_{2}$ & $\square_{1}$ & $\square_{2}$ & $\square_{3}$ & $\square_{4}$ \\
\hline Disability Support Service & $\square_{1} \quad \square_{2}$ & $\square_{1}$ & $\square_{2}$ & $\square_{3}$ & $\square_{4}$ \\
\hline
\end{tabular}

F8. During term-time, how many HOURS PER WEEK do/did you spend on the following activities? (Please enter the total hours over the whole week including the weekend.)

\begin{tabular}{|l|c|}
\hline Lectures/Tutorials/Practicals etc. & No. of Hours per Week \\
\hline Personal Study, doing assignments/project work at home & $\mathbf{h r s / w k}$ \\
\hline Playing sports/taking part in clubs and societies & $\mathbf{h r s} / \mathbf{w k}$ \\
\hline Travelling between accommodation and college (to \& from) & $\mathbf{h r s} / \mathbf{w k}$ \\
\hline
\end{tabular}

F9. In relation to your Higher Education (HE) studies, to what extent do you agree or disagree with the following statements? (Please tick one box on each line)

\begin{tabular}{|c|c|c|c|c|c|c|}
\hline & & $\begin{array}{l}\text { Strongly } \\
\text { Agree }\end{array}$ & Agree & Disagree & $\begin{array}{l}\text { Strongly } \\
\text { Disagree }\end{array}$ & $\begin{array}{l}\text { Not } \\
\text { Applicable }\end{array}$ \\
\hline 1 & $\begin{array}{l}\text { The teaching and learning on my course was very } \\
\text { different to school }\end{array}$ & $\square_{1}$ & $\square_{2}$ & $\square_{3}$ & $\square_{4}$ & \\
\hline 2 & My schoolwork prepared me for my HE studies & $\square_{1}$ & $\square_{2}$ & $\square_{3}$ & $\square_{4}$ & \\
\hline 3 & My PLC studies prepared me for my HE studies & $\square_{1}$ & $\square_{2}$ & $\square_{3}$ & $\square_{4}$ & $\square_{5}$ \\
\hline 4 & $\begin{array}{l}\text { I studied the course I wanted in the Institution of my } \\
\text { choice }\end{array}$ & $\square_{1}$ & $\square_{2}$ & $\square_{3}$ & $\square 4$ & \\
\hline 5 & My course involved a lot of project work & $\square_{1}$ & $\square_{2}$ & $\square_{3}$ & $\square_{4}$ & \\
\hline 6 & My course involved a lot of tests and exams & $\square_{1}$ & $\square_{2}$ & $\square_{3}$ & $\square_{4}$ & \\
\hline 7 & I could get extra help with my coursework if needed & $\square_{1}$ & $\square_{2}$ & $\square_{3}$ & $\square_{4}$ & \\
\hline 8 & $\begin{array}{l}\text { I could get advice on future careers or courses in } \\
\text { college if required }\end{array}$ & $\square_{1}$ & $\square_{2}$ & $\square_{3}$ & $\square 4$ & \\
\hline 9 & I got useful feedback on my performance & $\square_{1}$ & $\square_{2}$ & $\square_{3}$ & $\square_{4}$ & \\
\hline 10 & I had the chance to give feedback on my course & $\square_{1}$ & $\square_{2}$ & $\square_{3}$ & $\square_{4}$ & \\
\hline 11 & There was someone I could talk to if needed & $\square_{1}$ & $\square_{2}$ & $\square_{3}$ & $\square_{4}$ & \\
\hline 12 & The facilities in the college were good & $\square_{1}$ & $\square_{2}$ & $\square_{3}$ & $\square_{4}$ & \\
\hline 13 & I had access to all the equipment that I needed & $\square_{1}$ & $\square_{2}$ & $\square_{3}$ & $\square_{4}$ & \\
\hline 14 & $\begin{array}{l}\text { The teachers/tutors had a lot of relevant knowledge on } \\
\text { subject matter to share }\end{array}$ & $\square_{1}$ & $\square_{2}$ & $\square_{3}$ & $\square_{4}$ & \\
\hline 15 & $\begin{array}{l}\text { The course modules were relevant to the skills the } \\
\text { course was designed to teach }\end{array}$ & $\square_{1}$ & $\square_{2}$ & $\square_{3}$ & $\square 4$ & \\
\hline 16 & $\begin{array}{l}\text { The work experience was relevant to the skills the } \\
\text { course was designed to teach }\end{array}$ & $\square_{1}$ & $\square_{2}$ & $\square_{3}$ & $\square_{4}$ & $\square_{5}$ \\
\hline
\end{tabular}


F10. The following are some difficulties which sometimes affect students in their first year of further study. For each, please indicate to what extent these are/were a problem for you in your first year. (Please tick one box on each line)
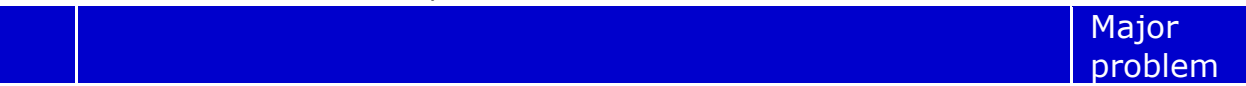

\begin{tabular}{l|l} 
Moderate \\
problem
\end{tabular}

\section{Minor} problem

Paying fees or any other study costs

roblem

$\square_{2}$

$\square_{3}$

$\square_{1}$

$\square_{2}$ problem

\section{Juggling work and study commitments}

Level of difficulty of the course

Caring for children or other family members

Completing coursework on time

Knowing what standard was expected of you

Balancing personal relationships with studies

Fitting in with other students and making new friends

Finding time for other interests such as sports, hobbies, religion

10 Coping with long breaks between terms and during the summer

F11. How would you describe your relationships with each of the following (Please tick one box on each line):

\begin{tabular}{|c|c|c|c|c|c|c|}
\hline & $\begin{array}{l}1 \\
\text { Unavailable, } \\
\text { unsupportive, sense of } \\
\text { alienation }\end{array}$ & 2 & 3 & 4 & 5 & $\begin{array}{l}6 \\
\text { Available, } \\
\text { supportive, } \\
\text { considerate }\end{array}$ \\
\hline Other Students & $\square_{1}$ & $\square_{2}$ & $\square_{3}$ & $\square_{4}$ & $\square_{5}$ & $\square_{6}$ \\
\hline Teaching Staff & $\square_{1}$ & $\square_{2}$ & $\square_{3}$ & $\square_{4}$ & $\square_{5}$ & $\square_{6}$ \\
\hline Administrative Personnel & $\square_{1}$ & $\square_{2}$ & $\square_{3}$ & $\square_{4}$ & $\square 5$ & $\square 6$ \\
\hline
\end{tabular}

F12. During the course, about how often did you do the following?

\begin{tabular}{|l|c|c|c|c|c|}
\hline $\begin{array}{l}1 \\
\text { Classroom based learning combined with workplace } \\
\text { experience }\end{array}$ & $\square_{1}$ & $\square_{2}$ & $\square_{3}$ & $\square_{4}$ & $\square_{5}$ \\
\hline $\begin{array}{l}\text { Learning during the course improved your } \\
\text { knowledge and skills that contributed to your } \\
\text { employability }\end{array}$ & $\square_{1}$ & $\square_{2}$ & $\square_{3}$ & $\square_{4}$ & $\square_{5}$ \\
\hline $\begin{array}{l}\text { Explored how to apply your learning in the } \\
\text { workplace }\end{array}$ & $\square_{1}$ & $\square_{2}$ & $\square_{3}$ & $\square_{4}$ & $\square_{5}$ \\
\hline Industry placement / work experience & $\square_{1}$ & $\square_{2}$ & $\square_{3}$ & $\square_{4}$ & $\square_{5}$ \\
\hline $\begin{array}{l}\text { Acquiring job-related or work-related knowledge } \\
\text { and skills }\end{array}$ & $\square_{1}$ & $\square_{2}$ & $\square_{3}$ & $\square_{4}$ & $\square_{5}$ \\
\hline
\end{tabular}

F13. How do/did you fund your studies during your Higher Education studies (HE)?

\begin{tabular}{|l|c|}
\hline Money from your family & Tick all that apply \\
\hline Indirect support from your family (e.g. food, accommodation) & $\square_{\mathbf{1}}$ \\
\hline Earnings from employment & $\square_{\mathbf{2}}$ \\
\hline A State grant & $\square_{\mathbf{3}}$ \\
\hline Back to Education Allowance & $\square_{\mathbf{4}}$ \\
\hline Other Social welfare payment & $\square_{\mathbf{5}}$ \\
\hline A bank loan & $\square_{\mathbf{6}}$ \\
\hline Savings & $\square_{\mathbf{7}}$ \\
\hline Employer assistance & $\square_{\mathbf{8}}$ \\
\hline Other, please specify & $\square_{\mathbf{9}}$ \\
\hline
\end{tabular}




\section{Section G: Post-School Transitions - Other CoURSES/TRAIning}

G1. Since leaving school, did you ever apply for an apprenticeship or any course such as FAS Specific Skills Training (SST), Traineeship etc. $\quad$ Yes.......... $\square_{1} \rightarrow$ Go to G2 No........ $\square_{2} \rightarrow$ Go to H1

G2. Since leaving school, did you ever take an apprenticeship/ FAS Specific Skills Training Course, Traineeship or any other course?

$$
\text { Yes.......... } \square_{1} \rightarrow \text { Go to G3 No........ } \square_{2} \rightarrow \text { Go to } H 1
$$

G3. If yes, please provide details of all apprenticeship/SST or any other course below:

\begin{tabular}{|l|l|l|l|l|l|l|l|}
\hline $\begin{array}{l}\text { Course Name } \\
\text { /Apprenticeship Title }\end{array}$ & $\begin{array}{l}\text { Institution/ } \\
\text { Employer }\end{array}$ & $\begin{array}{l}\text { Field of } \\
\text { Study }\end{array}$ & Level & $\begin{array}{l}\text { Start } \\
\text { Date }\end{array}$ & $\begin{array}{l}\text { End } \\
\text { Date }\end{array}$ & $\begin{array}{l}\text { Completed Overall } \\
\text { (Tick one) } \\
\text { Yes No }\end{array}$ & $\begin{array}{l}\text { Grade } \\
\text { Nos }\end{array}$ \\
\hline & & & & & & $\square_{1} \square_{2}$ & \\
\hline & & & & & & $\square_{1} \square_{2}$ & \\
\hline & & & & & & $\square_{1} \square_{2}$ & \\
\hline & & & & & & $\square_{1} \square_{2}$ & \\
\hline
\end{tabular}

\section{SECTION H: CURRENT Job}

H1. Did you hold a job last week, even for a short time?

$$
\text { Yes......... } \square_{1} \rightarrow \text { Go to } \mathrm{H} 2 \quad \text { No........ } \square_{2} \rightarrow \text { Go to I1 }
$$

H2. In relation to this job, how would you describe it?

$$
\begin{aligned}
& \text { Regular, full-time ....................... } \square_{1} \\
& \text { Temporary, full-time.................... } \square_{2} \\
& \text { Regular, part-time....................... } \square_{3} \\
& \text { Temporary, part-time .................. } \square_{4}
\end{aligned}
$$

H3. When did you take up this job? Month Year

H4. In relation to this job, what is your occupation? (Please write in the job title and describe the nature of the work done.)

H5. What is the nature of the business carried out by your employer (or yourself, if you are self-employed)? (Please describe the process carried out, and the end-product, if any)

H6. What is the usual number of hours (per week) you work in this job? hours

H7. Do you work in the public or private sector?

\begin{tabular}{|c|c|c|c|}
\hline Public sector & $\begin{array}{c}\text { Private sector, } \\
\text { not for profit }\end{array}$ & $\begin{array}{c}\text { Private sector, } \\
\text { for Profit }\end{array}$ & \begin{tabular}{c} 
Other, please specify \\
\hline$\square_{1}$
\end{tabular}$\square_{2}$ \\
$\square_{3}$ & $\square_{3}$ \\
\hline
\end{tabular}

H8. How many people work in your organisation and, if applicable, your own location? (Please tick one box in column $A$ and, if there is more than one branch or outlet, one box in column B)

Number of people
$1-9$
$10-49$
$50-99$
$100-249$
$250-999$
1000 or more
Not Applicable
Total Organisation Your Location

$\begin{array}{ll}\square 1 & \square_{1} \\ \square 2 & \square_{2} \\ \square 3 & \square_{3} \\ \square 4 & \square_{4} \\ \square 5 & \square 5 \\ \square 6 & \square 6 \\ & \square 7\end{array}$

H9. In relation to this job, how much do you usually earn per week OR per month? (to nearest $€$ )

\begin{tabular}{|c|c|c|c|}
\hline \multicolumn{2}{|c|}{ Per week Or Per month } \\
Gross (before deductions) & \multicolumn{2}{c}{ Ot (take-home pay) Gross (before deductions) } & \\
\hline
\end{tabular}


16. What was the nature of the business carried out by your employer (or yourself, if you are selfemployed)? (Please describe the process carried out, and the end-product, if any)

17. What was the usual number of hours (per week) you work in this job? hours

18. Did you work in the public or private sector?

\begin{tabular}{|c|c|c|c|}
\hline Public sector & $\begin{array}{c}\text { Private sector, } \\
\text { not for profit }\end{array}$ & $\begin{array}{c}\text { Private sector, } \\
\text { for Profit }\end{array}$ & Other, please specify \\
\hline$\square_{1}$ & $\square_{2}$ & $\square_{3}$ & $\square_{4}$ \\
\hline
\end{tabular}

19. How many people worked in your organisation and, if applicable, your own location? (Please tick one box in column $A$ and, if there is more than one branch or outlet, one box in column B)

\begin{tabular}{lcc}
\multicolumn{1}{c}{ Number of people } & Total Organisation & Your Location \\
$1-9$ & $\square_{1}$ & $\square 1$ \\
$10-49$ & $\square_{2}$ & $\square_{2}$ \\
$50-99$ & $\square_{3}$ & $\square 3$ \\
$100-249$ & $\square_{4}$ & $\square 4$ \\
$250-999$ & $\square 5$ & $\square 5$ \\
1000 or more & $\square 6$ & $\square 6$ \\
Not Applicable & $\square$ & $\square 7$
\end{tabular}

110. In relation to this job, how much did you usually earn per week OR per month? (to nearest $€$ )

\begin{tabular}{|l|l|l|l|}
\hline Gross (before deductions) & Net (take-home pay) Gross (before deductions) Net (take-home pay) \\
\hline & & & \\
\hline
\end{tabular}

I11. DID YOU RECEIVE ANY TRAINING IN THIS JOB? YES

1 .. NO

112. To what extent were your knowledge and skills utilized in this work? (Please answer on a scale from 1 to 5 , where 1 means 'Not at all' and 5 means 'To a very great extent.)

\begin{tabular}{|c|c|c|c|c|}
\hline $\begin{array}{c}1 \\
\text { Not at all }\end{array}$ & 2 & 3 & 4 & 5 \\
\hline$\square_{1}$ & $\square_{2}$ & $\square_{3}$ & $\square_{4}$ & To a very great extent \\
\hline
\end{tabular}

113. To what extent did this work demand more knowledge and skills than you could actually offer? Please answer on a scale from 1 to 5 , where 1 means 'Not at all' and 5 means 'To a very great extent.

\begin{tabular}{c|c|c|c|c|}
$\begin{array}{c}1 \\
\text { Not at all }\end{array}$ & 2 & 3 & 4 & 5 \\
\hline$\square_{1}$ & $\square_{2}$ & $\square_{3}$ & $\square_{4}$ & To a very great extent \\
\hline
\end{tabular}

114. (a) What type of education do you feel is most appropriate for this work?

$\begin{array}{rrr}\text { Postgraduate } \square_{1} & \text { Leaving Certificate } \square_{5} \\ \text { Bachelor } \square_{2} & \text { Junior Certificate } \square_{6} \\ \text { PLC } \square_{3} & \text { Other (Please specify): } & \square 7 \\ \text { Apprenticeship } \square & \square\end{array}$

115. (b) What field of study do you feel is most appropriate for this work?

My field of study is the only possible/the best field for this area of work Some other fields could also prepare people for this area of work Another field of study would have been more useful

The field of study does not matter very much for my area of work

Other, please specify: 
I16. How satisfied were you with this work?

\begin{tabular}{|c|c|c|c|}
\hline Very dissatisfied & Dissatisfied & Satisfied & Very Satisfied \\
\hline$\square_{1}$ & $\square_{2}$ & $\square_{3}$ & $\square_{4}$ \\
\hline
\end{tabular}

I17. How secure did you feel your job was?

8.1

\begin{tabular}{|c|c|c|c|}
\hline Very secure & Fairly Secure & Insecure & Very insecure \\
\hline$\square_{1}$ & $\square_{2}$ & $\square_{3}$ & $\square_{4}$ \\
\hline
\end{tabular}

I18. Were you a member of a trade union? Yes

$\square 1$ No $\square_{2}$

\section{SECTION J: FAMILY BACKGROUND}

The following are some questions about you and your family. The information is needed so that we can look at the experiences of people in different situations. I would like to repeat that the information you provide will be treated in the strictest confidence.

J1. Which of the following best describes (a) your Father's current situation (b) your Mother's current situation with regard to employment? (Tick one box in each column)

\begin{tabular}{|l|c|c|}
\hline At work as an employee & Father & Mother \\
\hline At work as an employer & $\square_{1}$ & $\square_{1}$ \\
\hline Self-employed without employees & $\square_{2}$ & $\square_{2}$ \\
\hline Unemployed & $\square_{3}$ & $\square_{3}$ \\
\hline Retired & $\square_{4}$ & $\square_{4}$ \\
\hline Engaged on home duties & $\square_{5}$ & $\square_{5}$ \\
\hline Unable to work due to disability & $\square_{6}$ & $\square_{6}$ \\
\hline Other & $\square_{7}$ & $\square 7$ \\
\hline
\end{tabular}

32. (a) What is (or was) your father's main occupation?

(If farmer or relative assisting, state acreage or hectares farmed)

(b) What is (or was) your mother's main occupation?

J3. Could you tell me the highest level of education reached by your (a) father and (b) mother:

\begin{tabular}{|l|c|c|}
\hline Primary or below & Father & Mother \\
\hline Lower Secondary (Junior/Inter Cert or equiv) & $\square_{1}$ & $\square_{1}$ \\
\hline Upper Secondary (Leaving Cert or equiv) & $\square_{2}$ & $\square_{2}$ \\
\hline Post-Secondary Non-Tertiary (e.g. PLC) & $\square_{3}$ & $\square_{3}$ \\
\hline Non-Degree (Certificate/Diploma) & $\square_{4}$ & $\square$ \\
\hline Degree or Higher & $\square_{5}$ & $\square 5$ \\
\hline Don't know & $\square 6$ & $\square 6$ \\
\hline
\end{tabular}

34. Are you a member of the Traveller Community? Yes......... $\square_{1}$

No......... $\square_{2}$

J5. (a) Was your mother born in Ireland? Yes........ $\square_{1} \quad$ No......... $\square_{2}$

(b) Was your father born in Ireland? Yes......... $\square_{1} \quad$ No.......... $\square_{2}$

j6. (a) Is the address on accompanying letter still your main address? Yes...... $\square_{1} \quad$ No....... $\square_{2}$

(b) If No, where are you now living? Ireland....... $\square_{1}$ Abroad....... $\square_{2}$

If Ireland, County:

If abroad, Country:

Could you please provide us with your phone number or email address: we will need contact details in the event you are a winner in the prize draw.

Phone number:

Email Address:

May we contact you at a future date to invite you to answer some follow up questions?

Yes.......... $\square_{1}$

No.........

Thank you very much for your co-operation. 


\section{APPENDIX E: QUESTIONNAIRE FOR SURVEY OF PLC PROVIDERS}

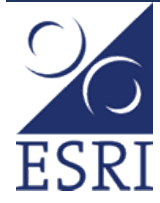

\section{SURVEY OF PLC PROVIDERS 2015}

PIN No.

Thank you for agreeing to participate in our survey. All of the information provided is confidential. Your identity will not be disclosed to anyone outside the ESRI. The reports we produce deal only with general results. Individual college information is not reported. You do not need to answer any particular question if you do not wish to.

\section{SECTION A: DETAIL OF COLLEGE STRUCTURE AND SIZE}

A1. How would you best describe your college/institution?

\begin{tabular}{|l|l|}
\hline ETB Stand-alone Further Education College/Institute & $\square_{1}$ \\
\hline ETB Second-level school which offers PLC courses & $\square_{2}$ \\
\hline Voluntary secondary/community/comprehensive school offering PLC courses & $\square_{3}$ \\
\hline Other (please specify: & $\square_{4}$ \\
\hline
\end{tabular}

A2. (a) How many PLC students (full-time) are currently registered in your college?

(b) Over the past five years, has the number of PLC students coming to this school....

\begin{tabular}{|c|c|c|}
\hline Increased & Decreased & Remained Fairly Stable \\
\hline$\square_{1}$ & $\square_{2}$ & $\square_{3}$ \\
\hline
\end{tabular}

(c) To what extent does your college have the capacity to enrol more PLC students?

\begin{tabular}{|c|c|c|}
\hline Yes, to a great extent & Yes, to some extent & No, not at all \\
\hline$\square_{1}$ & $\square_{2}$ & $\square_{3}$ \\
\hline
\end{tabular}

A3. (a) Are all of the people who apply for PLC courses in this college generally accepted?

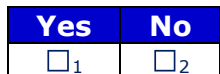

(b) If no, what criteria are used to admit learners [Please tick all that apply]?

\begin{tabular}{|l|c|}
\hline Having a Leaving Certificate & $\square_{1}$ \\
\hline Leaving Certificate grades & $\square_{2}$ \\
\hline Performance in interview & $\square_{3}$ \\
\hline Written application & $\square_{4}$ \\
\hline Date of application & $\square_{5}$ \\
\hline Recognition of prior learning (RPL) & $\square_{6}$ \\
\hline Ability to pay fee & $\square_{7}$ \\
\hline VTOS eligibility & $\square_{8}$ \\
\hline Other, please specify: & $\square_{9}$ \\
\hline
\end{tabular}

A4. How has the cap impacted on the PLC provision in your school/college over the past five years?

\begin{tabular}{|c|c|c|c|c|c|}
\hline & $\begin{array}{c}\text { Not at } \\
\text { all }\end{array}$ & \multicolumn{3}{|c|}{$\longleftrightarrow$} & $\begin{array}{c}\text { To a Great } \\
\text { Extent }\end{array}$ \\
\hline Has limited our ability to meet the demand for places & $\square_{1}$ & $\square_{2}$ & $\square_{3}$ & $\square_{4}$ & $\square_{5}$ \\
\hline Has limited the range of courses offered & $\square_{1}$ & $\square_{2}$ & $\square_{3}$ & $\square_{4}$ & $\square_{5}$ \\
\hline Has reduced our ability to respond to labour market gaps/needs & $\square_{1}$ & $\square_{2}$ & $\square 3$ & $\square_{4}$ & $\square_{5}$ \\
\hline Has impacted on funding for supports/staff & $\square_{1}$ & $\square_{2}$ & $\square_{3}$ & $\square_{4}$ & $\square 5$ \\
\hline Has impacted on the quality of provision & $\square_{1}$ & $\square_{2}$ & $\square_{3}$ & $\Pi_{4}$ & $\square_{5}$ \\
\hline
\end{tabular}




\section{Section B: Principal Profile}

B1. Are you male or female? Male $\ldots . . \square_{1} \quad$ Female...... $\square_{2}$

B2. To which age group do you belong?

$20-29$ yrs....... $\square_{1} \quad 30-39$ yrs.... $\square_{2} \quad 40-49$ yrs..... $\square_{3} \quad 50-59$ yrs.... $\square_{4} \quad 60$ yrs or older.... $\square_{5}$

B3. For how many years have you been Principal:
(a) in this college? years
(b) in other FE settings? ___ years
(c) in other second-level settings? years

\section{SeCtion C: Profile of Teaching Staff (INC. TUtORS)}

Please answer this section in relation to ALL staff teaching a PLC course in your college, even if they also teach second-level courses.

C1. Current PLC Teacher Provision by broad categories: Please give the total number of teachers and tutors on PLC programmes in your college/school over the broad categories below. Also, for each field, please estimate the proportion of teachers/tutors in this field of study who are qualified in this specific field.

\begin{tabular}{|l|l|l|l|l|l|}
\hline \multicolumn{1}{|c|}{$\begin{array}{l}\text { General } \\
\text { Programmes } \\
\text { or Humanities } \\
\text { and Arts }\end{array}$} & $\begin{array}{l}\text { Education, } \\
\text { Social } \\
\text { Sciences, } \\
\text { Business, } \\
\text { Law }\end{array}$ & $\begin{array}{l}\text { Science, Maths, } \\
\text { Computing, } \\
\text { Engineering, } \\
\text { Manufacturing, } \\
\text { Construction }\end{array}$ & $\begin{array}{l}\text { Agriculture, } \\
\text { Veterinary, } \\
\text { Health and } \\
\text { Welfare }\end{array}$ & $\begin{array}{l}\text { Services } \\
\text { (e.g. hair } \\
\text { dressing, } \\
\text { fitness) }\end{array}$ \\
\hline $\begin{array}{l}\text { Total number of teachers of PLC } \\
\text { programmes (full-time and part-time, } \\
\text { including casual) }\end{array}$ & & & & & \\
\hline $\begin{array}{l}\text { Total number of tutors on PLC } \\
\text { programmes (full-time and part-time, } \\
\text { including casual) }\end{array}$ & & & & & \\
\hline $\begin{array}{l}\text { What proportion of these teachers } \\
\text { and tutors hold a technical/specialist } \\
\text { qualification in this specific field? }\end{array}$ & & & & & \\
\hline
\end{tabular}

C2. If you are a second-level school, how many teachers teach both PLC and second-level (junior/senior cycle) courses? (number)

C3. How often do teachers in your college/school do the following? (Please tick one box on each line)

\begin{tabular}{|c|c|c|c|c|c|c|}
\hline & Never & $\begin{array}{l}\text { Less than } \\
\text { once a year }\end{array}$ & $\begin{array}{l}\text { Once } \\
\text { per year }\end{array}$ & $\begin{array}{l}\text { 3-4 times } \\
\text { per year }\end{array}$ & Monthly & Weekly \\
\hline Attend staff meetings to discuss college planning & $\square_{1}$ & $\square_{2}$ & $\square_{3}$ & $\square_{4}$ & $\square_{5}$ & $\square_{6}$ \\
\hline $\begin{array}{l}\text { Discuss and decide on the selection of instructional } \\
\text { materials (e.g. textbooks) }\end{array}$ & $\square_{1}$ & $\square_{2}$ & $\square_{3}$ & $\square_{4}$ & $\square_{5}$ & $\square 6$ \\
\hline Exchange teaching materials with colleagues & $\square_{1}$ & $\square_{2}$ & $\square_{3}$ & $\square_{4}$ & $\square_{5}$ & $\square_{6}$ \\
\hline $\begin{array}{l}\text { Ensure common standards in evaluations for } \\
\text { assessing student progress }\end{array}$ & $\square_{1}$ & $\square_{2}$ & $\square_{3}$ & $\square 4$ & $\square 5$ & $\square 6$ \\
\hline $\begin{array}{l}\text { Engage in discussion about the learning } \\
\text { development of specific students }\end{array}$ & $\square_{1}$ & $\square_{2}$ & $\square 3$ & $\square 4$ & $\square_{5}$ & $\square 6$ \\
\hline Teach jointly as a team in the same class & $\square_{1}$ & $\square_{2}$ & $\square_{3}$ & $\square_{4}$ & $\square_{5}$ & $\square 6$ \\
\hline $\begin{array}{l}\text { Take part in professional learning activities (e.g. } \\
\text { school-based course, reading group etc.) }\end{array}$ & $\square_{1}$ & $\square_{2}$ & $\square_{3}$ & $\square_{4}$ & $\square 5$ & $\square 6$ \\
\hline $\begin{array}{l}\text { Observe other teachers' classes and provide } \\
\text { feedback }\end{array}$ & $\square_{1}$ & $\square_{2}$ & $\square_{3}$ & $\square 4$ & $\square_{5}$ & $\square 6$ \\
\hline Engage in joint activities across different classes & $\square_{1}$ & $\square_{2}$ & $\square 3$ & $\square_{4}$ & $\square_{5}$ & $\square 6$ \\
\hline
\end{tabular}

C4. (a) Approximately how many members of the PLC teaching staff underwent continuous professional development during the academic year 2014-2015 through short (e.g. one day) courses or spent a period in industry?

Please give a reasonable estimate if you do not have exact numbers (number)

(b) Approximately how many members of the PLC teaching staff underwent continuous professional development during the academic year 2014-2015 through extended courses (e.g. qualification in Information Technology)?

Please give a reasonable estimate if you do not have exact numbers (number) 
If 'yes', does it include provision for: Tick one box on each line

If 'yes', does it include provision for:
\begin{tabular}{|l|r|}
\multicolumn{1}{|c|}{ Tick one box on each line } & Yes No \\
\hline Training Leave & $\square_{1} \square_{2}$ \\
\hline Payment of Fees & $\square_{1} \square_{2}$ \\
\hline Refund of Expenses & $\square_{1} \square_{2}$ \\
\hline Direct Provision of Training & $\square_{1} \square_{2}$ \\
\hline Professional development organised through ETB networks & $\square_{1} \square_{2}$ \\
\hline Other (please specify: & $\square_{1} \square_{2}$ \\
\hline
\end{tabular}

\section{SECTION D: SERVICES AND RESOURCES FOR STUdENTS}

D1. In your college/school, do your students have access to the following supports?

If Yes, please indicate approximately how many students avail of these supports.

\begin{tabular}{|l|c|c|}
\multicolumn{1}{|c|}{$\begin{array}{c}\text { Tick one } \\
\text { No Yes }\end{array}$} & If Yes, how many students avail of these? \\
\hline Career Guidance & $\square_{1} \square_{2}$ & \\
\hline Personal Counselling & $\square_{1} \square_{2}$ & \\
\hline Childcare & $\square_{1} \square_{2}$ & \\
\hline Disability Support Service & $\square_{1} \square_{2}$ & \\
\hline Financial Support (other than SUSI grant) & $\square_{1} \square_{2}$ & \\
\hline Students Union & $\square_{1} \square_{2}$ & \\
\hline Class Tutor Support & $\square_{1} \square_{2}$ & \\
\hline DSP Support & $\square_{1} \square_{2}$ & \\
\hline
\end{tabular}

D2. How adequate to the needs of the college/school and the students are the college's resources in each of the following areas?

\begin{tabular}{|c|c|c|c|c|}
\hline & Poor & Fair & Good & Excellent \\
\hline Number of teachers & $\square_{1}$ & $\square_{2}$ & $\square_{3}$ & $\square_{4}$ \\
\hline Number of classrooms & $\square_{1}$ & $\square_{2}$ & $\square_{3}$ & $\square_{4}$ \\
\hline Books and worksheets & $\square_{1}$ & $\square_{2}$ & $\square_{3}$ & $\square 4$ \\
\hline Computing facilities & $\square_{1}$ & $\square_{2}$ & $\square_{3}$ & $\square_{4}$ \\
\hline Technical equipment & $\square_{1}$ & $\square_{2}$ & $\square_{3}$ & $\square 4$ \\
\hline Sports facilities & $\square_{1}$ & $\square_{2}$ & $\square_{3}$ & $\square_{4}$ \\
\hline Library / Media centre & $\square_{1}$ & $\square_{2}$ & $\square_{3}$ & $\square 4$ \\
\hline Learning support provision & $\square_{1}$ & $\square_{2}$ & $\square 3$ & $\square 4$ \\
\hline Administrative support & $\square_{1}$ & $\square_{2}$ & $\square_{3}$ & $\square 4$ \\
\hline Condition of the school building, classrooms etc. & $\square_{1}$ & $\square_{2}$ & $\square_{3}$ & $\square 4$ \\
\hline Facilities for learners with disabilities & $\square_{1}$ & $\square_{2}$ & $\square_{3}$ & $\square 4$ \\
\hline Career Guidance & $\square_{1}$ & $\square_{2}$ & $\square_{3}$ & $\square_{4}$ \\
\hline
\end{tabular}

\section{Section E: Course Planning}

E1. Please give the title of any new courses that received approval in the last five years under the following broad categories below:

\begin{tabular}{|c|c|c|c|c|}
\hline $\begin{array}{l}\text { General } \\
\text { Programmes or } \\
\text { Humanities and } \\
\text { Arts }\end{array}$ & $\begin{array}{l}\text { Education, Social } \\
\text { Sciences, } \\
\text { Business, Law }\end{array}$ & $\begin{array}{l}\text { Science, Maths, } \\
\text { Computing, Engineering, } \\
\text { Manufacturing, } \\
\text { Construction }\end{array}$ & $\begin{array}{l}\text { Agriculture, } \\
\text { Veterinary, } \\
\text { Health and } \\
\text { Welfare }\end{array}$ & $\begin{array}{l}\text { Services (e.g. } \\
\text { hair dressing, } \\
\text { fitness) }\end{array}$ \\
\hline & & & & \\
\hline & & & & \\
\hline & & & & \\
\hline
\end{tabular}


E2. Below is a list of potential influences on the decision to establish new courses. To what extent do you think each of the following influences was important (or is important in any deliberations on courses being considered for approval)? (Please tick one box on each line)

\begin{tabular}{|c|c|c|c|c|c|c|}
\hline \multicolumn{5}{|c|}{$\begin{array}{l}\text { Not } \\
\text { at all }\end{array}$} & \multicolumn{2}{|c|}{$\begin{array}{l}\text { To a great } \\
\text { extent }\end{array}$} \\
\hline 1 & The course meets the demands of students & $\square_{1}$ & $\square_{2}$ & $\square_{\mathbf{3}}$ & $\square 4$ & $\square 5$ \\
\hline 2 & The course is in line with existing resources & $\square_{1}$ & $\square_{2}$ & $\square_{3}$ & $\square_{4}$ & $\square_{5}$ \\
\hline 3 & The course meets the demand for workers in the local labour market & $\square$ & $\square_{2}$ & $\square_{3}$ & $\square 4$ & $\square_{5}$ \\
\hline 4 & The course meets the demand for workers in the regional labour market & & & & & \\
\hline 5 & The course meets the demand for workers in the national labour market & $\square$ 品 & $\square_{\mathbf{2}}$ & $\square \mathbf{3}$ & $\square 4$ & $\square 5$ \\
\hline 6 & There are staff with relevant skills in the college & & & & & \\
\hline 7 & The course has been requested by employers & $\square_{\mathbf{1}}$ & $\square_{2}$ & $\square_{3}$ & $\square_{4}$ & $\square_{5}$ \\
\hline 8 & $\begin{array}{l}\text { The course has been highlighted as an area of demand by government policy } \\
\text { documents }\end{array}$ & $\square_{1}$ & $\square_{2}$ & $\square \mathbf{3}$ & $\square_{4}$ & $\square_{5}$ \\
\hline 9 & $\begin{array}{l}\text { The course has been highlighted as an area of high demand by occupational } \\
\text { forecasts }\end{array}$ & $\square \mathbf{1}$ & $\square_{2}$ & $\square 3$ & $\square 4$ & $\square_{5}$ \\
\hline 10 & ETB Framework & $\square_{1}$ & $\square_{2}$ & $\square \mathbf{3}$ & $\square 4$ & $\square 5$ \\
\hline 11 & Other, please specify: & $\square_{1}$ & $\square_{2}$ & $\square_{3}$ & $\square_{4}$ & $\square_{5}$ \\
\hline
\end{tabular}

E3. Please give the titles of any courses discontinued in the last five years under the following broad categories below:

\begin{tabular}{|l|l|l|l|l|}
$\begin{array}{l}\text { General } \\
\text { Programmes or } \\
\text { Humanities and } \\
\text { Arts }\end{array}$ & $\begin{array}{l}\text { Education, Social } \\
\text { Sciences, } \\
\text { Business, Law }\end{array}$ & $\begin{array}{l}\text { Science, Maths, } \\
\text { Computing, Engineering, } \\
\text { Manufacturing, } \\
\text { Construction }\end{array}$ & $\begin{array}{l}\text { Agriculture, } \\
\text { Veterinary, } \\
\text { Health and } \\
\text { Welfare }\end{array}$ & $\begin{array}{l}\text { Services (e.g. } \\
\text { hair dressing, } \\
\text { fitness) }\end{array}$ \\
\hline & & & & \\
\hline & & & & \\
\hline & & & & \\
\hline
\end{tabular}

E4. Below is a list of potential influences on discontinuing courses. To what extent do you think each of the following influences was important (or is important in any deliberations on courses being considered for discontinuation)? (Please tick one box on each line)

\begin{tabular}{|c|c|c|c|c|c|c|}
\hline & & $\begin{array}{l}\text { Not } \\
\text { at al }\end{array}$ & & & To & \\
\hline 1 & The course does not meet the demands of students & $\square_{1}$ & $\square_{2}$ & $\square_{3}$ & $\square_{4}$ & $\square_{5}$ \\
\hline 2 & The course is not in line with existing resources & $\square_{1}$ & $\square_{2}$ & $\square_{3}$ & $\square_{4}$ & $\square_{5}$ \\
\hline 3 & The course does not meet the demand for workers in the local labour market & $\square$ & $\square_{2}$ & $\square_{3}$ & $\square_{4}$ & $\square_{5}$ \\
\hline 4 & The course does not meet the demand for workers in the regional labour market & $\square_{1}$ & $\square_{2}$ & $\square_{3}$ & $\square_{4}$ & $\square_{5}$ \\
\hline 5 & The course does not meet the demand for workers in the national labour market & $\square_{1}$ & $\square_{2}$ & $\square_{3}$ & $\square_{4}$ & $\square_{5}$ \\
\hline 6 & There are no staff with relevant skills in the college & $\square_{1}$ & $\square_{2}$ & $\square_{3}$ & $\square_{4}$ & $\square_{5}$ \\
\hline 7 & The course has not been requested by employers & $\square_{1}$ & $\square_{2}$ & $\square_{3}$ & $\square_{4}$ & $\square_{5}$ \\
\hline 8 & The course has not been highlighted as an area of demand by government policy documents & $\square_{1}$ & $\square_{2}$ & $\square_{3}$ & $\square_{4}$ & $\square_{5}$ \\
\hline 9 & Falling enrolments/undersubscribed & $\square_{1}$ & $\square_{2}$ & $\square 3$ & $\square_{4}$ & $\square 5$ \\
\hline 10 & The course has not been highlighted as an area of high demand by occupational forecasts & $\square_{1}$ & $\square_{2}$ & $\square_{3}$ & $\square_{4}$ & $\square_{5}$ \\
\hline 11 & Over supply of similar courses in adjacent colleges & $\square_{1}$ & $\square_{2}$ & $\square_{3}$ & $\square_{4}$ & $\square_{5}$ \\
\hline 12 & ETB Framework & $\square_{1}$ & $\square_{2}$ & $\square_{3}$ & $\square_{4}$ & $\square_{5}$ \\
\hline 13 & Other, please specify: & $\square_{1}$ & $\square_{2}$ & $\square_{3}$ & $\square_{4}$ & $\square_{5}$ \\
\hline
\end{tabular}

E5. What in your opinion is the purpose of PLC provision? (Please tick one box on each line)

\begin{tabular}{|l|c|c|c|c|c|}
\hline & $\begin{array}{c}\text { Strongly } \\
\text { Agree }\end{array}$ & $\begin{array}{c}\text { Agree } \\
\text { nor disagree }\end{array}$ & $\begin{array}{c}\text { Disagree } \\
\text { Strongly } \\
\text { disagree }\end{array}$ \\
\hline They equip learners for entry to specific occupations & $\square_{1}$ & $\square_{2}$ & $\square_{3}$ & $\square_{4}$ & $\square_{5}$ \\
\hline They provide learners with general education & $\square_{1}$ & $\square_{2}$ & $\square_{3}$ & $\square_{4}$ & $\square_{5}$ \\
\hline They enable progression to higher education & $\square_{1}$ & $\square_{2}$ & $\square_{3}$ & $\square_{4}$ & $\square_{5}$ \\
\hline They facilitate life-long learning & $\square_{1}$ & $\square_{2}$ & $\square_{3}$ & $\square_{4}$ & $\square_{5}$ \\
\hline Facilitate Social Inclusion & $\square_{1}$ & $\square_{2}$ & $\square_{3}$ & $\square_{4}$ & $\square_{5}$ \\
\hline
\end{tabular}

\section{E6. What percentages of your PLC courses are focused on:}

\begin{tabular}{|l|l|r|}
\hline 1 & Gaining Employment & $\%$ \\
\hline 2 & Progression to 3rd Level & $\%$ \\
\hline 3 & Personal Development & $\%$ \\
\hline 4 & Reducing Social Exclusion & $\%$ \\
\hline 5 & Other (please specify: & $\%$ \\
\hline
\end{tabular}


E7. (a) How often would you or your staff meet with employers in the local area?

\begin{tabular}{|l|c|}
\hline Never & $\square_{1}$ \\
\hline Less than once a year & $\square_{2}$ \\
\hline Once per year & $\square_{3}$ \\
\hline 3-4 times per year & $\square_{4}$ \\
\hline 5+ times per year & $\square_{5}$ \\
\hline
\end{tabular}

(b) If so, in relation to which issues do you have contact with local employers?

in relation to which issues do you have contact with local employers?
\begin{tabular}{|l|c|}
\hline Work experience placements & $\square_{1}$ \\
\hline Job Placement & $\square_{2}$ \\
\hline Planning new courses & $\square_{3}$ \\
\hline Deciding whether to keep running specific courses & $\square_{4}$ \\
\hline Input into specific courses & $\square_{5}$ \\
\hline Running mock interviews & $\square_{6}$ \\
\hline Develop/modify curriculum & $\square_{7}$ \\
\hline Other (please specify) & $\square_{8}$ \\
\hline
\end{tabular}

E8. (a) Do learners take part in work experience as part of their PLC course?
Yes, all..... $\square_{1}$
Yes, most ...... $\square_{2}$
A few $\ldots . . . \square_{3}$
None $\ldots . . . \square_{4}$ [If none, skip to Section F]

(b) What length of time do they typically spend on a work experience placement? days

(c) Who mainly organises the work experience placement? (Please tick one)

\begin{tabular}{|l|l|}
\hline The student & $\square_{1}$ \\
\hline The course coordinator & $\square_{2}$ \\
\hline Someone else in the college/school & $\square_{3}$ \\
\hline Other (Please specify: & $\square_{4}$ \\
\hline
\end{tabular}

(d) In general, how easy is it for learners to obtain placements? Very easy .......... $\square_{1} \quad$ Easy..... $\square_{2} \quad$ Quite difficult..... $\square_{3} \quad$ Very difficult.... $\square_{4}$

(e) Is the employer asked for feedback on the learner?

(f) Are learners assessed on the basis of their placement? Yes, all placements.... $\square_{1} \quad$ Yes, some placements..... $\square_{2} \quad$ No ... $\square_{3}$

(g) What percentage of your PLC learners:

\begin{tabular}{|l|l|r|}
\hline 1 & Get relevant work experience as part of their course & $\mathbf{\%}$ \\
\hline 2 & Do work experience organised on a block basis & $\mathbf{\%}$ \\
\hline 3 & Do work experience organised on a day release basis & $\mathbf{\%}$ \\
\hline
\end{tabular}

(h) Is there a requirement that students can practise the skills learned on the programme during their work experience?

\begin{tabular}{|c|c|c|c|}
\hline Not at all & Very Little & To Some Extent & To a Great Extent \\
\hline$\square_{1}$ & $\square_{2}$ & $\square_{3}$ & $\square_{4}$ \\
\hline
\end{tabular}

(i) To what extent do students subsequently obtain employment in the companies where they did their work experience?

\begin{tabular}{|c|c|c|c|}
\hline Not at all & Very Little & To Some Extent & To a Great Extent \\
\hline$\square_{\mathbf{1}}$ & $\square_{\mathbf{2}}$ & $\square_{\mathbf{3}}$ & $\square_{\mathbf{4}}$ \\
\hline
\end{tabular}

\section{Section F: Completion, Certification And Outcomes}

F1. Overall, approximately what percentages of students in your college/school complete their PLC courses?

\begin{tabular}{|l|r|r|}
\hline & 1 year courses & $\mathbf{2}$ year courses \\
\hline Percentage of students completing the course & $\%$ & $\%$ \\
\hline Percentage of students who obtain a major award & $\%$ & $\%$ \\
\hline
\end{tabular}

F2. In your opinion, what are the main reasons for students not completing their course? 
F3. In your opinion, what are the main reasons for students not obtaining a major award, even if they complete the course?

F4. Does your college/school track the destinations of PLC leavers?
Yes ...... $\square_{1} \rightarrow$ Go to F5
No $\ldots . . . \square_{2} \rightarrow$ Go to F6

F5. Please provide details of the progression pattern of PLC completers:

\begin{tabular}{|l|l|r|}
\hline 1 & Percentage progressing directly to employment & $\mathbf{\%}$ \\
\hline 2 & Percentage becoming unemployed & $\mathbf{\%}$ \\
\hline 3 & Percentage remaining who enter \remain FE & $\mathbf{\%}$ \\
\hline 4 & Percentage entering apprenticeships & $\mathbf{\%}$ \\
\hline 5 & Percentage progressing directly to HE & $\mathbf{\%}$ \\
\hline 6 & Percentage progressing to HE through Higher Education links scheme & $\mathbf{\%}$ \\
\hline 7 & Percentage in other (please specify: & $\mathbf{\%}$ \\
\hline
\end{tabular}

F6. (a) Does your college/school have links with particular third-level institutions? (Tick all that apply)

\begin{tabular}{|l|l|l|}
\hline University in Ireland & $\square_{1}$ & Institutes of Technology in Ireland \\
\hline
\end{tabular}

\begin{tabular}{l|l|l|}
\hline UK University & $\square_{2}$ & No, none
\end{tabular}

(b) If so, please name the third-level universities or institutions below.

(b) How satisfied are you with progression opportunities for PLC leavers into higher education?
Very Satisfied
Satisfied
Dissatisfied
Very Dissatisfied

$\square_{1}$

$\square_{2}$

$\square_{3}$

Please give reasons for your answer.

\section{Section G: Issues for the PLC SeCtor}

G1. What do you think are the main advantages to how PLC courses are run in your college/ school?

G2. What do you think are the main advantages of how PLC courses are run nationally?

G3. What do you think are the main challenges for the future of provision in your college/ school?

G4. What do you think are the main challenges for the future of PLC provision nationally? 
G5. Is there anything else that you would like to add regarding PLC provision? 
Whitaker Square,

Sir John Rogerson's Quay,

Dublin 2

Telephone +35318632000

Email admin@esri.ie

Web www.esri.ie

Twitter @ESRIDublin

ISBN 978-0-7070-0428-0 